$$
\therefore \therefore
$$

\title{
LIQUID METAL PLASMA VALVE DEVELOPMENT
}

High Voltage Technology Staff

Hughes Research Laboratories

3011 Malibu Canyon Road

Malibu, CA 90265

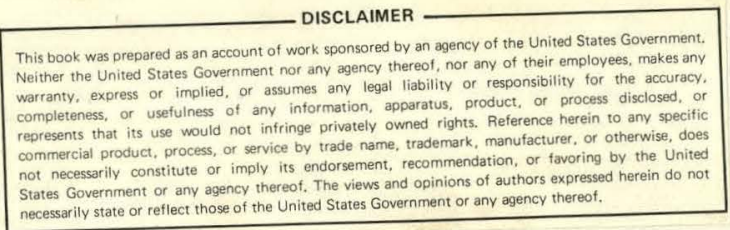

June 1978

Contract EX-76-C-01-2149 ACOI-76ET

For period 15 January 1975 through 30 April 1978

Prepared for

DEPARTMENT OF ENERGY

Washington, DC 20240

\section{MASTL.}




\section{DISCLAIMER}

This report was prepared as an account of work sponsored by an agency of the United States Government. Neither the United States Government nor any agency Thereof, nor any of their employees, makes any warranty, express or implied, or assumes any legal liability or responsibility for the accuracy, completeness, or usefulness of any information, apparatus, product, or process disclosed, or represents that its use would not infringe privately owned rights. Reference herein to any specific commercial product, process, or service by trade name, trademark, manufacturer, or otherwise does not necessarily constitute or imply its endorsement, recommendation, or favoring by the United States Government or any agency thereof. The views and opinions of authors expressed herein do not necessarily state or reflect those of the United States Government or any agency thereof. 


\section{DISCLAIMER}

Portions of this document may be illegible in electronic image products. Images are produced from the best available original document. 


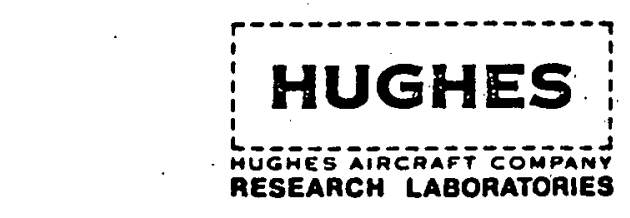

LIQUID METAL PLASMA VALVE DEVELOPMENT

High Voltage Technology Staff

JUNE 1978

Contract EX-76-C-01-2149

FINAL TECHNICAL REPORT

For period 15 January 1975 through 30 April 1978

Prepared for

DEPARTMENT OF ENERGY

Washington, DC 20240 


\section{ACKNOWLEDGMENTS}

Subject Liquid Metal Plasma Valve Development was performed under Robert W. Flugum, Assistant Director for Transmission Division of Electric Energy Systems, Department of Energy, Washington, D.C.

The actual investigation and hardware development activity under Contract EX-76-C-01-2149 was managed by Dr. Ken Arnold, under the guidance of Mr. Arthur Dickerson, Manager of High Voltage Systems Program.

Dr. Gunter Hagen was responsible for the synthetic testing program, and developed a major portion of this final technical report.

Mr. Neil Marshall was designated as Program Manager during the final phases of contractual activity, including subject submittal. He also was responsible for the Transient Event Recording System presently installed at the Celilo Converter Station of the Bonneville Power Administration, D.O.E.

Final work was performed under the auspices of a new departmental organization at the Hughes Research Laboratories. This department, High Voltage Technology, is headed by Dr. Harry King.

Other technical staff members of HVT contracting materially to program execution are Dr. Wilfred Eckhardt (basic LMPV concepts), Mr. Roy Hasselquist (auxiliary and support systems designs), Mr. Henry Palmer (tube design), Mr. Nog Komatsu (controls and monitors), and Mr. Eugene Malloy (test support). 
LIST OF ILLUSTRATIONS

1 INTRODUCTION

A. LMPV Principles

B. LMPV Auxiliaries

C. Monitoring Station DESIGN AND DEVELOPMENT OF CONVERTER VALVES

A. Engineering Prototype Valves

B. Cathode Development

C. Ignitor Development

D. EM Pump Development

E. Condenser

F. Alumina Insulator

G. Anode

H. Anode Cooling system

I. Condenser Cooling System

J. Control, Fault Indication, and Monitoring

K. Valve Auxiliaries

L. Integration

M. Interface with BPA Facllities

3 : TESTING OF THE ENGINEERING PROTOTYPE VALVES AT HRL

A. Introduction

B. Synthetic Testing 
C. Test Schedule . . . . . . . . . . .

D. Fault-Detection System . . . . . . . .

E. Anode Film Formation

F. Testing Techniques

G. The Current-Injection Valve . . . . . .

H. X-Radiation Shielding . . . . . . . .

APPENDIX A - Hypothesis to Explain Molybdenum Deposits in

EN1 and L.1 LMPVS

APPENDIX B - Molybdenum Transport Rate as a Function of Oxygen

Concentration .

APPENDIX C - Specifications of the Deliverable Auxiliaries

APPENDIX D - Field Strength and View Factor Calculations for LMPV Designs z . . . . . . . . . .

APPENDIX E - Monitoring of System Operating Conditions . . . . . . . 
Two engineering prototype valve packages under test at $\mathrm{HRL}$

Liquid metal plasma valve

Vacuum envelope of the LMPV; it also acts as a condenser

Breakdown voltage in mercury vapor as a function of number density, and LMPV number densities as a function of voltage

Auxiliary electronics package for the first engineering prototype and the annunciation console

Completed cathode as seen from anode

External end of cathode

LMPV cathode during assembly

LMPV anode

Anode rear view

Sputter shield spun from molybdenum

Model of an LMPV package installed at Celilo

Fiber-optic assemblies for the valve hall at Celilo

Engineering LMPV and electronics package Basement aisle at Celilo

Dowtherm recirculating system Transient event recorder 
19. Valve current sensor . . . . . . . . . . .

20 Voltage divider

21 Current sensors and voltage dividers

installed in Group I at Celilo

Transient event recorder installed at Celilo

Engineering prototype LMPV

Engineering prototype valve on bakeout station

Engineering prototype valve No. 1:

pressure and temperature as a function of time during processing

Engineering prototype valve No. 1:

pressure as a function of time with ionpumps disconnected

Cathode igniter geometries

Condenser data

Equipotential lines in the LMPV

Equipotential lines intersection of the alumina and fiberglass bushings

DOE valve bakeout

Anode heat transfer characteristics

Dowtherm recirculating system

RIl flow diagram

LMPV control, fault indication, and monitoring

Block diagram of valve auxiliary electronics Fluid cooling systems 
Synthet1c test setup . . . . . . . . . .

DOE/LMPV program synthetic test set-ups

DOE/LMPV program synthetic test set-up . . . .

Elevation of $\mathrm{V}_{1}$ valve and electronics package

Side elevation of $\mathrm{v}_{2}$ valve

1:10 scale model of LMPV

1:50 scale model of Group I at Cel110

Valve bridge

Valve bridge - Group I .

Valve hall layout . . . . . . . . . . .

Shielded potential divider

Installed LMPV

Typical assembly - voltage divider

\section{Installed LMPV}

Rll chiller-condenser cooling

Dowtherm A-anode cooling

\section{Dowtherm A system: comparison of} facility installations

Fiber-optic assemblies for the valve hall at Celilo

\section{Estimated typical test conditions}

Synthetic valve test facility parameters . . . . Arc-back rate versus anode blocking duty . . . . 
62 Switching surge tests of the DOE LMPV

63 BIL tests of the DOE LMPV . . . . . . . . . . .

64 Oscilloscope waveforms monitored in the control room . . . . . . . . . . . . . .

Metallic film on valve anode - side view . . . . .

Metalif film on valve anode nose . . . . . . .

Appearance of sputtered cathode face . . . . . . .

Appearance of sputtered cathode shroud

Cathode shroud heaters

71

Tracking on outside of vanadium-oxidecoated insulator - • 


\section{SECTION 1}

\section{INTRODUCTION}

Contract EX-7.6-C-01-2149 (formerly E(49-18)-2149) from the Department of Energy (DOE) provided funds to implement a program for the development of liquid-metal plasma valves (LMPVS). The program consisted of two tasks. The first was the development and testing of valves in the laboratory and the fabrication, instrumentation, testing and in-service operation of two valves at the Bonneville Power Administration (BPA) facilities of the Pacific Intertie. HVDC Power Transmission System at Celilo; Oregon. The second task was the design, development, fabrication, installation, and operation of a voltage and current monitoring station and the transient event recording system to go with it.

\section{A. LMPV PRINCIPLES}

Figure 1 shows two engineering prototype valve packages in the synthetic test facility at Hughes Research Laboratories (HRL). The package comprises an LMPV and the auxiliaries necessary to support it.

Unlike the conventional. mercury converter valve, the LMPV is a single-gap, single-anode device that utilizes the rapid recovery properties of high vacuum to give good voltage hold-off characteristics following current conduction in the vacuum arc mode. Since the ambient vapor density in the LMPV is much lower than in the multi-anode device, voltage holdoff between electrodes is determined by the dielectric properties of vacuum.: Because there is then no reed to subdivide the interelectrode gap to support the applied high voltage, no interelectrode grids are required and the valve size can be substantially reduced. Additionally, the LMPV has only one anode (shown in Figure 2), rather than the six of a conventional valve.

Because the active volume of the valve is small (the vacuum envelope is about $30 \mathrm{~cm}$ in diameter by $60 \mathrm{~cm}$ in length), and because temperature control requirements of the valve are not stringent, the valve and most of its auxiliaries can be prepackaged at the factory. This allowed pretesting the valve at HRL before shipping and final installation. 

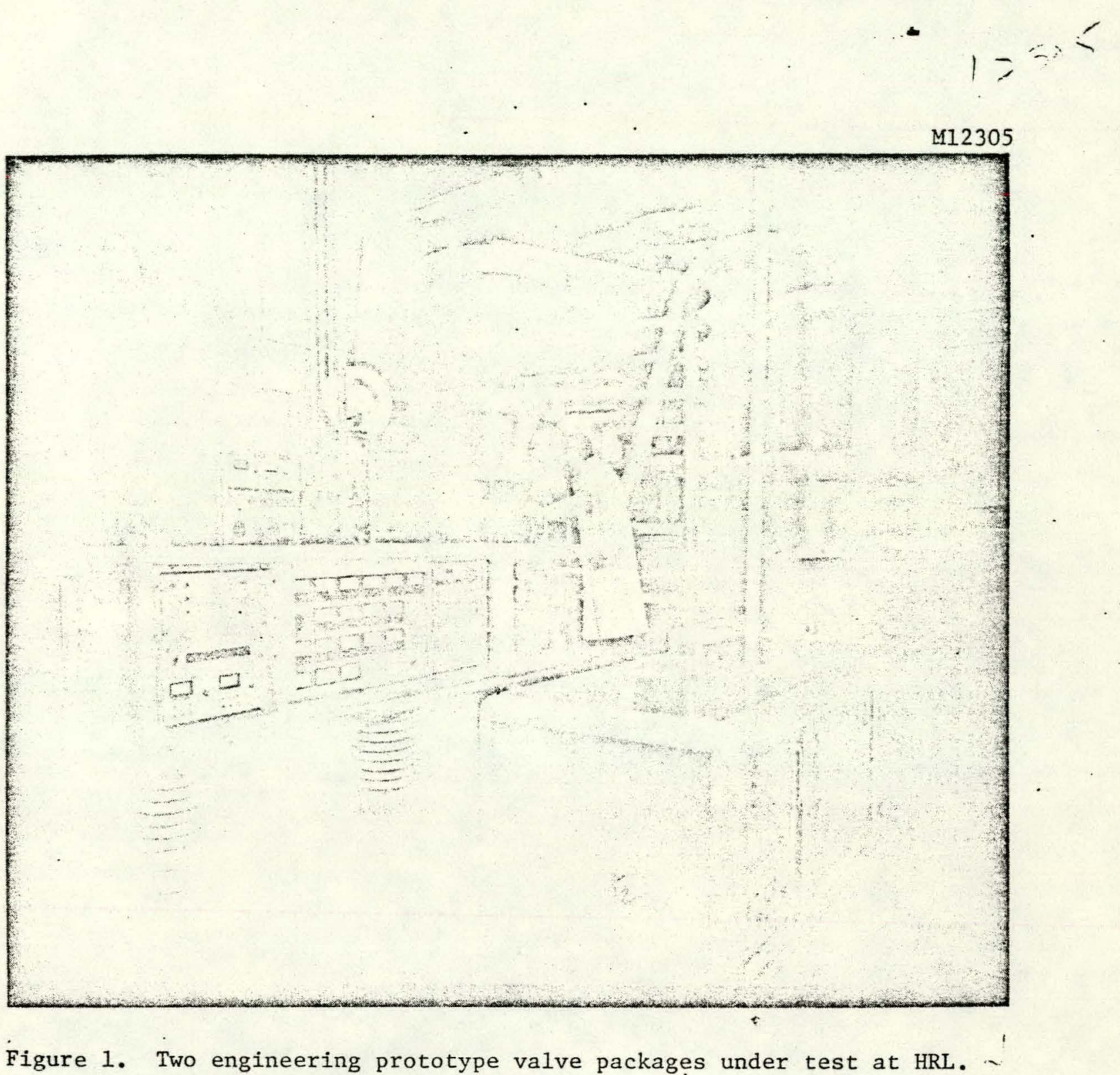

Figure 1. Two engineering prototype valve packages under test at HRL.

$$
1.0
$$




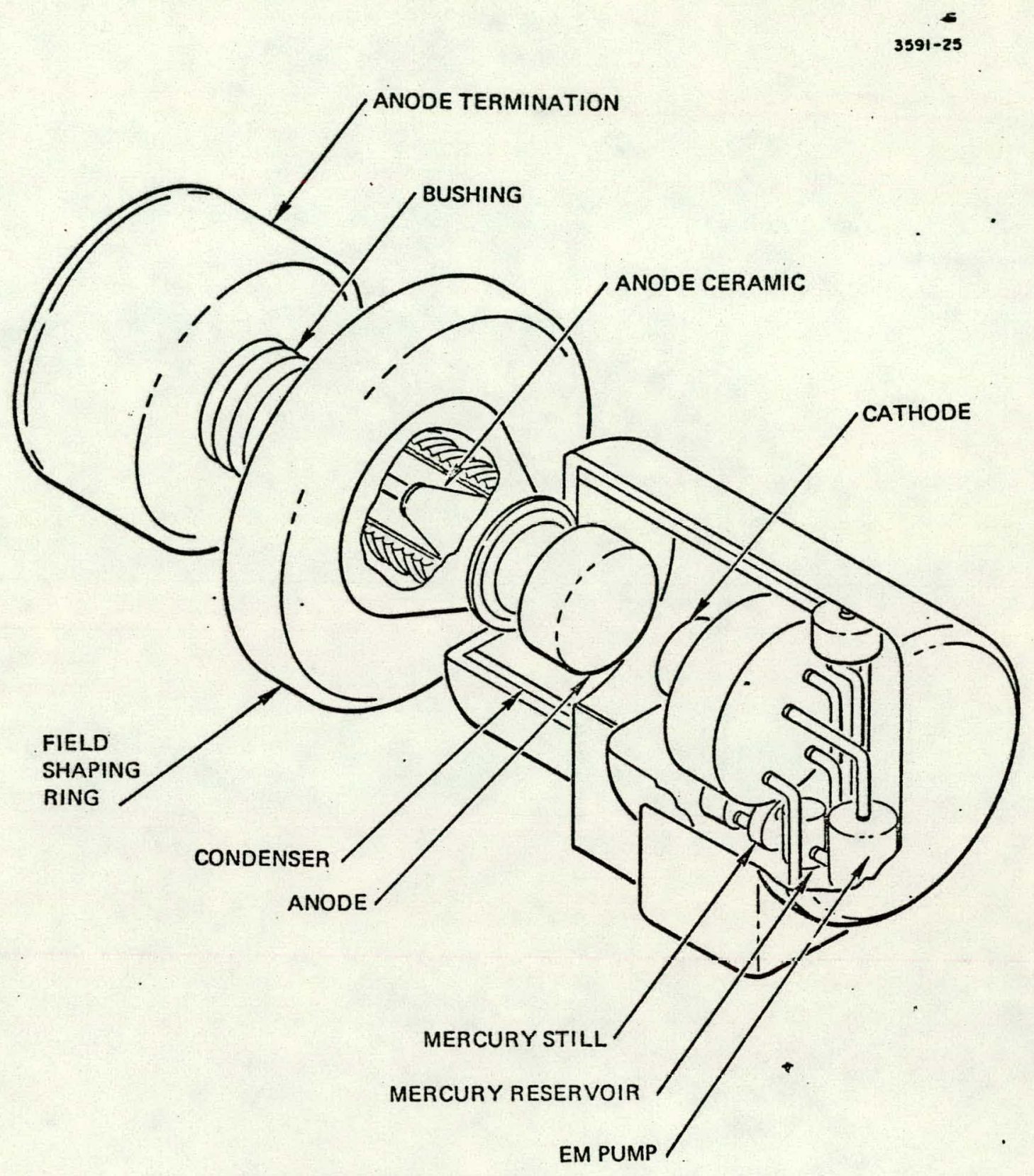

Figure 2. Liquid metal plasma valve. 
The Hughes valve is a simple, rugged structure consisting of three main components: anode, cathode, and condenser.

The vacuum envelope of the valve acts as a condenser (Figure 3 ). Because its temperature is kept below $-35^{\circ} \mathrm{C}$, impinging mercury atoms are rapidly condensed, and mercury can be returned to the cathode for reuse. The condenser temperature limits the ambient vapor pressure in the valve, with a consequent improvement in the voltage holdoff capability. The condenser area can be kept relatively small since the amount of mercury emanating from the cathode is small, this is a result of the limited free surface of mercury in the cathode throat. The cathode is force-fed mercury in such quantities that only an amount of mercury necessary to provide short-term overcurrents is actually exposed to the discharge chamber. At an operating electron-to-atom emission ratio of 50 (much larger than that of a normal mercury arc discharge), the amount of mercury in the cathode throat is so small that it can be held in place by surface tension forces. The LMPV derives'its orientation independence from this fact.

Mercury ions and neutrals impinging on the anode are reflected to the condenser wall, which is also the vacuum envelope of the valve. Since. the condenser temperature is kept below $-35^{\circ} \mathrm{C}$ and since the sticking coefficient at that temperature (even for relatively fast mercury atoms) is close to unity, nearly al1 mercury particles are rapidly condensed. The ambient vapor pressure can thus be kept at a low level, with conse- quent improvement in the dielectric integrity of the valve (see Figure 4 ).

The LMPV has a cylindricatl vacuum envelope surmounted by a conical field-shaping cone and toroid, a fiberglass cylindrical bushing, and a second toroidal termination. The fiberglass bushing is pressurized with $\mathrm{SF}_{6}$ to about $24 \mathrm{psig}$. A single molybdenum anode suspended on a molybdenum shaft, which projects into the vacuum envelope through an alumina feedthrough bushing. The anode itself is spun from molybdenum sheet stock, and electron-beam (E-beam) welded to its backplate, shaft, and the molybdenum sputter shield. 


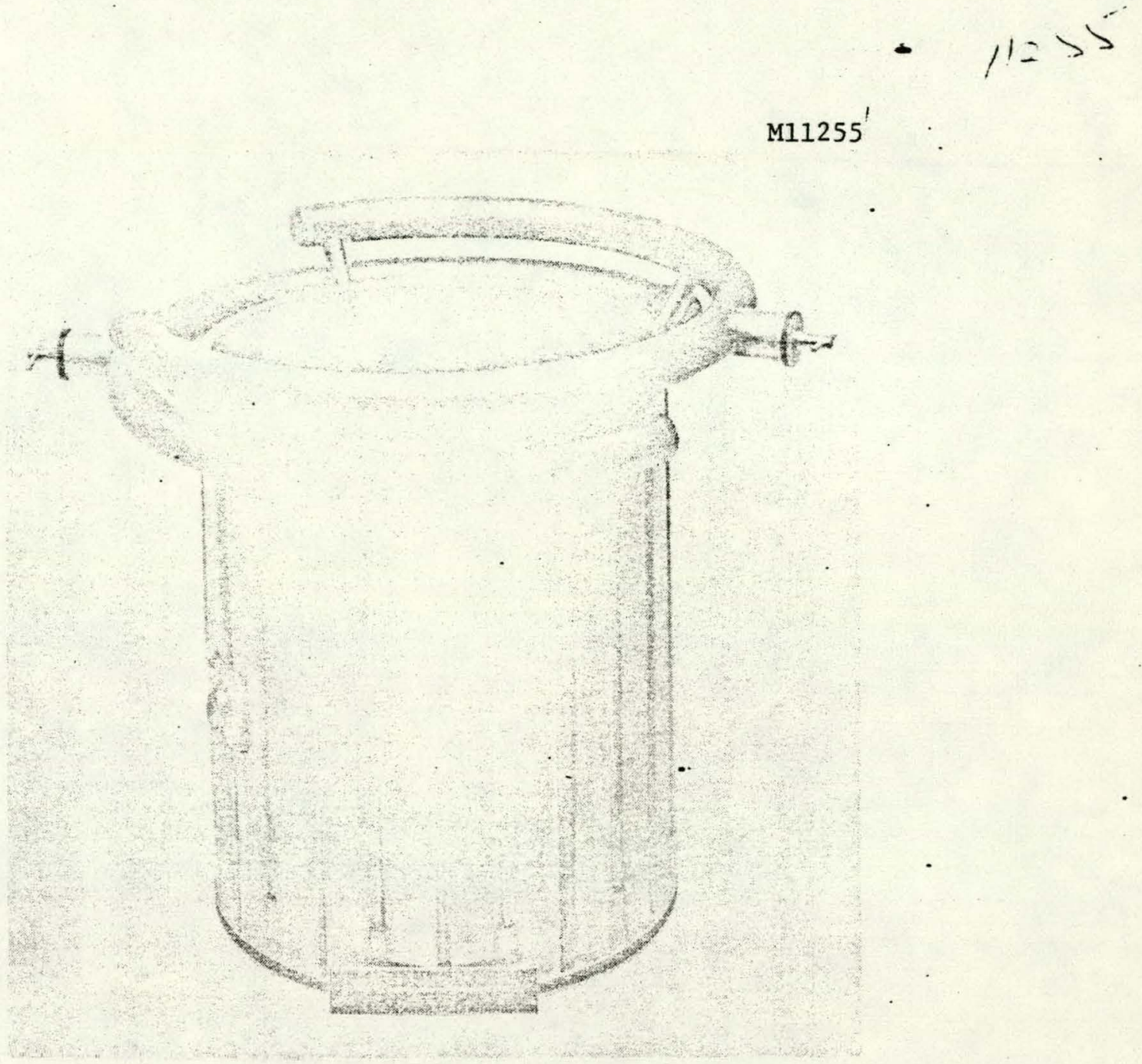

Figure 3. Vacuum envelope of the LMPV; it also acts as a condenser. 
$3591-\frac{1}{8}$

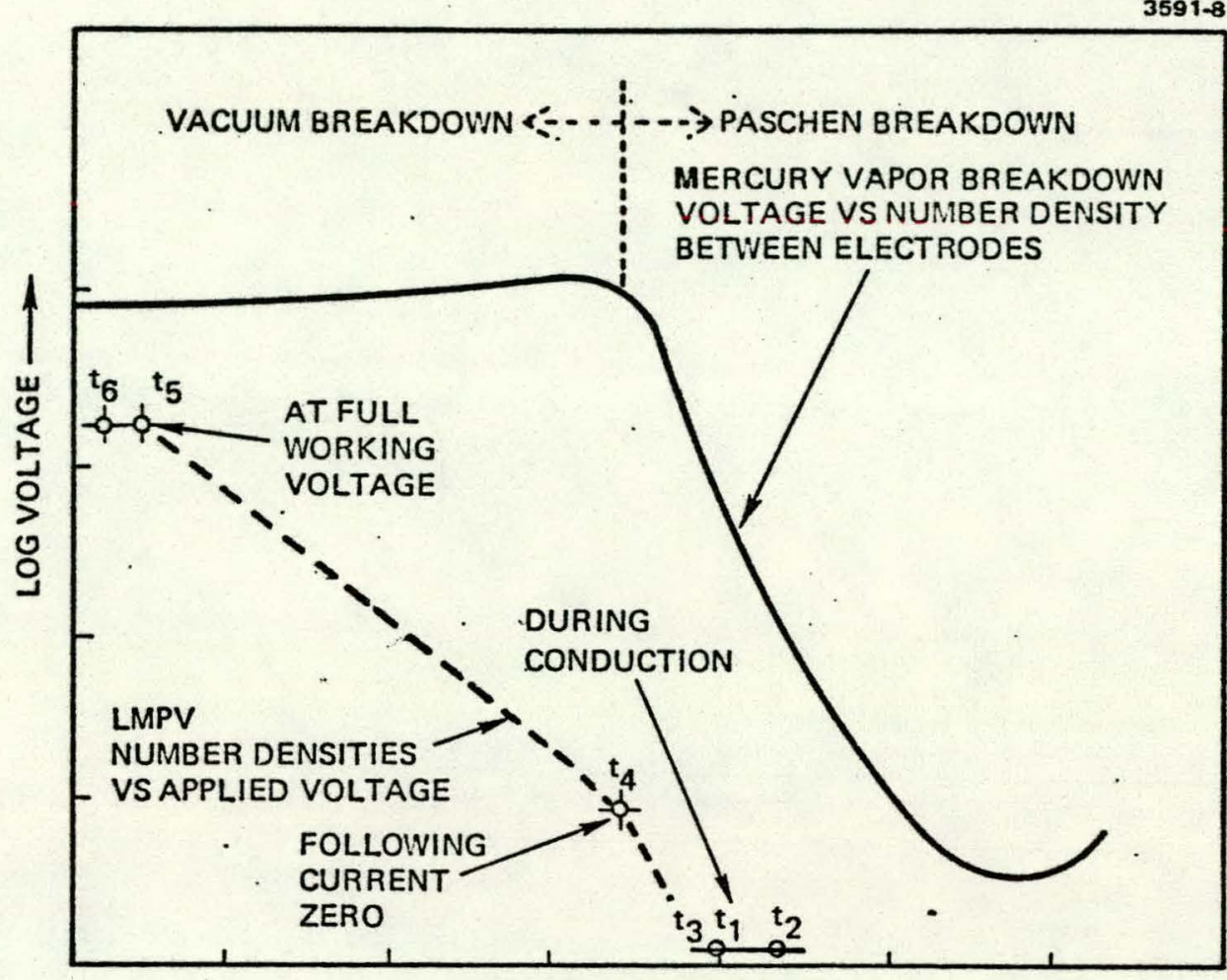

LOG NUMBER DENSITY $\longrightarrow$

Figure 4. Breakdown voltage in mercury vapor as a function of number density, and LMPV number densities as a function of voltage.

The anode is about $5 \mathrm{rm}$ ahove the face of the cathode; the cathode is at the same potential as the cylindrical vacuum envelope and is an integral part of it. Mercury from the cathode is condensed on the inside of the cylindrical vacuum envelope (which is kept at $-35^{\circ} \mathrm{C}$ ), so that the vapor pressure in the valve is $2 \times 10^{-6}$ Torr. The.pressure of permanent gases in the valve is much lower than this because during processing the valve is baked out to $400^{\circ} \mathrm{C}$. Appendage ion pumps, which have no moving parts, maintain a low internal pressure in the valve and also measure the pressure.

There is no grid between anode and cathode; the valve is ignited at the beginning of each conduction cycle. In the LMPV, conduction between the electrodes occurs when they are bridged by a plasma. This plasma is composed of an equal number density of mercury ions and electrons from the cathode which impinge on the anode.

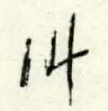


The discharge has highly mobile, luminous cathode spots anchored at the mercury-molybdenum interface in the cathode poolkeeping structure. The free surface of mercury in the cathode is small so that thermal evaporation is low. As a result of the low pressure, the valve can be made to operate continuously in the vacuum arc mode of discharge. This mode is the type of gas discharge characteristic of vacuum interrupters and triggered vacuum gaps. However, all of the prior dwvices are limited to intermittent duty operation, whereas the mercury cathode of the LMPV permits continuous operation. The voltage drop across the plasma during the conduction phase is 20 to $30 \mathrm{~V}$ (discharge voltage) and is almost independent of valve current. This voltage is considerably lower than that for either the conventional mercury or the solid-state valve, resulting in greatly reduced operating losses.

The ions and neutrals leaving the cathode come either from the spot itself or from the very limited free surface of mercury in the cathode throat. Particles from the spot have velocities thä̈ are high compared with those from the free surface and that are an order of magnitude or more higher than thermal velocity $\left(\sim 4 \times 10^{4} \mathrm{~cm} \mathrm{~s}^{-1}\right)$. Since the average particle transit time between electrodes is about $20 \mu \mathrm{s}$, clean-up of plasma in the anode-cathode gap is very fast following a current zero, as compared to a conventional mercury valve, in which the majority of particles have slow thermal velocities. The rate of application of reverse voltage (rectifier operation) that can be tolerated without flashover is higher and the deionization margin needed (inverter operation) is lower than for conventional mercury valves. With fast plasma decay, the valve can recover rapidly against applied voltage, and the valve can handel greater rates of current change prior to current zero. Following the plasma decay, voltage hold-off between electrodes is determined by the valve geometry and the dielectric properties of vacuum. 


\section{B. LMPV AUXILIARIES}

Figure 5 shows the electronics package for the engineering prototype valve and the fault annunciation console. This package includes the igniter power supplies, the electromagnetic pump that controls the mercury flow to the cathode, various temperature-sensing meters and flow meters, and the multiplex system for transmitting data from the valve to ground. It also sends the ignition signal to the valve.

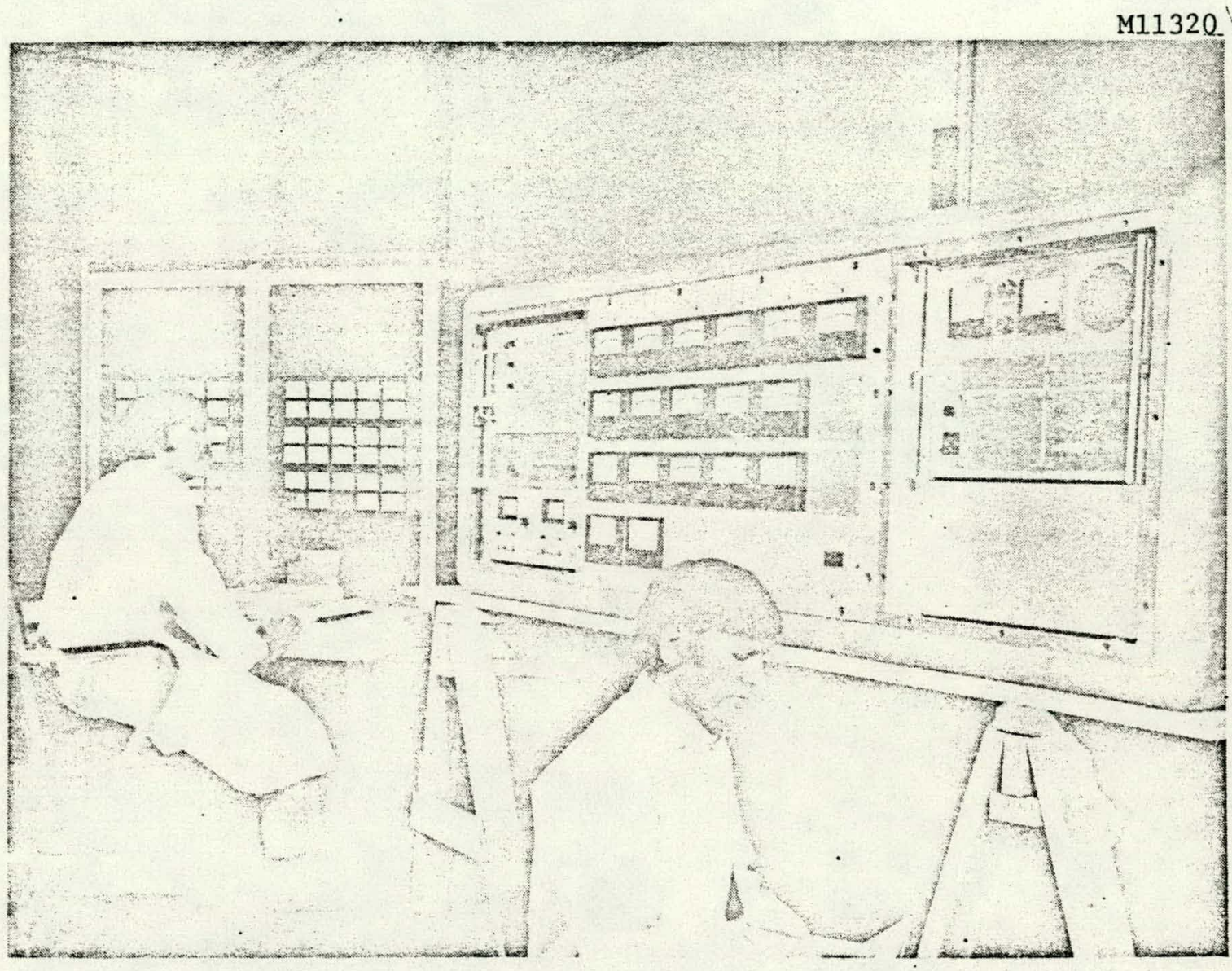

Figure 5. Auxiliary electronics package for the first engineering prototype and the annunciation console. 
The valve uses three cooling loops, which ultimately reject their heat to the facility process cooling water. The first of these is liquid freon. R11; since it maintains the vacuum envelope-condenser at about $-35^{\circ} \mathrm{C}$, the mercury vapor pressure is low but the mercury remains liquid and can be recirculated to the cathode. The R1I is in turn cooled by a compressor using R502. The second cooling system uses Dowtherm A (an organic coolant) to remove the heat from the valve anode, maintaining it at about $125^{\circ} \mathrm{C}$ during operation, but not less than $100^{\circ} \mathrm{C}$ during stand-by (to prevent mercury condensation). The third cooling system uses deionized water to remove heat from the cathode.

Figures 6 through 13 show some of the technology involved in making at IMPV package. The condenser (Figure 3 ) is made of stainless steel, with four cooling quadrants through which liquid freon RlI is circulated. The cathode (Figures 6 to 8 ) is made mainly of arc cast molybdenum, with the faceplate E-beam welded to the poolkeeping structure and the shroud spun from 0.25 in. thick molybdenum sheet stok. The anode (Figures 9 and 10) is also made from a molybdenum spinning, E-beam welded to its cylindrical sputter shield with toroidal termination (Figure 10). The molybdenum anode shaft, which is about $30 \mathrm{in.}$ long and is E-beam welded to the anode backplaie, supports the anode and allows Dowtherm to be circulated to cool the anode face. Figure 11 shows the sputter shield through which the annie shaft enters the condenser; this sputter shield, including the toroidal termination, is also spun from molybdenum sheet stock.

Figure 12 is a scale model of the LMPV package as it would have looked when installed at Celilo. $\mathrm{SF}_{6}$-filled porcelain insulators (Figure 13) carry fiber optics to provide commands to the electronic package in the valve cart (Figures 14 and 15) and to return data to the control console, which would have been installed in the basement aisle at Celilo (Figure 16).along with the R11-R502 refrigeration system to cool the valve condensers, and the Dowtherm system (Figure 17) to cool the valve anodes. Figure 14 gives the dimensions of the LMPV cart, the valve, and the voltage divider in parallel with it. 


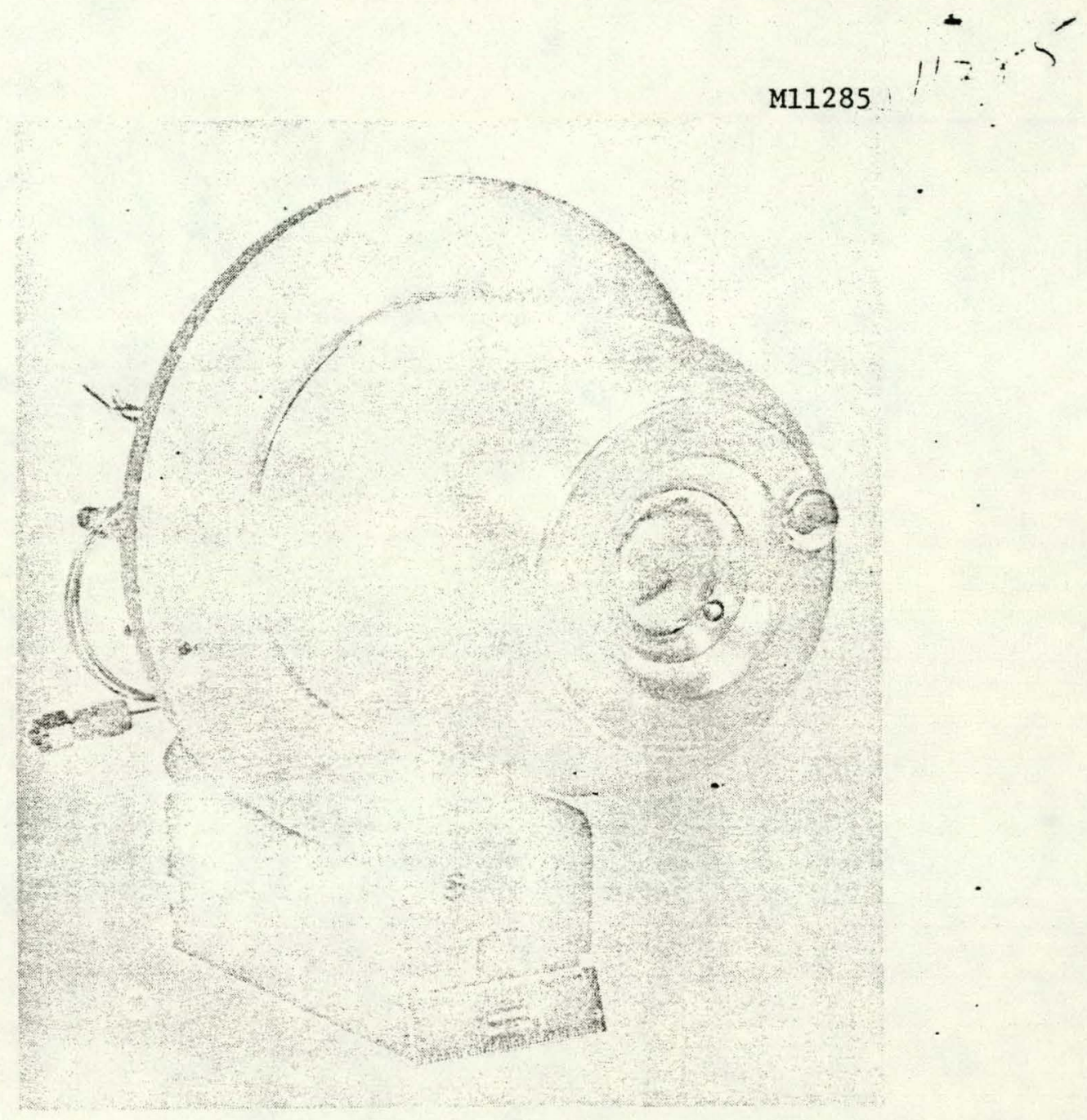

Figure 6. Completed cathode as seen from anode. 


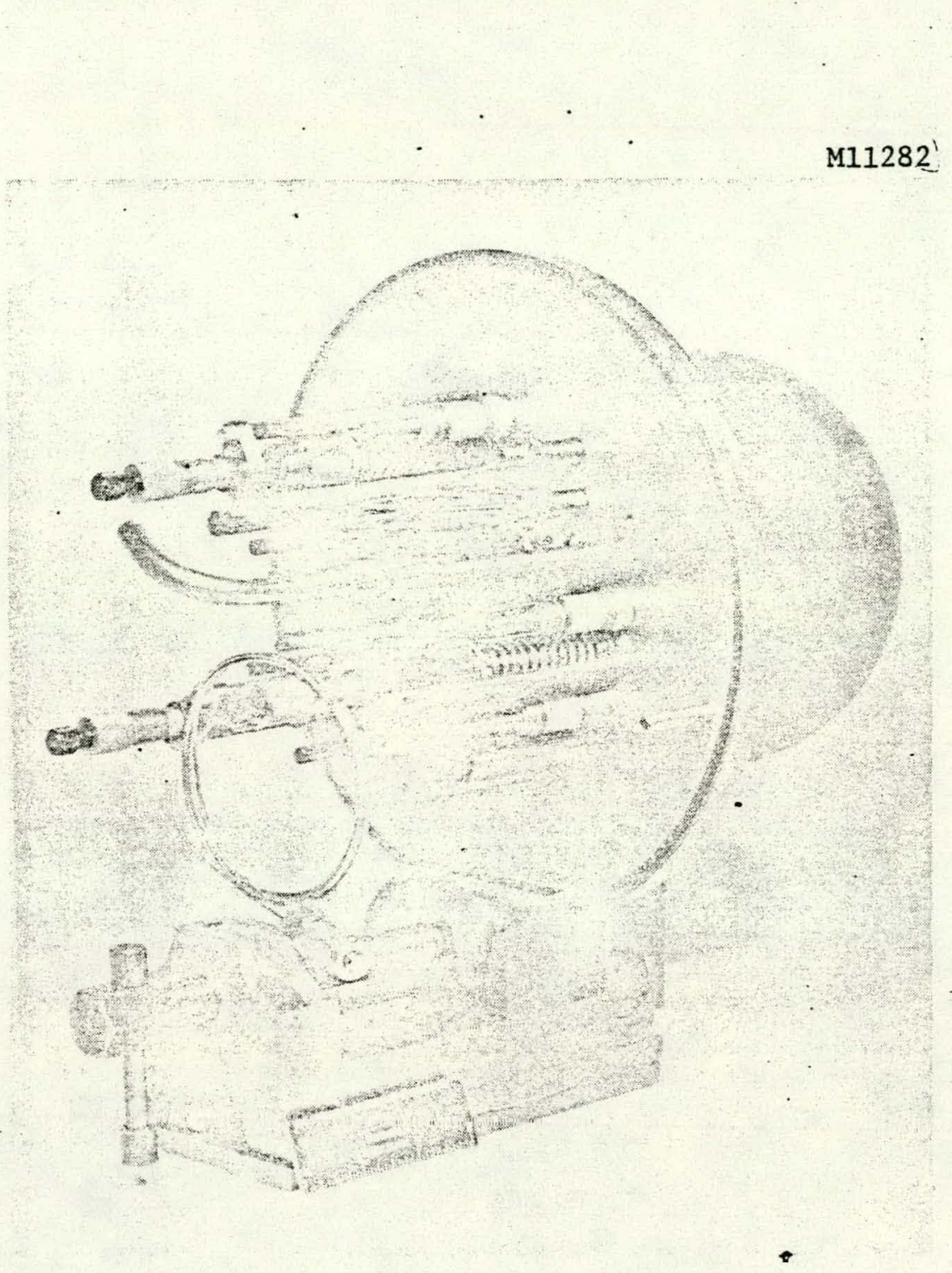

Figure. 7. External end of cathode. 
M11251

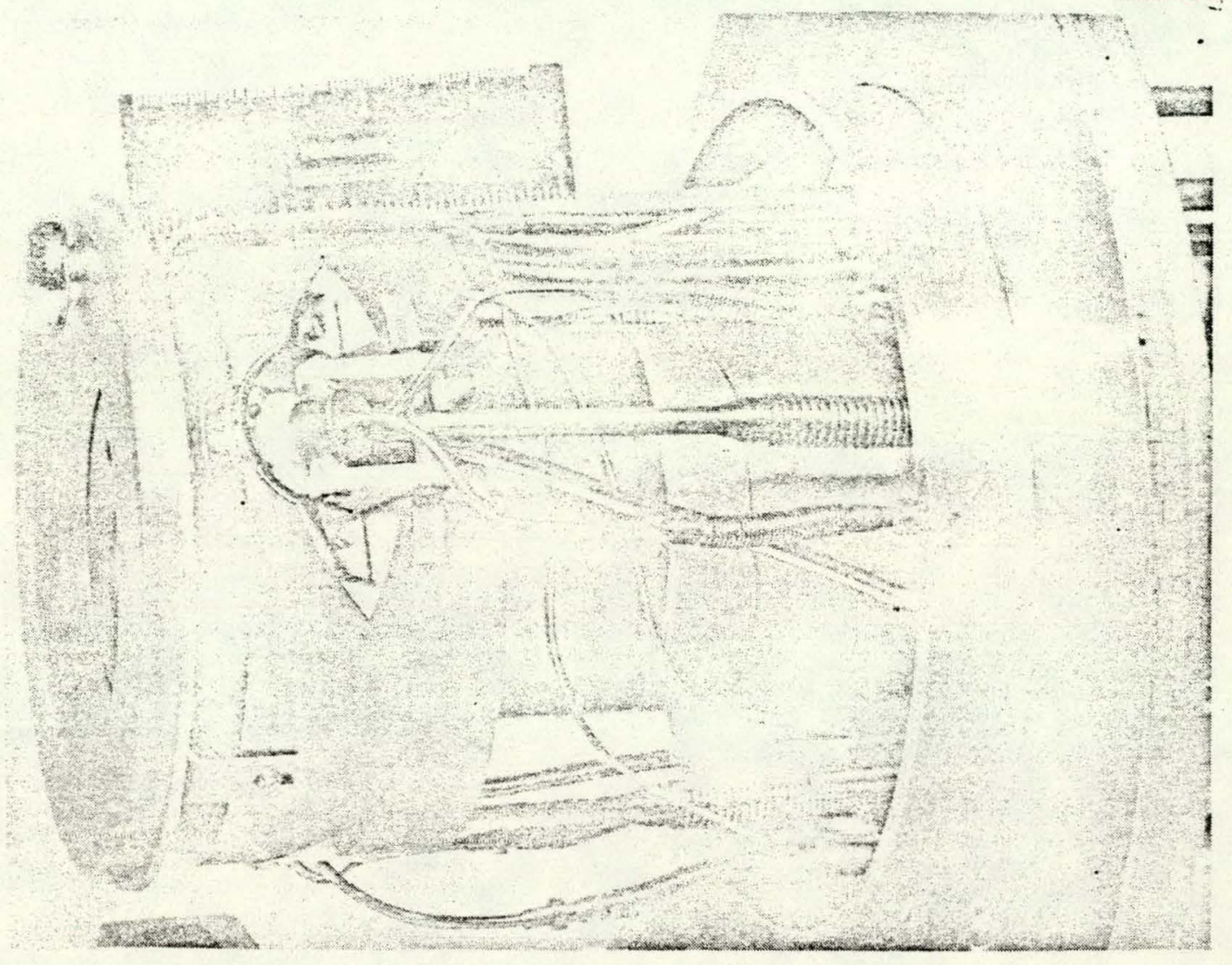

Figure 8. LMPV cathode during assembly. 

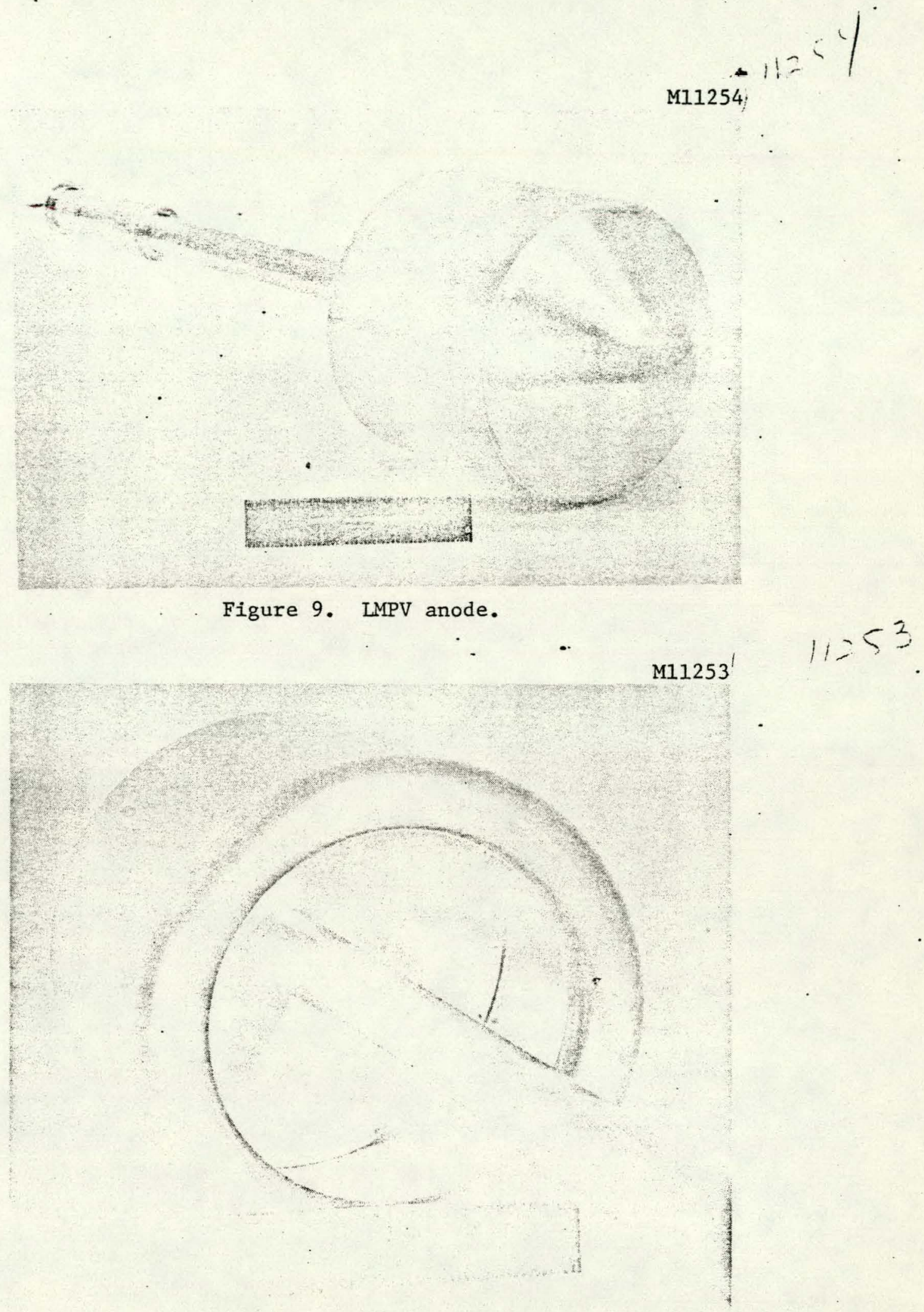

Figure 10. Anode rear view. 


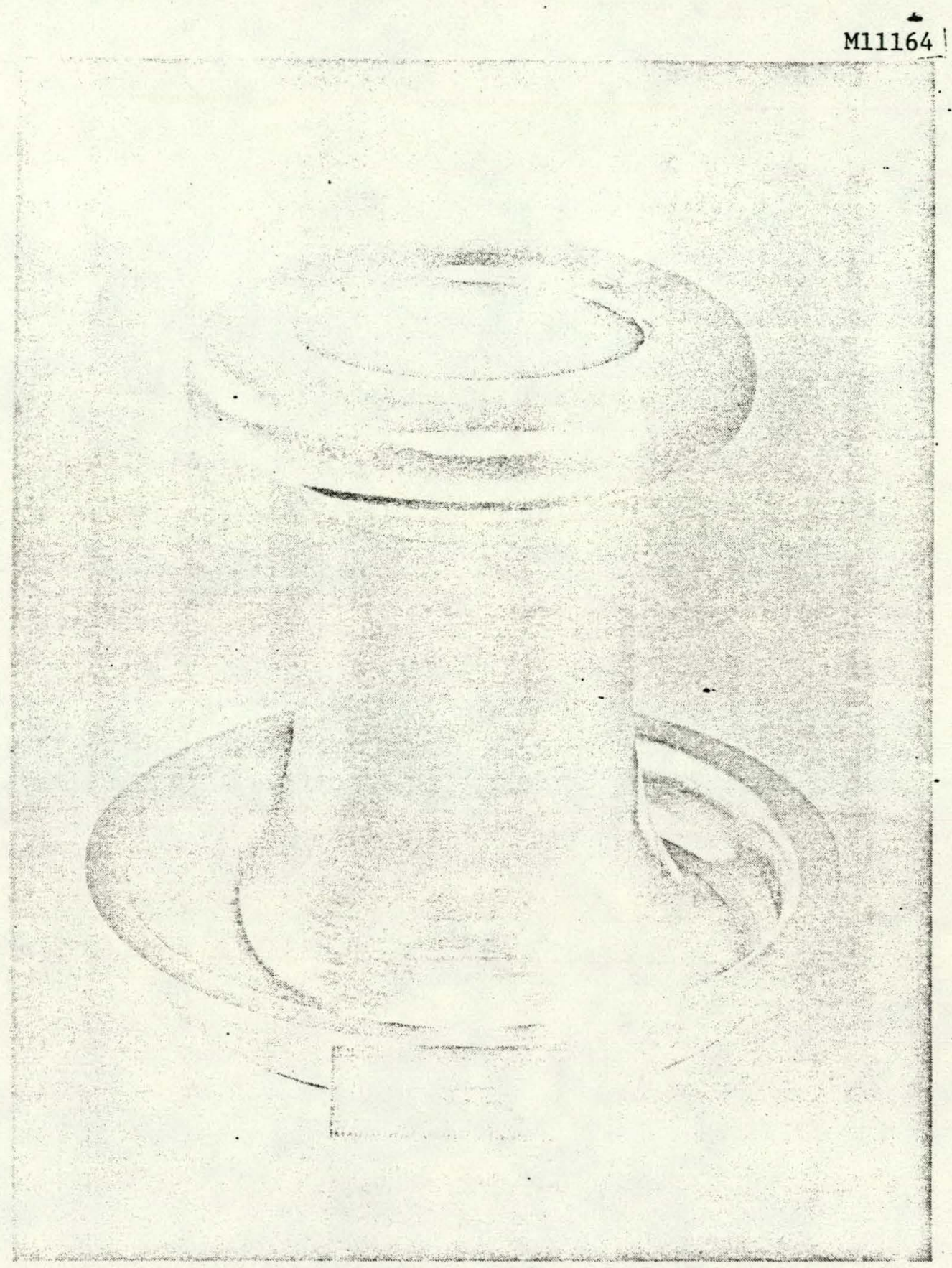

Figure 11. Sputter shield spun from molybdenum.

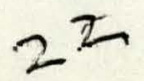




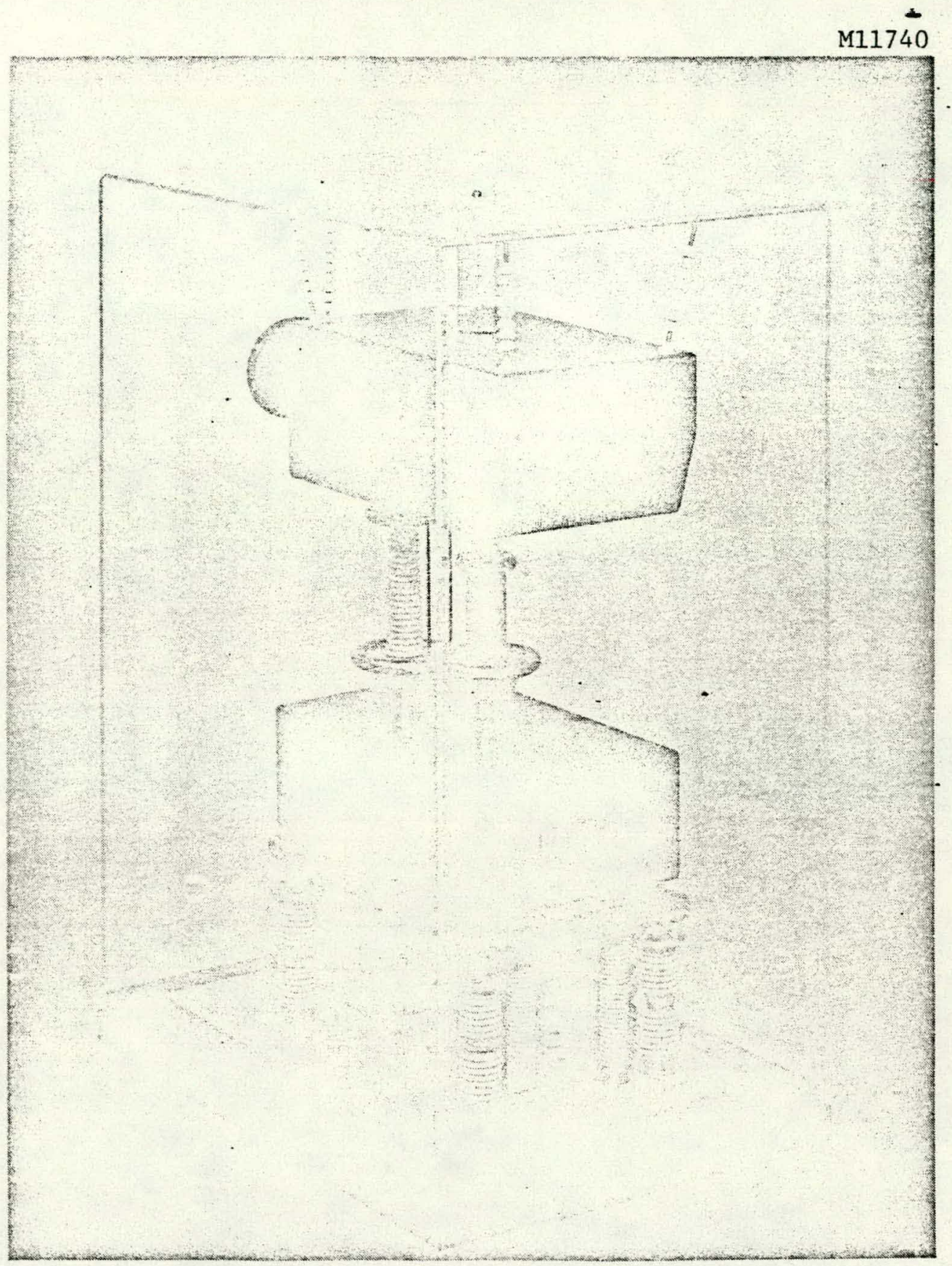

Figure 12. Model of an LMPV package installed at Celilo. 


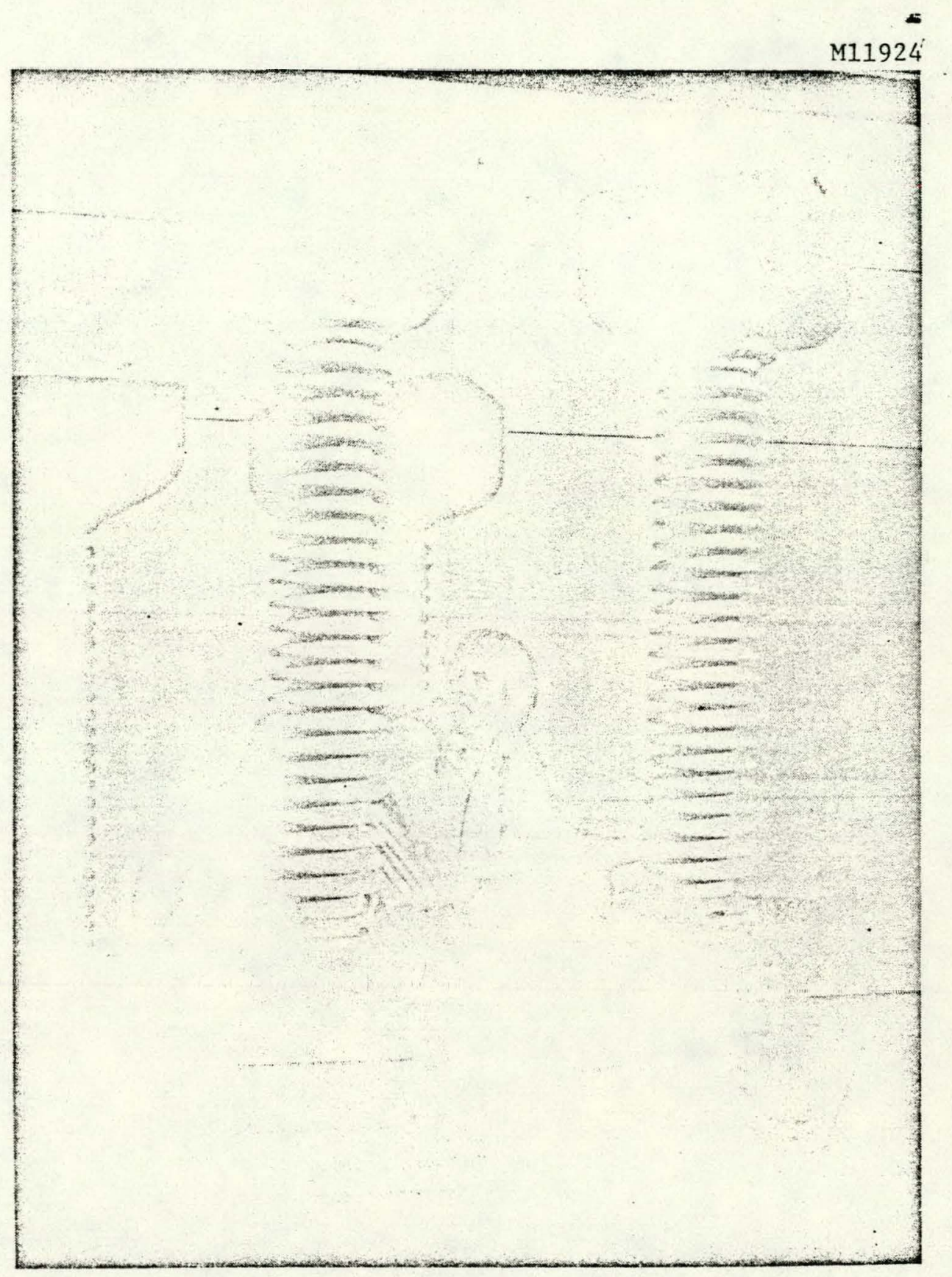
Figure 13. Fiber-optic assemblies for the valve hall at !
Celilo. 


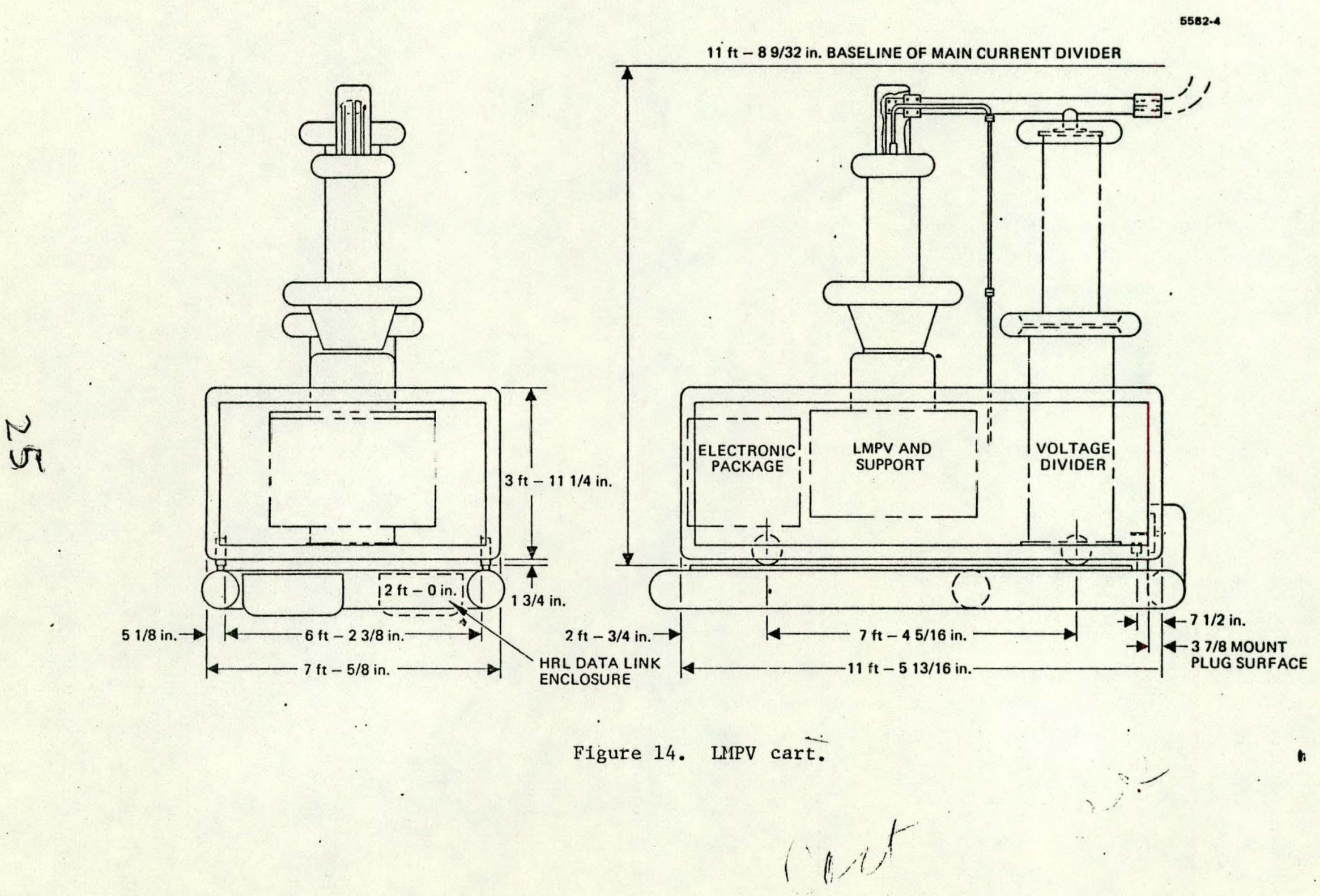




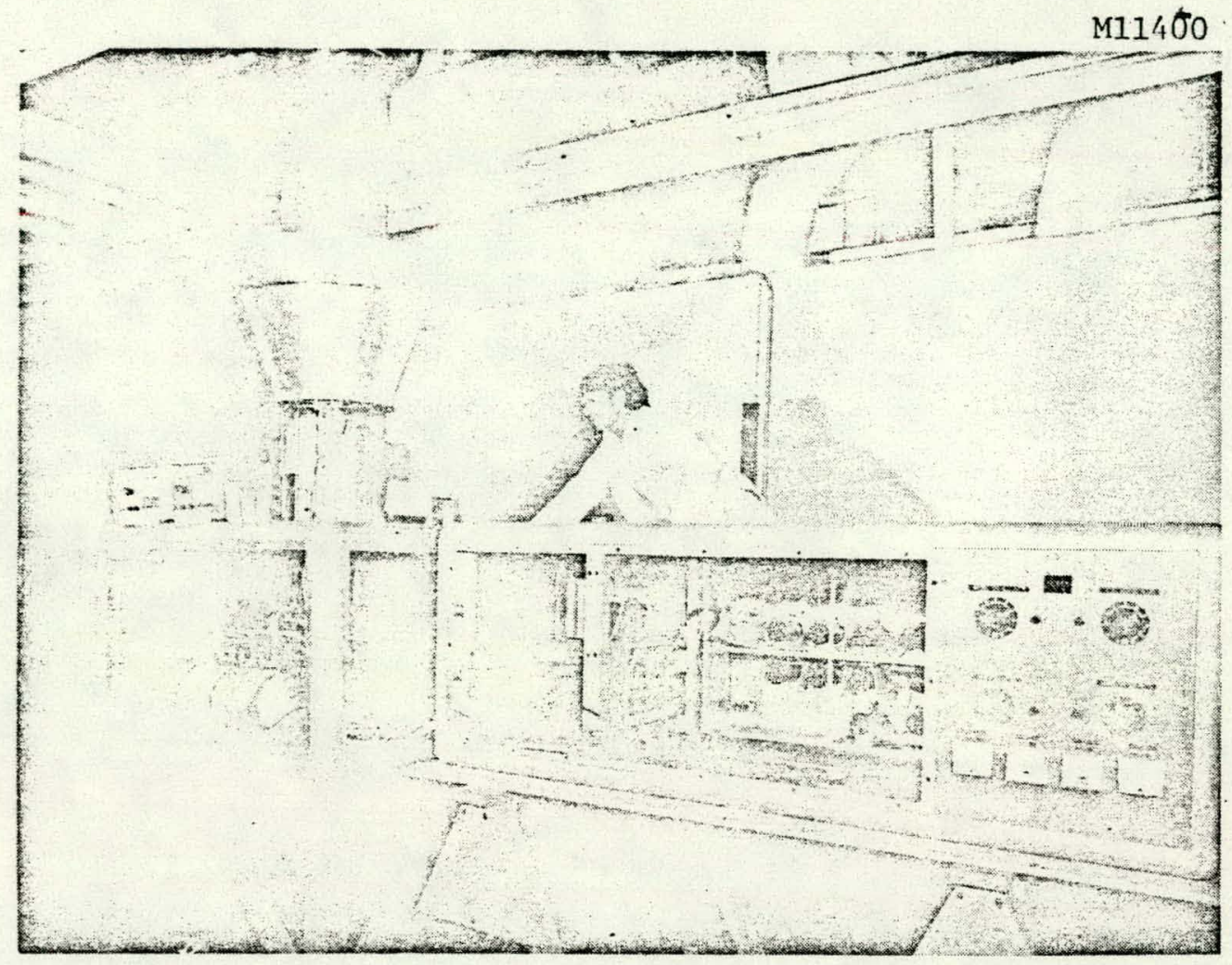

Figure 15. Engineering LMPV and electronics package.

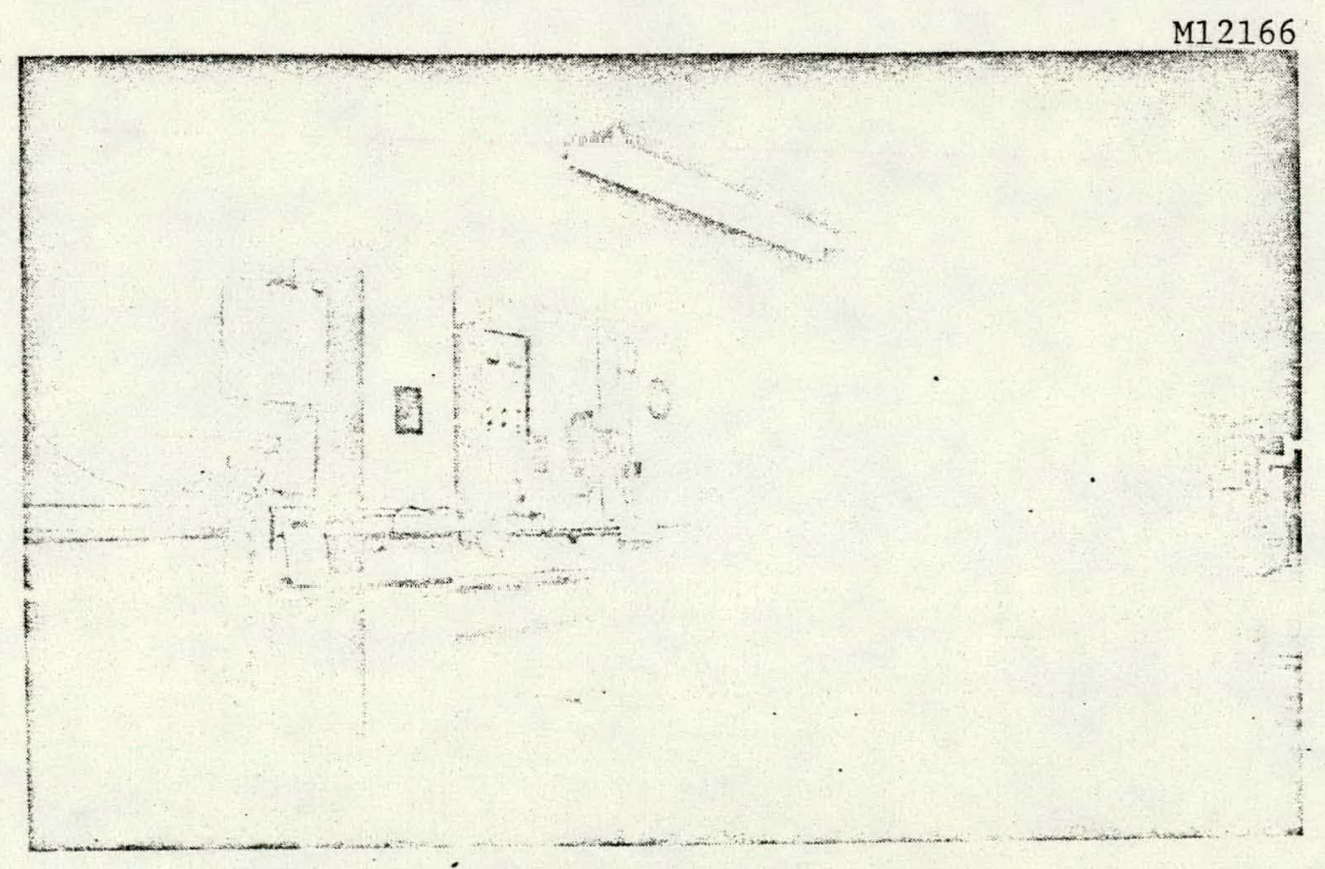

$1=166$

- Figure 16. Basement aisle at Celilo. 


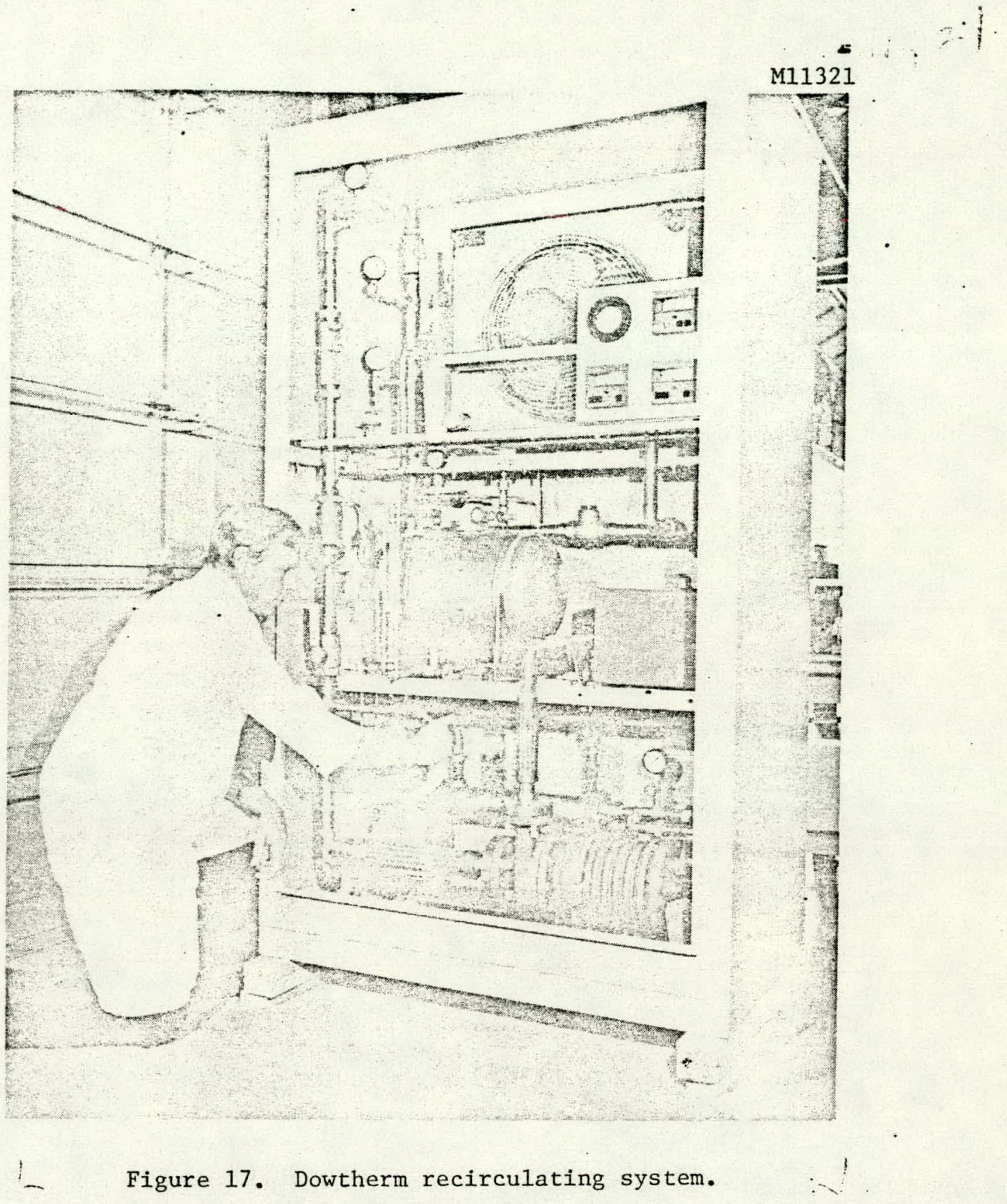


During the LMPV development program, we built (and modified) two engineering prototype valves and their auxiliaries. The synthetic test facility was upgraded to allow testing in excess of $3000 \mathrm{~A}$ peak and $240 \mathrm{kV}$. Facility changes to Group I in Celilo were also made.

\section{MONITORING STATION}

The goal of the second program task was to acquire and analyze data on valve and system characteristics for the system operating under normal and abnormal service conditions. Analysis of this data was to be used to define specifications for the valve and other apparatus and to design tests to demonstrate compliance with these specifications. A system monitoring package was designed and installed at Celilo to record transient phenomena, with both pre- and post-disturbance data, in the current and voltage waveforms of valves and the bridge group under normal and abnormal conditions. The system at Celilo is being monitored. Figure 18 shows the transient event recorder electronics prior to its shipment to Celilo.

Voltage dividers and current sensors were installed in Group I of the BPA converter station at Celilo to monitor the bridge current and voltage and the current and voltage of the converter valves in the SA and SC positions. Figure 19 shows one of the current sensors in position; Figure 20 shows one of the voltage dividers. Figure 21 is a general view of the valve hall showing all three voltage dividers and current sensurs. Data from the sensors and dividers in the vaìve hall is transmitted to the control room via fiber optics, which was laid in cushioned panduit (shown in the upper left-hand corner of Figure 16, the basement aisle at Celilo). In the control room, a transient event recorder with memory (Figure 22) stores both pre- and post-disturbance data, so that, for the AC, SA, and SC positions in Group I, the current and voltage waveforms unter normal and abnormal conditions can be examined. This system monitors the performance of the ASEA valves in the SA and SC positions. 


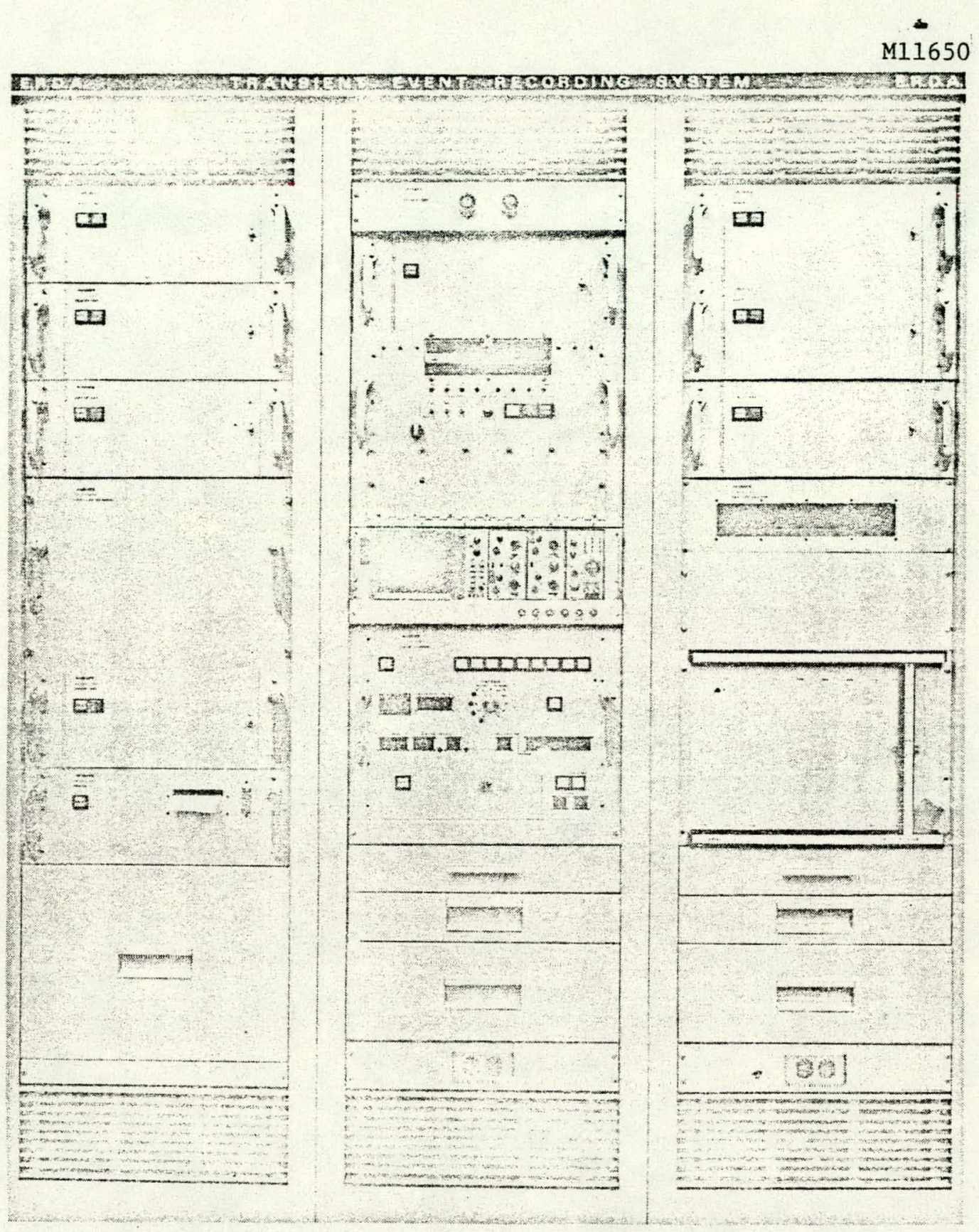

Figure 18. Transient event recorder. 


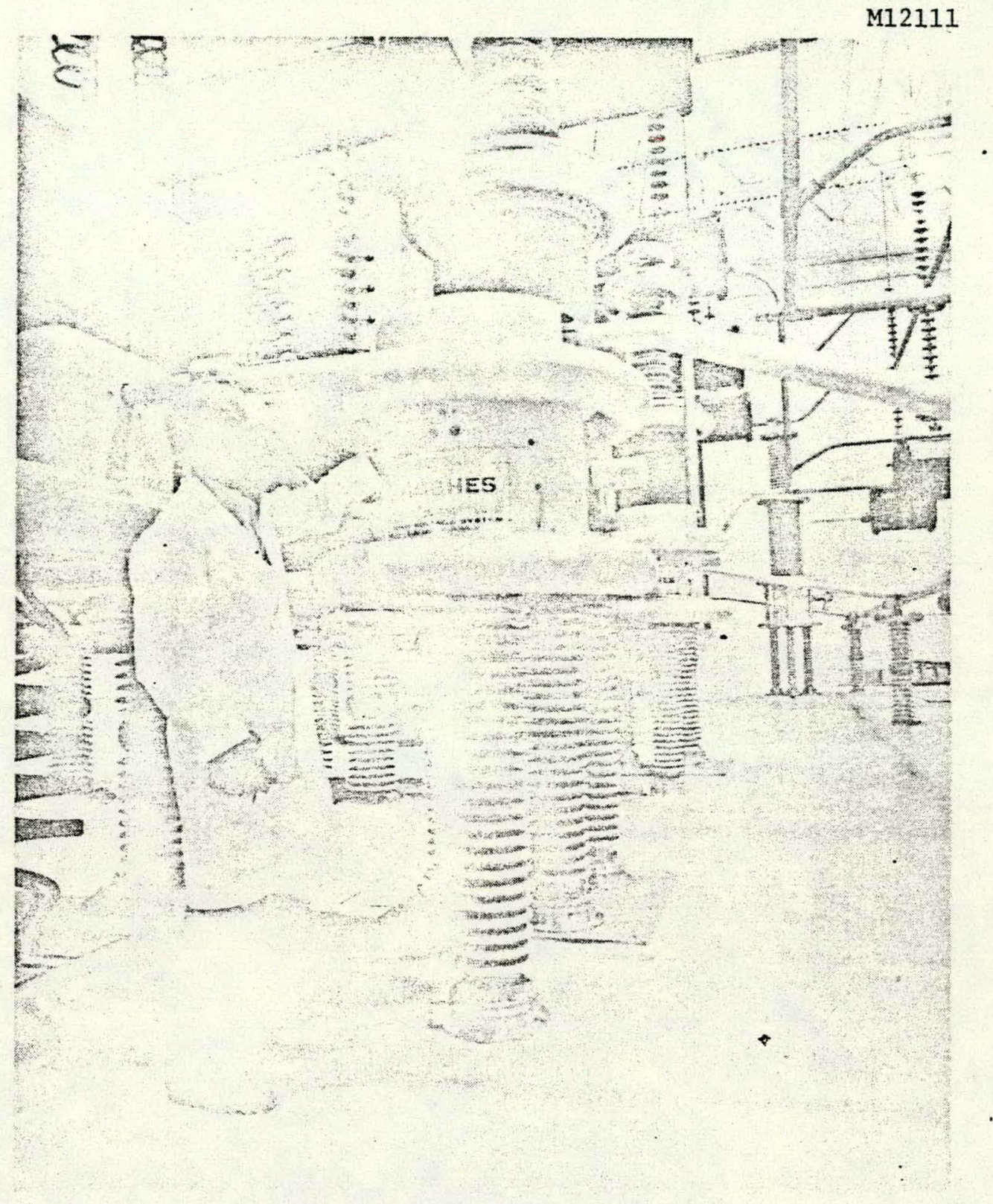

Figure 19. Valve current sensor. 


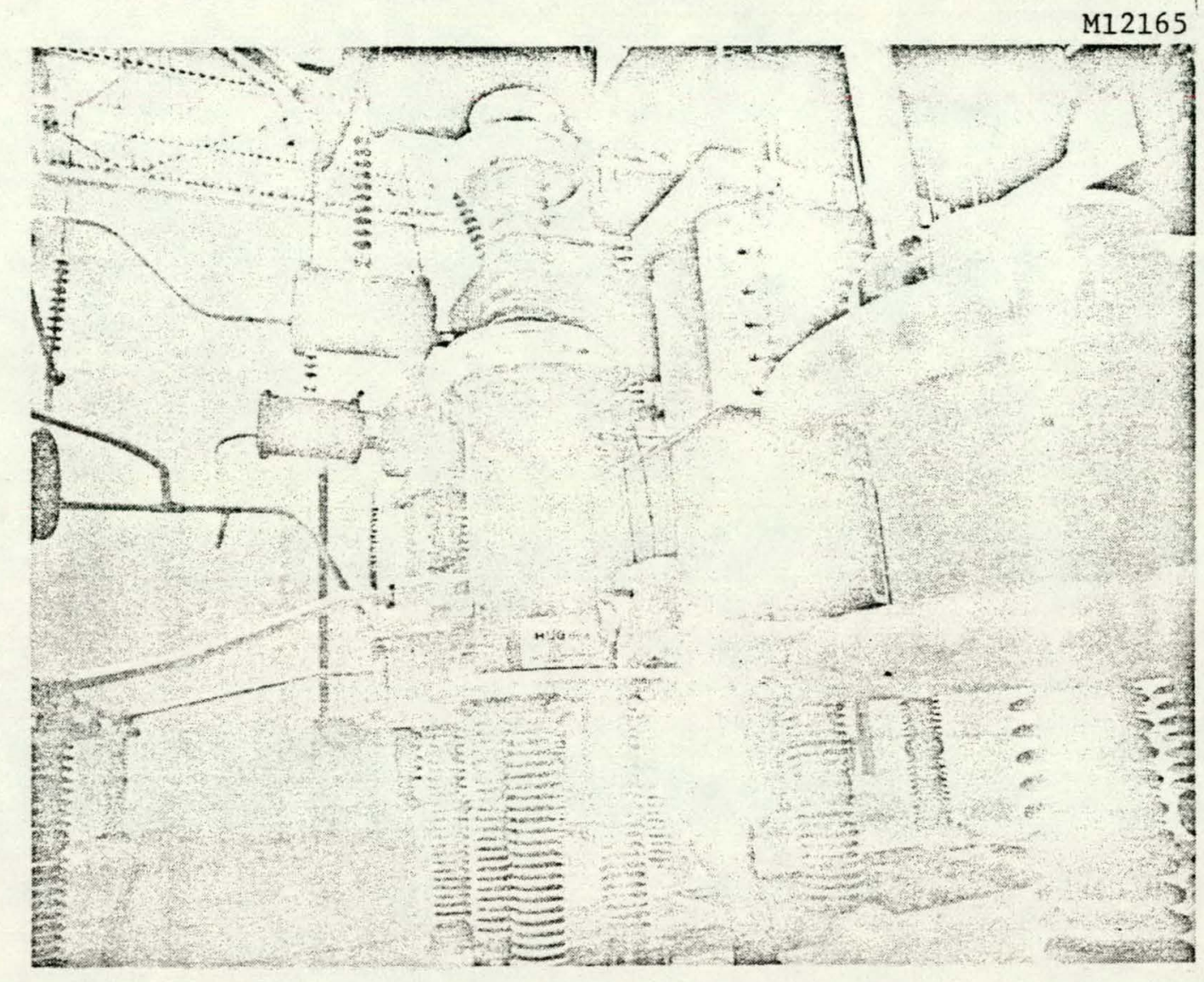

Figure 20. Voltage divider.

31 


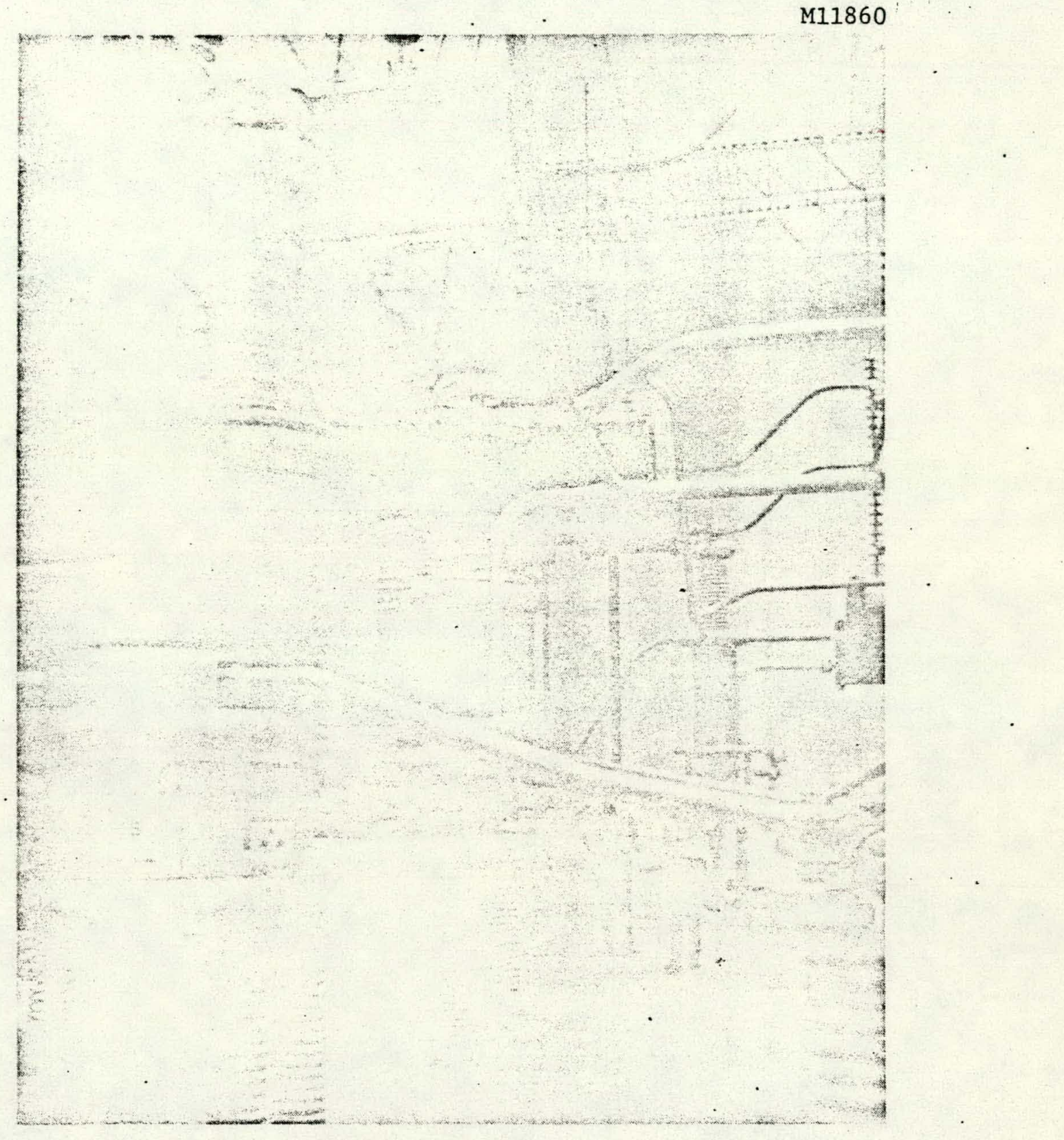

Figure 21. Current sensors and voltage dividers installed in Group I at Celilo. 


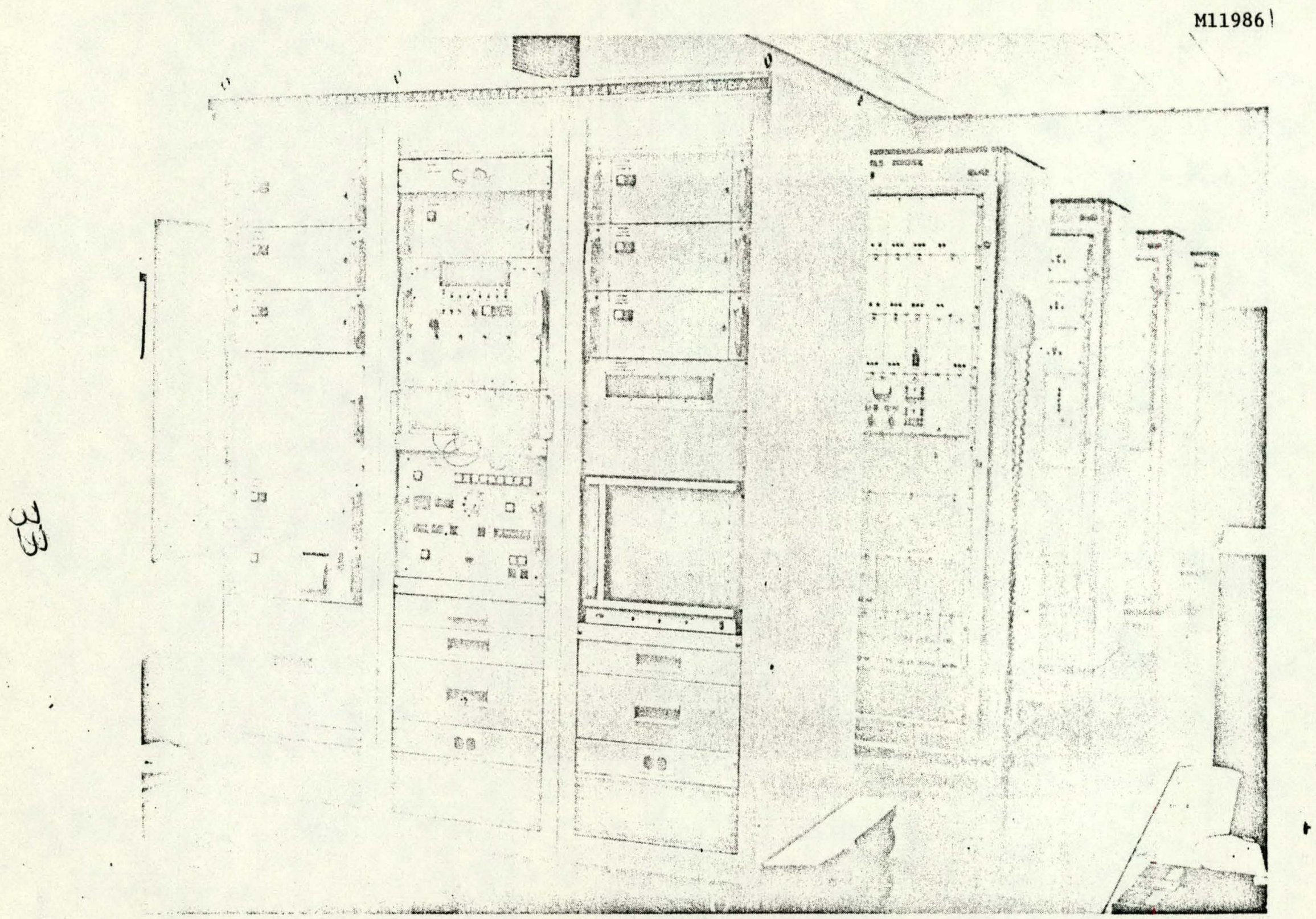

Figure 22. Transient event recorder installed at Celilo. 
THIS PAGE

\section{WAS INTENTIONALLY LEFT BLANK}




\section{SECTION 2}

\section{DESIGN AND DEVELOPMENT OF CONVERTER VALVES}

\section{A. ENGINEERING PROTOTYPE VALVES}

Figure 23 shows the engineering prototype LMPVs that were fabricated. The valve comprised several specific components: cathode, condenser, alumina insulator, anode, etc. These are integrated first as a vacuumtight assembly and then with auxiliaries to form a valve package.

The first engineering prototype valve was completed while the second valve was being assembled. Minor leaks (which were repaired) were found in the condenser of the first valve. This valve was placed on bakeout on 7 November 1975 and was tipped off on 22 November 1975 with a base pressure of $8 \times 10^{-8}$ Torr. While on the bakeout station, the valve was hipotted to $100 \mathrm{kV}$ (power supply limit) without showing either breakdowns or outgassing.

For processing, the valye was mounted on the bakeout facility and connected to a large ion pump. Figure 24 shows the valve being prepared for processing. The bakeout oven consists of a large metal bell with heaters in three zones on its outside surface. With the bell in position, a rough vacuum ( $10 j \mathrm{~m} \mathrm{Hg}$ ) can be held on the outside of the valve while a high vacuum ( $\sim 10^{-8}$ Torr) is maintained on the inside. The temperature of the valve can be raised to $450^{\circ} \mathrm{C}$ in slow stages to outgass all components thoroughly. When the ambient pressure is sufficiently low, indicating a proper level of internal cleanliness, the valve is sluwly coolcd, and the pumping tube is pinched off, Residual outgassing of permanent gases is removed by one or more small appendage ion pumps attached at the cathode end of the valve. Ion pumps do not have any moving parts: pumping is achieved by sputter deposition.

The temperature of the valve was raised in slow stages ot outgas all components thoroughly (the temperature outgassing was done at a pressure of above $1 \times 10^{-5}$ Torr; however, at $300^{\circ} \mathrm{C}$ the ion pump became overloaded. 


\section{THIS PAGE WAS INTENTIONALLY LEFT BLANK}




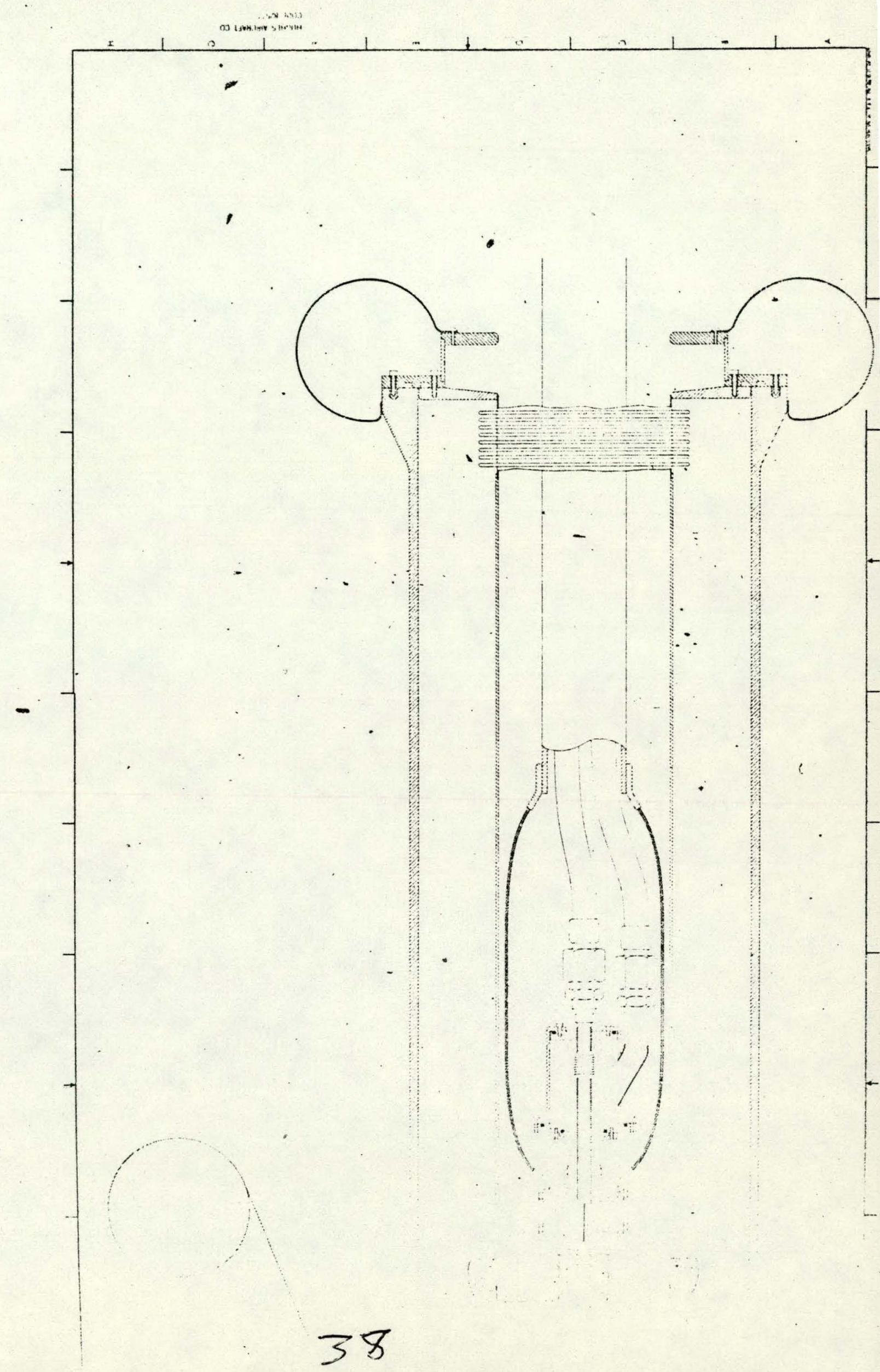




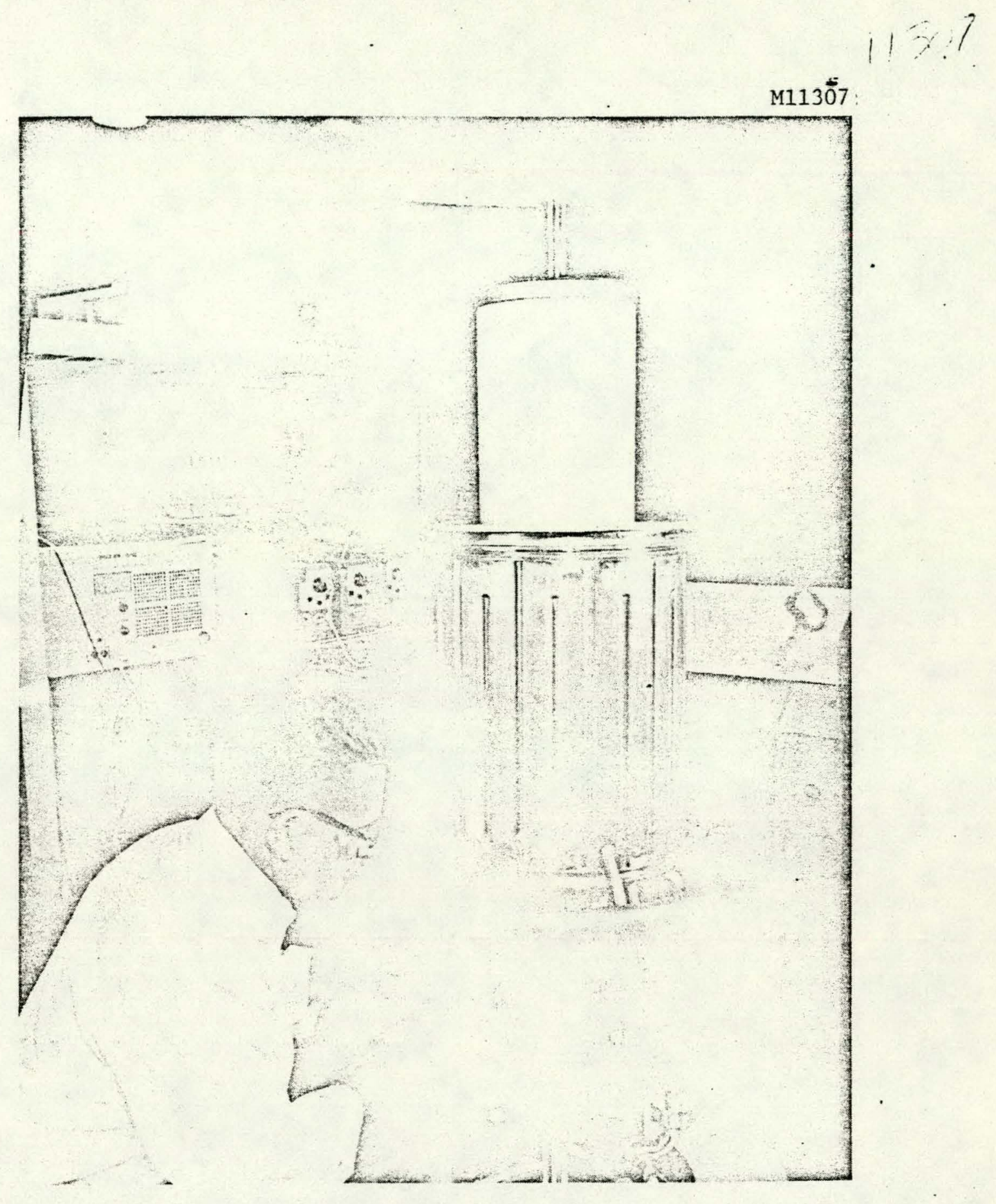

Figure 24. Engineering prototype valve on bakeout station. - 
When the pump was restarted, the valve was raised in temperature to $350^{\circ} \mathrm{C}$ at an internal pressure of about $8 \times 10^{-6}$ Torr. At this point, the valve was allowed to cool down. Figure 25 shows the change in temperature as a function of time; it also shows the different equlibrium pressures at each temperature.

Figure 26 shows the relationship between the valve pressure and time when the appendage ion pumps were disconnected. This allows the outgassing rate of the valve at room temperature to be calculated. This rate, measured manually in Tarr liters $\mathrm{s}^{-1} \mathrm{~cm}^{-2}$, is a measure of how well the valve is processed. Figure 26 shows a value between 6 and $20 \times 10^{-13}$ Torr liters $\mathrm{s}^{-1} \mathrm{~cm}^{-2}$, which is quite 'satisfactory.

The first engineering prototype valve was integrated with its auxiliary electronics package (Figure 15 shows this in process) and installed in the synthetic test facility. At the time of installation, the moving company accidentially dropped the valve package, causing the small support insulators that separate the valve structure from the surrounding box to fracture. Since no other damage was apparent at that time, installation proceeded as planned.

The initial valve test was a straightforward dc high voltage with stand test, with the aim of holding $465 \mathrm{kV}$ for 1 min. During the conditioning process, external discharges occurred across the large ceramic insulator that constitutes the feed-through bushing (see Figure 23) at voltages $>220 \mathrm{kV}$. Replacing the opaque fiber glass cylinder surrounding the ceramic with a glass cylinder permitted these discharges to be clearly observed. At first, the integrity of the fiber glass cylinder and the $\mathrm{SF}_{6}$ insulating gas was questioned, but this was not borne out by experiment. Some slight improvement occurred when the design of the external corona shields at the top and bottom of the ceramic were altered. An initial hypothesis was that the inside surface of the ceramic was becoming electrically charged, perhaps by field emission of electrons. Suspecting that internal damage had occurred during installation, we had the valve package $X$ rayed to check on possible component misalignment. The $X$ rays, although they did not show any misalignment, did show the possibility of a longitudinal crack on the cathode potential sputter 


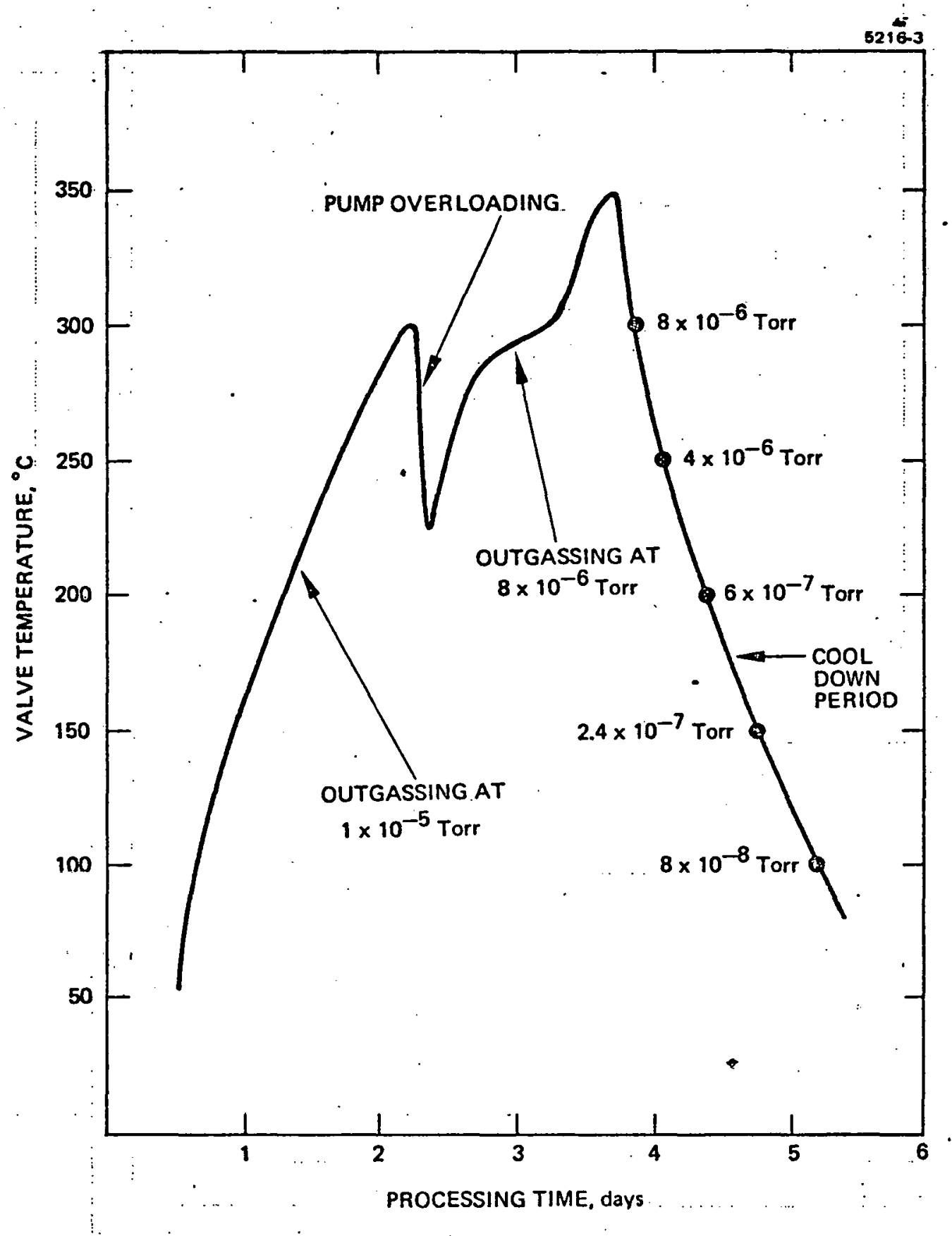

Figure 25. Engineering prototype valve No. 1: pressure and temperature as a function of time during processing. 


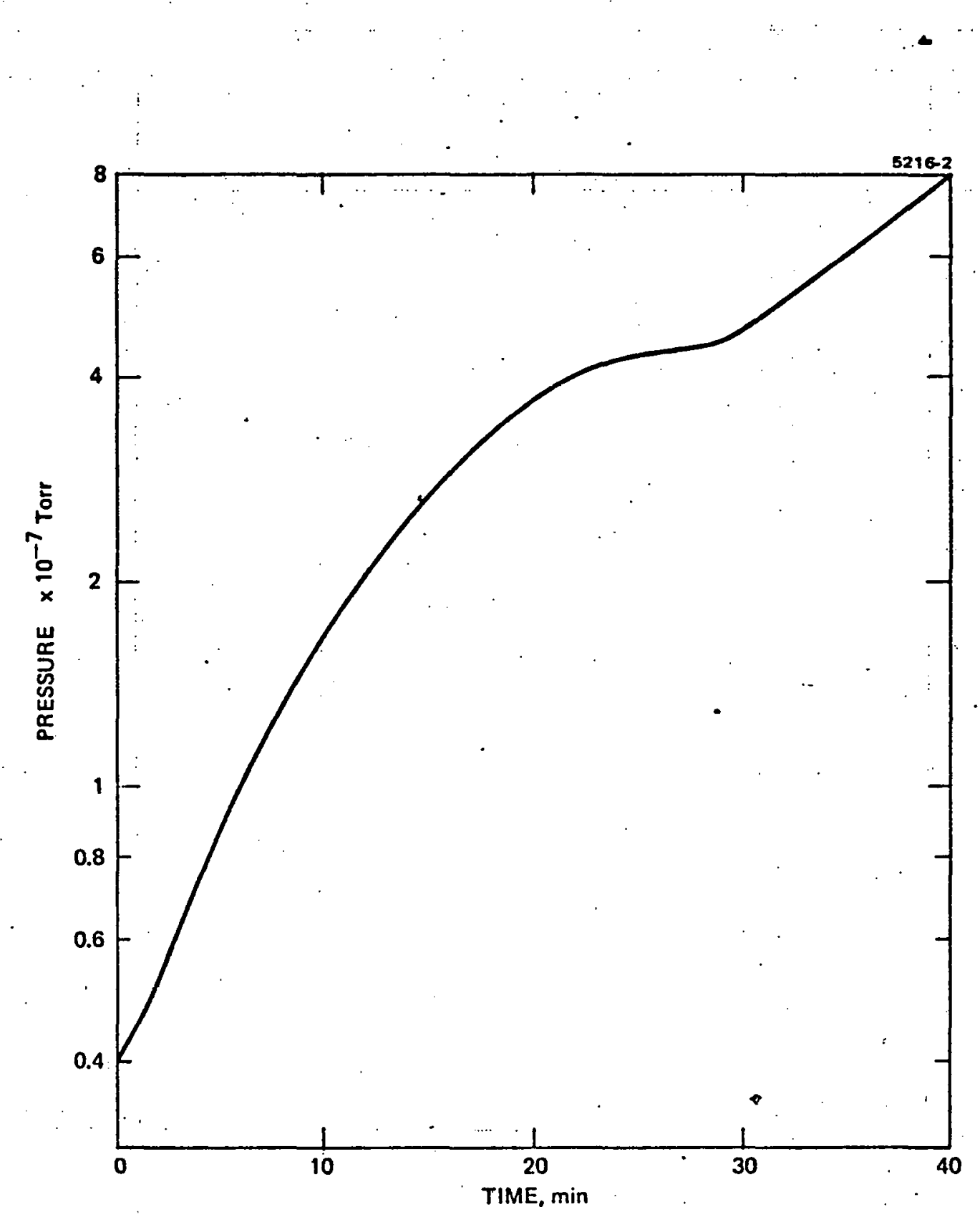

Figure 26. Engineering prototype valve No. 1: pressure as a function of time with ion pumps disconnected. 
shield surrounding the anode shaft (see Figure 23). We then used Polaroid f11m attached to the outside of the valve to map the emission of $X$ rays from internal components while voltage was applied to the valve anode: these photographs appeared to confirm a crack in the sputter shield as a source of electrons.

During a subsequent attempt to raise the applied voltage $\$ 250 \mathrm{kV}$, the ceramic was punctured by an electrical discharge. A decision was made to open the valve and visually inspect the components; and this was done in the presence of representatives of the moving company. A substantial crack was found in the sputter shield, which must have been caused during the installation. - The valve was repaired and reprocessed. A claim for the whole of the incurred expenses was filed with the company's insurance agent.

Subsequently, the second engineering prototype valve was processed to $400^{\circ} \mathrm{C}$ and sealed off.

The only design modification made was to add a movable auxiliary anode (on the cathode face) to improve the ease of processing the cathode. As far as assembly techniques are concerned, the valves have had their components pre-baked and assembled without compromising the surface finish of the electrodes, the interelectrode spacing, or other factors affecting the quality of the valve. The only two problem areas were to eliminate small leaks. in the cathode and in the bakeable electromagnetic pump.

Fitted with a fiber glass bushing and corona rings, the second valve, was subjected to a high-voltage dc test to observe its response. Similar breakdowns were observed, this time at $270 \mathrm{kV}$, and the ceramic of the second valve was punctured at a slightly higerh voltage. It was then clear that there was a problem inherent in the design of the feedthrough bushing. At that time, the hypothesis was that puncture of the ceramic occurred because of the build-up of surface charges: there is some (unpublished) experimental evfdence to support this. The immediate solutions were to: (1) voltage grade the ceramic either by using a resistive coating or by using gradient rings brazed to the ceramic or (2) to make the ceramic substantially thicker (see Table.1). A separate 
test station was built to enable experiments to be made on the feedthrough bushing by itself while the valve was being repaired and re-baked. We chose to use a resistive coating on the alumina ceramic as a means of allowing the accumulated charge to dissipate. Table 2 summarizes the two types of coatings examined.

Table 1. HV Feedthrough Bushing Design

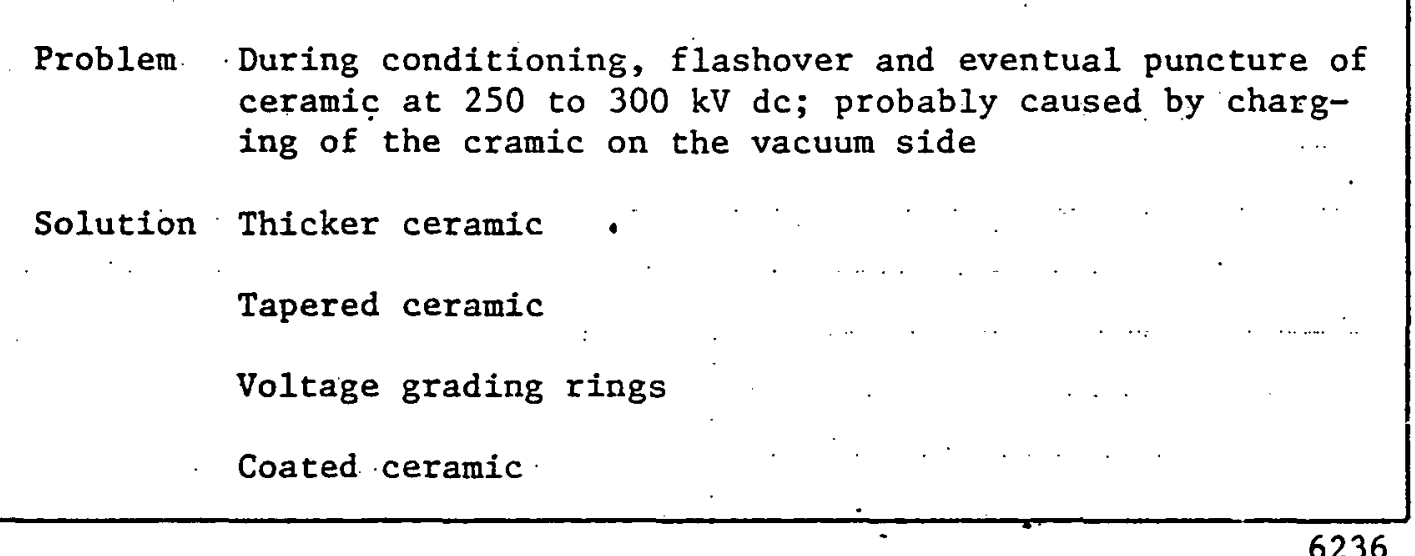

Table 2. Resistive Coatings

Two types of coating Chromium sesquioxide

Vanadium oxide

Both outgas unless well processed (baked)

In vacuum, chromium sesquioxide technology less well enntrot1e.d

Vanadium oxide

Well developed (Litton)

technology

Durable, sputter-

resistant coating

Not affected by mercury 
Table 3 summarizes the test results. With coatings that werề not baked out, the limitation in holdoff voltage is caused by outgassing. The vanadium oxide coated bushing (Litton II), which was baked easily, allowed the valve to satisfy the high-voltage l-min dc withstand voltage of $465 \mathrm{kV}$.

Table 3. Test Results

Chromium sesquioxide ceramic

Vanadium oxide (Litton I) (ceramic coated inside and out)

Vanadium oxide (Litton I) (ceramic coated inside only)

Vanadium oxide (Litton II)
$7 \times 10^{10} \Omega$

$460 \mathrm{kV}$ as stand-off insulator

Limited by outgassing as feedthrough bushing

$8 \times 10^{8} \div 7 \times 10^{7}$

Limited by thermal characteristics

$2 \times 10^{9} \Omega$

$460 \mathrm{kV}$ as stand-off insulator

Limited by outgassing as feedthrough bushing unless vacuum-baked

$2 \times 10^{9} \Omega$

$-320 \mathrm{kV}$ as feedthrough bushing before bakeout

$\pm 470 \mathrm{kV}$ as feedthrough bushing after bakeout

Valve conditioning in negartve polarity easier than in positive.. polarity

Valve hi-pot tests show theimportant of all three design changes made in the feedthrough bushing $\mathrm{X}$ radiation varies as $\mathrm{V}^{3}$ : negligible below $275 \mathrm{kV}$ 


\section{Valve Components}

Figures 6 through 11 are photographs of components of the first engineering prototype valve. Figure 6 shows the completed cathode as seen from the anode. It shows the auxiliary anode (the approximately 1/2-in.-diameter button on the right of the cathode face), the three. Igniters in the pool-keeping structure, and the cathode nose. All parts (with the exception of the igniter tips) are made from molybdenum, with the cathode shroud spun from a single, 1/4-in.-thick molybdenum plate.

Figure 8 shows the cathode during assembly with the shroud removed. One of the igniter actuating mechanisms and coolant tubulation can be clearly seen. Figure 7 shows the external end of the cathode, with thermocouple, heater, and coolant feedthroughs. Also visible are the 3-micrometer screws for adjusting the igniter tip pressure and the colled capillary. impedance through with the mercury is forced to the cathode throat.

Figure 9 shows the anode and shaft, also made from molybdenum. The conical nose of the anode, about 8 in. in diameter, is spur from a thick molybdenum sheet. The shaft is E-beam-welded into the anode backplate (Figure 10), which in turn is wleded into the anode nose. FollowIng a comprehensive leak check while pressurized with helium, the outer cylindrical sputter shield with toroidal termination is also welded to the anode nose. The sputter shield with torus is also spun from a single, thin sheet of molybdenum. At the end of the shaft, a kovar adapter collar is brazed to the molybdenum to allow for later TIG welding to a kovar plate, which in turn is attached to the feedthrough alumina insulator of the valve.

Figure 3 shows the stainless-steel condenser, with its entrance and exit manifolds for the refrigerant. The condenser has four quadrants of six cooling channels each. Also visible is the fixture for the sapphire window which allows direct observation of the cathode during initial processing. The condenser was pressure checked and leak checked under vacuum while cooled in a dry-ice, alcohol mixture to simulate operating conditions. The baseplate holding the cathode fits into the condenser at the manifold end. This plate (not showin in the photograph) has 
cooling fins brazed in place and contains the entrance ports for the $8 \mathrm{liter} / \mathrm{s}$ ion pumps. At the anode end of the condenser, the center plate attachment involves kovar-to-kovar, moly-to-kovar, and moly-to-moly brazes, using nickle-based brazing material.

During assembly and E-beam-welding of the anode, some redesign of the internal molybdenum baffle was found to be necessary. Essentially, this involved shortening the spacer legs of the baffle to avoid thermal expansion problems caused by differential heating during welding. The baffle was still held in place by the close fit inside the anode; but additional pre-loading of the center shaft with Belleville springs . maintained the close tolerance between the baffle and the inside of the anode nose during operation.

Tube No. 1 (refurbished) with a coated ceramic and a nose piece added to the inner shield, was placed on exhaust on 17 August 1976 and tipped off on 26 . August 1976. The gases evolved during bakeout were observed with a residual gas analyzer and were found to be mainly water vapor, nitrogen, carbon monoxide, and carbon dioxide. Sma11 amounts of gases in the metahne, propane series were noted. Tip-off pressure was in the low $10^{-8}$ Torr range, which is somewhat higher than the previous tube, perhaps because salvaged tubes are rarely as clean as initial. tubes or because a higher gas pressure is somehow associated with the vanadium oxide coating. When hi-potted, the tube was able to withstand in excess of the desired $465 \mathrm{kV}$.

Some problems were encountered with the mercury feed system on the rectifer valve. A second EM pump was added in series to this system to. help overcome deficiecies in the performance of the original pump. This system operated adequately but below expectations for some time; subsequently, the original pump ceased functioning. This failure was presumably due to a marginal head of mercury at the pump inlet; such effects have betin noted previoucly. This pump was removed from the system and a second pump with molybdenum electrodes and Kapton insulation was installed so that the mercury head was increased by about $6 \mathrm{~cm}$. This pump worked well enough along to operate the LMPV. However, on the basis 
of previous tests with the pump in which the output pressure was measured as a function of pump current, the mercury flow rate was $38 \%$ of that expected. This suggested that the capillary bore was restricted. After operating pump No. P4 for a short while, it developed a vacuum leak while being worked on. It was replaced with an EM pump with Kovar electrodes and Kapton insulation. This pump also operated at $38 \%$ of theoretical on the basis of previous results obtained with it. This pump and the second seried pump were used to operate the LMPV.

Rework of the second engineering prototype valve consisted principally of replacing the uncoated ceramic feedthrough with a vanadiumoxide-coated ceramic and repairing the cathode igniters and their mechanims. The mercury contaminated LMPV was connected to a vacuum station and baked out and subsequently dismantled. There was no mercury visible in the dismantled tube nor was any detected with the mercury detector, thus verifying the projected overhaul procedure.

The contaminated tube was mounted on the bakeout station so that the station oven could be lowered over the tube. The tube was then connected to a specially constructed glass vacuum system with a mercury diffusion pump and two liquid nitrogen traps. A stainless-steel mesh trap was placed between. the diffusion pump and the baker to reduce the possibility of contaminating the backer with mercury. Tests indicated that no mercury was being discharged into the air when the system was running. However, when the system was partially dismantled later, there was a small but detectable indication of mercury at the inlet port of the backer. This indicates that the mesh trap is not $100 \%$ efficient and also that the pump and its exhaust trap prevent mercury from being discharged into the air.

The tube was connected to the system with stainless-steel tubing with bellows at each end to prevent strain from being transmitted to the glass system. The tubing and the part of the vacuum system to the first cold trap were wrapped with heating tape and heated to approximately $150^{\circ} \mathrm{C}$. The vacuum system was started and the valve between the tube and the tubing was opened. The oven was partially lowered over the tube and the air bake was begun. The tube was baked for six days with 
the maximum temperatures being $285^{\circ} \mathrm{C}$ on the ceramic (the hottest part) and $150^{\circ} \mathrm{C}$ on one ion pump (the coldest part). Pressures as high as $30 \mathrm{~m}$ were noted on the thermocouple gauge. (Its temperature was $158^{\circ} \mathrm{C}$. )

The maximum temperature of the bakeout was somewhat restricted because residual Dowtherm in the anode began to boil out over the tube and station at about $270^{\circ} \mathrm{C}$. However, the mercury was apparently completely removed at temperatures around $150^{\circ} \mathrm{C}$ or less.

Two methods were used to determine when mercury removal was completed. The first involved noting when the pressure dropped in the ion: ization gauge. The ultimate pressure observed was $3 \times 10^{-5}$ Torr. The second method involved thawing the mercury being collected in the cold trap, causing a flat surface to be formed by the molten mercury. The mercury was then refrozen and examined from time to time. Additional mercury collected in the cold trap disturbed the flat surface previously established by the molten mercury.

The tube was baked for six days, as noted above, but mercury removal was apparently completed in about four days. When the bakeout was completed, the cold trap was removed and weighed. It was found that approximately 2.7 ib of mercury had been collected.

The valve was disassembled after bakeout and examined. Some mechanical damage to the igniters was noted and the auxiliary anode showed some signs of heating and sputtering. It was corcluded that an immediate redesign of the affected areas was required and that, the redesign should be incorporated into subsequent tubes. The cathode areas requiring design was the auxiliary anode, igniters, and igniter drive mechanism. The redesign of the interface for the valve was completed. and the condenser and freon manifold were modified. Additionally, the inner shield was modified by adding a nosepiece. 


\section{B. CATHODE DEVELOPMENT}

Tẅo cathode faceplate designs were considered for use in the deliverable valves: one in which the faceplate is clamped to the OPKS (as in the engineering prototype tubes) and a second in which the faceplate is E-beam welded to the OPKS. The two designs were expected to exhibit differences in heat transfer and mercury film behavior at the joint between the faceplate and OPKS. This in fact did occur (see Section 3.F). In the original welded design, the faceplate was heated by heater wire while the OPKS was water cooled. The two areas are separated by a heat dam in the form of a section of molybdenum thinned down to a thickness of $0.060 \mathrm{in.}$ Thermal separation is achieved in the demountable design by keeping the above two areas as two separate parts and clamping them together with three screws so that only a hairline. crack exists where the two parts meet. Questions were raised about the mechanical strength of the clämping action under repeated thermal cyciing and about mercury ingress into the crack where the parts meet. It seemed there would be less possibility of part cracking if the thermally induced strain could be relieved by permitting small movements at the boundary of the two areas having different thermal requirements. It was not clear if the desired thermal gradients were obtained, if the hairline crack filled with mercury, or the consequences of either action would le.

From the assembly point of view, the demountable faceplate design offered the following advantages:

- Easier to produce a clearn cathode and easier to fabricate

- Less breakage of heater and thermocouple wires

- Easier to install auxiliary anode

- Lower cost.

However, these advantages were not compelleing enough to determine which design would be used in the deliverable tubes. If the two designs were deemed to be technically equal, then the above advantages would have caused one to lean toward the use of the demountable faceplate. 
The design changes which would be made in construction of the deliverable cathodes were:

- Modify water channels in cooling jacket to eliminate leaks.

- Use multipin feedthroughs for the heaters and thermocouples.

- Use insulated metal linkage blocks instead of all ceramic

- The possible use of a demountable cathode faceplate instead of a welded one.

- The elimination of all brazes containing phosphorus because of its high vapor pressure. Hughes Electron Dynamics Division will not braze on parts containing phosphorus for fear of contaminating their furnaces and we wish to use their excellent facility.

\section{IGNITOR DEVELOPMENT}

A comprehensive review of igniter techniques was prepared to permit comparing their important characteristics. These techniques included boron carbide, surface breakdown, pulsed high voltage, mechanical make and break, mercury stream, evaporative break, multipactor, thin wire, crossed-field, pulsed plasma, thermionic, Paschen, laser, and electron and ion beam igniters. The best alternative to the boron carbide igniters was the surface breakdown igniter, and the pulsed high voltage and mechanical make/break types as interesting possibilities.

Three types of surface breakdown igniters were inttially evaluated: beryllium oxide, a semiconductive surface coating, and a bulk semiconduc tor. The latter showed the best results. Later tests showed that the semiconductor must be hidden from the region of high discharge current. Optimization was based on tradeoffs among proximity. of the semiconductor surface to the mercury pool, shielding from the discharge, and igniter-cathode configuration. Some reliable results were obtained ar discharge currents to $200 \mathrm{~A}$ at an electron-to-atom ratio of 30 . Tests were directed at assessing the influence of semiconductor type and cooling on surface breakdown igniter performance. 
A preliminary design of a hydraulic, conductively cooled boron carbide igniter was completed. The purposes for the change from a mechanical linkage to transmit movements produced external to the vacuum enclosure were to increase, the reliability of the igniter assembly and to reduce its cost. These were accomplished by reducing the basic complexity of the assembly, by cooling the igniter tip by conduction rather than by direct water cooling, and by providing a more positive igniter contact-force adjustment. Mercury was used as a hydraulic fluid to activate the igniter.

The objective of the igniter/feed system life test program was to evaluate some innovations, including (1) an E-beam-welded inner poo1keeping structure/outer pool-keeping structure (IPKS/OPKS), (2) an integral IPKS/OPKS water-cooling structure, and (3) a capillary flow impedance that is brazed into the OPKS from the side and is contained entirely within the cathode enclosure.

Two conductively cooled $\mathrm{B}_{4} \mathrm{C}$ igniter designs were examined. To allow some versatility in initial processing of the cathode, one is capable of contacting both the IPKS and the OPKS. The second design allows contact only with the OPKS, but it has the advantage of being hydraulically activated.

As an alternative to a $\mathrm{B}_{4} \mathrm{C}$ igniter, various other arc ignition schemes were examined. The most. satisfactory approach involves the formation of an arc spot through the discharge of electrical energy across an insulating surface. Such surface breakdown igniters have been operated for many hours with good results.

Operation in the IPP switch was simulated in the BIdg. 250 test facility. Hore than $10^{4}$ shots were fired with $99.9 \%$ reliability at peak LMPV currents in the range of 3 to $10 \mathrm{kA}$; 30 shots were fired at $10 \mathrm{kA}$ peak and at a rate of $0.12 \mathrm{~Hz}$ with no misfires. Also, swing mode operation was simulated (peak discharge current $=260 \mathrm{~A}$, LMPV conduction period $-120 \mu \mathrm{s}$, frequency $=60 \mathrm{~Hz}$ ) for $3 \mathrm{hr}$ with no observed misfires. The SBI was subsequently removed and inspected; measurements of semiconductor erosion suggest that the lifetime of a single SBI is $>2 \mathrm{yr}$. The cathode in which the SBI has been evaluated was then modified to perform

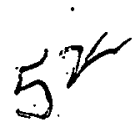


more switch simulation tests. A conductively cooled SBI design suitable for retrofit was completed. This design utilized five parts, including the vacuum wall feedthrough.

Figure 27 shows the two cathode igniter geometries that were compared in the igniter life-test facility. Tests performed with the watercooled surface breakdown igniters suggest that the open circuit of the pulser must be about $6 \mathrm{kV}$ to ensure reliable spark formation under all conditions.

A thermoelectric trap was completed and successfuliy tested. The purpose of this device, which would be located in the vacuum line between the Vac Ion pump and the LMPV, was to reduce the partial pressure of $\mathrm{Hg}$ at the pump entrance and, thereby, to extend the pump lifetime. The conductance of the trap was $\sim 5 \mathrm{~L} / \mathrm{s}$; the trap was designed to operate continuously for in excess of five years (with the LMPV condenser at $-30^{\circ} \mathrm{C}$ ). In tests with the hot junction at $10^{\circ} \mathrm{C}$, the trap operated at $-37^{\circ} \mathrm{C}$ (or within $13 \%$ of the expected temperature difference). 'At this temperature, the Hi-Q Vac Ion pump pressure was $6 \times 10^{-7}$ Torr; with the trap off, the pump pressure was $\sim 20$ times higher. With a cold junction temperature of $-60^{\circ} \mathrm{C}$ (obtained by cooling the hot junction to $-35^{\circ} \mathrm{C}$ ), the $\mathrm{Hg}$ partial pressure will be $<1 \times 10^{-7}$ Torr; and the lifetine will be in excess of five years for both Hi-Q and $8 \mathrm{~L} / \mathrm{s}$. Vac Ion pumps.

\section{EM PUMP DEVELOPMENT}

The first engineering prototype recirculating mercury feed system was completed, filled with $40 \mathrm{lb}$ of mercury, and tested in February 1976 . The mercury flow rate through a $60-\mathrm{cm}$ length of $0.018 \mathrm{~cm}$ i.d. capillary was measured to be $29 \%$ of the expected value. This unexpected result necessitated.moving the engineering prototype feed system to a location on top of the LMPV cabinet to eliminate the head that it was necessary to overcome in the original location; this was considered a temporary solution until the desired feed system performance could be obtained. Similar results were obtained with other EM pump assemblies used with

$$
53
$$




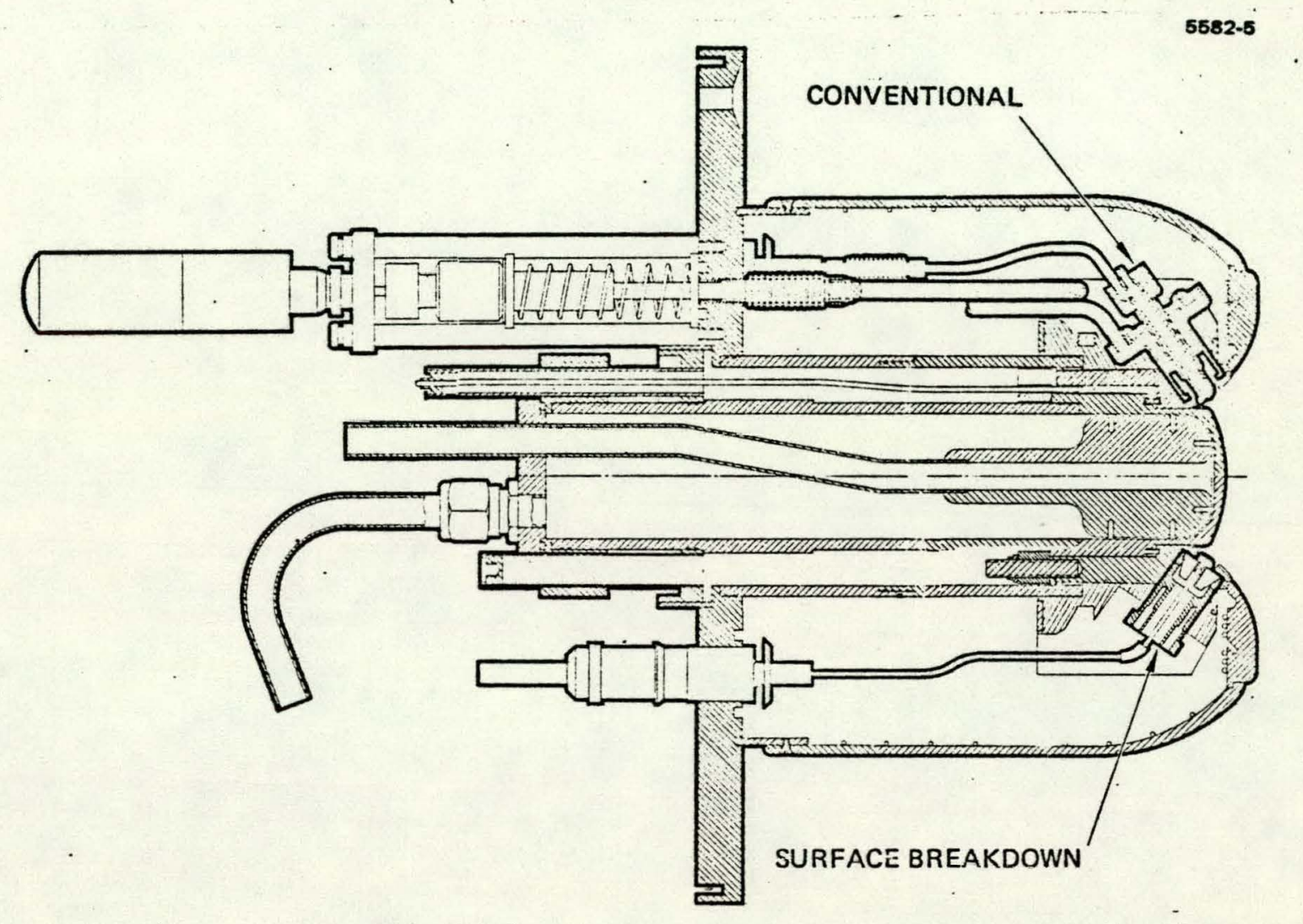

Figure 27. Cathode igniter geometries. 
laboratory prototype feed system. The various possible causes for the poor performance.were evaluated. It was suspected that the efficiency loss was due to electrical shunting of the pumping region by the inlet/ outlet flow channels as a result of a low surface contact resistance caused by the migration of braze material during EM pump assembly. A nonbakeable pump design was prepared to evaluate and eliminated this factor. This design was evaluated in the laboratory prototype feed system that was installed in the life test facility.

This prototype recirculating mercury feed system was successfully operated. System tests were performed on unbaked components, using.a 160-cm-long, 0.018-cm-i.d. stainless-steel capillary tube as an impedance for the EM pump. The mercury flow rate varied linearly with EM pump current, as expected, with a good mercury flow rate achieved for $23 \mathrm{~A}$. After several hours of operation, the pump impedance dropped to the theoretical value of $3 \times 10^{-3} \Omega$, showing that resistive electrode surface layers were inconsequential even without significant processing. The EM pump consumes $1.6 \mathrm{~W}$ at $23 \mathrm{~A}$. Subsequently, progress was made in the development of a glass frit bonded EM pump, and tests indicated that reliable sandwich assemblies could be obtained using Mullite $\left(70 \% \mathrm{Al}_{2} \mathrm{O}_{3}\right.$, $30 \% \mathrm{SiO}_{2}$ ) in place of pure $\mathrm{Al}_{2} \mathrm{O}_{3}$; Mullite more closely matches the thermal expansion of molybdenum. Two alternate approaches suitable for applfcation in deliverable hardware were pursued. One involved sealing the $\mathrm{Al}_{2} \mathrm{O}_{3}-\mathrm{Mo}^{-\mathrm{Al}_{2} \mathrm{O}_{3}}$ sandwich solely with a copper braze. This has the drawback that conduction of current through the braze will result in a 10 to $20 \%$ reduction of pump efficiency. The second approach was to effectively glue the.sandwich together using a braze and then to seal it with glass.

An optimized design pcakage for the cathode mercury feed system was completed. The design of the EM pump was solidified on the basis of tests performed on the magnetic circuit and assembly plucedurc. The magnetic circuit was constructed using available Alnico $V$ magnets and pole pieces fabricated from $2 \%$ Vanadium-Permendur. A $21.5 \mathrm{kG}$ field was obtained with this circuit in two gaps, each $1 \mathrm{~cm} \times 2 \mathrm{~cm}$ in area and $1.25 \mathrm{~mm}$ in width. This is close to the maximum expected value of $24 \mathrm{kG}$. The magnetic circuit was cycled to $450^{\circ} \mathrm{C}$ to deternine the change in field strength that 
would result from bakeout. The EM pump itself consists of an aluminamolybdenum-alumina sandwich bonded together with a glass frit. The bonding procedure was evaluated in the glass laboratory at the Hughes Aircraft Company's facilities in Culver City, California.

The integration of the feed system includes helium leak detection, final freon/alcohol flush, bakeout, and attachment to the LMPV cathode. It is then connected to the EM pump power supply in the electronics package. The system is then filled and further processed before admitting mercury to the valve. After the cathode is wetted, the flow system is calibrated and the feedback loop constants are adjusted.

The efficiency of the $V_{1}$ EM pump was much greater than that of $V_{2}$. The problem was that a small change in EM pump current produced a large mercury flow rate to the cathode.

With a reliable setting of the EM pump holding current, it was only possible to obtain the correct mercury flow rate to the cathode at one cathode current. To overcome this problem and its associated instability, it was decided to change the existing EM pump power supply from a dc supply to a pulsed supply. The intent was to apply large current pulses to the EM pump to overcome the sticktion associated with the very low mercury flow. The system has a variable pulse repetition rate and variable pulse width with proportional pulse height in addition to the normal offset current.

This technique was successful in modulating the average mercury flow with adequate long-term stability. In a parallel effort, another supply was constructed in which constant-amplitude current puises with proportional pulse width modulation and constant offset current were used. This second system also operated satisfactorily and was installed in $v_{2}$.

E. CONDENSER

The condenser, which is pall of the vacullm envelope of the valve (see Figure 3), collects the mercury that reaches it either directly from the cathode or following impingement on the anode. Because there

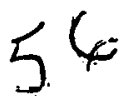


is a relatively high heat flow to the condenser from the vacuum arc discharge and because it is necessary to retain a temperature of $-35^{\circ} \mathrm{C}$ on the inside of the condenser, we decided to use liquid cooling of the condenser rather than to cool it by direct expansion of refrigerant into the cooling channels. Liquid cooling has several advantages, one of which is that temperature gradients at the condenser can be made small (see Figure 28).

Detailed design of the condenser was completed in conjunction with a refrigeration consultant. A new viewport design was completed to take account of the new cryowall design and the near-vertical orientation of the valve.

The final condenser design chosen was a cylindrical stainless-steel shell with external liquid cooling channels. The liquid freon R-11 circuit is divided into four quadrants; since each quadrant circulates the liquid with six passes, the 24 cooling channels need only be monitored at four places. This grealy simplifies assembly and assumes uniform fluid flow.

The view port (which is used principally to observe the cathode during initial current (processing) has a sapphire window which protected from sputtering by a shutter. The shutter could be activated from outside of the condenser by a magnetic field. The assembly was brazed, rather than welded, to improve the reliability and reduce outgassing problems on exhaust. The basis for the thermal calculations shown in Figure 28 was that the heat flux is uniformly deposited along the wall of the cylinder. When the valves were taken apart to reprocess them, we found that the principal discolored portion was located in. regions between the anode and cathode. This observation plus the appearance of the mercury film on the cryowall during high-current operation confirmed that the actual band of power deposition was quite narrow, possibly less than $7 \mathrm{~cm}$ wide. This heat flux density is more than a factor of three greater than the design level. This results in a similar factor greater $\Delta T$, resulting in a higher mercury vapor pressure. Using the latest available published breakdown characteristics of mercury vapor on steel electrondes and our appropriate spacing to 


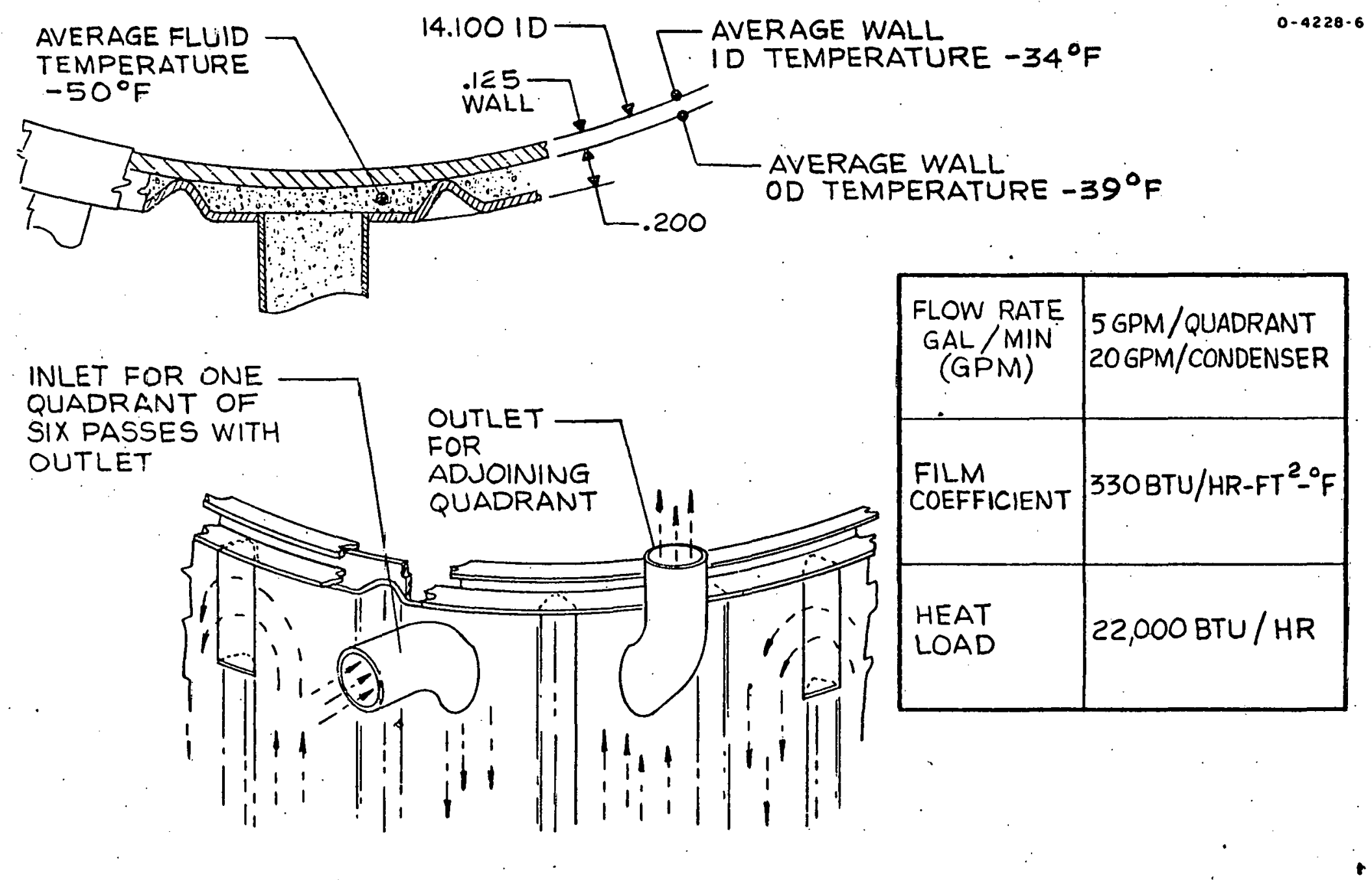

Figure 28. Condenser data. 
determine the pressure-distance similarity relationship, a breakdown criterion was determined. To verify this calculation, an experiment was done with an LMPV at room temperature with an expected vapor pressure of 1 mTorr. A breakdown of $45 \mathrm{kV}$ was observed which is in agreement with the published data.

\section{F. ALUMINA INSULATOR}

In the laboratory prototype valve, the insulator that acted as the feedthrough bushing for the anode shaft was a tapered, convoluted cylinder of alumina. Principally, it had this geometry because originally the insulator projected into the valve condenser rather than projecting from it. For the engineering prototype valves, the insulator was redesigned to be a straight-walled cylinder of high-quality alumina (see Figure 23) with drawn rather than spun Kovar cups brazed with copper to the molybdenum-manganese metalized ends. Experiences with the laboratory prototype valves showed that spun Kovar sometimes retains residual tool marks, giving rise to localized strains and possible failure under stress. By using a straight, unconvoluted cylinder, we reduced the cost and minimized the delivery time for this component.

We examined the distribution of quipotentials for the whole of the valve and feedthrongh bushing in a series of field plots made on the IBM 370 computer using the Stanford SLAC electro-optics program. This program solves Laplace's equation (no space-charge distribution) in cylindrical coordinates, taking account of the dielectric changes between vacuum, the alumina insulator, and the fiberglass cylinder.

The equipoentials are shown in Figures 29 and 30 , together with the electric fields at particular locations calculated for an anode-cathode potential difference of $465 \mathrm{kV}$ (the $1 \mathrm{~min}$ dc holdoff requirement for a nominal $150-\mathrm{kV}$ valve). As far as elecrflcal brcaldown in vacuum is concerned, we had to dietingulsh between three different areas in the valve. In the first case, the field on the inside of the condenser surface was kept low $(55 \mathrm{kV} / \mathrm{cm})$ because it would be possible to form instabilities on the surface of the liquid mercury condensed there.

$$
59
$$




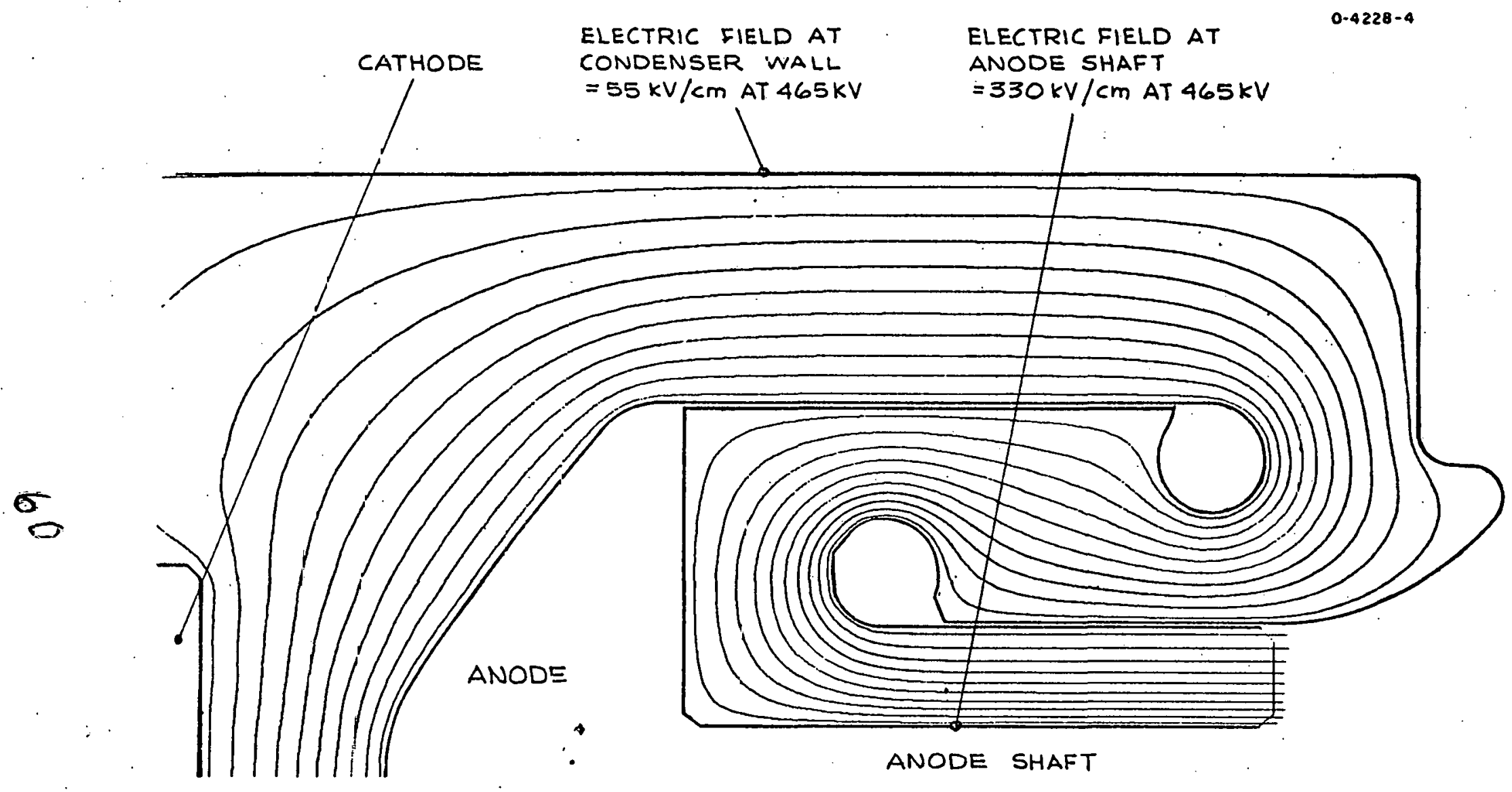

Figure 29. Equipotential lines in the LMPV. 


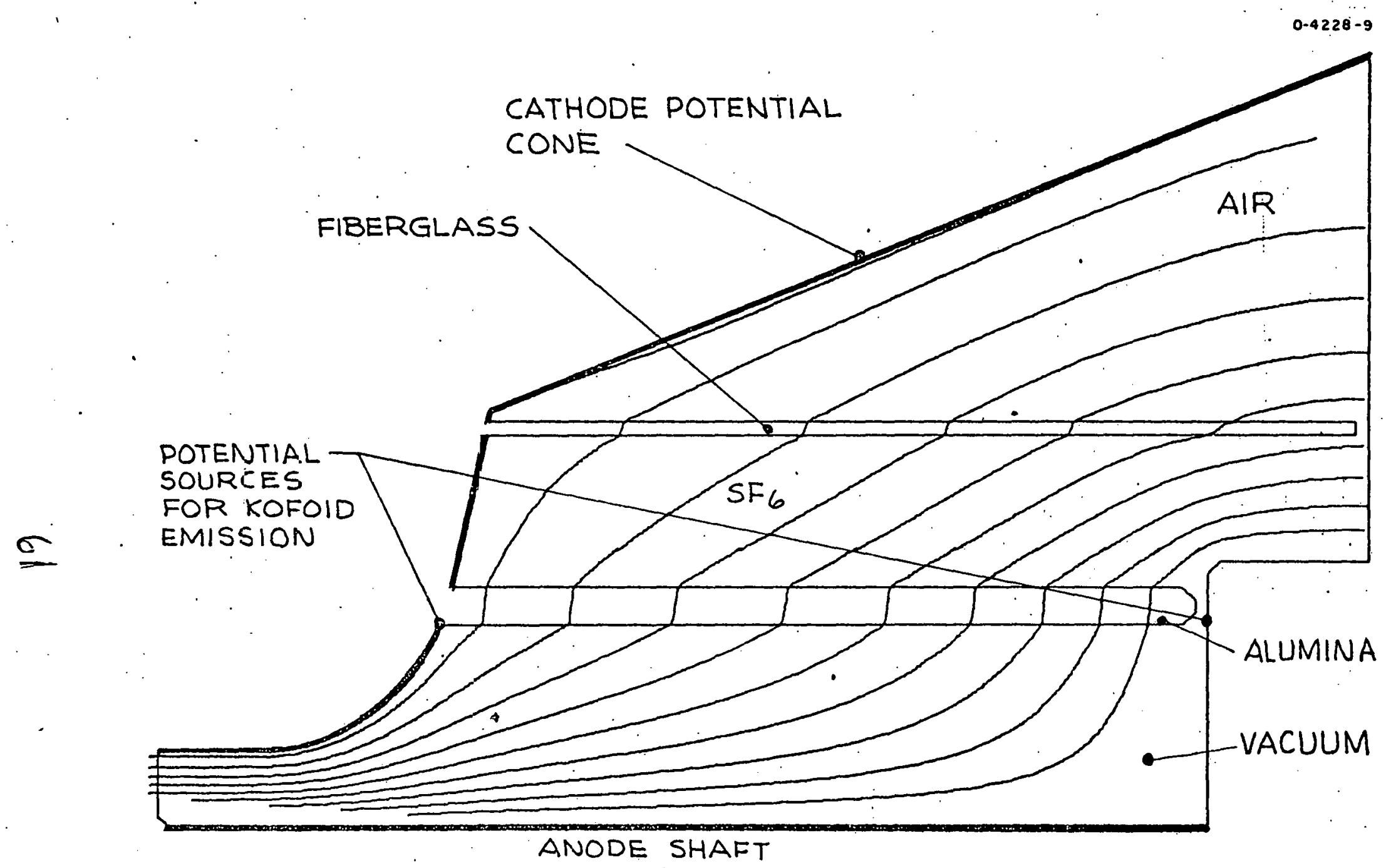

Figure 30. Equipotential lines intersection of the alumina and fiberglass bushings. 
Liquid droplets pulled off the surface would then act as Cranberg clumps initiating breakdown. Second, the critical field for breakdown between metal surfaces is about $4 \times 10^{7} \mathrm{~V} / \mathrm{cm}$, the onset of Fowler-Nordheim field emission. The highest macroscopic field strengths in Figure $29^{\circ}$ show that a localized field intensification factor greater than 100 can be present before significant field emission of electrons will occur. Third, there is the possibility of emission of electrons from the alumina-metal-vacuum triple point (Kofoid emission); this has been guarded against in the present design by recessing the interfaces inco a field-free region.

Figure 30 shows the equipotential lines and their distribution with respect to the alumina cylinder and the fiberglass cylinder. It is important to obtain a fairly uniform voltage gradient on the inside of the alumina cylinder this is achieved by using a metal cone terminating in a toroidal spinning (see Figure 23). However, if the outside of the alumina cylinder is left in air, surface breakdown will occur because the localized fields exceed the nominal corona-onset criterion of $20 \mathrm{kV} / \mathrm{cm}$. This surface flashover was prevented by surrounding the alumina cylinder with $\mathrm{SF}_{6}$ at a pressure of about 30 psig. This raised the critical field strength for surface flashover to greater than $\therefore$. $100 \mathrm{kV} / \mathrm{cm}$. The $\mathrm{SF}_{6}$ is contained by a fiberglass cylinder with a diameter selected that permits the axial electric field on the outside surface to be low enough to avoid surface flashover in atmospheric air, even at the $465-\mathrm{kV}$ test level. The overall length of the fiberglass cylinder was $122 \mathrm{~cm}$ ( $48 \mathrm{in.}$ ). Slute samples of the fiberglass material used were tested for flashover characteristics in air at voltages up to $100 \mathrm{kVdc}$. Voltage breakdown relaionships ranging from $\mathrm{V}=22 \mathrm{~d}^{0.85}$ to $\mathrm{V}=28 \mathrm{~d}^{0.76}$, where $\mathrm{V}$ is in kilovolts and $\mathrm{d}$ is in inches, were obtained. This led to bushing lengths of 36 to $40 \mathrm{in}$. for $465 \mathrm{kVdc}$, the 1 -min withstand criterion. The present bushings, $49 \mathrm{in}$. 10ng, were then fabricated. 
Computer calculations and vicw factor calculations were made for both the present LMPV and an alternative design in which some insulator shielding efficiency was sacrificed for lower electrical field strength values. In searching for reduced field strength designs, it became apparent that there was a tradeoff between minimum field strength and insulator shielding effectiveness. If experiments show that the high degree of shielding present in the existing design is not required, then the calculations show that a more simply constructed valve having lower electrical field strengths can be designed within the same dimensions as the present LMPV (see Appendix D).

During testing, the first and second engineering prototype valves failed to hold off $465 \mathrm{kVdc}$ for $1 \mathrm{~min}$. Breakdowns occurred at 240 to $270 \mathrm{kV}$, and the alumina insulator eventually was punctured. We hypothesized that the puncture was caused by a build-up of surface charges. Regarding possible solutions we consulted with engineers at Stanford University and Eimac and simultaneously began to build a separate test station that would permit conducting experiments on the bushing by itself while the valves were being refurbished.

Stanford and Eimac agreed with our hypothesis and advanced four solutions: (1) thicker ceramics, (2) tapered ceramics (to avoid charge multiplication in the electric field), (3) voltage grading rings as an integral part of the ceramic, or (4) a ceramic coated with a resistive material that would allow the charge to drain off while still preserv-. ing the high voltage integrity of the bushing. Additionally, some redcsign of the internal and external field-shaping elements close to the ceramic was suggested: Stanford has found that the Kofoid design ${ }^{1}$ cannot be successfully extrapolated above $250 \mathrm{kV}$ (although this had been done at CERN in conjunction with very large high-voltage charged particle separators).

We chose to try sulution (4) in conjunction with a redesign of the field-shaping elements. Starting with chromium sesquioxide as a resistive coating, we were able to hold off $>500 \mathrm{kVdc}$ using the ceramic as a stand-off insulator. As a feedthrough bushing (that is, with a central anode shaft in position), only $400 \mathrm{kV}$ could be supported. The limitation was caused apparently by outgassing of the coating. Triggered by electron bombardment. 
We obtained a ceramic with a vanadium oxide coating from Litton Industries. This is a more closely controlled and more durable coating than chromium sesquioxide, but it does exhibit a negative resistance characteristic:. Initially, we found that the ceramic (coated inside and outside with vanadium oxide) went into a runaway condition at $200 \mathrm{kV}$, such that the current drain increased as the bushing got warmer. By grinding off the outside vanadium oxide coating, the resistance was increased from $2 \times 10^{8} \Omega$ to $1 \times 10^{9} \Omega$, which was enough to make it stable. With this ceramic, $500 \mathrm{kVdc}$ was supported as a stand-off insulator.

A second bushing from Litton with a vanadium oxide coating of $2 \times 10^{9} \Omega$ was tried in the same configuration. This coating showed excellent thermal stability, and again $>500 \mathrm{kVdc}$ could be supported in the stand-off insulator mode. As a feedthrough bushing, however, electron bombardment of the coating causes emission of water vapor, raising the local pressure and limiting the holdoff voltage to $320 \mathrm{kVdc}$. The solution to this problem was to bake the ceramic under vacuum before test.

Meanwhile, the second engineering prototype valve was rebuilt and rebaked. This valve did not incorporate a coated ceramic, but did incorporate the changes in the external field-shaping elements suggested by Stanford. This valve was hipotted to $220 \mathrm{kVdc}$ (a limit set to avoid the possibilities of repuncturing the ceramic) without breakdown. Conditioning was very rapid, and the conclusion that can be drawn is that the redesign of the field-shaping elements helped greatly to increase the high-voltage capability of the LMPV.

The second Litton bushing (resistance $>2 \times 10^{9} \Omega$ ) was incorporated into the first engineering prototype valve, which was being rebuilt. This was the valve that had been damaged by the moving company while it was being installed in the synthetic test facility. The valve (and hence the vanadium oxide coated bushing) was baked out to $400^{\circ} \mathrm{C}$, removing water vapor from the coating. This, in conjunction with the redesign of field-shaping elements inside and outside the ceramic, allowed the valve to be hipotted to $465 \mathrm{kVdc}$.

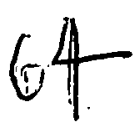


Figure 31 shows the bake-out sequence of an LMPV. As the temperature was slowly raised, the pressure rose quickly to about $4 \times 10^{-6}$ Torr. As it fell, the temperature was raised again until the internal pressure was about $1 \times 10^{-6} \operatorname{Torr}$ at $400^{\circ} \mathrm{C}$. When the oven was turned off and the valve cooled down, the valve was pinched off and pumped by its own ion pumps. The internal pressure (at room temperature) was then about $8 \times 10^{-10}$ Torr.

G. ANODE

The valve anode consists of an E-beam-welded, mushroom-shaped molybdenum nose with a molybdenum backplate and sputter shield. The heat flux to the anode during current conduction is removed by cooling the anode with a forced flow of Dowtherm (a dielectric fluid with good heat transfer properties). 'As shown in Figure 2, Dowtherm enters the anode cavity through a central feed pipe and flows radially otward through a narrow channel between the inside of the anode nose and a baffle. When the valve is not in use, the Dowtherm is heated to about $100^{\circ} \mathrm{C}$ to prevent mercury condensation on the anode nose and, therefore, the possibility of cathode spots forming there during rectifier duty; otherwise, the Dowtherm is cooled at ground potential to remove excess heat.

The heat flux to the anode was high enough to require that a careful study be made of flow rates, channel dimensions, etc. This scudy, completed at HRL, revealed the need for small channel dimensions (Figure 32), wh1ch result in high film soefficients. There was some doubt about the validity of the model which was used for these calculations in view of this result, and so an additional check was performed. This check was made by personnel in the Laser Laboratory (Culver City, California) because the analysis was directly relevant to in-house work on the cooling of large laser mirrors. Both theoretically, and by reference to their cxperimenrs, the check showed that the first analysis, was valid (see Appendix E). This shows that anode-baffle gaps n-ed. to be as low as $0.020 \mathrm{in}$. to reduce the Dowtherm-anode temperature differential, even with a flow rateof $7.5 \mathrm{gpm}$. Tolerances on anode prints were tightened to reflect the need to maintain these dimensions. 


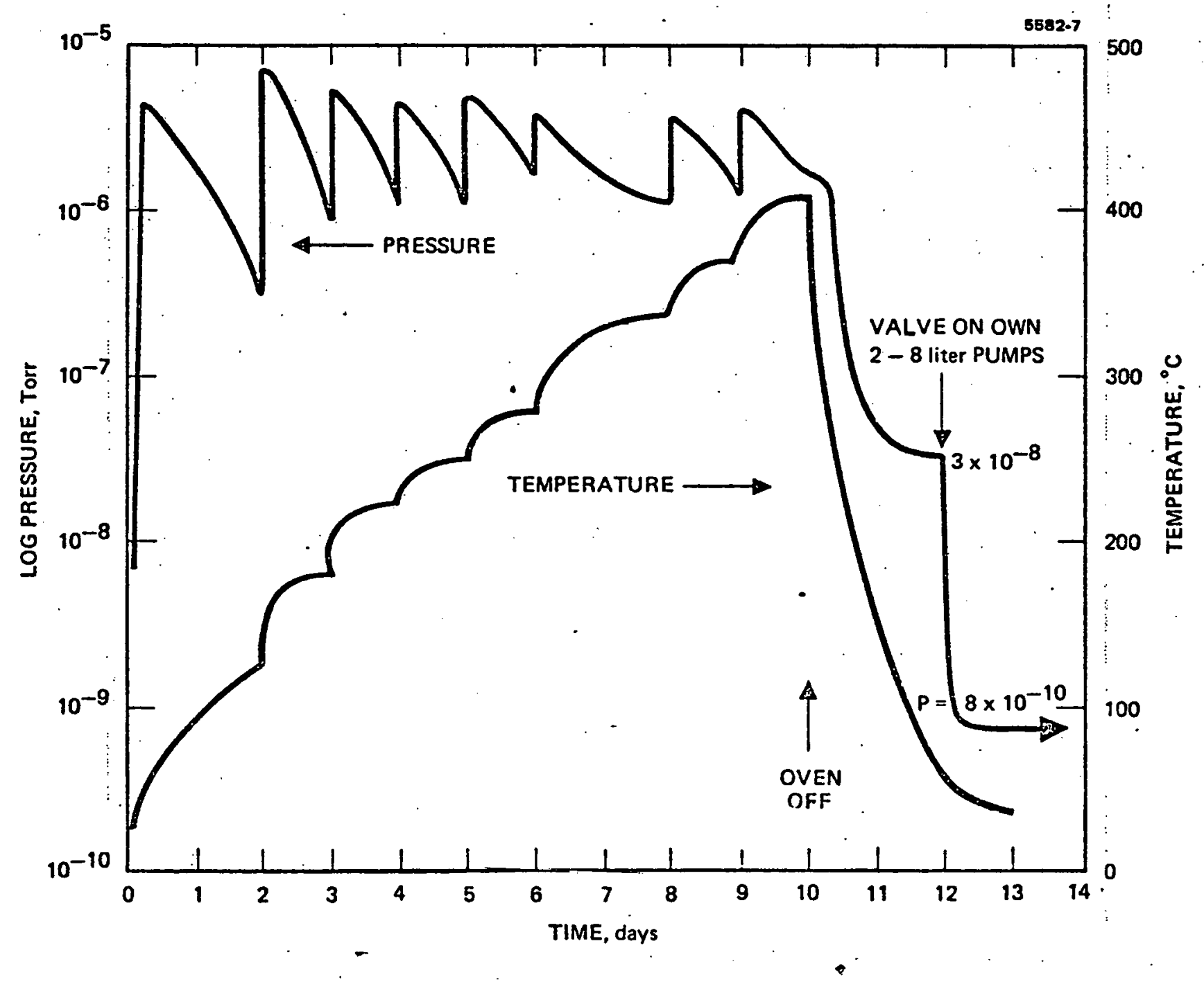

Figure 31. DOE valve bakeout. 


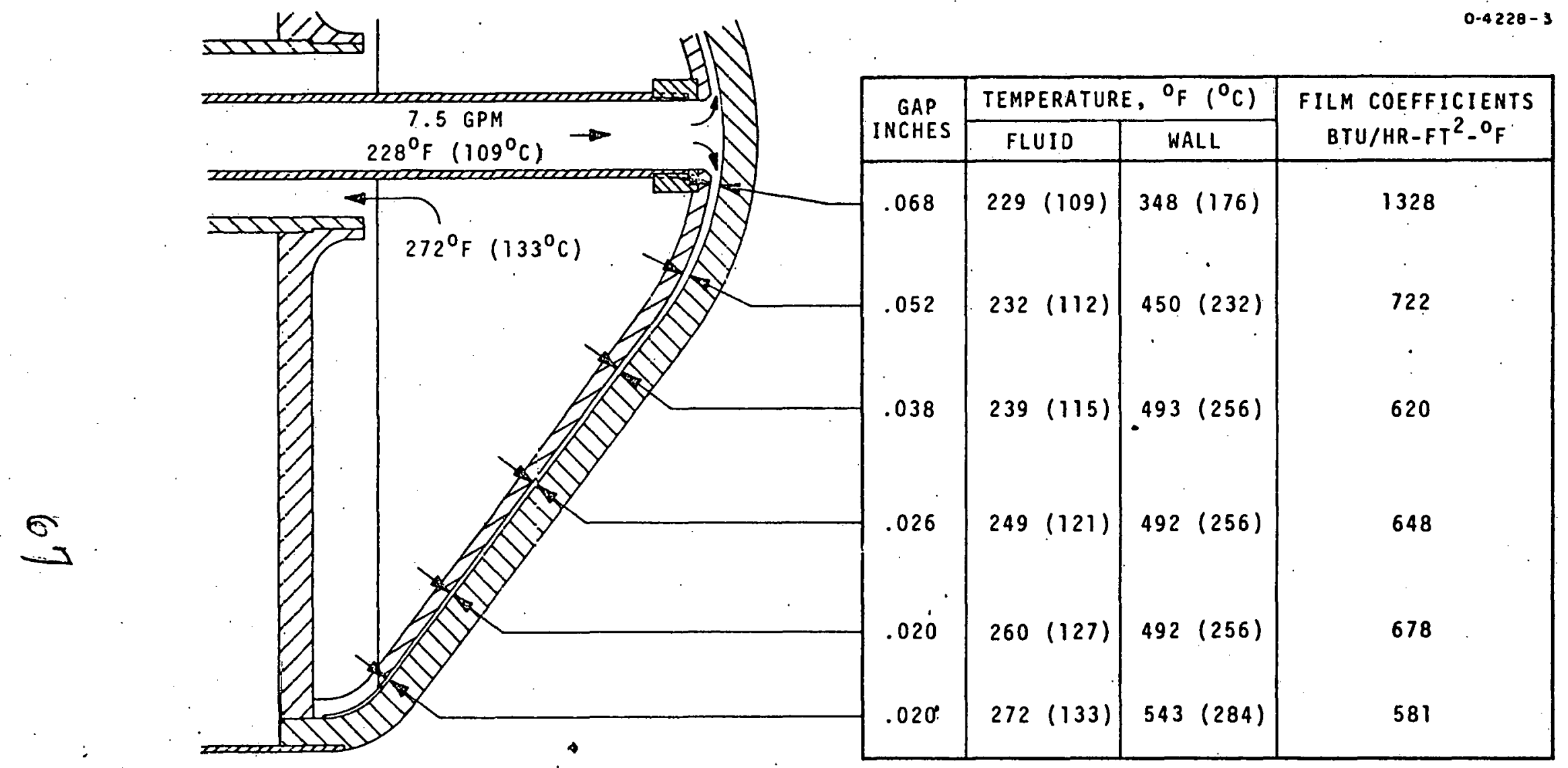

Figure-32. Anode heat transfer characteristics.

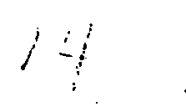


The fabrication of the anode structure required an extensive development program since it was necessary to make all the parts from molybdenum. The conical nose was spun from a $1 / 2$ in.-thick molybdenum plate on an iron mandrel at high temperature on a special spinning lathe. The fron was removed by melting it out and then etching the remainder. The etch removed the excess iron but did not attack the molybdenum. The rough part was rough machined on a computer-controlled lathe to get the approximately correct profile. The part was stress relieved in a controlled-atmosphere furnace and then final machined (also by a computercontrolled lathe) to the correct dimensions and correct profile. A critical part of the final machining process that took considerable development was the choice of a correct lubricant. After final machining, the part was again stress relived and checked. The parts for the anode assembly were E-beam welded and further stress relieved.

Many test parts were joined by E-beam welding to achieve proper process control. These test parts were photomicrogfaphed to measure weld penetration and recrystalization. The final joint design for successful E-beam welding was a mechnically holding joint that closed rather than opened under electron bombardment. Essentially, the joint had mechanical integrity on its own merit and the E-beam weld essentially sealed the joint. The anode shaft to back plate seal was made in a similar manner.

A simple analysis of the natural frequency of the first mode of the anode shaft in bending was performed. The results suggest that the natural. frequency is less than $27 \mathrm{~Hz}$; however, in reality, the shaft is not a fixed cantilever, and the actual means of joining the shaft to the insulator does complicate the analysis.

\section{H. ANODE COOLING SYSTEM}

Dowtherm, which was used to cool the anodes of the LMPVs is an organic fluid (a mixture of diphenyl and diphenyl oxide) that has a high dielectric strength. The two LMPVs contribute a maximum operating load of $100,000 \mathrm{Btu} / \mathrm{hr}$ to the Dowtherm unit, which is ultimately rejected to 
process cooling water. During operation and during standby, the Dowtherm was kept at about $100^{\circ} \mathrm{C}$ to prevent it from carburizing and to keep the mercury from condensing on the anode surface. The Dowtherm system was also equipped with a means of deaerating the liquid and removing gas pockets from all anode cavities; without this, the maximum cooling potential would not have been achieved.

Figure 33 shows the Dowtherm recirculating system, which was built in-house because no viable bids were received from outside vendors. It includes the circulating pump (bottom, right), reservoir (center), and air heat exchanger (top), with heaters, flow valves and filter. Figure 34 is the flow diagram. For the engineering prototype valves, reinforced nylon hoses were used to convey the Dowtherm from ground potential to the valve anodes. Since Dowtherm is an excellent dielectric fluid, no flashover problems were experienced. The Dowtherm circulation system reflects the anode requirements (shown in Figure 32) with a feed rate of 7.5 gpm to each anode.

In addition to the analysis of the flow problem described in Section 2.E, we also evaluated the local geometry where the Dowtherm leaves the central feed pipe at the anode nose. The points in question were (1) whether a significant volume of Dowtherm of Dowtherm vapor could remain at the nose under stable equilibrium, thereby contributing to a localized hot spot at the anode nose, and (2) whether the relatively sharp transition from the circular tube to the narrow channesi would result in a particularly high pressure drop. With the high flow rates involved, no null point in the flow was expected, and the pressure drop at the tube exit was not significant.

\section{CONDENSER COOLING SYSTEM}

Beginning with the known heat loads and gross condenser dimensions (dirtated by the spacing required for voltage holdoff inside the valve), a series of calculations were performed to optimize the channel dimensions, quadrant geometry, flow rate of refrigerant, etc. consistent with 


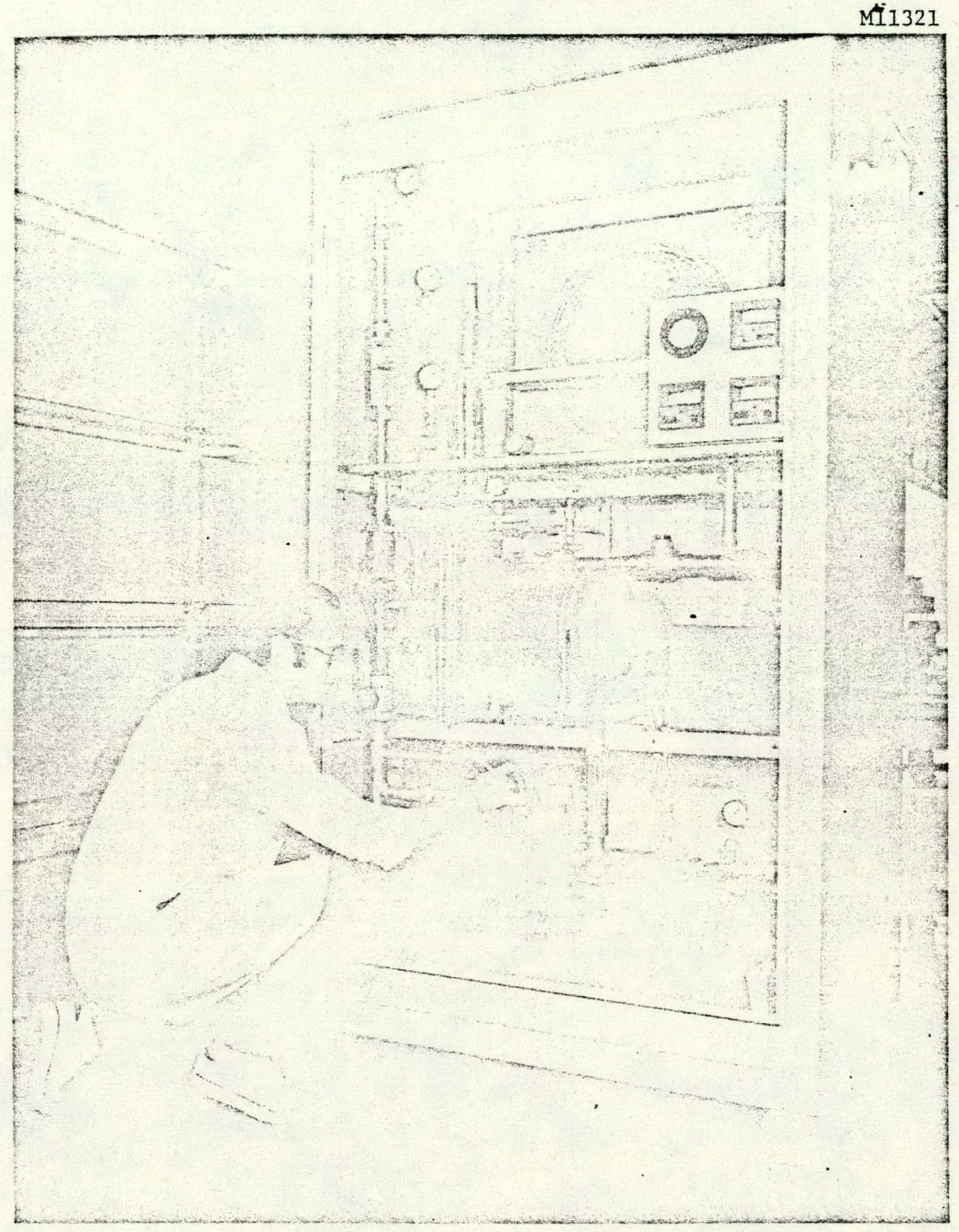

Figure 33. Dowtherm recirculating system.

70 


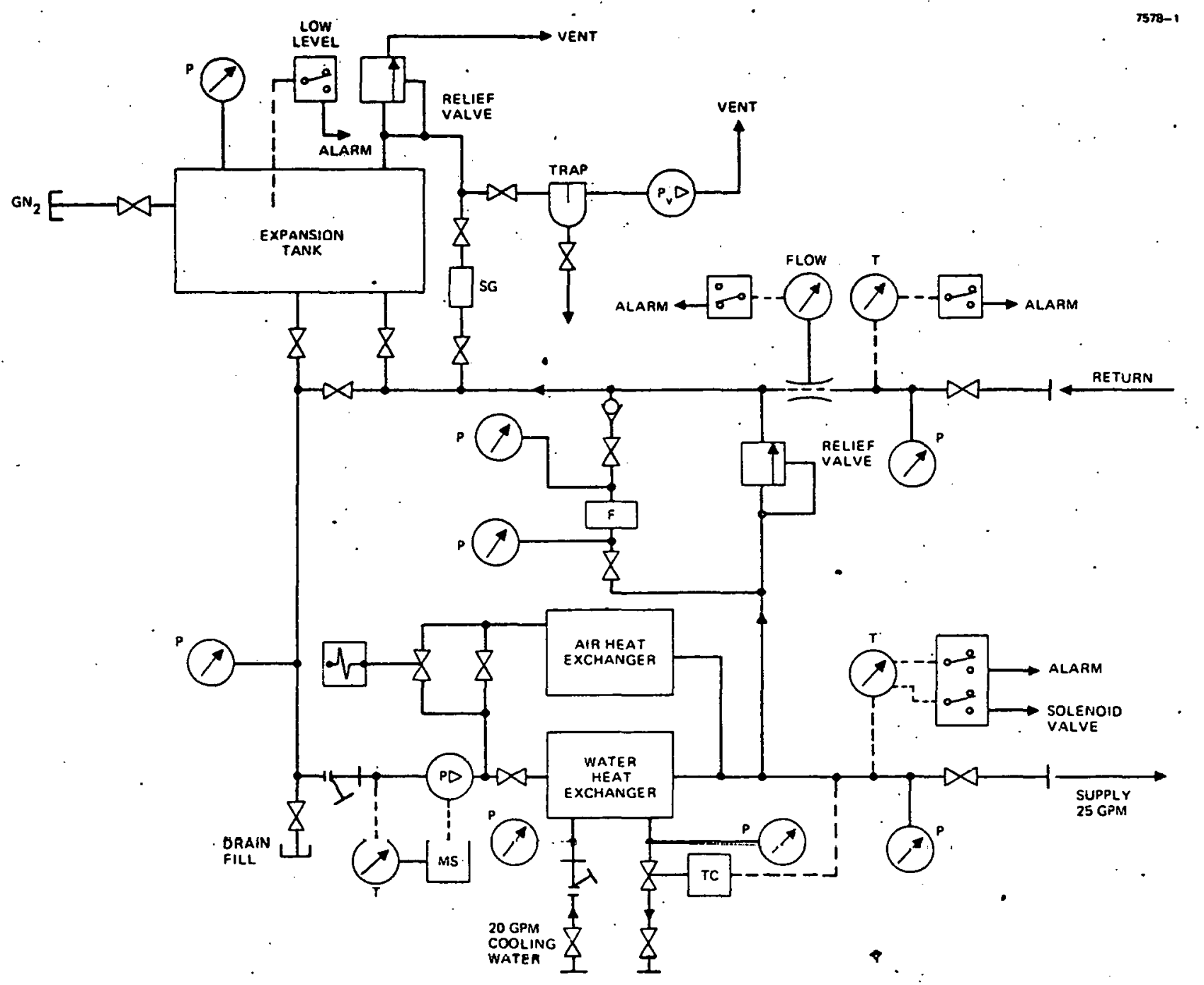

Figure 34. Flow diagram of Dowtherm system. 
allowable temperature gradients. This analysis showed that a totä̀ flow rate of $20 \mathrm{gpm}$ of chilled fluid through the condenser was sufficient to handle the heaviest sustained load. An alternative approach, cooling by expanding the refrigerant at the condenser, caused excessive temperature differentials.

There was choice between mounting the refrigeration system at cathode potential or at ground potential. If the system is at cathode potential, there is no need for dielectric hoses to carry the refrigerant to the condenser; if the system is at ground potential, control and redundancy of key components are much easier to engineer. However, the system had to be at ground potential at the Celilo terminal because there was insufficient power available at cathode potential to operate the compressor.

Figure 35 is a simplified diagram of the LMPV condenser cooling system. The compressor circulates refrigerant $\mathrm{R} 502$ through a heat excahnger that chills a secondary refrigerant Rll. - Liquid Rll is circulated to cool the condenser of each LMPV. Leaving the circulating pump, the Rl1 pressure and temperature are monitored at ground potential before the fluid passes up a dielectric hose to the condenser. On return to ground potential, the return temperature is determined and the control system operates the three-way valve. If the LMPV experiences a low heat load, this valve circulates less Rll through the chiller so that the temperature of the condenser can be maintained. Under a full load, the three-way valve circulates all of the Rll through the chiller.

AC.L-Filco fabricated the system to $\operatorname{cool}$ the engineering prototype valves. The LMPV condensers can each generate a maximum operating load of $22,000 \mathrm{Btu} / \mathrm{hr}$, giving a total load of $44,000 \mathrm{Btu} / \mathrm{hr}$.

The line insulation adds another $6000 \mathrm{Btu} / \mathrm{hr}$ to this load. The nominal load temperature can range from $-38^{\circ}$ to $-32^{\circ} \mathrm{C}$ (corresponding to a mercury saturated vapor pressure of $1.45 \times 10^{-6}$ to $3.59 \times 10^{-6}$ Torr). To provide ample capacity for both condensers at maximum load, the chiller package was sized to supply $40 \mathrm{gpm}$ of Rll fluid at a temperature of $-48^{\circ} \mathrm{C}$, requiring that the chiller have a capacity of $65,000 \mathrm{Btu} / \mathrm{hr}$. 


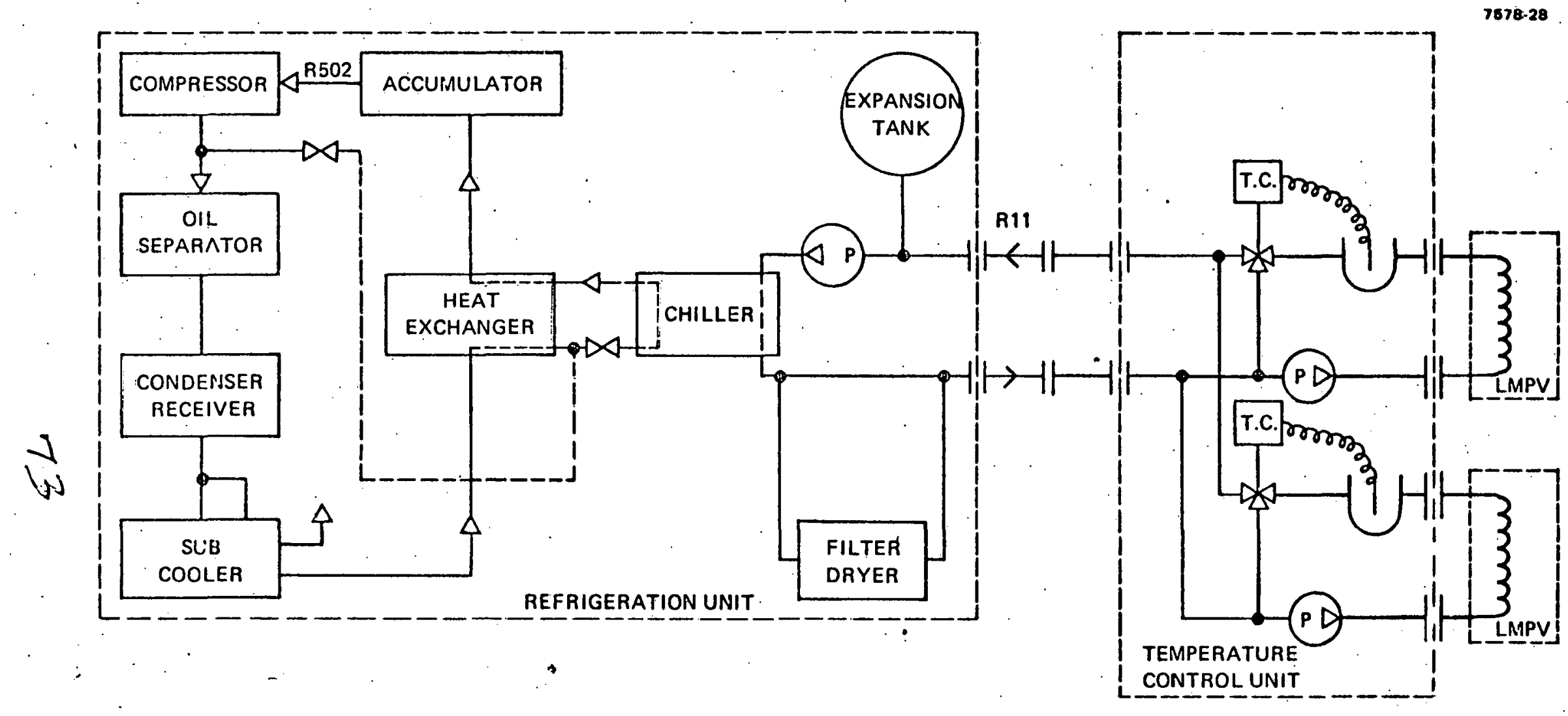

Figure 35. R11 flow diagram. 
The line insulation adds another $6000 \mathrm{Btu} / \mathrm{hr}$ to this load. The nominal load temperature can range from $-38^{\circ}$ to $-32^{\circ} \mathrm{C}$ (corresponding to a mercury saturated vapor pressure of $1.45 \times 10^{-6}$ to $3.59 \times 10^{-6}$ Torr). To provide ample capacity for both condensers at maximum load, the chiller package was sized to supply $40 \mathrm{gpm}$ of RIl fluid at a temperature of $-48^{\circ} \mathrm{C}$, requiring that the chiller have a capacity of $65,000 \mathrm{Btu} / \mathrm{hr}$. The pressure at the cryowall, nominally $12 \mathrm{psig}$, could exceed $30 \mathrm{psig}$ under any combination of operating modes and environments. The power requirements for the system were $480 \mathrm{~V}, 3$ phase, $75 \mathrm{~A}$, with cooling water at $40 \mathrm{gpm}$ for ultimate heat rejection. High voltage isolation was provided by $10-f t$ lengths of nylon braided nonconductive hose.

\section{J. CONTROL, FAULT INDICATION, AND MONITORING}

To initiate conduction in the valve for each cycle, a small volume of plasma is created at the cathode surface. This plasma then ignites a vacuum arc discharge in the presence of a sustaining voltage, which can either be between the cathode and the auxiliary anode or between the catho-e and the main valve anode. The igniter and auxiliary anode power supplies are contained in a single unit, with buffered outputs of parameters for fault processing and monitoring. In normal operation, the three valve igniters are fired in sequence; each firing occurs when a gate is received through the light link each $16.6 \mathrm{~ms}$. In the event of a misfire, as determined by the absence of auxiliary anode current, the succeeding igniter will be pulsed to start the auxiliary anode current. flow (see Table 4). However, each igniter will be pulsed only once during each conduction period (5.6 ms). The auxiliary anode power supply will be gated on during the valve conduction period to prevent cathode spot extinctions caused by fluctuations in the main anode-cathode voltage.

Fault intormation $1 \mathrm{~s}$ divided into threc levels. The lowest level fault (III) is indicated on the instrumentation console at ground potential, but does not inhibit reset of the valve in the event of an arc back. Fault level II annunciates the fault and prevents automatic reset

$$
74
$$


in the event of an arc back in the group. The origin of the fault remains recorded on the console until a manual reset is made, or a fault-bypass switch is activated. Fault level.I refers only to two critical parameters (anode temperature and $\mathrm{SF}_{6}$. pressure in the feedthrough bushings and voltage divider) which have proven to be very stable during laboratory prototype valve operation. If one of these parameters exceeds a preset tolerance condition, the group is shut down and the bypass valve is activated. Figure 5 shows the auxiliary electronics package for the first engineering prototype, and the annunciation console. Connections between the two are made with fiber optics to achieve requisite EMI shielding and high voltage isolation. The electronics package includes several meters to monitor the temperatures of key valve components during operation, so that comprehensive data can be obtained, for example, on the rate of warm up of the condenser in the event of a compressor outage. (Deliverable auxiliaries will have considerable built-in redundancy: The Rll chiller would switch to a standby compressor in the event of such an outage.)

Figure 36 is a representation of the control, fault indication, and monitoring scheme for the LMPV. The monitoring function described here is not to be confused with the system monitoring package described under task B. As shown in the figure, valve control pulses pass through the buffer and interface to the igniter power supply via a fiber optic link. The igniter current and/or voltage waveform can be transmitted back to groun potential through another link.

Table 4. Valve Auxiliary Electronics

Control

Signal via fiber-optic link to valve

Igniter power supply used in conjunction with three igniters

Each igniter fired in sequence

Current to auxiliary anode sensed. . If discharge not initiated, second and even third igniter fired at $20 \mu \mathrm{s}$ intervals

Cathode current modulates EM pump current to control mercury flow 


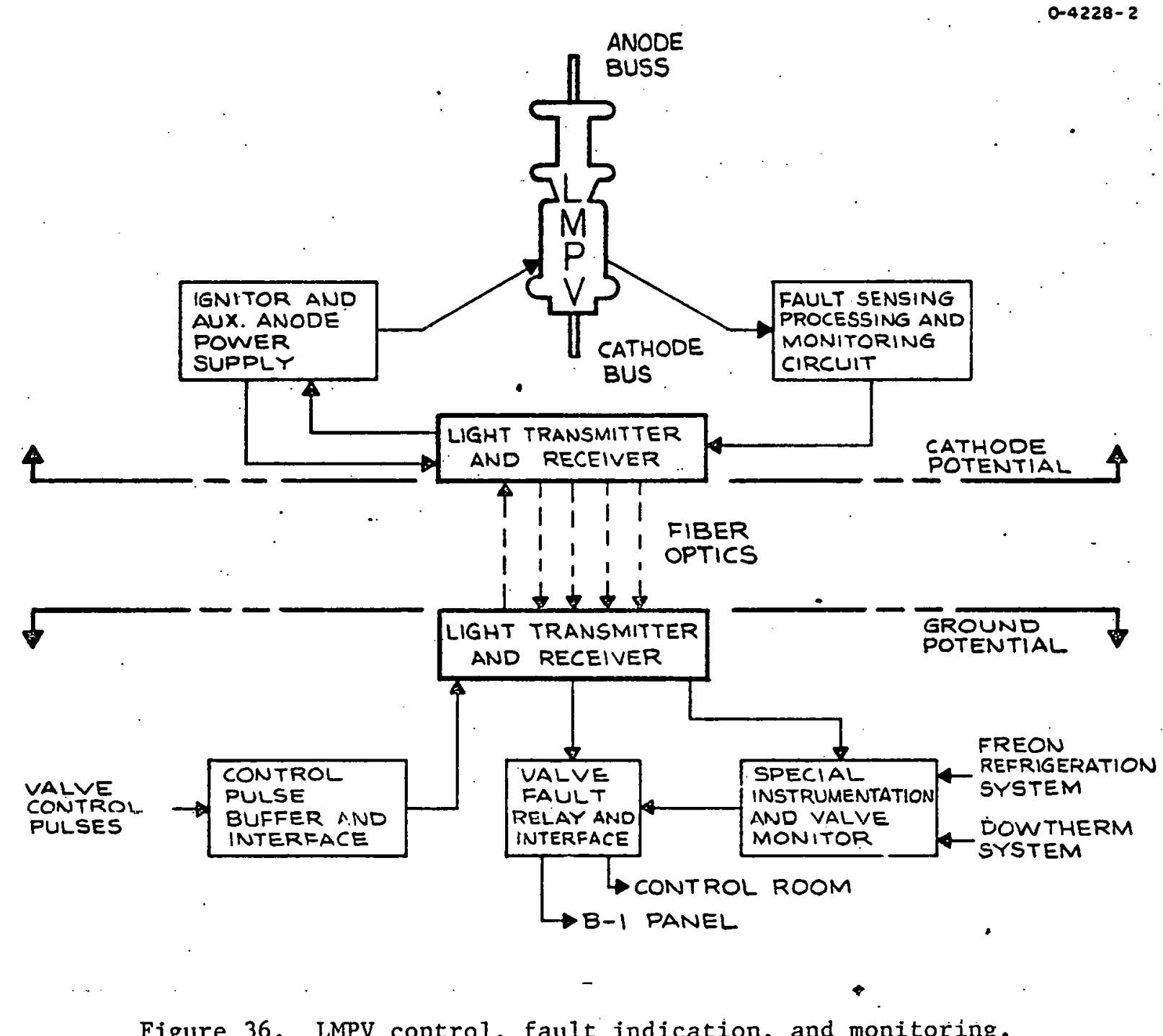

Figure 36. LMPV control, fault indication, and monitoring. 
Table 5. Valve Auxiliary Electronics

\section{Monitoring}

Temperatures, pressures, coolant flow EM pump current

Display at cathode potential

Information to ground via fiber-optic link

Anunciation at ground potential

Protection

Three levels - III annunciate only

II annunciate and prevent reset

I shụt down - two critical parameters only

Fault bypass switches

Two types of information are required. of the valve instrumentation subsystems. The first is summary fault indication to enable a decision to be made within transmission control concerning readiness of the Hughes converter package for proper in-service operation and early detection of unacceptable shifts in operational parameters (precursors to out-oftolerance conditions that would force the associated converter group to be taken off-line). Annunciation levels are based un predetermined functional design limits. To the extent practicable, parameters sampled and limits set are compatible with both the present physical interface and the decisional methodology used in transmission control. Inputs are obtained from ground potential. The second type of instrumentation will accrue functional data of the more refined diagnostic type for in-service assessment of valve performance. This includes the capability of transmitting engineering instructions to selected elements of the valve package. In this way, technical overrides can be instituted or performance limits modified

Table 6 shows some of the parameters of interest together with their normal, cautionary; critical, and mandatory conditions. These out-oftolerance conditions are communicated to ground via fiber optic cable, where they can be recorded-and appropriate action initiated. Mandatory 
action includes blocking the ignition pulse, as for example the cầse when the condenser temperature becomes unacceptably high. . Table 6 shows that there is generally a wide margin between the action levels for the different parameters.

Figure 36 is a block diagram of the control, fault indication, and monitoring functions for the LMPV package. The igniter power supply and the fault sensing and monitoring circuitry are at cathode potential, and signals are transmitted to ground potential via fiber optic links. Similarly, valve control pulses are transmitted to the electronic package at cathode potential through a separate fiber optic link.

Figure 37 shows the valve auxiliary electronics in more detail. In particular, the diagram shows the three levels (designated I, II, and III) into which the fault information is divided.

\section{K. VALVE AUXILIIARIES}

The valve auxiliares comprise the anode cooling system; the condenser cooling system; the control, fault indication, and monitoring system; and (in the case of the deliverable valves) the support system cart. For the engineering prototype valves, which were tested in the synthetic valve test facility at Malibu, the cooling systems were installed outside of the EMI perimeter of the facility and the coolant brought into the facility through EMI-proof feedthroughs. For the deliverable valves, these cooling systems would have been installed in the basement aisle of the valve hall, adjacent to Group I. Electronic systeris for the most part would have been located in the metal framework of the valve cart.

Figure 15 shows the auxiliary electronics package for engineering prototype valve No. 1 being integrated with the valve. The feedthrough bushing and $\mathrm{SF}_{6}$-gas reservoir can be seen on the valve assmelby, while the rear of the meter-relay panel can be seen in the electronic box on the right of the figurc.

The fluid cooling systems for the valve are shown in Figure 38. Both systems perform above specifications, as shown in Table 7. 


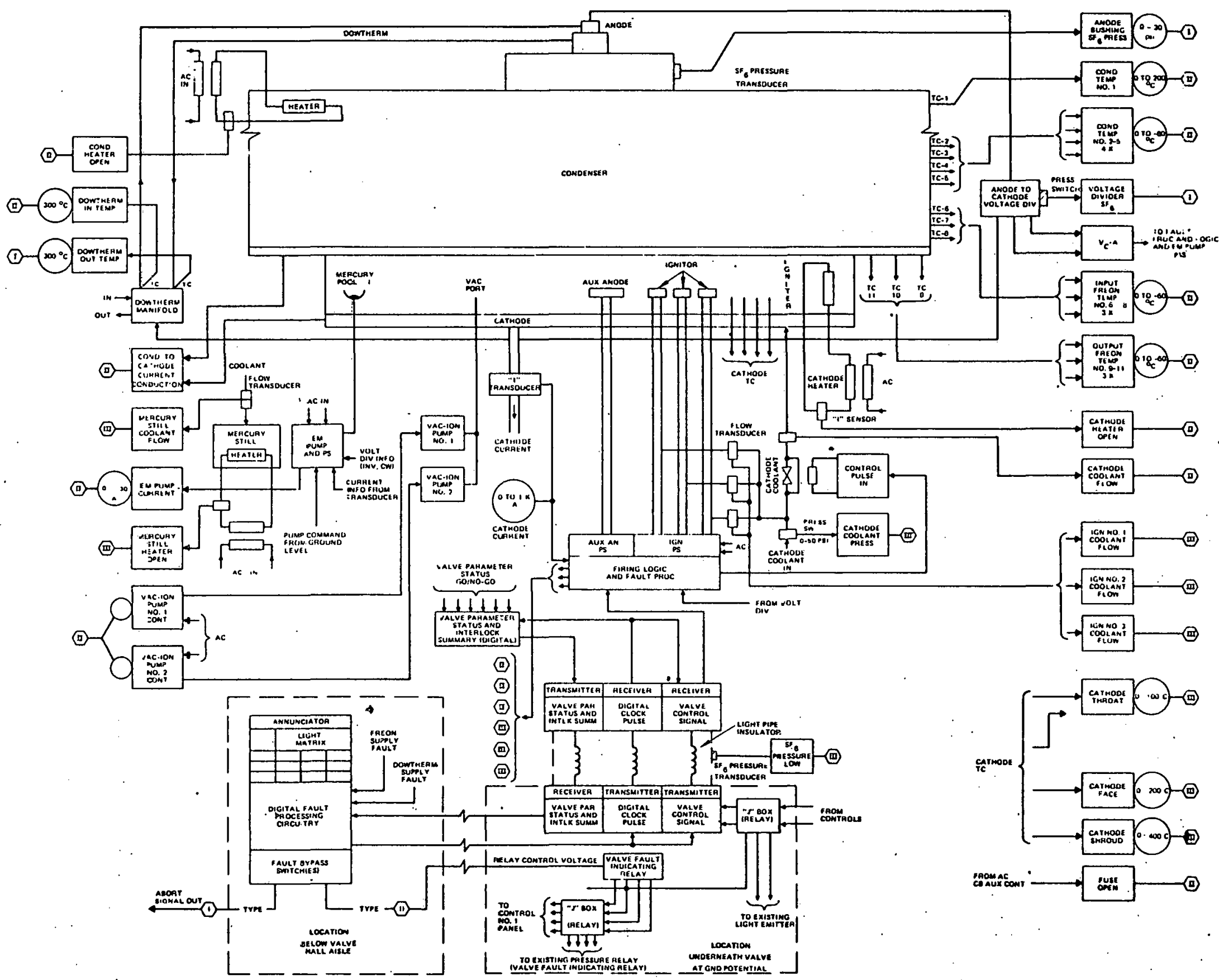

Figure 37. Block diagrm of valve auxfliary electronfes. 
Table 6. Out-of-Tolerance Condttions

\begin{tabular}{|c|c|c|c|c|c|}
\hline Function & & Normal & Cautionary & Critical & Mandatory \\
\hline \multirow{2}{*}{ Dowtherm temperature, ${ }^{\circ} \mathrm{C}$} & High & 150 & 180 & 210 & 250 \\
\hline & Low & 100 & 80 & 一 & $\longrightarrow$ \\
\hline \multirow{3}{*}{$\begin{array}{l}\text { Flow } \\
\text { Pressure, psig }\end{array}$} & GPM & 7.5 & 5 & 2.5 & - \\
\hline & High & 100 & 140 & $\longrightarrow$ & 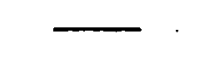 \\
\hline & Low & 100 & 60 & - & $\longrightarrow$ \\
\hline \multicolumn{2}{|l|}{ SF bushing pressure, psig } & 60 & 40 & 20 & -5 \\
\hline \multirow[t]{2}{*}{ Condenser temperature, ${ }^{\circ} \mathrm{C}$} & High & -36 & -28 & -18 & -5 \\
\hline & Low & -36 & -40 & - & - \\
\hline Freon II temperature, ${ }^{\circ} \mathrm{C}$ & High & -54 & -46 & $\longrightarrow$ & - \\
\hline Sputter shield temperature, ${ }^{\circ} \mathrm{C}$ & & 150 & 100 & 50 & - \\
\hline Cathode shroud temperature, ${ }^{\circ} \mathrm{C}$ & . & 150 & 100 & 50 & - \\
\hline Cathode throat temperature, ${ }^{\circ} \mathrm{C}$ & & 50 & 75 & 100 & 150 \\
\hline Cathode coolant flow, gpm & $\vdots$ & 2 & 1 & 0.5 & 0 \\
\hline Ion pump current, $\mathrm{mA}$ & $\vdots$ & 10 & 100 & 500 & 1000 \\
\hline
\end{tabular}


5216.

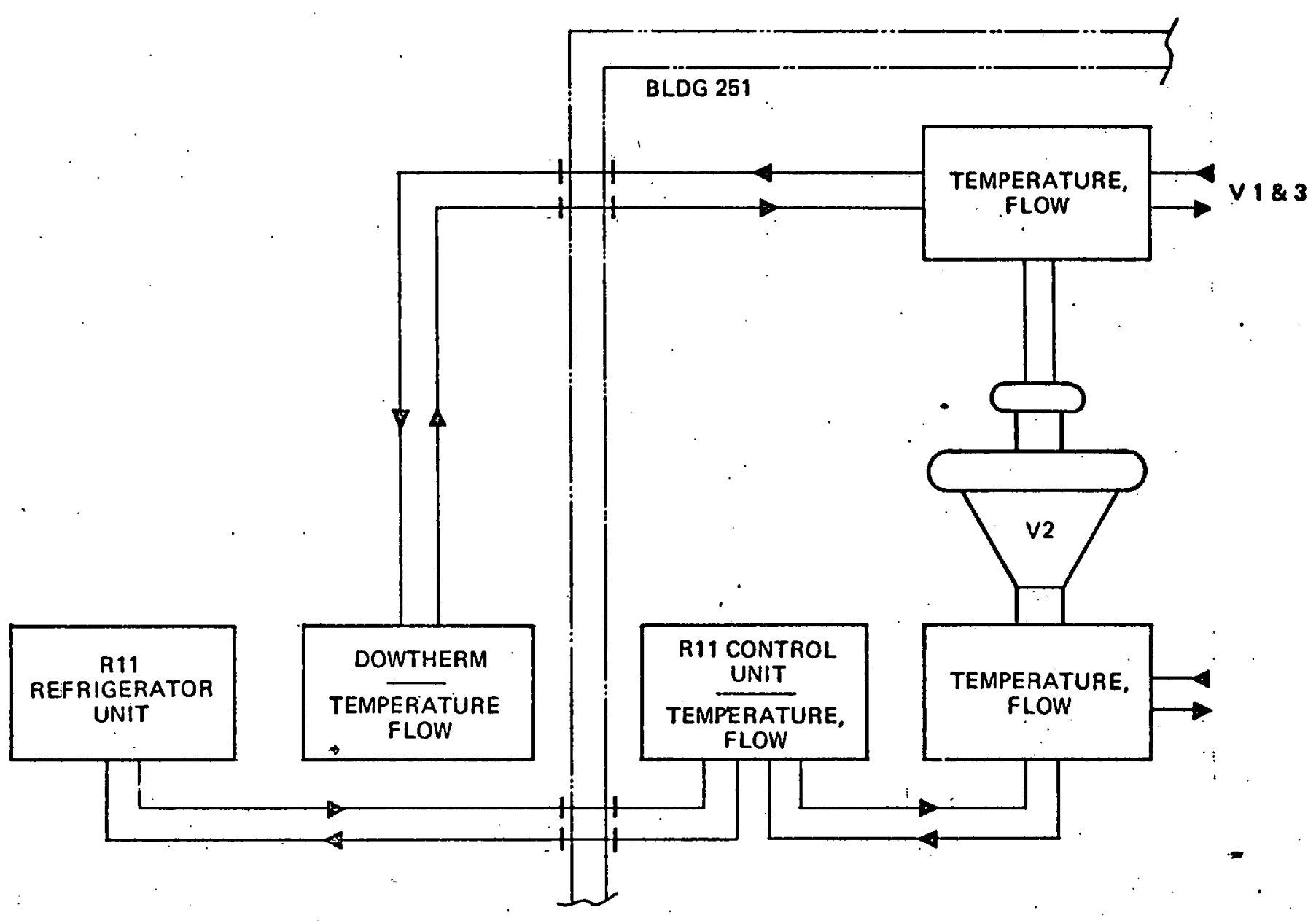

Figure 38. Fluid cooling systems. 
Table 7. Preliminary Heat Transfer Performance

\begin{tabular}{|c|c|c|}
\hline Coolant & Maximum Load Requirement & Test Performance \\
\hline $\begin{array}{c}\text { R11 } \\
\text { at }-50^{\circ} \mathrm{F}\end{array}$ & $\begin{array}{c}44,000 \mathrm{Btu} / \mathrm{hr} \\
(1.3 \mathrm{~kW})\end{array}$ & $\begin{array}{c}51,200 \mathrm{Btu} / \mathrm{hr} \\
(15 \mathrm{~kW})\end{array}$ \\
$\begin{array}{c}\text { Dowtherm } \\
\text { at } 190^{\circ} \mathrm{F}\end{array}$ & $\begin{array}{c}103,000 \mathrm{Btu} / \mathrm{hr} \\
(30 \mathrm{~kW})\end{array}$ & $\begin{array}{c}144,000 \mathrm{Btu} / \mathrm{hr} \\
(42 \mathrm{~kW}) \\
\text { Specification } \\
\text { Specification }\end{array}$ \\
\hline
\end{tabular}

\section{INTEGRATION}

This task is related to the preparation and modifications of the synthetic test facility to accept and test the engineering prototype valves. The differences between these and the earlier valves occur because of ( 1 ) the change in orientation from near-horizontal to nearhorixontal to near-vertical and (2) the use of chilled fluid (R11) to cool the valve condensers rather than direct expansion of refrigerant at the condenser input.

Modifying the test circuit (Figure 39) required information from BPA personnel concerning the actual rates of change of current and voltage experienced at the Celilo facility. Power supply EI and the commutation circuit were modified (not chargeable to the contract). Other equipment changes and installations were funded by Hughes include the relocatiuu of some componente; the up-grading of the valve damping network; and the installation of a BIL test set, high current transformer, and fault current injection system.

Figures 40, 41, and 42 show, respectively, the original plan of the synthetic test facility, the new facility layout for the engineering prototype valves, and the external equipment installation. The engineering prototype valve and auxiliary electronic equipment housings are separate from each other to facilitate installation in the test facility. 


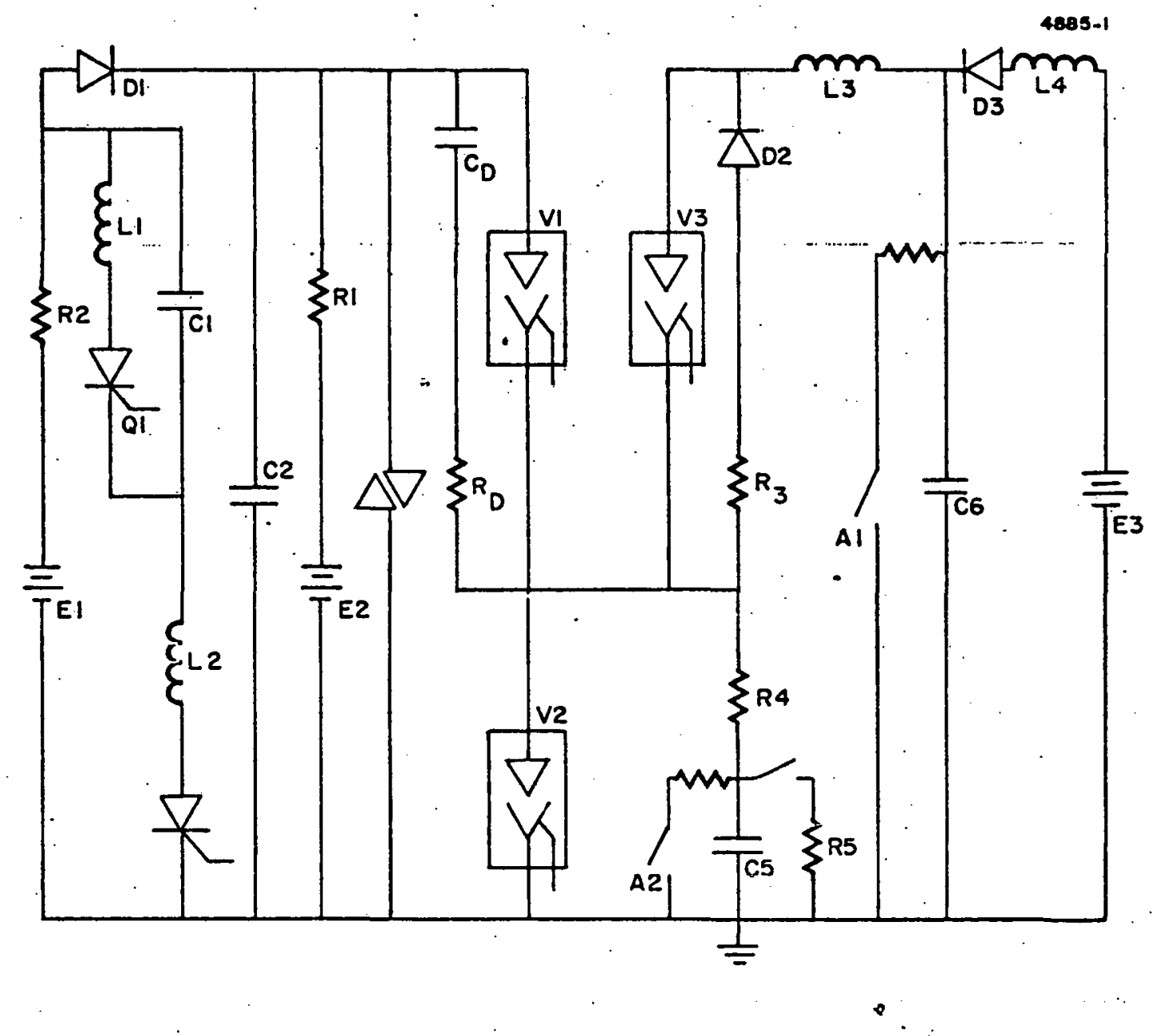

Figure 39. Synthetic test setup. 
7578-3

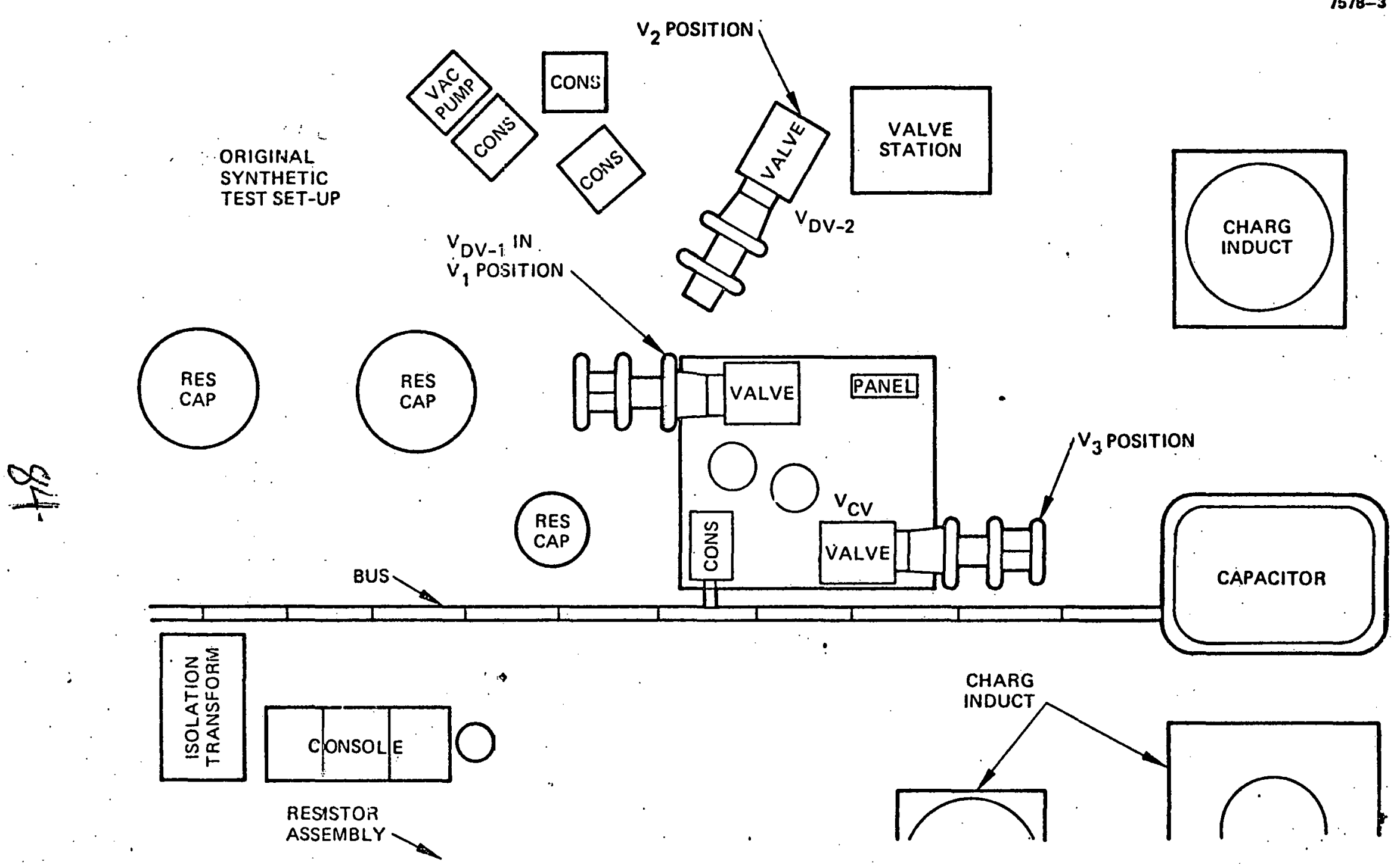

Ffgure 40. DOE/LMPV program synthet1c test set-ups. 


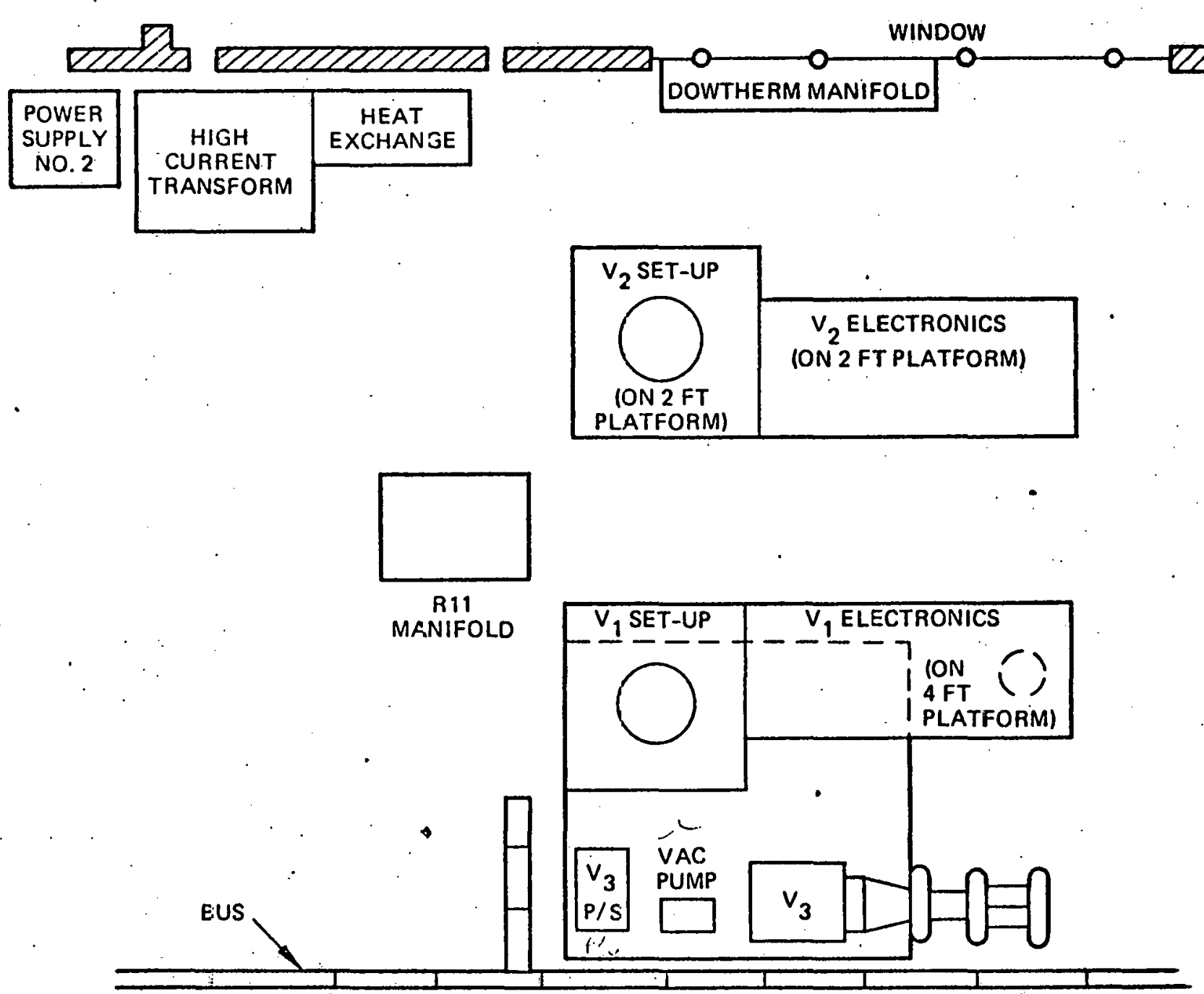

7678-4

a)

Ti

Figure 41. DOE/LMPV program synthetic test set-up. 


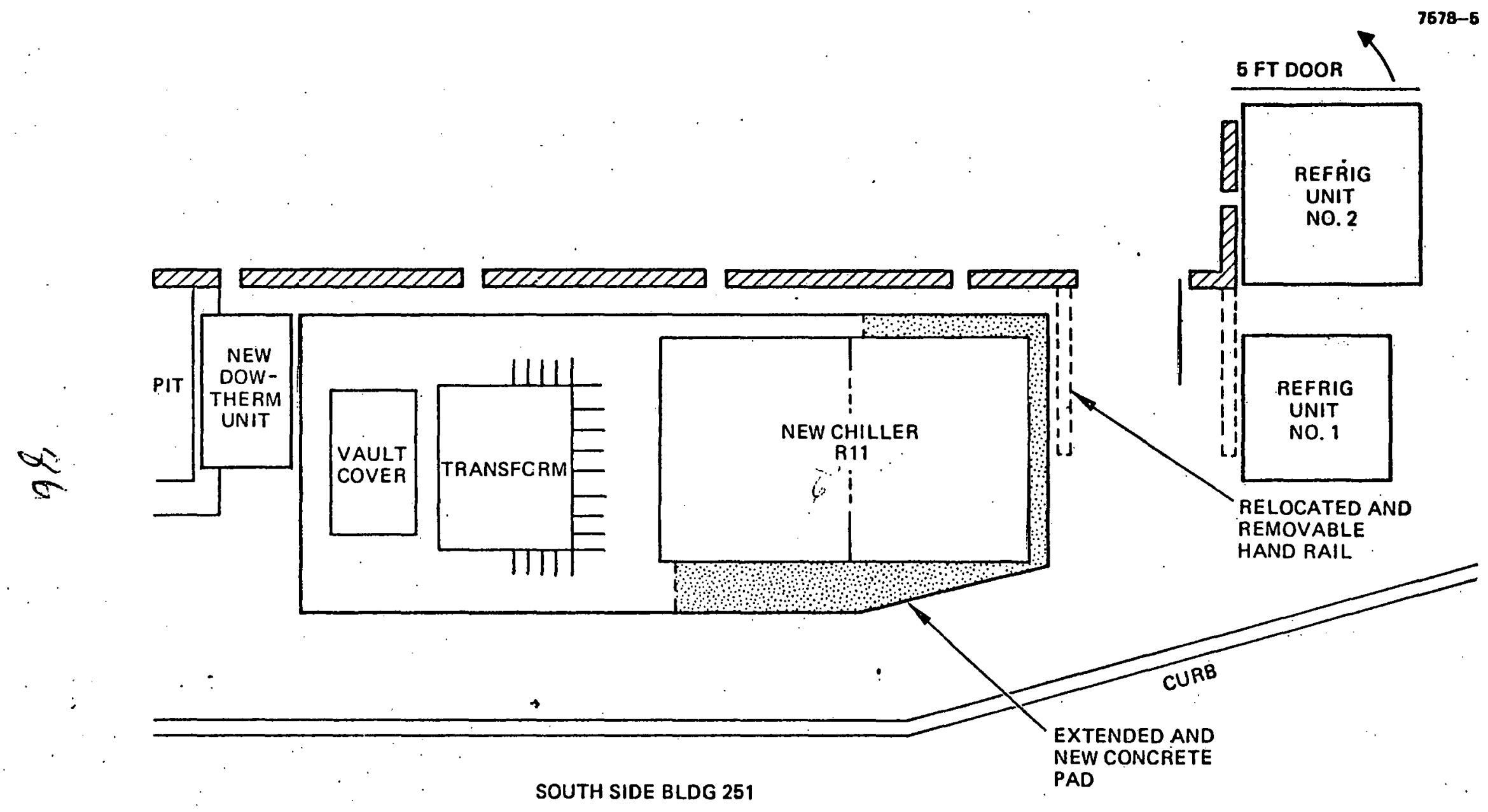

Figure 42. DOE/LMPV program equipment installations. 
In elevation, the auxiliary packages are positioned to allow easy observation of monitoring equipment from the control room window. Figure 42 shows the locationsof the RII chiller unit and the Dowtherm circulation units.

Figures 43 and 44 . show the elevation of valves $v_{1}$ and $v_{2}$ with their electronic packages as installed in the test facility. The action items completed are listed below:

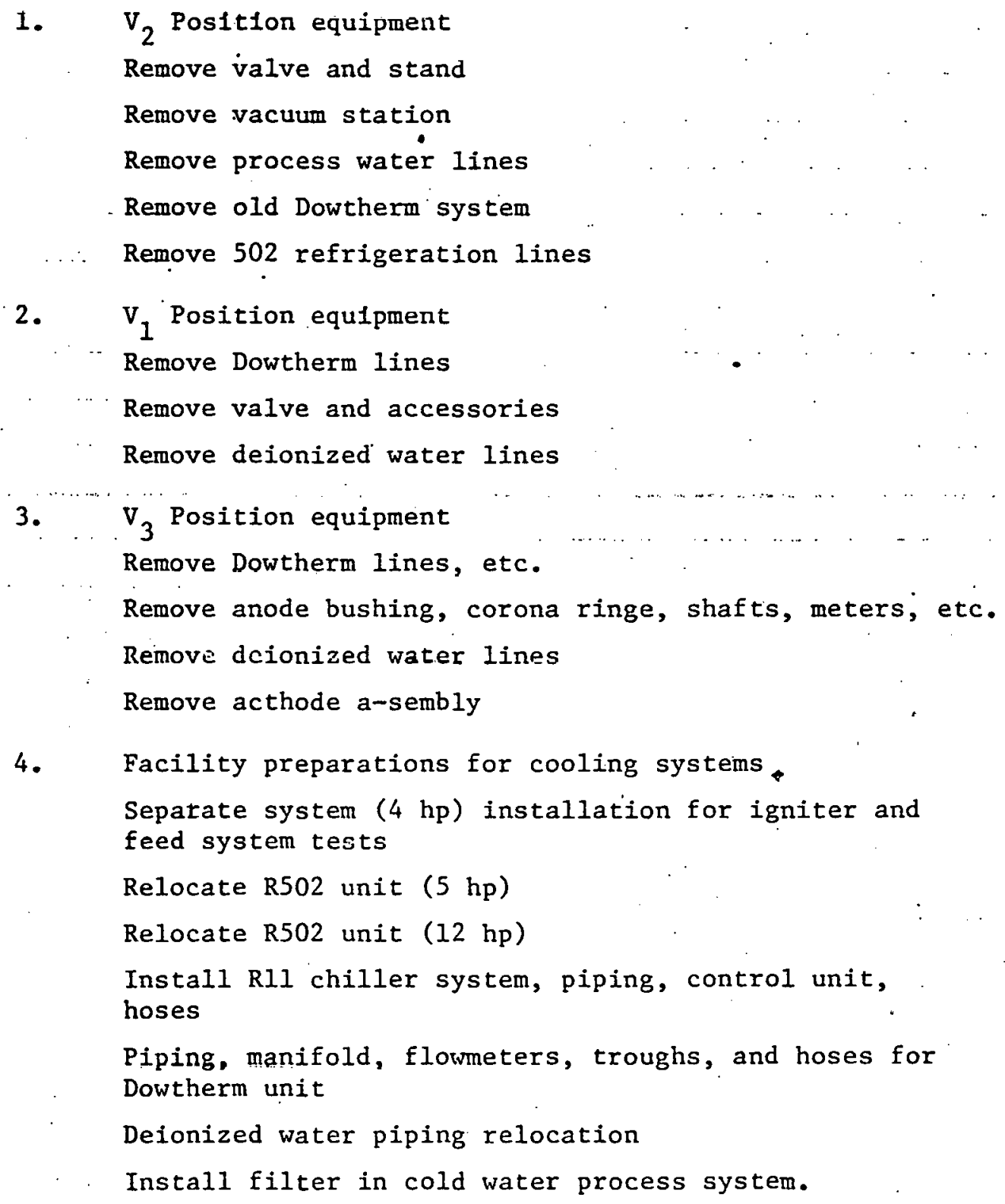




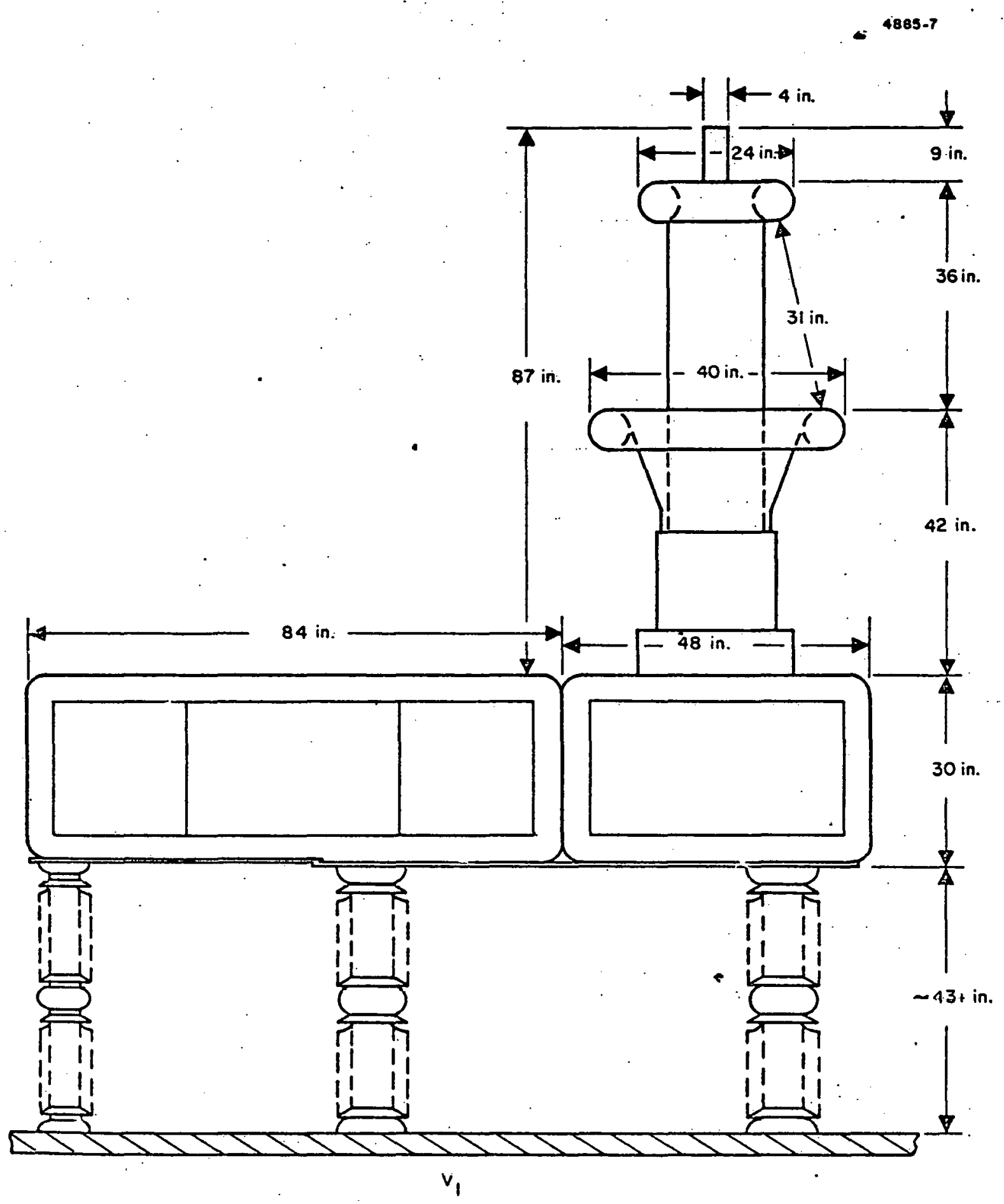

Figure 43. Elevation of $v_{1}$ valve and electronics package. 


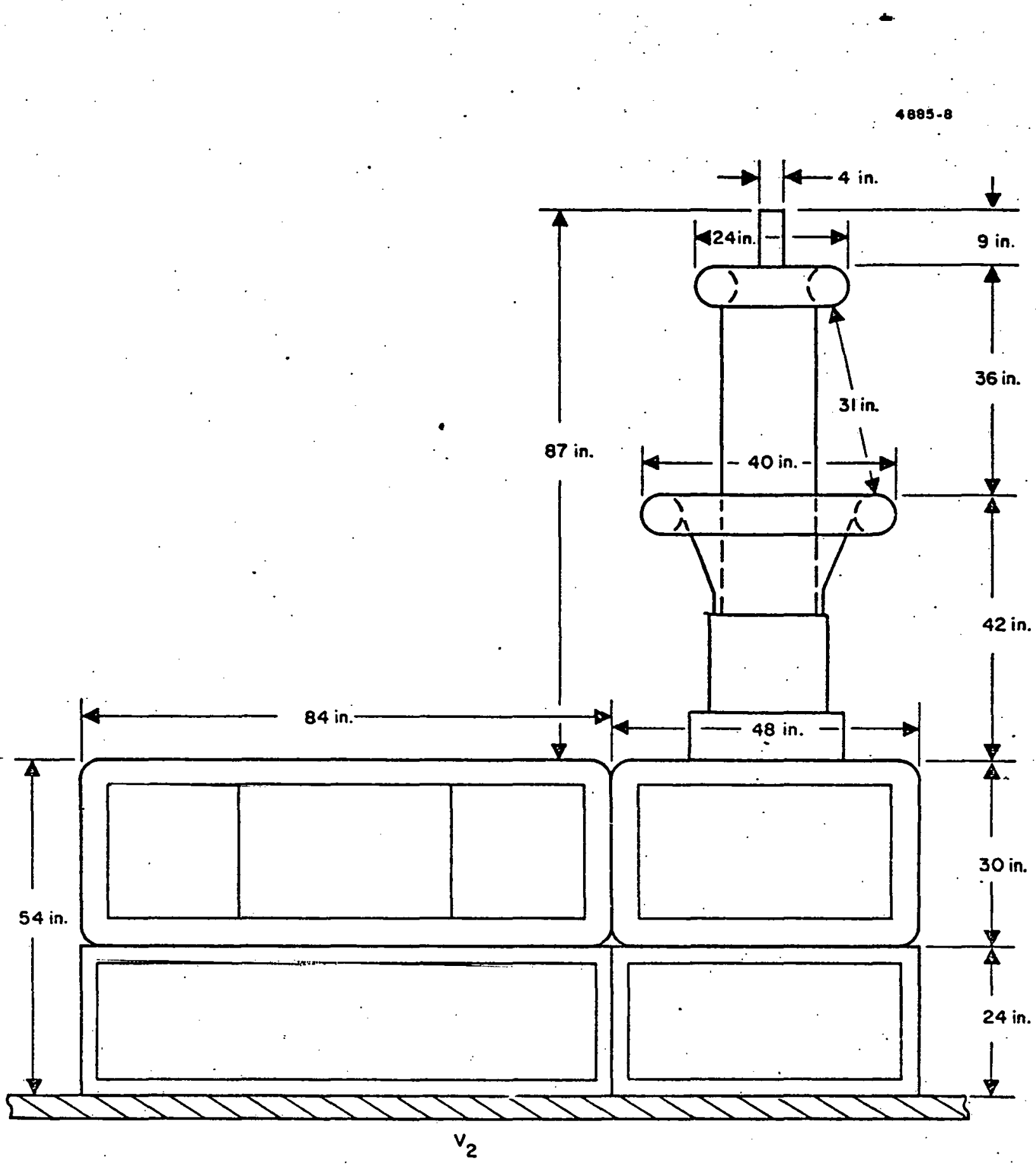

Figure 44. Side elevation of $v_{2}$ valve. 
5. $V_{1}$ position: new test setup assembly

Vertical valve stand installation

Install development valve

Install Dowtherm, deionized water, R502, vacuum system, etc.

Install electronic, light links, controls

6. $\nabla_{2}$ position: new test setup assembly

Install wood support frames, valv̈e stand, and electronic enclosure

Install valve and accessories

Install Dowtherm, Rll, process water lines, etc.

Install light link, controls, etc.

7. $v_{3}$ position: new test setup assembly

Install platform extension

Relocate valve stand

Reassemble anode shafts, bushing, corone ring

Install $1 / 2$ in. Dowtherm lines

Install cathode assembly

Install deionized water lines

Relocate anode reactor

Install electric lines, light link, controls

3. Contrul room

Install new monitor console and check out the monitor. system

9. Circuit components

Relocate $A_{2}$ switch and voltage divider

Relocate $\dot{V}_{3}$ anode reactor

Finish high current transformer installation and impulse tester

10. Deionized water piping

Install hangers and piping

Install and relocate fee and return lines

Manufactur and install ground connections 
Install flowmeters, valves and purity controls

Install marifolds, control valves, and lines to $v_{1}$ and $V_{3}$ positions

System checkout and testing

11. Process cooling water

Install filter

Log lines

12. Dowtherm-A system instaliation

Piping,-manifold, flowmeter, troughs, hoses

Main unit, water, electrical, gas

System checkout and testing

13. BIL, switching surge, and dc withstand test system

Installation (Hughes purchased)

System checkout and testing

14. High current ( $30 \mathrm{kA})$ transformer

Installation (Hughes purchased)

Conduit wiring and controls

Anode connection design and fabrication

Anode connection installation

Cathode connection installation

System checkout and test

M. INTERFACE WITH BPA FACILITIES

Figure 45 shows a 1.:10 -cale model of the LMPV mounted in place of an ASEA valve; the model was built to help delineart the specific interface areas. Figure 46 shows a 1:50 scale model of Group. I at Celilo, showing the six regular ASEA valves and the one bypass valve in position. Other models (not shown in this figure) to the same scale have been made of the Hughes valves and of the voltage dividers to be used tih the monitoring station. 


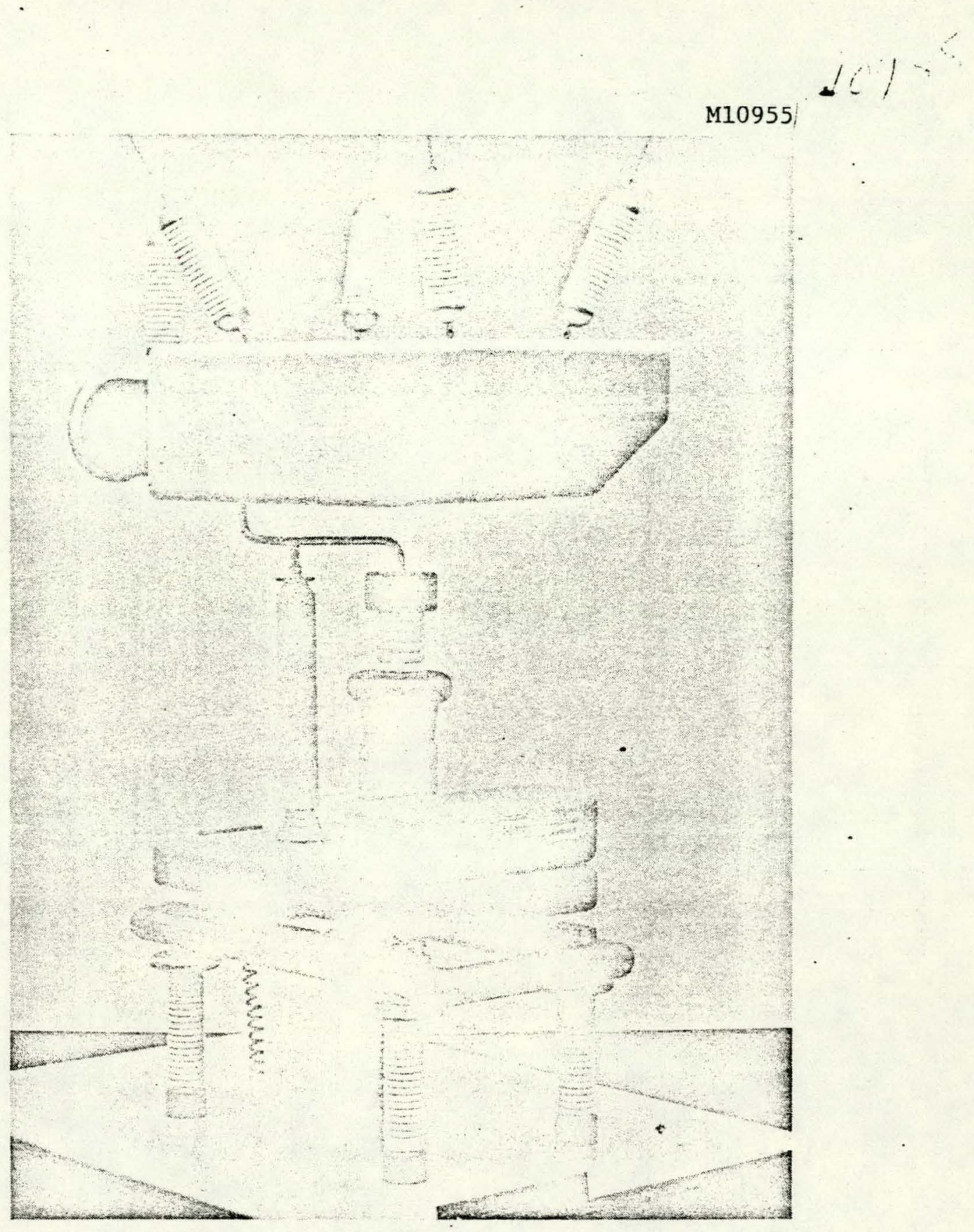

Figure 45. 1:10 scale model of LMPV. 


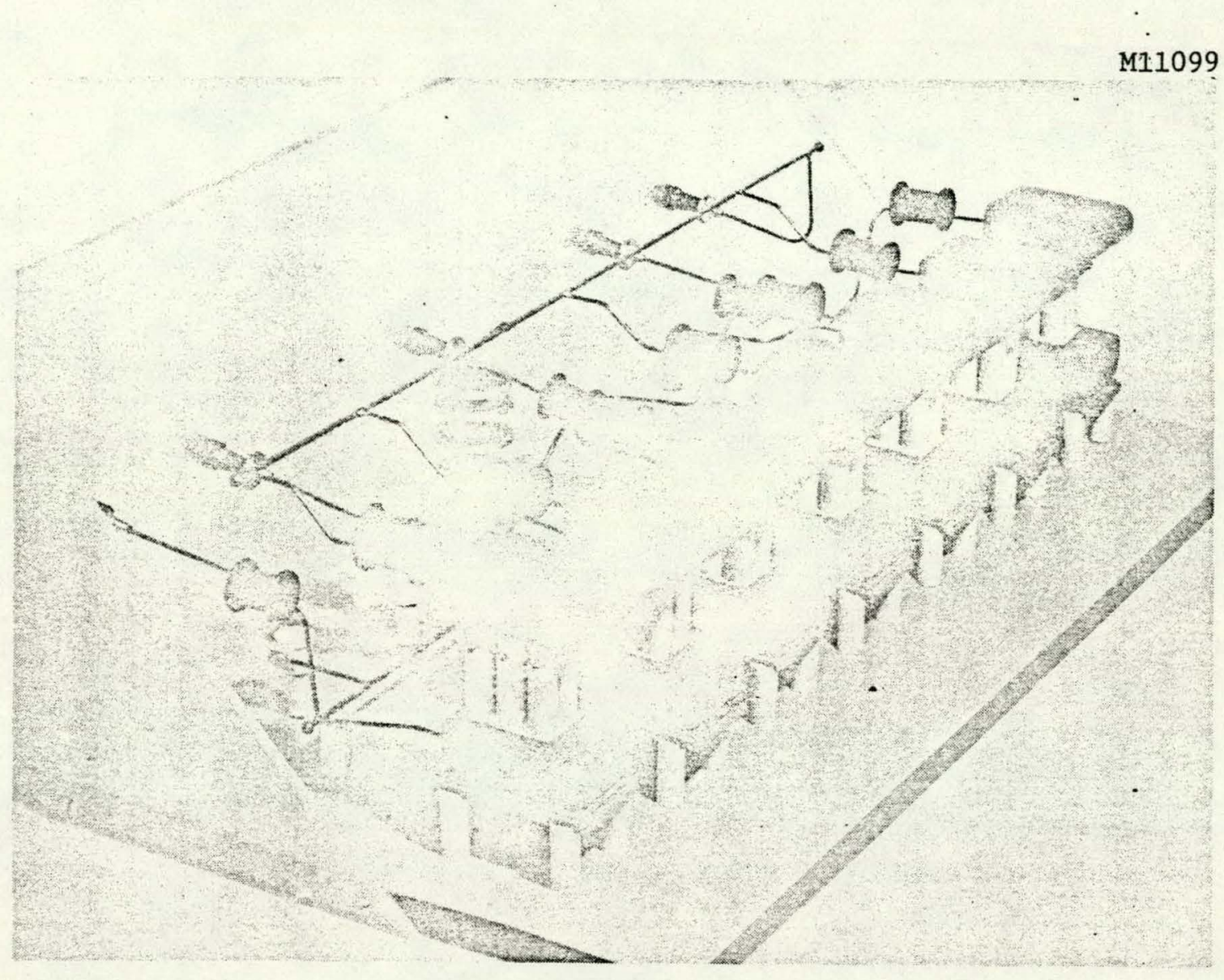

Figure 46. 1:50 scale model of Group I at Celilo. 
Valve positions SA and SC were chosen for substitution of the HAC valve; Figures 47 and 48 show the positions in which monitoring current and voltage waveform sensors were installed. The valve hall layout for Group I at Celilo is shown in Figure 49, with fiber optics from the current and voltage sensors carried to the roof of the cable spreading room, which is vertically below the converter station control room. Figure 50 shows a voltage divider assembly that is typical of those installed in three places in the valve hall, with the fiber optics traversing the valve hall floor in a protective conduit at below floor level (see Figure 51). Figure 52 shows the dimensions of the voltage divider, and Table 8 details the basic specifications.

Contracts were given to qualified electrical and mechanical contractors in Oregon to cut a surface trench in the valve hall floor to receive the light links from the voltage dividers and current sensors. The trench will have a structurally strong cover, and the fiber optics will be protected inside foam-lined panduit. Two approximately 14-in.diameter horizontal holes were bored under the valve hall floor to below the SA and SC positions for the Dowtherm and refrigeration lines, which were to be installed later.

Panduit was installed from the basement aisle adjacent to the valve hali to the cable spreading room, which is immediately below the converter station control room. This is for the fuil length fiber-optic runs from the valve hall to the control room, where the monitoring station console was installed.

Table 8. Voltage Sensor.

$$
\begin{aligned}
& \text { P.O. for H.V. Divider placed 6-16-75 } \\
& \text { Shieldcd Divider } \\
& 150 \mathrm{kV} \text { rms } 60 \mathrm{~Hz} \\
& \pm 225 \mathrm{kVdc} \\
& \pm 465 \mathrm{kVdc} 1 \mathrm{~min} \text { transient } \\
& 650 \mathrm{kV} \text { BIL (1.2 } 250 \mathrm{~s}) \\
& \pm 5 \% \text { accuracy (dc to } 100 \mathrm{kHz})
\end{aligned}
$$

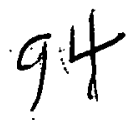




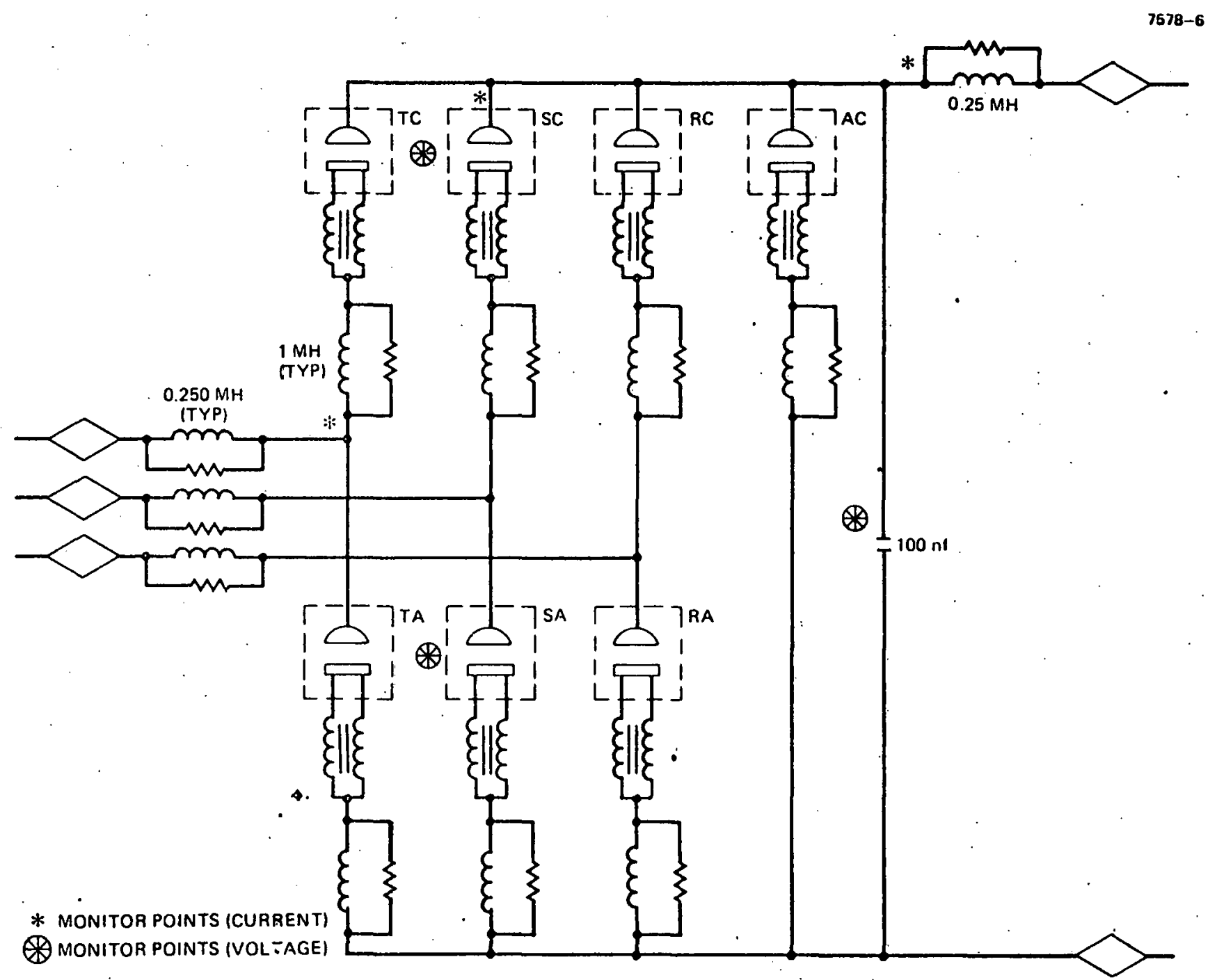

Figure 47. Valve bridge. 


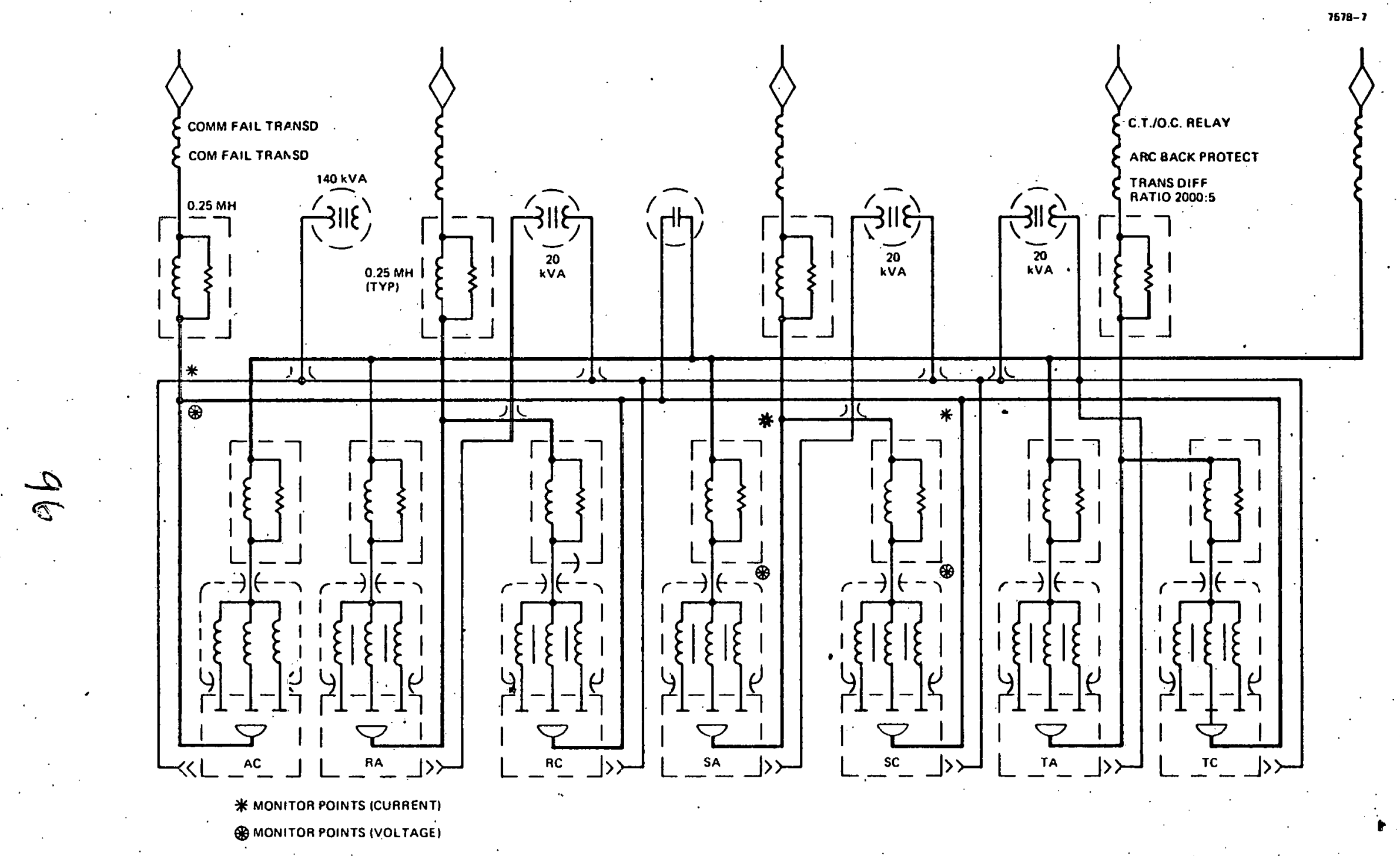

Flgure 48. Valve bridge - Group I. 


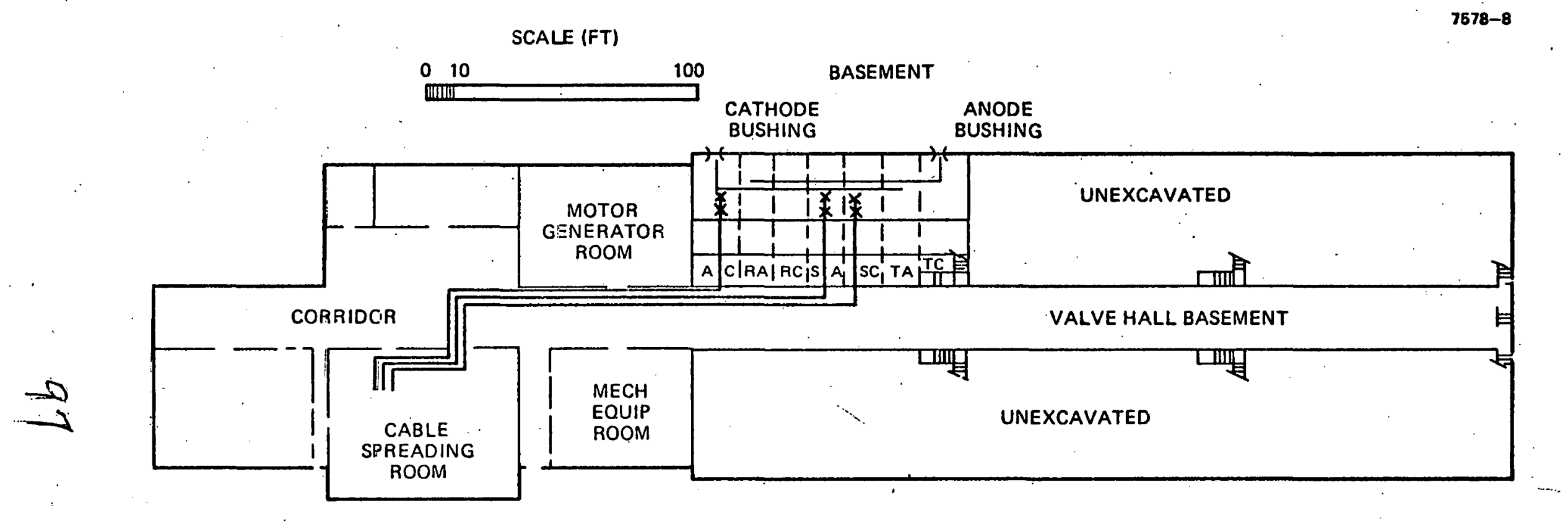

Figure 49. Valve hail layout. 


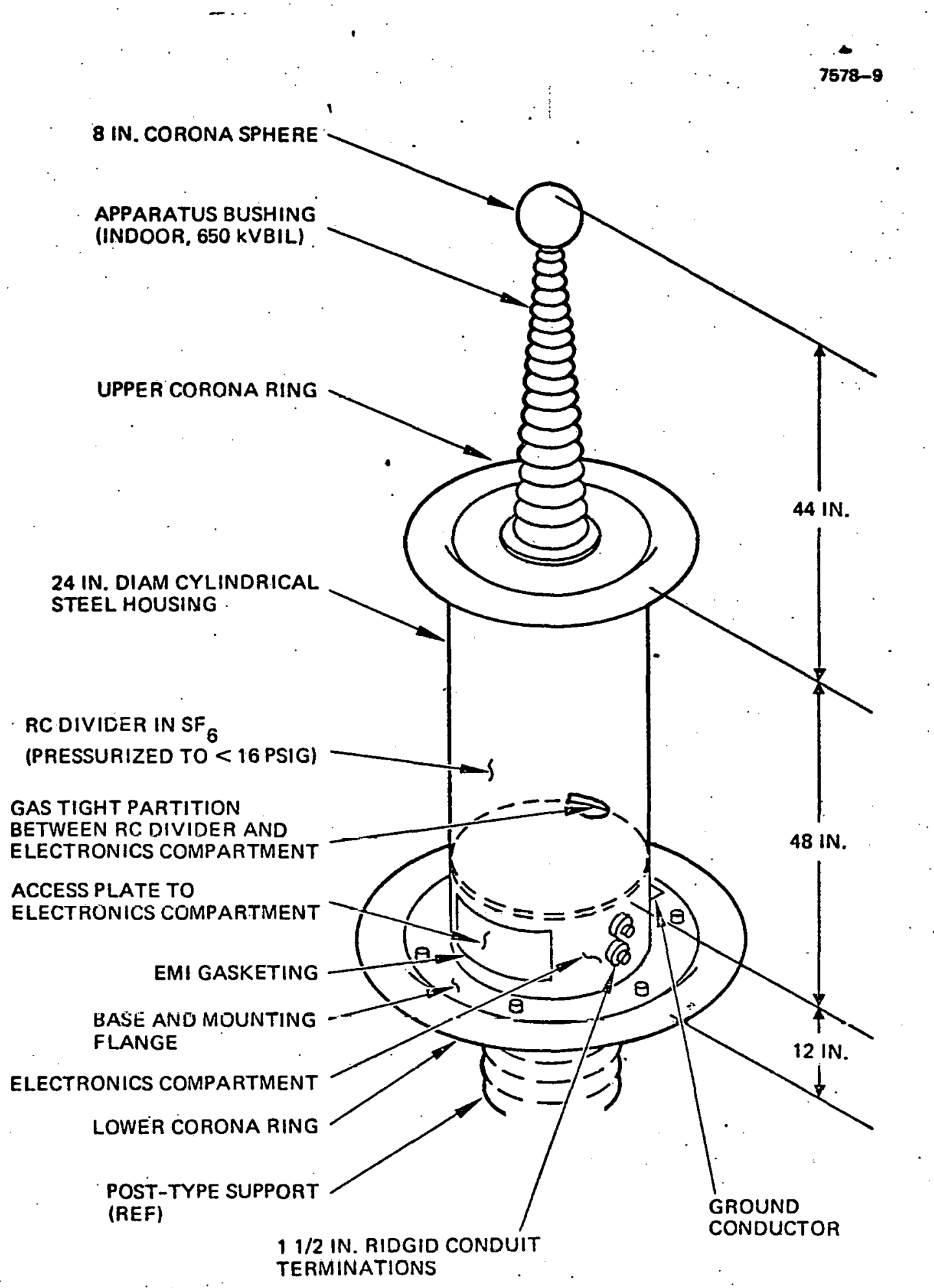

Figure 50. Shielded potential divider. 


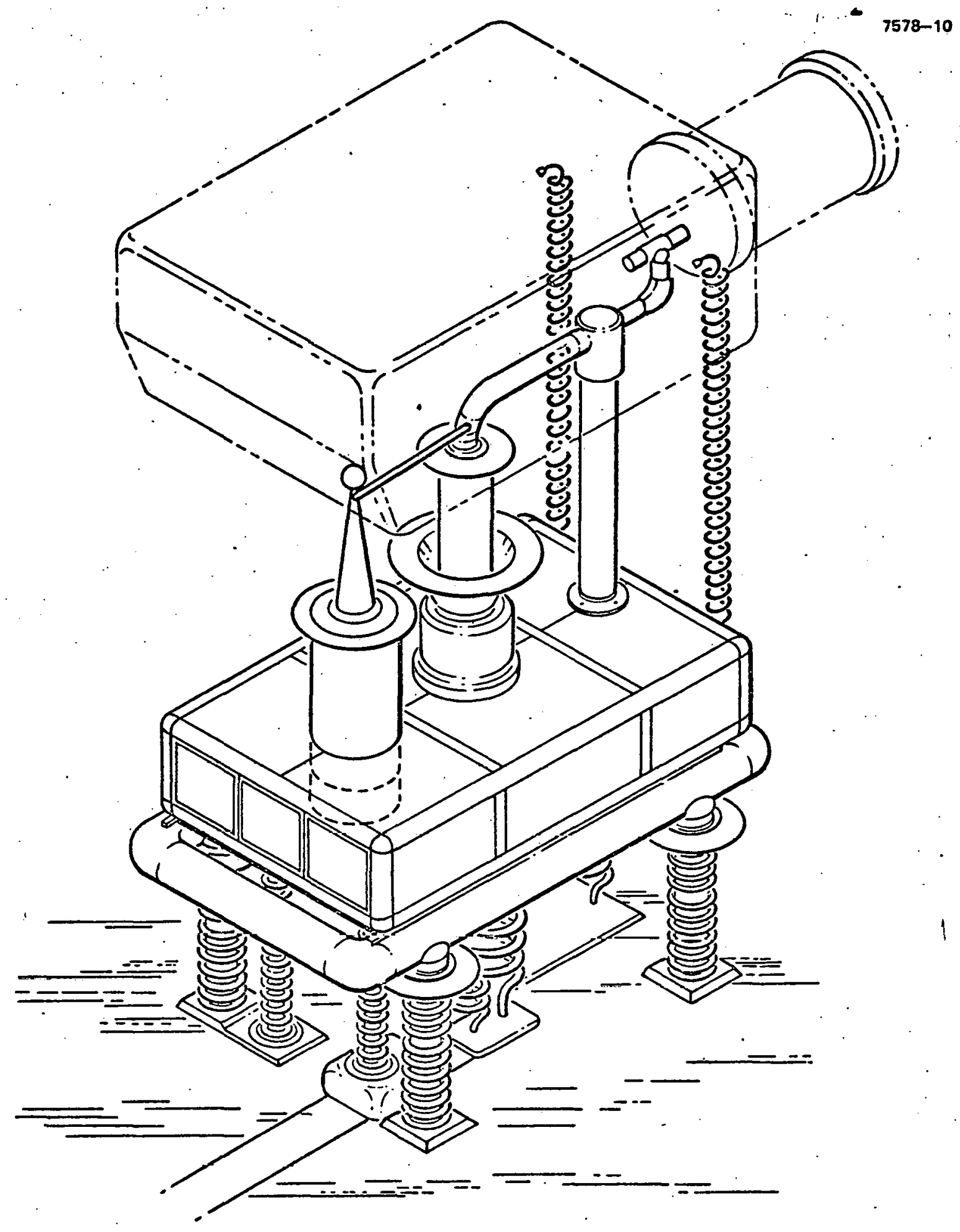

Figure 51. Installed LMPV.

99 


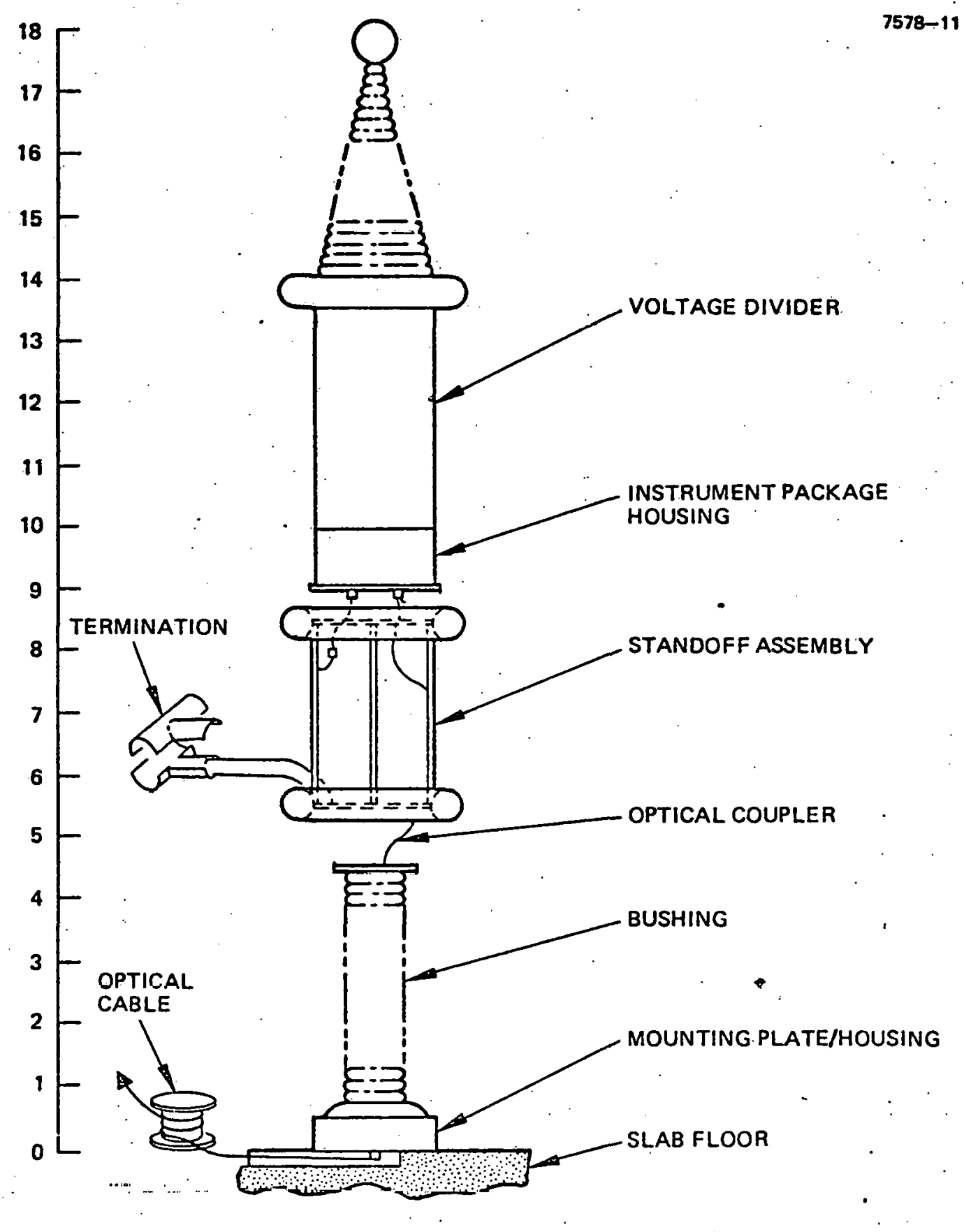

Figure 52. Typical assembly - voltage divider. 
Figure 53 shows the cart that was to carry the LMPVs at Celito. It was to be the same size, shape, and color as the existing ASEA carts, : although much of the interior of the cart would be empty. The valve and electronics boxes would be inserted in the cart after testing at HRL, because the cart was too large for the synthetic test facility at HRL. The electronics box was designed to be at the end of the cart closest to the valve aisle for visibility and accessibility, the LMPV near the electronic $s$ box to minimize lead lengths, and the voltage divider (the heaviest 1 tem) closest to the rear of the cart.

The LMPV subsystems (shown in Figure 54) are listed below:

$-\quad$ Anode
$\therefore \quad$ Dowtherm
$\quad \mathrm{SF}_{6}$

- Condenser

Heaters

Thermocouples

Cooling system (R11)

Current sensor

- '. Cathode

Cooling water

Mercury feed system

Igniters: power, contro, cooling

- Heaters

Thermocouples

Vac Ion pumps

Auxiliary anode

Current sensor

- Annunciator

Data link bushing

Connections to Celilo circuitry

The deliverable auxiliaries are listed in Table 9.

Figure 55 is a review of the $\mathrm{R} \perp 1$ chiller performance showing that the design parameter is met or exceeded in each case. Figure 56 presents data on the Dowtherm $A$ cooling for the valve.anodes. Figure 57 compares the facility needs at Celilo with those at HRL. 



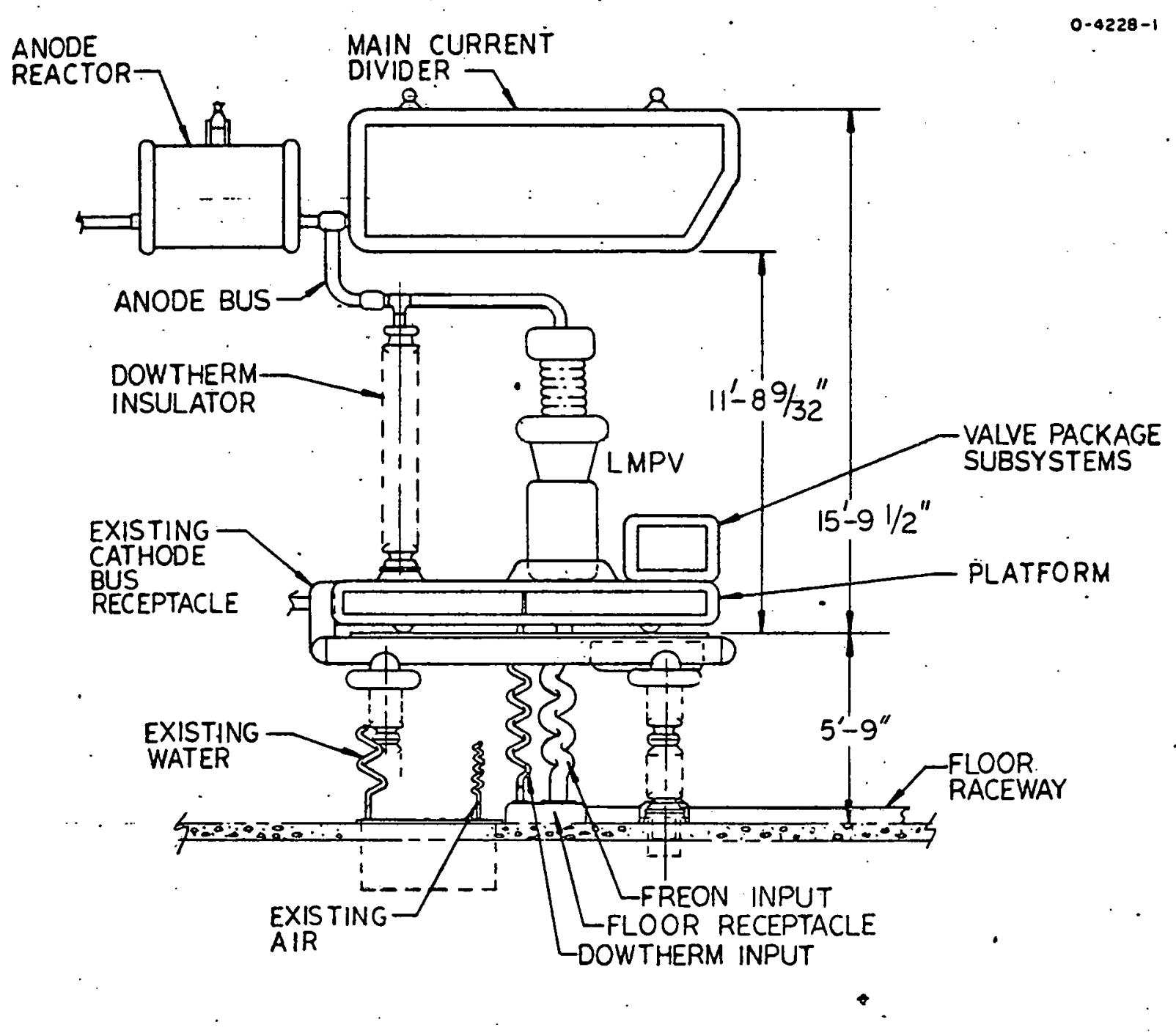

Figure 54. Installed LMPV. 


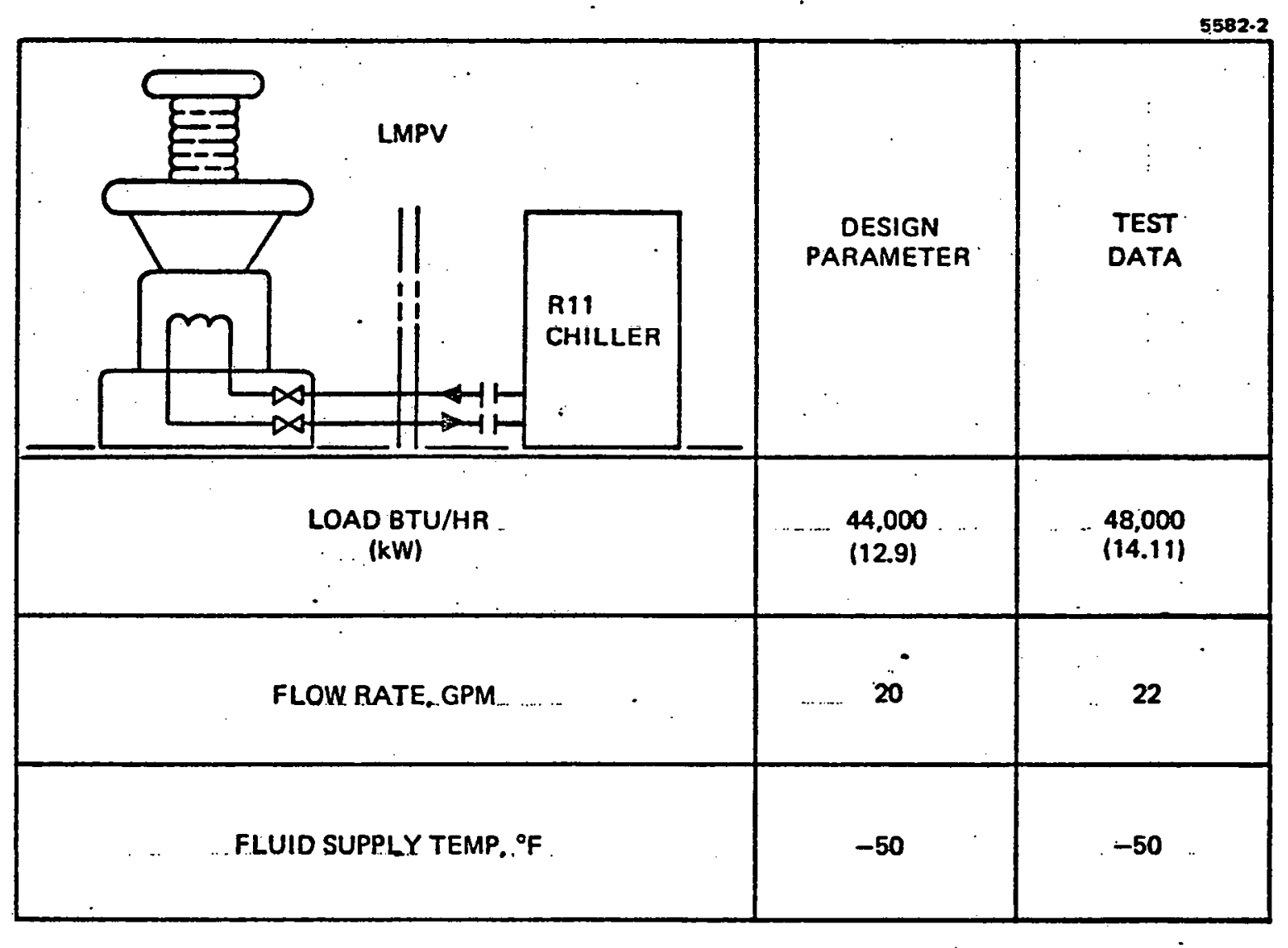

Figure 55. R1I chiller-condenser cooling. (Condition: 720 A Avg. -1 hr). 


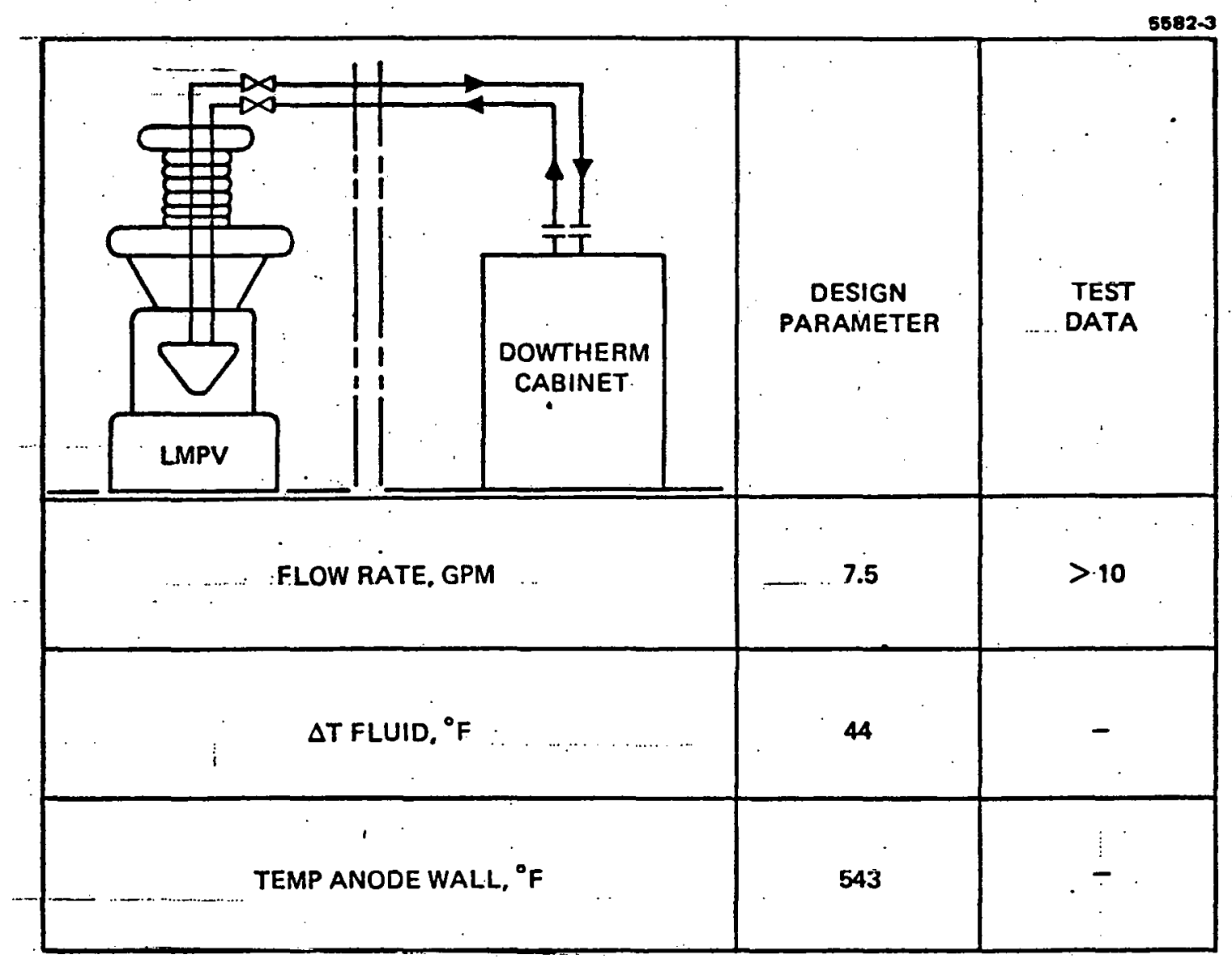

Figure 56. Dowtherm A-anode cooling. (Condition: 1000 A Avg.:-1 min). 


\begin{tabular}{|c|c|c|}
\hline$\cdot$ & $\begin{array}{l}\text { HUGHES } \\
\text { TEST FACILITY }\end{array}$ & CELILO \\
\hline SPACE ENVELOPE, FT ${ }^{3}$ & 70 & 45 \\
\hline AIR HEAT EXCHANGER & REOD & NOT REOD \\
\hline PUMPS & (1) $5 \mathrm{HP}$ & $\begin{array}{l}\text { (2) } 3 \text { HP } \\
\text { (REDUNDANT) }\end{array}$ \\
\hline VACUUM PUMMP & REQD & NOT REOD \\
\hline $\begin{array}{l}\text { INSTRUMENTS AND } \\
\text { CONTROLS }\end{array}$ & REQD & SIMPLIFIED \\
\hline
\end{tabular}

Figure 57: Dowtherm A system: comparison of facility installa- tions.

Table 9. Deliverable Auxiliaries

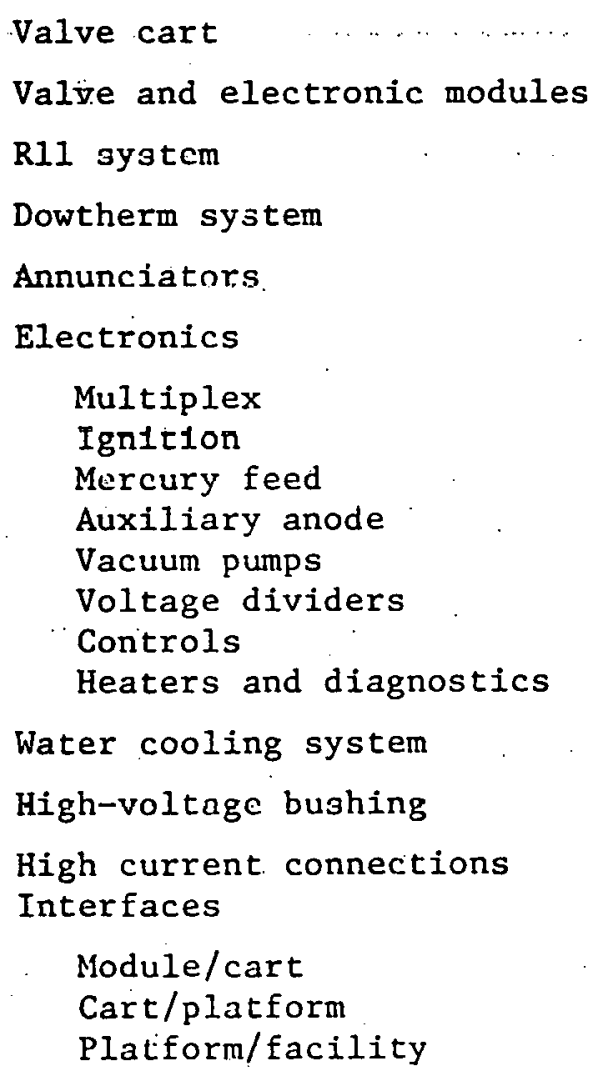


Figure 58 shows the completed assemblies carrying the fiber optics for use with the valve data links; one of these assemblies will be installed under each platform (SA and SC positions in Group 1). We now plan to supply $S_{6}$ to the voltage dividers and valve feedthrough bushings through : these insulating assemblies.

Design and manufacture of the electronics packages proceeded with occasional changes originating from the synthetic tests. These changes are described in Appendix $\mathbf{E}$.

Table 10 specifies the second grade power requirements for the R11 chiller and Dowtherm $A$ systems to be located in the basement aisle at Celilo. After reviewing the noise measurements made at Malibu and Celilo, it was agreed to install the R11 chiller without specific noise insulation. Table 11 lists the required interfaces with the LMPV cart, wherever Table 12 reviews the details of the support cart. Table 13 defines the changes. in. the anode and condenser heat rejection.

Table 10. Second Grade Power Requirements for the R11 Chiller and Dowtherm A Systems at Celilo

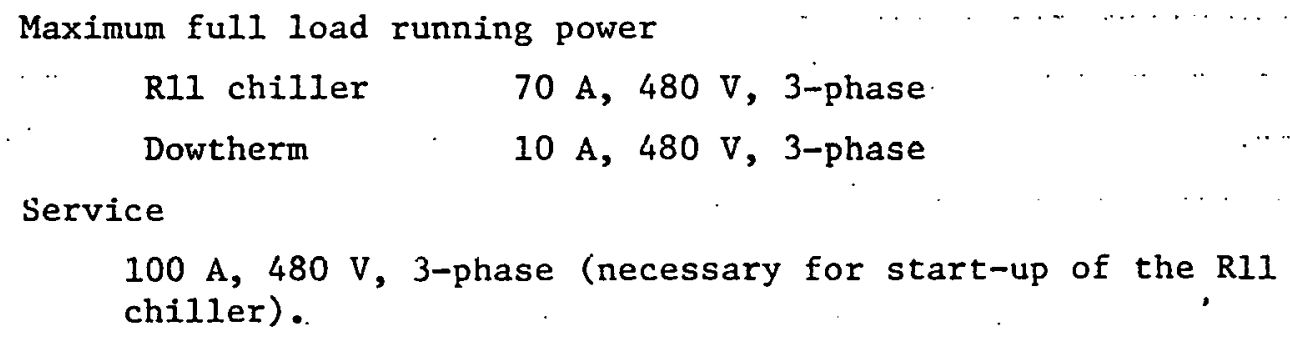

Table 11. Interfaces. with LMPV Cart

Anode bus

ASEA anode arms

RII and Dowtherm hoses

Fiber-optic data links 


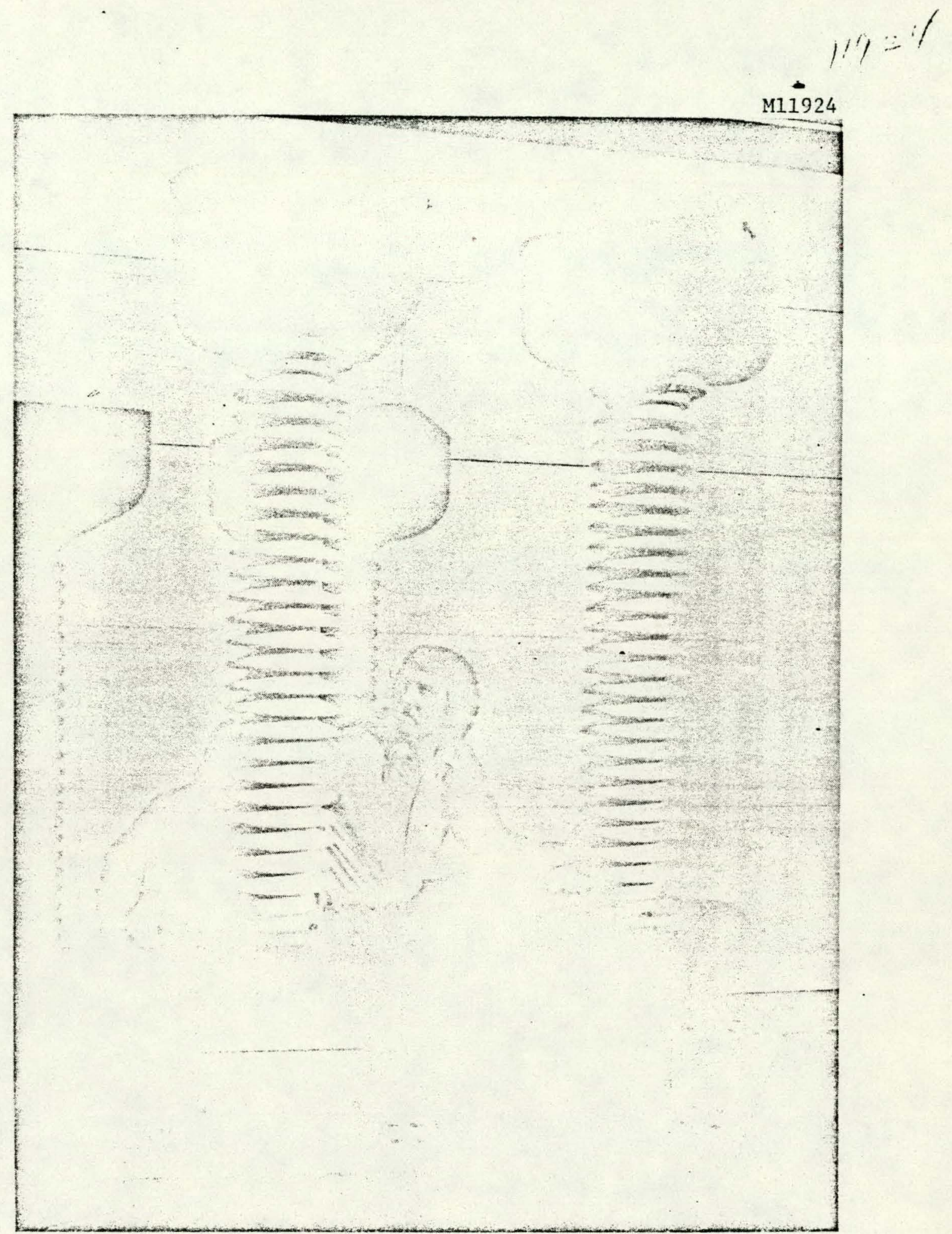

Figure 58. Fiber-optic assemblies for the valve hall at Celilo.

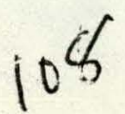


Table 12. Support Cart

Function Keeps LMPV in standby state; is small and light enough to be easily moved

Systems · Dowtherm circuculation for anode

Freon circulation for condenser

Deionized water for cathode (Celilo facility)

AC power for heaters; ion pump supply, etc. (Celilo facility)

Detail Dowtherm - 3 gpm pump, 5 gal reservoir, heater, temperature controller, water-cooled heatexchanger, manual valves, visual flow meter, filter connection to valve with hoses

Freon - I hp unit, water-cooled, connection to valve with hoses

Table 13. Anode and Condenser Heat Rejection

\begin{tabular}{|ll}
\hline Rll chiller & Simplified version of existing unit \\
Dowtherm system & Conservative rating \\
& Built by ACL-Filco \\
& Smaller than existing unit \\
& Two 3 -hp pumps (one as backup unit) \\
& Simplified controls \\
& $\begin{array}{l}\text { Provision for water-cooled heat } \\
\text { exchanger }\end{array}$ \\
& $\begin{array}{l}\text { Confirm anode and condenser design, } \\
\text { and the ratio of heat rejected } \\
\text { (anode: condenser } \approx 2: 1 \text { ) }\end{array}$
\end{tabular}


THIS PAGE

\section{WAS INTENTIONALLY LEFT BLANK}


SECTION 3

TESTING OF THE ENGINEERING PROTOTYPE VALVES AT HRL

\section{A. INTRODUCTION}

The objective of the test program at HRL was to establish the LMPV package as viable entity for substitution in the SA and SC positions of Group 1 at the Celilo Converter Station. Additionally, the test program explored the LMPV's-ability to operate reliably at higher than normal voltages, currents, and rates of change of voltages and currents and (in the inverter mode) at low deionization margins.

Testing was performed in the synthetic test facility at HRL. The test circuit (see Figure 39) can be separated into two sections: the low voltage, high current components allow a high current o pass through the valves under test. When this current is forced to zero, a high voltage pulse is applied to those valves by firing a third valve.

The parameters $I, V, d I / d t$, and $d V / d t$ in the facility cannot be independently varied: Figure 59 gives the available range of parameters for a fixed current. Notice that two ranges are available, depending on the size of the inductance used. These ranges are shown in threedimensional space in Figure 60.

Figure 61 is a plot of the ars-back rate versus ancde blocking duty for a mercury arc rectifier. The arc-back rate for an LMPV might follow the same kind of dependence on $I, V, d I / d t$, and $d V / d t$. If that is so, and if, for example, the arc-back rate for a mature valve was one per month at normal working voltage, changing dV/dt from 3 to 5.4 should. raise the arc-back rate to six per month if no other parametric changes were involved. But raising $\mathrm{V}$ to get increased $\mathrm{dV} / \mathrm{dt}$ also increases $\mathrm{dI} / \mathrm{dt}$, so that an increased arc-back rate could be expected to result from this also.

A good measure of the capability of the valve is its arc-back rate, its dependence is summarized in Table 14, where $I$ and $\dot{I}$ are the current and rate of change of current and $V$ and $V$ are the voltage and rate of change of voltage. The factors $Q_{1}, Q_{2}$, etc. are quality factors; $Q_{1}$ 
related to how well the valve is made, $Q_{2}$ to the basic operating conditions, etc. $Q_{1}$ is best measured by the outgassing rate of the valve, measured at room temperature in Torr litres $/ \mathrm{s} \mathrm{cm}^{2}$. This refers to the production of permancnet gases in the valve by diffusion from the bulk of the metal components; this gas is removed by the appendage ion pumps. $Q_{2}$ is an operation quality factor. It reflects such parameters as the condenser temperature, anode temperature, and the electron-to-atom emission ratio at the cathode.

Because the valve is a single-anode, single-gap device with a relatively simple mode of operation, the arc-back probability should vary as some simple function of the operating parameters, such as that shown in Figure 61. In that function, the anode blocking duty is the produce of the peak voltage across the valve multiplied by the rate of change of current going into current zero. The slope that pertains to an individual valve is determined by the parameters $Q_{1}, Q_{2}$, etc.

\begin{tabular}{|l|c|c|c|cc|}
\hline & $\mathrm{V}$ in $\mathrm{kV}$ & $\mathrm{V}$ in $\mathrm{kV} / \mu \mathrm{s}$ & $\mathrm{I}$ in $\mathrm{kA}$ & I in $\mathrm{A} / \mu \mathrm{s}$ \\
\hline \multirow{2}{*}{ Celilo } & 133 & 1 & 1.8 & 1.5 & $\alpha=15^{\circ}$ \\
SVTF (2L) & 150 & 3 & 1.8 & 1.9 & $\gamma \approx 4^{\circ}$ \\
& 200 & 4 & 1.8 & 2.6 & $\ldots$ \\
& 150 & 4.1 & 1.8 & 4.2 & \\
& 200 & 5.4 & 1.8 & 5.7 & \\
\hline
\end{tabular}

Figure 59. Estimated typical test conditions. 


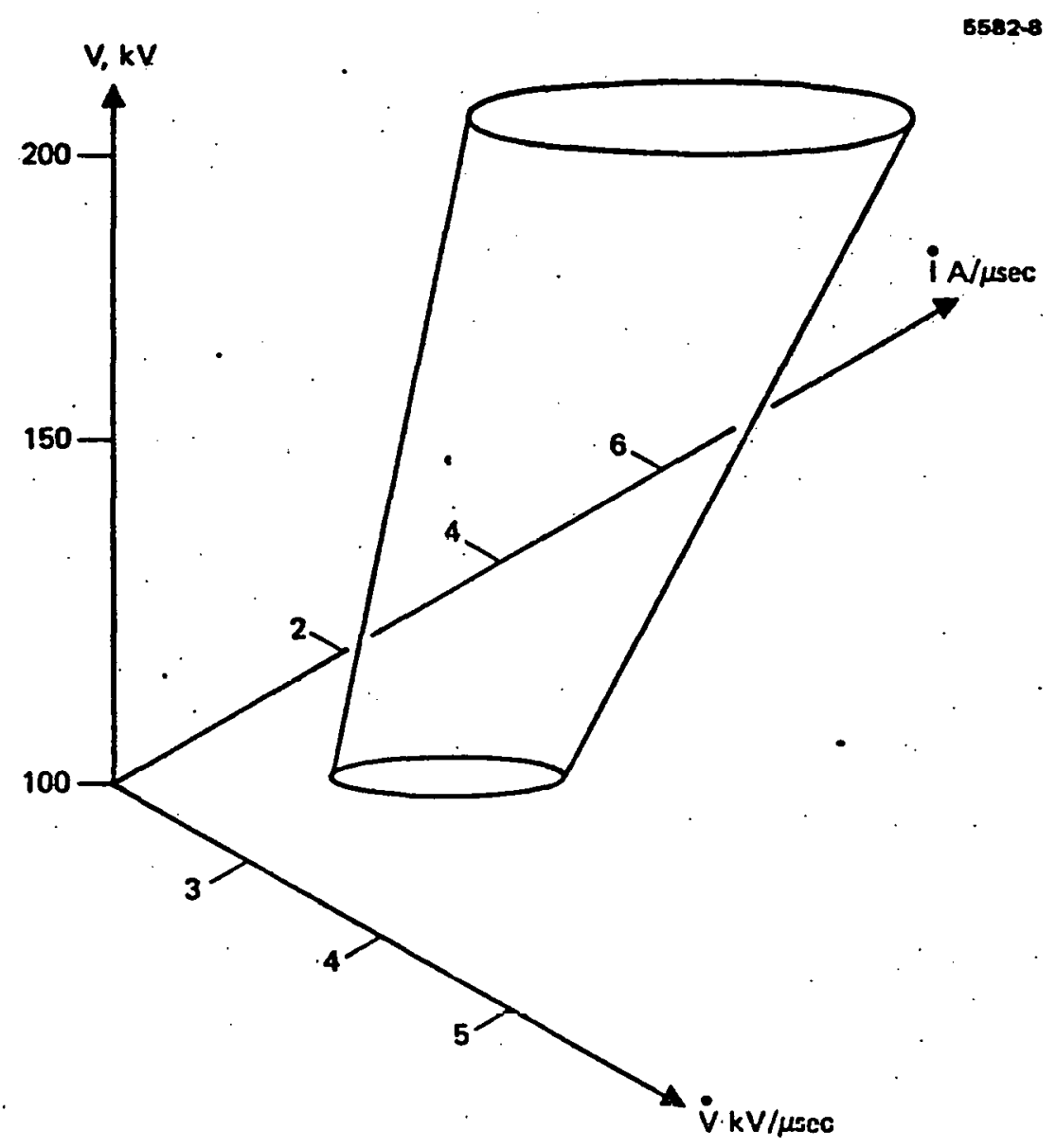

Figure 60. Synthetic valve test facility parameters.

113 


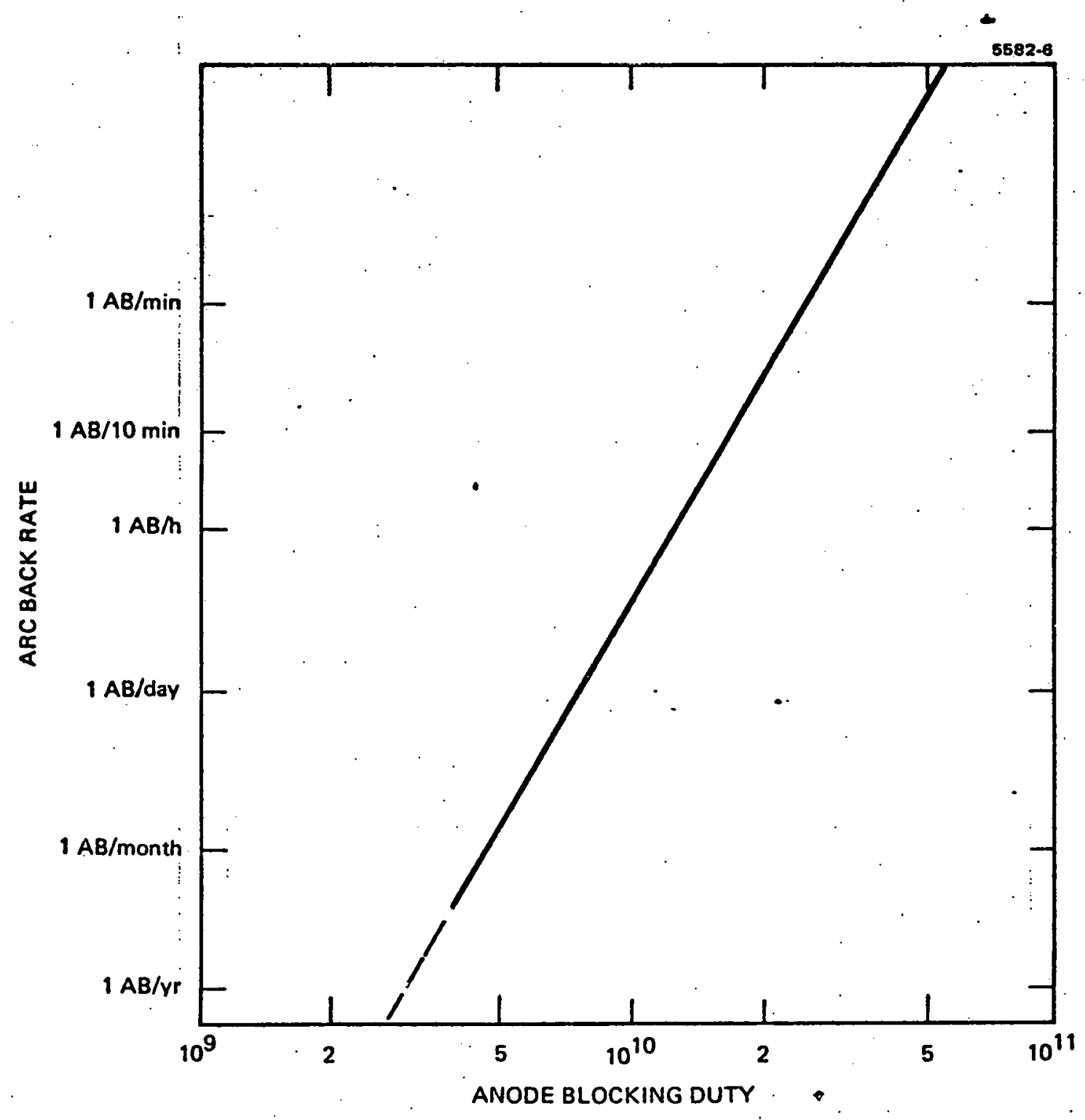

Figure 61. Arc-back rate versus anode blocking duty.

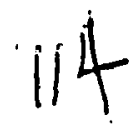


Table 14. Vaive Testing Program

Objectives

Arc back probability = function $\left(I, \dot{I}, V, \dot{V}, Q_{1}, Q_{2} \ldots\right)$

where $Q_{1}$ is a construction quality factor (outgassing rate, etc.)

$\mathrm{Q}_{2}$ is an operation quality factor $\left(\mathrm{K}_{\mathrm{e}} / \mathrm{K} \mathrm{K}\right.$, anode temperature, condenser temperature, etc.)

The expected ability to extrapolate the arc-back data in a straightforward way provides the approach to valve testing. We began by operating the valves under high stress conditions (Table 15). to get a maximum amount of data in a given time. By selectively changing the parameters, we attempted to establish the dependence of the arc-back probability on $\mathrm{I}, \dot{\mathrm{I}}, \mathrm{V}, \dot{\mathrm{V}}$. We can then estimate the arc back rate ar nominal working level by extrapolation, and check by an extended test period.

\section{B. SYNTHETIC TESTING}

Almost $500 \mathrm{hr}$ of synthetic testing were performed. In the final configuration, both converter valves were enginnering prototype bakedout, sealed-off versions. The inverter valve, $v_{1}$, was a reconditioned valve. The switching valve, $\mathrm{v}_{3}$, was a laboratory demountable valve. Successful experiments were conducted using a sustained voltage waveform. Voltage droop was $5 \%$, as had been predicted. Because of the tenuous reliability of the switch valve, experiments were limited to sustained voltages of $100 \mathrm{kV}$ (at which time the voltage across $\mathrm{V}_{3}$ was $220 \mathrm{kV}$ with $2 / 3$ duty). The presently installed $V_{3}$ has a demountable 
nongraded ceramic feedthrough bushing that has patches of different dielectric constant materials on its surface to seal several previous punctures.

The high $\alpha$ condition simulated with the sustained waveform did not appear to cause excessive sputtering, and no ignition problems were experienced.

With resistor $R_{5}$ (Figure 39 ) installed to produce a drooping waveform, testing was accomplished up to $185 \mathrm{kV}$. The limitation here was, again, the stress on switch valve $v_{3}$, resulting in excessive $v_{3}$ arcthrough rates. Problems were also encountered with the safety switches/ crowbars $A_{1}, A_{2}$ flashing over.' A study was initiated to look into the possibility of separating the safety switch and circuit protection functions by using the existing switrhe- as crowbars and sealed spark gaps for component protection.

High current conditioning of the cathodes was limited to short periods of $3.4 \mathrm{kA}$ peak low average current runs to process cathodes. Experiments were conducted varying the cathode cooling water temperature to investigate the effect of cathode temperature on cathode spot stability. It was found that the cathode spots would jump out of the pool-keeping structure under a given set of operating parameters. Such behavior would lead to excessively high arc-back rates.

Table 15. Valve Testing Program: Approach

Operate under high stress conditions (probability of higher arc back rate) to get maximum data in given time

By selectively changing the parameters, attempt to establish the dependence of the arc back probability on $I, \dot{I}$, $\mathrm{V}, \dot{\mathrm{V}}$

Estimate the arc back rate at noininal working level by extrapolation, and check by extended test period 
To investigate this phenomenon, several experiments were conducted. The most fruitful of these was-an optical.projection display of the cathode. A lens, mirror, and screen were arranged so that the poolkeeping structure was imaged onto the screen in such a way that the image was visible from the control room during synthetic testing. It was then possible to visually observe the spot pattern and to correlate this with arc-backs. Wherever an arc-back occurred, a spot had left the poolkeeping structure; however, not all spot departures from the pool-keeping structure caused arc-backs. Such behavior is consistent with our theory: of this phenomenon.

This phenomenon was used to advantage in processing the valves. By deliberately forcing the arc to exist the pool-keeping structure, it was possible, during dc conduction processing, to remove excess mercury from the cooled cathode end plate.

Further processing of the valves was accomplished by runing the system continuously. The test was terminated volunitarily after $27 \mathrm{hr}$. Voltages up to $150 \mathrm{kV}$ were used during this run. Although this experiment was not intended to measure failure rates, since the fault detection system's Butterworth filters had not yet been installed, arc-back rates of less than $1: 10^{5}$ were observed.

\section{TEST SCHEDULE}

The test schedule started with the high-voltage tests: 1 min holdoff at $465 \mathrm{kVdc}$, both polarities, the switching surge test, and the BIL test to $650 \mathrm{kV}$. After the cathode is filled with mercury and wetted, an extensive run-in period began with straight dc operation, followed by synthetic operation with a drooping voltage recovery waveform to allow comparison with old data.

With a sustained waveform, synthetic testing is then begun, workIng up. (as lle valves become conditioned) to $150 \mathrm{kV}, 1800 \mathrm{~A}$ at $55 \mathrm{~Hz}$. This is done with two inductors: $A n A B$ rate at $133 \mathrm{kV}$ and $150 \mathrm{kV}$ is established. The voltage is raised to $200 \mathrm{kV}$, and the change in the $A B$ rate is observed. Then one inductor was rmoved with the voltage left 
at $150 \mathrm{kV}$; this leaves $\mathrm{dV} / \mathrm{dt}$ unchanged, but increases dI/dt. Finally, the $A B$ rate is established with one inductor at $200 \mathrm{kV}$. The test sequence ends with the 28-kA single-cycle and 10 -cycle tests. Table 16 is a test sequence designed. to get data at maximum stress level to begin with, and then to try to establish the relationship between the arc back rate and the principal parameters $I, \dot{I}, V$, and $\dot{V}$.

The test results are summarized in Tables 17 and 18. The valve easily passed the: 1-min HVDC withstand test of $465 \mathrm{kV}$ after it had been fitted with a resistive bushing. Figure 62 shows typical traces of the switching surge tests, and Figure 63 shows two traces of the BIL tests.

The high current tests were equally successful. Tests of six current pulses of $6 \mathrm{~ms}$ each in 100 ms to $29 \mathrm{kA}$ were made without any anode spots forming. Commutation mode operation of $\geq 3 \mathrm{kA}$, dc conduction of $\geq 1 \mathrm{kA}$ for 1 min and prolonged operation at $720 \mathrm{~A}$ confirmed good cathode operation and satisfactory condenser and anode cooling.

Table 16. Test Sequence 


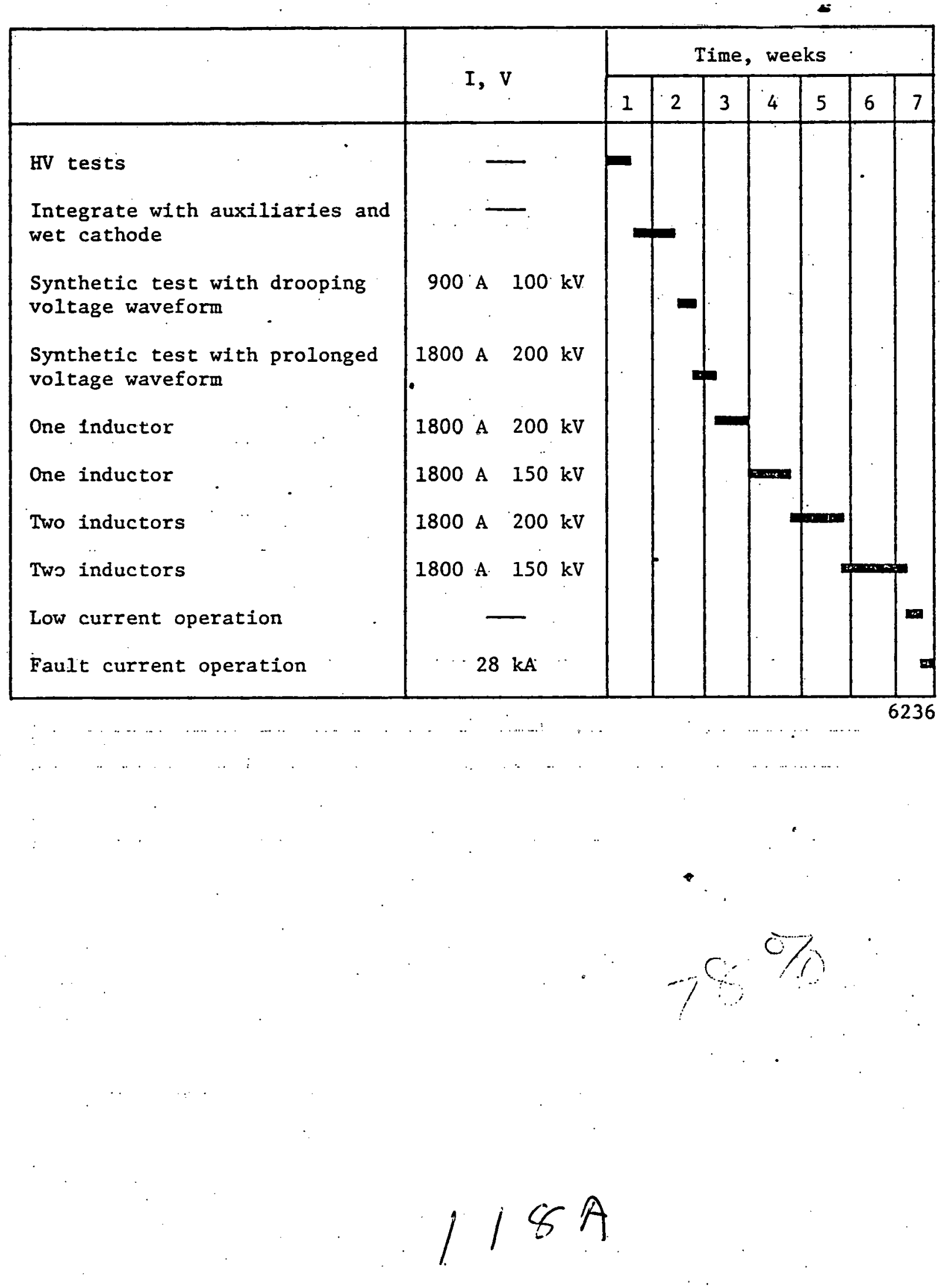



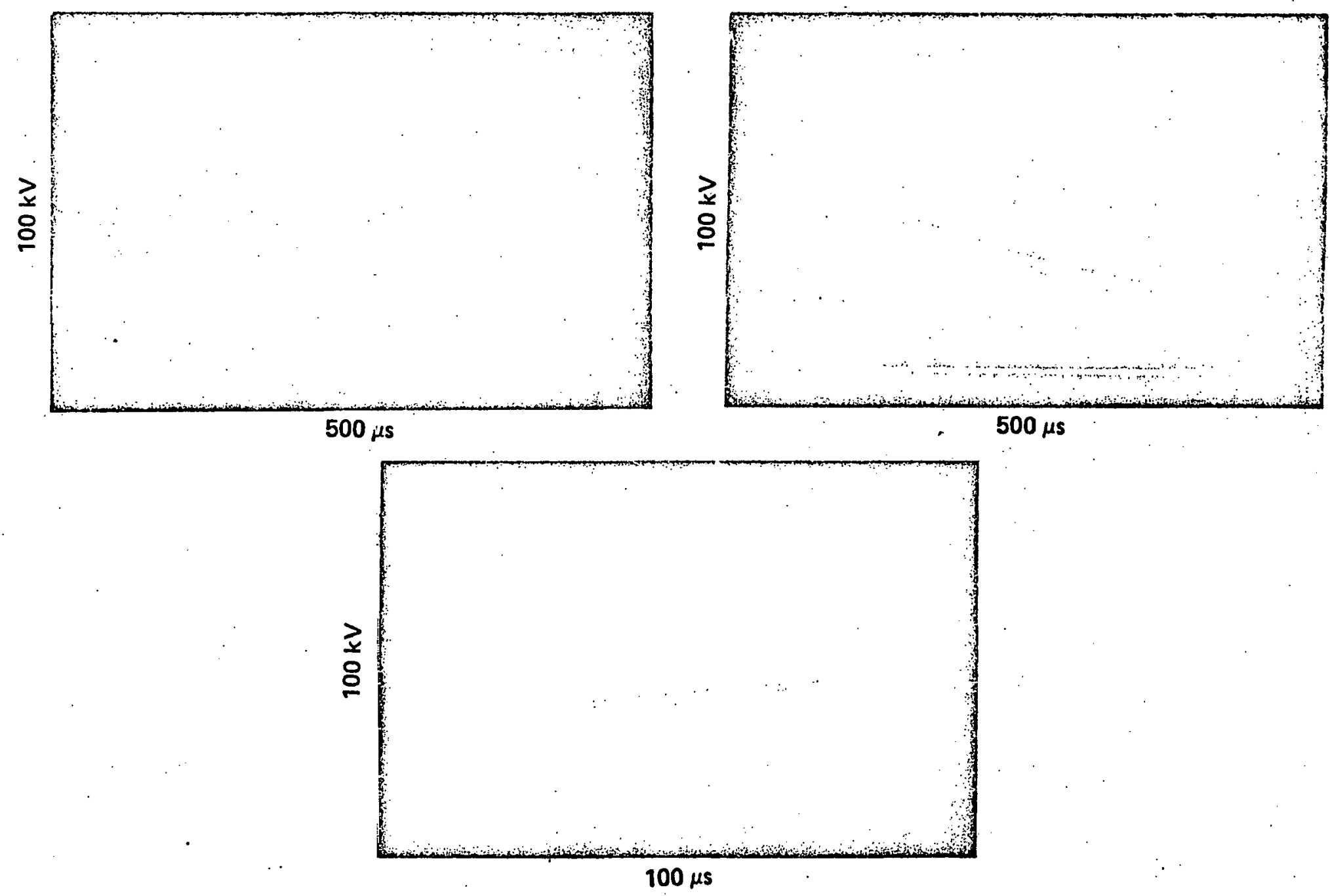

$500 \mu \mathrm{s}$

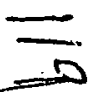

$100 \mu \mathrm{s}$

Figure 62. Switching surge tests of the DOE LMPV. 

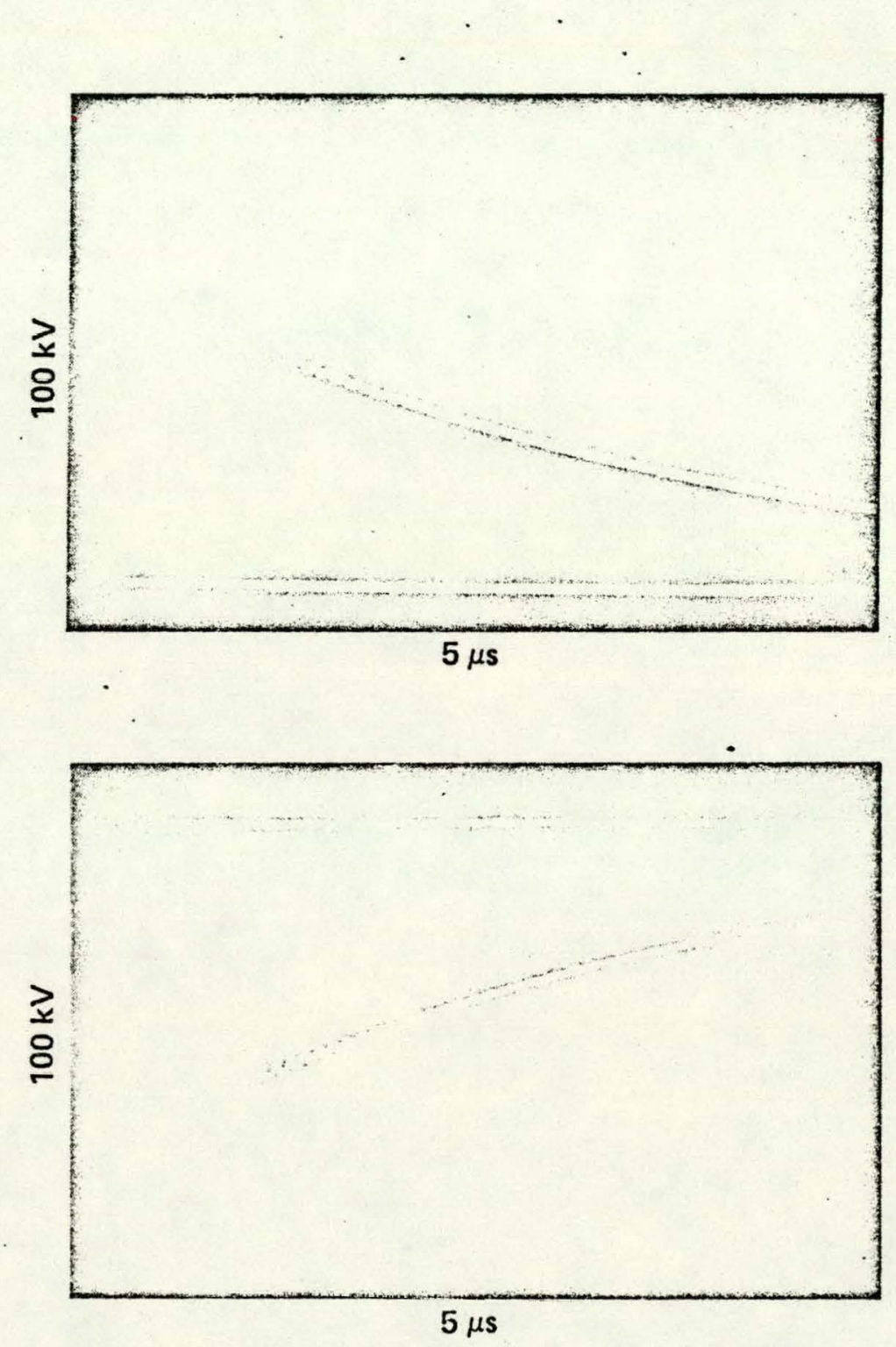

Figure 63. BIL tests of the DOE LMPV.

$$
.120
$$


Table 17. High-Voltage Testing Results

\begin{tabular}{|l|r|r|}
\hline 1-min HVDC withstand & $+470 \mathrm{kV}$ & $-470 \mathrm{kV}$ \\
Switching surge & $+450 \mathrm{kV}$ & $-400 \mathrm{kV}$ \\
BIL & $+400 \mathrm{kV}$ & $-450 \mathrm{kV}$ \\
\hline
\end{tabular}

Table 18. High Current Testing Results

\begin{tabular}{|l|c|ccc|}
\hline High current & 24 to $29 \mathrm{kA}$ & 6 pulses of $6 \mathrm{~ms}$ each in $100 \mathrm{~ms}$ \\
Commutation mode & $\geq 3 \mathrm{kA}$ & $\therefore$ & $\ldots$ &. \\
DC conduction & $\geq 1 \mathrm{kA}$ & $1 \mathrm{~min}$ & $\ldots$ & $\ldots$ \\
DC conduction & $720 \mathrm{~A}$ & $40 \mathrm{~min}$ &. \\
\hline
\end{tabular}

\section{FAULT-DETECTION SYSTEM}

Figure 64 shows current and voltage waveform- that are scanned in the control room. The anode of the inverter valve VI (which is close to ground potential) has a current transformer measuring the current through V1. The rectifier valve $\mathrm{V} 2$ has a high current shunt in the cathode lead measuring the current through V2. The current puise in the current injection valve $\mathrm{V} 3$ is measured by a current transformer that monitors the charge flow from a storage capacitor bank $\mathrm{C} 6$. A compensated voltage divider measures the voltage of the V1 cathode -V2 anode junction with respect to ground, this waveform can be either a drooping or a sustained (following current zero in V2) depending on the resistance between the junction and ground. The trigger pulses to each valve and the total voltage across both valves in series (not shown in Figure 64) are also monitored. The last measurement allows estimating the valve discharge voltage during conduction.

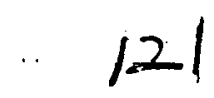




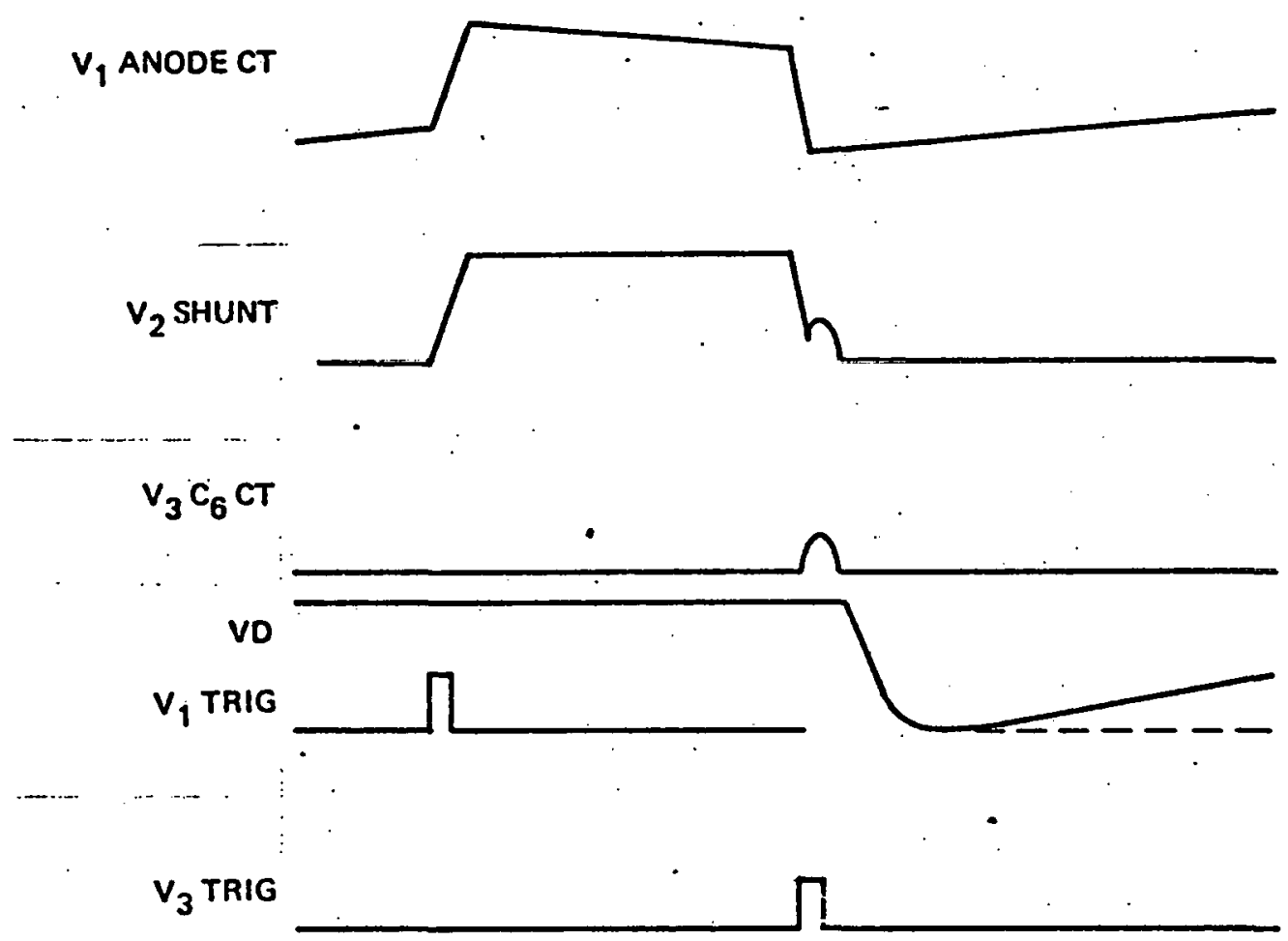

Figure. 64. Oscilloscope waveforms monitored in the control room.

A fault monitoring system records the number of arc-throughs in $V_{1}$, the number of arc-backs in $V_{2}$, and the number of times that no high voltage appears across the valves (this could be caused by a failure in $\mathrm{v}_{3}$ or, rarely, by an arc-back or arc-through occurring immediately after the current zero). The ignition failures of $v_{1}$ or $v_{2}$ and the total number of counts are also recorded. By varying the repetition rate, the average current through $\mathrm{v}_{1}$ and $\mathrm{V}_{2}$ and the peak current can be varied; the voltage applied following current zero can be varied independent of the repetition rate.

Signals from the V1 current transformer, the V2 current shunt, the V3 current transformer, and the compensated voltage divider are also fed into a fault monitoring system and examined as a function of time during each cycle. Thus, in the first two cases, signals from the VI 
current transformer or V2 current shunt would indicate an arc-through In V1 or an arc-back in V2. The lack of a signal in the V2 current shunt while the valves should be conducting is recorded as a V1 or V2 misfire. The signal from.the V3 current transformer can indicate a V3 arc-through or a V3 misfire, while the compensated divider signal can record the incidence of the absence of a high-voltage pulse to the valves under test. The fault monitoring system essentially looks at these signals, and counts the events as they occur, under the headings of:

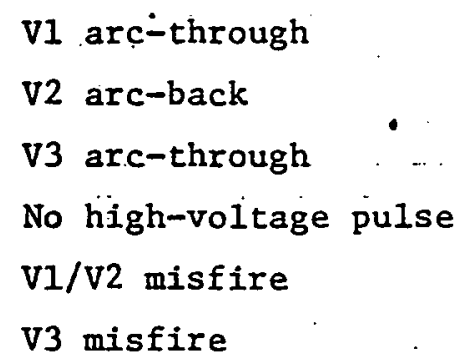

Total number of counts.

Additionally, a camera and oscilloscope is set up to record the voltage across the valves under test after a fault. The signal is . ramped so that the event and the next nine cycles are photographed at the same time so that consecutive failures can be determined. A printer prints out information for each event (nature of event, time code, etc.); this information is also siown on the photograph.

Finally, current and voltage signals are fed into a free-running ERDAC. When an event occurs, the ERDAC, triggered from the monitoring system, records prew and post-fault data. This allow confirming the nature of the faults recorded by the monitoring box.

While testing the valves, we found that some spurious counts are recorded on the monitoring system, particularly at higher voltages. These do not show up as disturbances on the oscilloscope traces, nor do they sho up on the ERDAC. They are probably caused by EMI generated in the facility.

Experiments were conducted to improve the performance of the fault detection system. As testing progressed to higher voltages, disturbances in the valve test hall caused greater levels of EMI, which resulted in spurious counting of faults by the fault-detection system. A . 
four-pole Butterworth filter was designed and constructed for one of the Inputs to the detection sys::m. When -installed, it significantly improved reliability. Based on this success, a unit consisting of three separately shielded four-pole Butterworth filters was constructed and Installed. System improvement ras good up to the $130-\mathrm{kV}$ level.

In parallel with these experiments, a search was made to identify the source of the EMI and to attempt to minimize the interference. A major contributor was found to be the resistor stack $R_{3}$. Many of the individual resistors comprising this stack were found to be defective, and these defective resistors were arcing or had changed value. Repairs and replacements were made where possible.

During calibration of the fault-detection system, experiments were conducted to attempt to make the rectifier valve break down at a specified time during the voltage hold-off period. This was done to check whether the appropriate detection and recording circuits were functioning properly without spurious crosstalk.

The operating conditions for this experiment were $1 \mathrm{kA}$ peak current, $300 \mathrm{~A}$ average, voltages up to $150 \mathrm{kV}$. At a time (variable) when the inverse voltage was at its peak value, a trigger pulse fired a thyraton igniter power supply to infect a $5 \mathrm{~J}$ pulse to an unused igniter on the cathode. The timing could be adjusted so that the valve should arc back from 15 to $150 \mathrm{kV}$. It was possible to arc through the inverter valve where the main anode voltage is positive with respect to the cathode; however, it was not possible to arc back the rectifier valve. Similar effects were noted in switching valve $v_{3}$ after great pains had been taken to deliverately induce arc-backs for purposes of high-voltage wave shaping.

\section{E. ANODE FILM FORMATION}

During the first quarter of 1977 we ran synthetic tests with DOE engineering valve EN1 in the rectifier position, laboratory prototype valve $\mathrm{Ll}$ in the inverter position, and a second laboratory prototype valve as the current injection valve. Table 18 shows the valve 
stand. We found a high arc-back rate in EN1, which was apparently independent of all parameters except for the average current through the valve. Towards the end of that quarter, we discovered that ENI had a film deposited on its anode. This film was luminescent for some time after the main discharge in the valve had been extinguished. We hypothesized that the film was a polymerized hydrocarbon, probably glyptal from the fixing of a leaking cathode feedthrough.

We decided early in April 1977 to try to get rid of the film by high current processing, by using high voltage pulses, or by both. Neither technique succeeded in: removing the bulk of the $f i l m$, although some small pieces did flake off. Before the valve was removed from the facility for examination, we recorded the optical spectra of the mercury discharge in the hope of determining the nature of the film. The spectra was very complex, which seemed to rule out boron from the igniters; it did not seem to be a simple hydrocarbon, or in fact anything that was clearly definable.

Before valve EN1 could be taken apart for examination, the mercury was removed by baking to about $200^{\circ} \mathrm{C}$ under vacuum. Mercury was collected in a liquid nitrogen cold trap and weighed. When all the mercury was rmoved from the valve, the cathode weld was ground away and the cathode removed from the valve. Subsequently, the anode and anode shaft and the vanadium oxide-coated ceramic were also removed for examination.

Table 18. Valve Status 


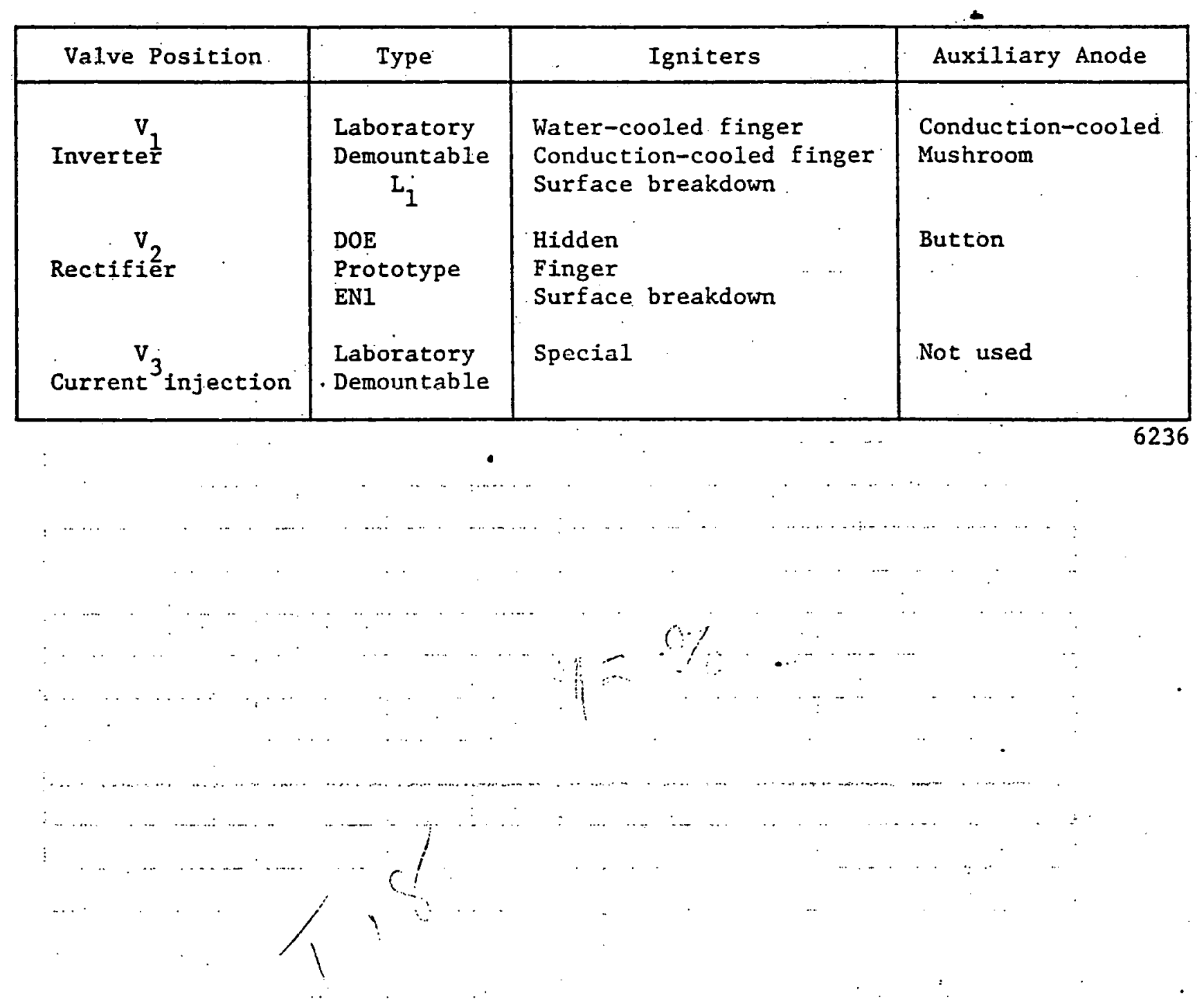

$125 A$ 
The appearance of the components was quite surprising. Where we had thought that there wa ifilm on the anode, no film was present. The rest of the anode face had an apparently metallic film covering 1.t, loosely attached in places, and up to 2 mils thick (Figures 65 and 66). The cathode face and shroud were covered with a black, finely divided granular dust (not unlike carborundum powder in appearance), and under the dust the molybdenum cathode showed signs of sputtering (Figures 67 and 68). Several metallic flakes (perhaps film from the center of the anode face) were found at the bottom of the condenser; some of these were larger than $I \mathrm{~cm}^{2}$. The visual appearance of the condenser surface was normal (Figure 69), except that there was an internal bulge about $6 \mathrm{~cm}$ wide extending most of the length of the condenser and parallel to its axis.

Samples of the deposit from various components were analyzed by $X$-ray techniques in our laboratory and were also sent out for separate analysis. Our results show that all of the materiai found, both granular and fiim, was molybdenum. The estimated volume of material was about $1 \mathrm{~cm}^{3}$, mostly from the cathode (there was, however, some evidence of a small amount of sputtering close to the anode nose). Examination of the inside of the cathode shroud showed that some gold had leached from Nioro the brazes into the protective nickle layer that was electroplated over it (Figure 70); this is indicative of high cathode shroud temperatures. There was no sign of the postulated film of hydrocarbon on the anode or elsewhere, and no traces of boron carbide (from the igniters) or of vanadium oxide (from the ceramic coating) were found.

The degree of sputtering in the valve was surprising: it substantially exceeded what we had observed in previous laboratory prototype valves and in the earlier DOE engincering prototype valve. To see in. what way this valve might have been treated differently from earlier ones, we reveiwed the operational history of the valve and the procedures used for removing the mercury from it before it was opened for analysis. It seems from the appearance of the sputtered material that the sputtering occurred during a high-pressure ( 0.1 Torr) discharge. A large quantitye of mercury was removed from the valve during bakeout 


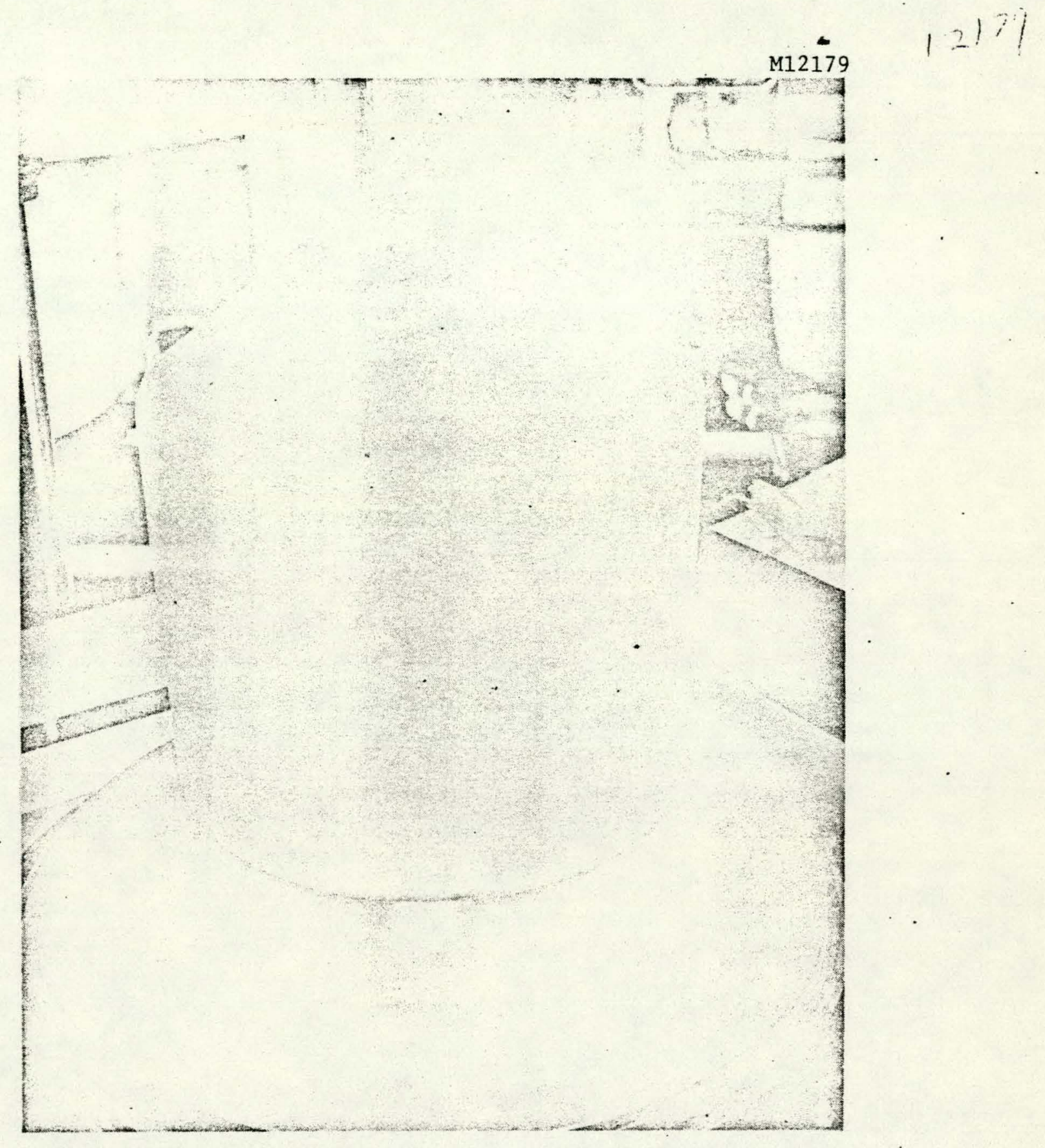

Figure 65. Metallic film on valve anode - side view. 


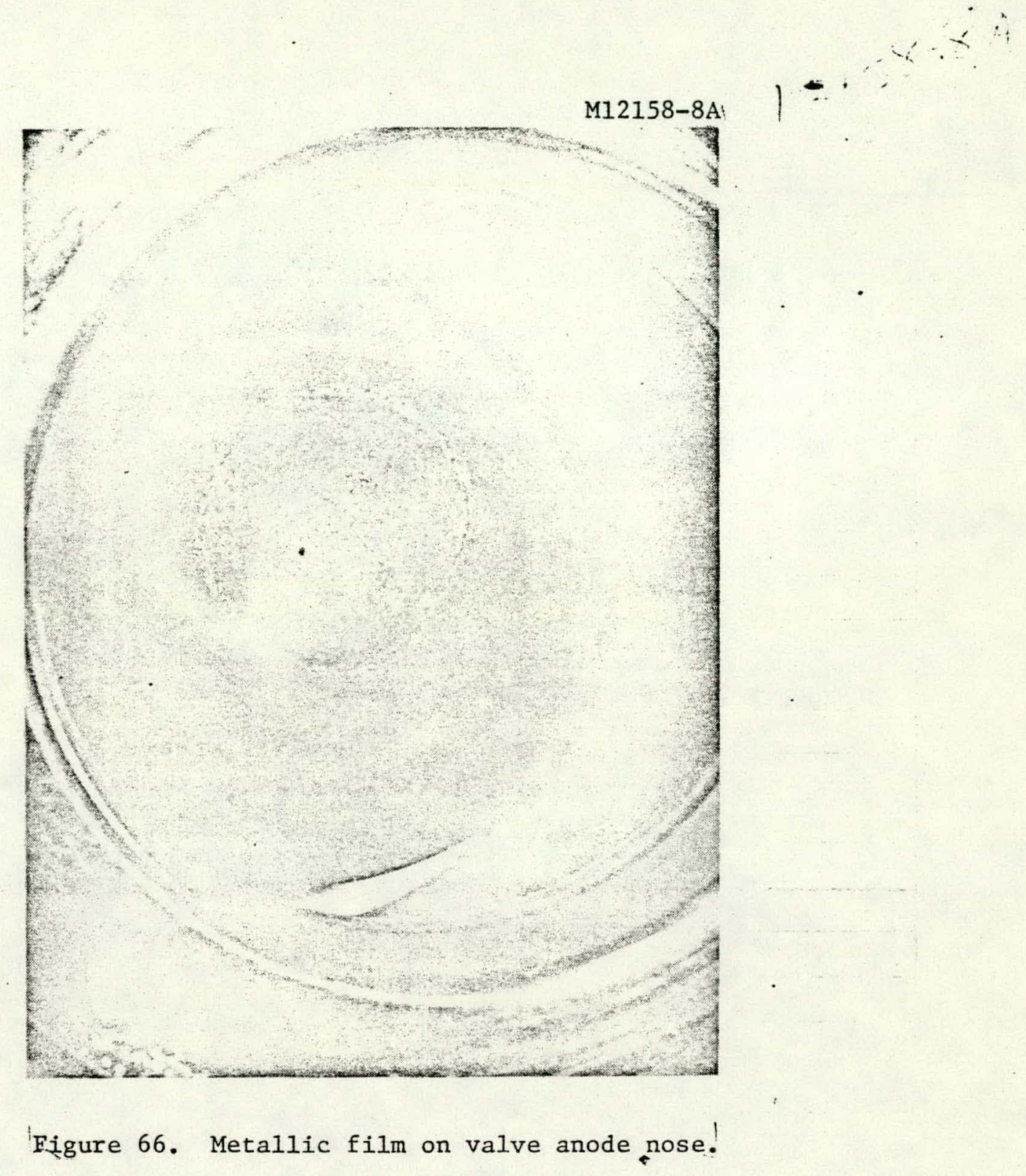

128 


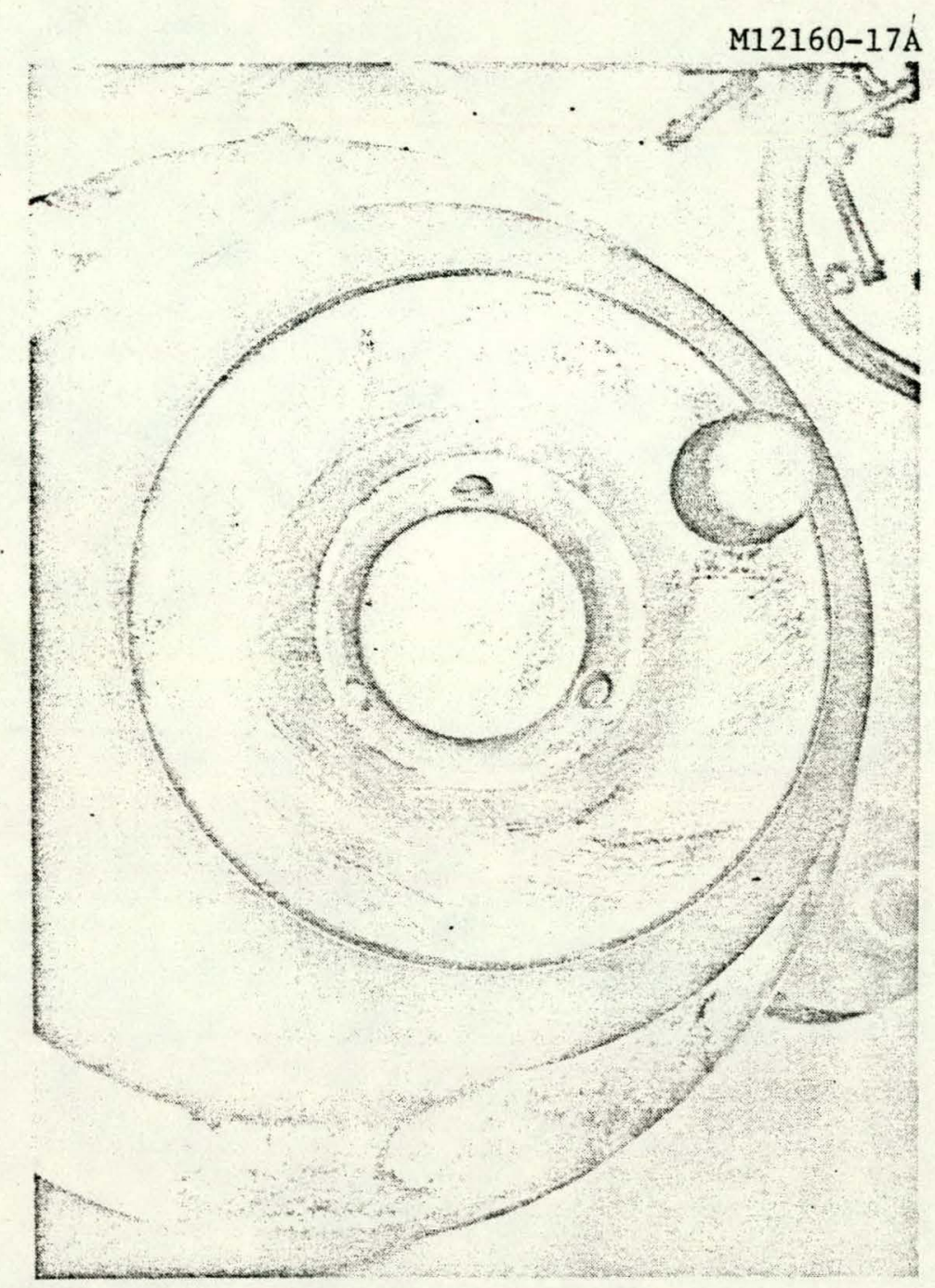

Figure 67. Appearance of sputtered cathode face. 


$$
12160-154
$$

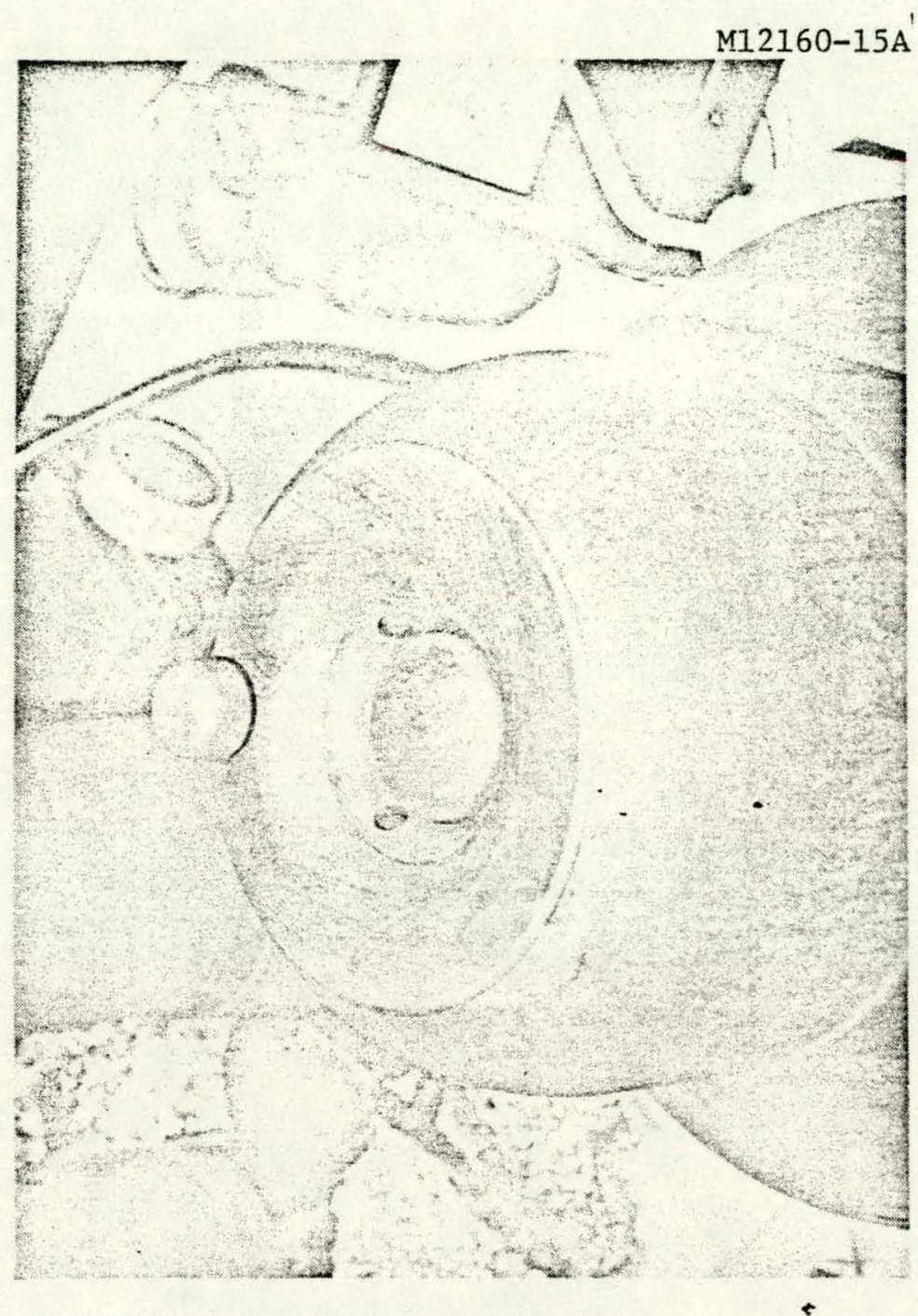

Figure 68. Appearance of sputtered cathode shroud. 


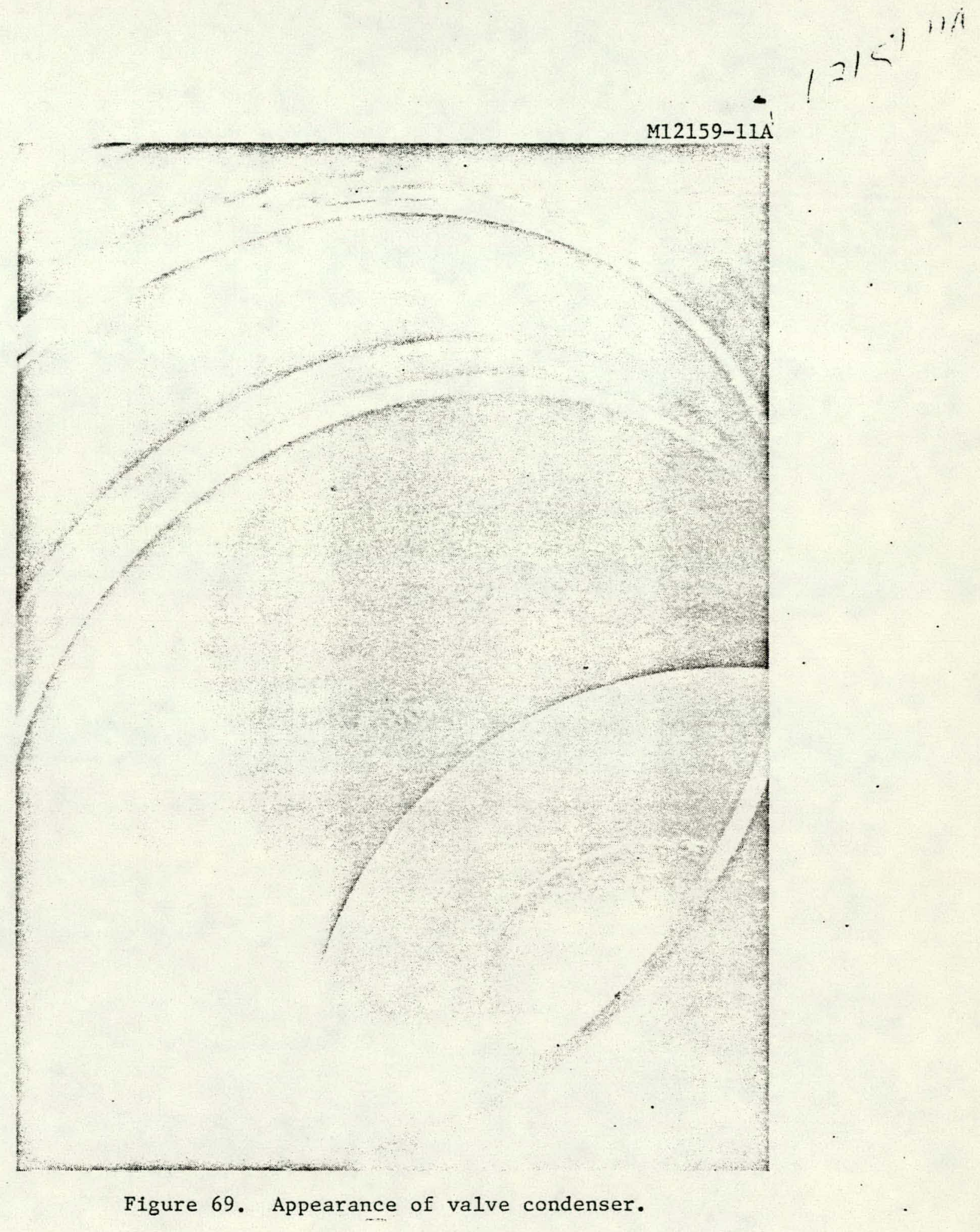


that normally should have drained back to the reservoir. This leads to the supposition that the drain line was obstructed in some manner. The mercury trapped in the valve settled the bottom of the cathode, where it could have obscured the ion pump ports in such a way that the internal valve pressure could have been high while the ion pumps (which look at a cooled baffle) registered a pressure on the order of $1 \times 10^{-5}$ Torr. However, this hypothesis is not consistent with the apparent ability of the valve to have few arc-backs at the $200 \mathrm{~A}$ average, $100 \mathrm{kV}$ level.

The internal cryowall bulge probably occurred when the valve was shut down for removal from the facility. The supposition is that it was caused by hydrostatic pressure of refrigerant in the condenser channels undergoing thermal expansion as it warmed while constrained by closed Roto-lok fittings.

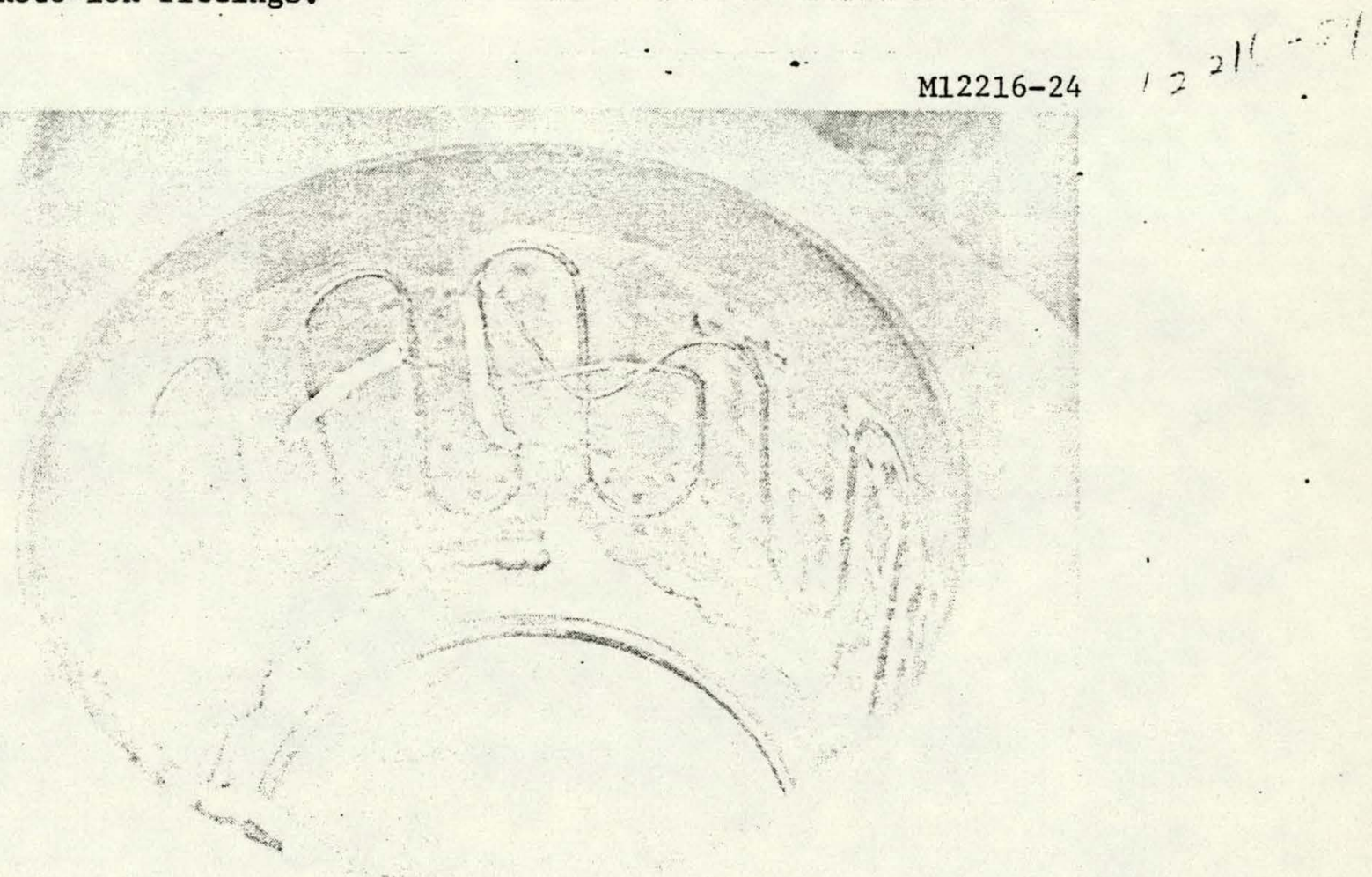

Figure 70. Cathode shroud heaters. 
When the fiber-glass insulator that contains the $\mathrm{SF}_{6}$ on valve EN1 was removed before bakeout, some tracking was observed on the outside of the vanadium-oxide-coated alumina feedthrough (Figure 71). This was probably caused during the $\pm 470 \mathrm{kVdc}$ or the $\mathrm{BIL} /$ switching surge tests and does not seem to be relevant to the high $A B$ rate measured with this. valve.

Valve EN2 went onto the exhaust pumps on 13 Apri1 1977 and proved to be quite gassy. It was at $100^{\circ} \mathrm{C}$ by 21 April, $200^{\circ} \mathrm{C}$ by $22 \mathrm{April}$, $300^{\circ} \mathrm{C}$ on $24 \mathrm{April}$, and $400^{\circ} \mathrm{C}$ on $26 \mathrm{April}$. The internal valve pressure at $400^{\circ} \mathrm{C}$ was then about $1 \times 10^{-6}$ Torr and still falling. The temperature was then turned down successively, and the valve was pinched off on schedule on 2 May, with an excellent base vacuum of $2 \times 10^{-9}$ Torr. It was integrated with its auxiliaries and installed in the rectifier position in the synthetic test facility. Before mercury had been forced into the cathode (Figures 72 and 73 ), the valve was hi-potted to remove whiskers and to help the outgassing process. We had planned to hi-pot to $\pm 225 \mathrm{kVdc}$ with a Universal Voltronics power supply, starting with negative polarity. We reached $-225 \mathrm{kV}$ with very few conditioning breakdowns, and went to $+195 \mathrm{kV}$ (gain with few breakdowns) before we developed a power supply problem. We then proceeded with the final hook-up for synthetic tests. The EN2 valve coated ceramic has an impedance of about $5 \times 10^{8} \Omega$.

After checkout of the thermocouples and heaters, mercury was admitted to EN2. The pressure in the valve, initially $1 \times 10^{-7} \mathrm{Torr}$, rose to $5 \times 10^{-7}$ Torr. The valve ignited the first time, using the hidden igniter and an open circuit power supply voltage of $200 \hat{\mathrm{V}}$. The discharge voltage was $8.6 \mathrm{~V}$ at $120 \mathrm{Adc}$. The valve pressure rose momentarily to $1.5 \times 10^{-6}$ Torr when the discharge was ignited, but fell quickly to an equilibrium level of $7 \times 10^{-7}$ Torr. We were surprised by the relatively large current to the valve condenser ( $14 \mathrm{~A}$ out of $120 \mathrm{Adc}$ total), so we checked the calibration of the measuring device and found it to be satisfactory. Running the valve to $600 \mathrm{Adc}$ and observing internal components (including the auxiliary anode) showed no component overheating. The valve was then run up to $1700 \hat{\mathrm{A}}, 480 \mathrm{~A}$ average to process the cathode. At this time, the current to the condenser was $56 \mathrm{~A}$, and the internal valve pressure was $3 \times 10^{-7}$ Torr. 


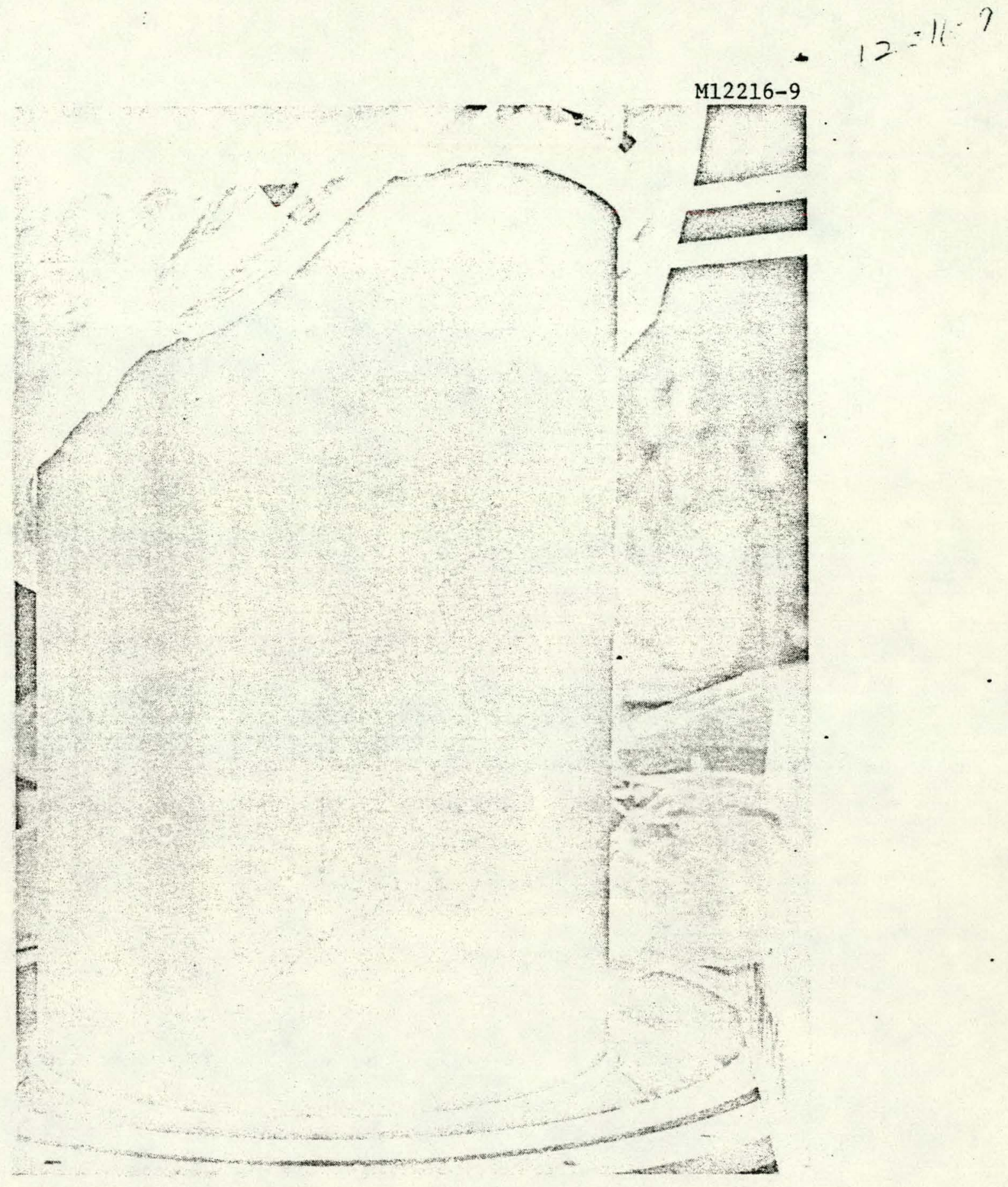

-Eigure 71. Tracking on outside of vanadium-oxide-coated insulator.

134 


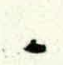

M12098.

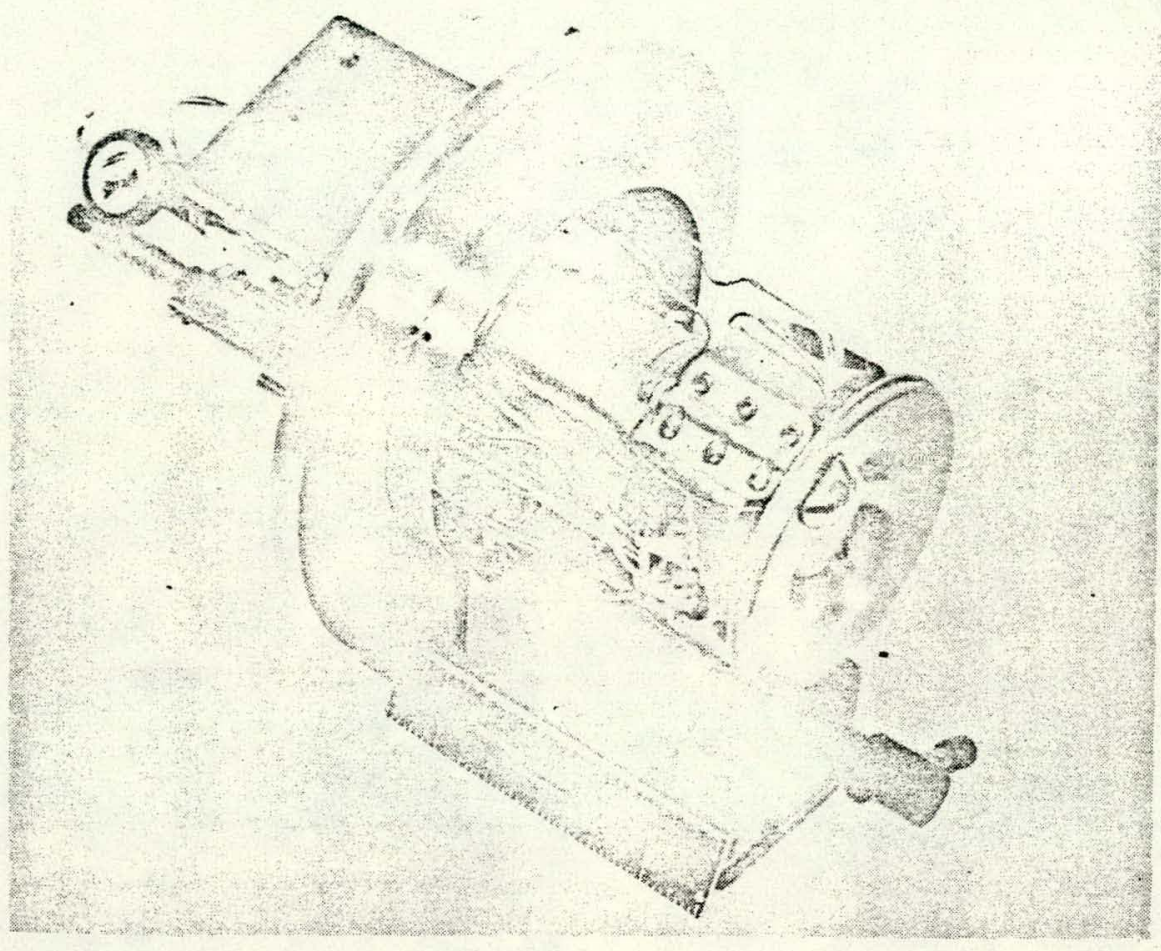

Figure 72. Cathode of EN2 during assembly. 


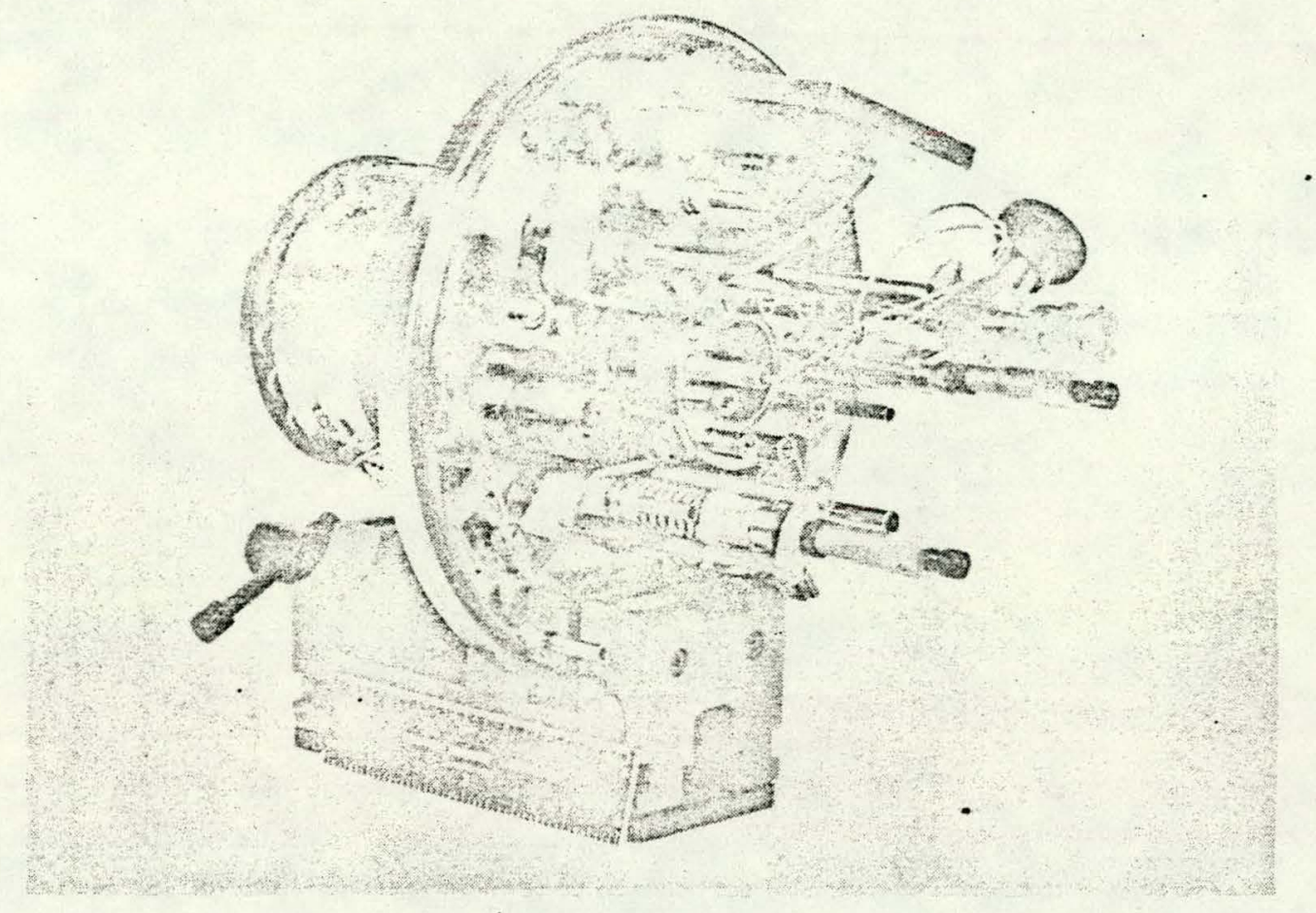

Figure 73. Cathode of EN2 - rear view.

During the preliminary stages of synthetic testing $(20 \mathrm{kV}$. and $300 \mathrm{~A}$ average), the arc-through rate of the inverter valve was high, and an incandescent film was observed on its anode (similar in appearance to that which had been seen on EN1). Because the inverter valve is a laboratory demnuntable LMPV, it had recently been cleaned, and the records show that only $35 \mathrm{hr}$ of operating time had elapsed between the last anode-cathode cleaning and the discovery of the anodefilm. Further, since careful observation of the anode prior to the final test run of $5 \mathrm{hr}$ had not shown a film (so far as could be judged through the valve window), the film had apparently grown in a very short time.

The laboratory valve was opened for inspection (this could be done without baking out to remove the mercury, unlike EN1). We observed sputtering of the cathode (similar to that seen in ENI), a blackish film on the cathode surface in the vicinity of the surface breakdown igniter, a 2-mil-thick metallic film on the anode (later analysis showed this to 
be molybdenum, with traces of mercury and carbon), and in the condenser a viscous sludge of molybdenum and mercury. This sludge had the visual appearance of gray putty and a texture as though it had been formed by mixing powdered molybdenum with liquid mercury. Since EN1 had been baked before opening to remove the mercury and the laboratory vavile had not, the appearance of both valves on opening was quite similar.

We have, on earlier occasions, operated laboratory prototype valves for well in excess of $35 \mathrm{hr}$ without observing anything like this sputtering or film deposition; we had estimated, on the basis of sensitive measurements, that it would take about 10 years of normal synthetic operation to build up a film 2 mils thick from sputtering. Further, the conditions in the laboratory valve were such that the chance of getting a high-pressure discharge that could cause sputtering were remote.

An explanation of these observations that is based on a chemical rather than a physical process, was developed. It is summarized here and reproduced in full in Appendices A and B. Briefly, the hypothesis suggests that oxygen from small leaks (present both in EN1 and the demountable valve $\mathrm{VI}$ ) reacts with carbon of the silicon carbide surface breakdown igniter to form carbon monoxide. This, in turn, attacks. molybdenum to give molybdenum carbonyl, which dissociates in the discharge to give metallic molybdenum and carbon monoxide. The carbon monoxide is then again available to attack the molybdenum.

The appendices give the likelihoods of the processes involved in terms of the free energies of formation. These suggest that, although the process can be significant for an oxygen leak while silicon carbide igniters are being used, boron carbide does not present the same likelihood for a reaction. This would account for the lack of an earlier observation of such "sputtering," even though earlier laboratory prototype valves probably had small oxygen leaks.

To attempt to verify the hypothesis, we modified an LM cathode by introducing a capillary tube into an unused igniter orifice. While operating the cathode with a $300 \mathrm{Adc}$ discharge in vacuum, we introduced a small partial pressure $\left(-10^{-4}\right.$ Torr) of carbon monoxide through the 
tube and observed the discharge. Within a few minutes, the anode began to discolor showing the formation of a film, while the cathode showed the signs of sputtering that we had previously observed in the other two valves.

In view of this result, the hypothesis of chemical sputtering seems to be valid. The question of how to avoid the problem involves the rates of reaction of oxygen with substances likely to form carbon monoxide. Although it is not possible to derive actual reaction rates, relative reaction rates do lead to useful conclusions. The calculations. (given in detail in the appendices) generally show that reducing the oxygen concentration by a factor of 100 would reduce the intensity of the reaction by a factor of $10^{8}$. In other words, the oxygen level in a wellprocessed, leak-tight valve is expected to be far below the level needed to make this process significant to life expectancy.

It is also possible to avoid the use of silicon carbide igniter material altogether. We purcahsed boron carbide samples that should be suitable for use in a surface breakdown igniter format.

The second bake-out engineering prototype valve was installed in the synthetic test facility in the inverter position so that both valves under test was of the same type. To accommodate the new inverter valve and its auxiliaries, the entire platform configuration was revised and the pl.atform area extended. Some initial time was spent in checking out the auxiliaries, nominal hi-potting of the valves (to $200 \mathrm{kV}$ ), and introducing mercury to the cathode of the new valve. Both valves were then operated in series to check their behavior at high currents and to adjust the mercury flow to the valve cathodes. In that arrangement, the discharge current through each valve is sensed and the output signal is used to modulate the EM pump power supply. The mercury flow to the valve cathode is proportional to the current through the EM pump after an initial offset. We had experienced some difficulty with the response of the EM pump of the newest valve installed in the V1 position, in that, after the offset current was adjusted to achieve minimal mercury flow, small changes in pump current resulted in relatively large changes in mercury flow rate. Thus, a small change in EM pump current produced a large mercury flow rate to the cathode. 
With a reliable setting of the EM pump holding current, it was only possible to obtain the correct mercury flow rate to the cathode at one cathode mercury flow rate to the cathode at one cathode' current. To overcome this problem and its associated instability, we decided to modify the existing EM pump power supply from a dc supply to a pulsed supply. The intent was to apply large current pulses to the EM pump to overcome the sticktion associated with the very low mercury flow. The system had a variable pulse repetition rate, a variable pulse width with proportional pulse height, and the normal offset current.

This technique was successful in modulating the average mercury flow with adequate long-term stability. Another supply was constructed in parallel with the above effort utilizing constant-amplitude current pulses with proportional pulse width modulation and constant offset current. This second system also operated satisfactorily and was installed in $\mathrm{V}_{2}$.

\section{F. TESTING TECHNIQUES}

Several major accomplishments in system operating techniques were achieved; these led to a considerable improvement in attaining reliable turn on and synthetic testing. The most important of these was the use of the $\mathrm{E}_{1}$ power supply.

The high-current, low-voltage power supply $E_{1}$ contains two fullwave, three-phase SCR bridges fed from separate $Y, \Delta$ secondary winding of a $480 \mathrm{~V}$, three-phase, 600 A transformer. The outputs of the two bridges charge a $0.3 \mathrm{~F}$ capacitor bank through an interphase transformer. The control of the SCR firing is accomplished by a control circuit phase locked to one of the incoming lines of the three-phase power feeder. The input line is filtered to reduce EMI.

A recurring problem with this power supply had been the blowing of fuses protecting the individual SCRs of the SCR bridges. The mechanism postulated for this problem is the incorrect firing of the SCRs caused by noise spikes. Considerable effort was expended to try different groudning and shielding techniques. Substantial improvement was 
achieved, with the greatest improvement obtained by using the greatest firing angle of the SCRs. Essentially, this means that the power supply is running at its maximum capability. This imposes fairly severe limits on the operational range available for testing.

Choosing a series limiting resistor of $0.168 \Omega$ (Figure 39, resistor R2) permitted testing at $2 \mathrm{kA}$ peak currents and over $600 \mathrm{~A}$ average. The configuration of the resistor is three parailel strings of four $0.126-\Omega$ resistors in series. Each resistor has a maximum current rating of 200 A average.

Using this configuration circumvented the fuse blowing problem but introduced the additional complication that, after approximately $2 \mathrm{hr}$ of maximum power conduction, a cutoff is activated disabling the system.

\section{G. THE CURRENT-INJECTION VALVE}

The current-injection valve in the test-facilizy isolates the highvoltage circuitry from the low-voltage circuitry. It provides the injected current pulse (some $400 \mu \mathrm{s}$ in total width) this allows the inverter valve the time to deionize. The actual -eionization margin can be varied frcm $I \mu$ s to the full $400 \mu \mathrm{s}$.

We felt that soine refurbishment of this valve was necessary: Accordingly, a new anode assembly was prepared, together with a new (vanadium-oxide-coated) feedthrough bushing. This was undertaken with company funding.

\section{H. X-RADIATION SHIELDING}

$\mathrm{X}$-rays are produced in the LMPV when energetic electrons strike a target, usually the anode. In experiments with the laboratory prototype valves, we found that the production rate for $X$ rays is approximately proportional to the voltage raised to the 3.4 power. This is consistent with early experiments done with mono-energetic E-beams produced by Van de Graaf generators. The three periods when $\mathrm{X}$ rays would be produced are 
- At the start of conduction

- Following current zero

- During high voltage withstand

It follows from the concept of the converter valve that valve currents are low. when voltage is high and hence that the integrated X-ray dose is low. Soft $X$ rays are absorbed by the condenser wall, and harder $X$ rays are attenuated substantially by a $1 / 4-1 n$.-thick lead shield coaxial with the condenser; still further attenuation occurs with increasing distance from the target (the inverse square law). Little $X$ radiation is emitted along the valve, axis. Using a variety of techniques calibrated with standard radioactive sources, we monitored the $\mathrm{X}$ radiation from the laboratory prototype tubes. Even under extreme operating conditions, measured radiation levels outside the high-voltage perimeter were always significantly less than those prescirbed as safe by the State of California. 


\section{THIS PAGE \\ WAS INTENTIONALLY \\ LEFT BLANK}

142 
APPENDIX A

HYPOTHESIS TO EXPLAIN MOLYBDENUM DEPOSITS IN EN1 AND LI LMPVS

Incapacitating molybdenum deposits formed recently, at different times, in two converter LMPVs under test in the Synthetic Valve Test Facility were observed. The first incident occurred in an engineering prototype valve ENI operating in the rectifier position; the second occurred in a laboratory-type valve $L 1$ operated in the inverter position. Both cases differed from other test experience, including that with.the cooperating valves during the same operating periods in the following, simultaneously prevailing conditions:

- The affected valves had small air leaks (undetected during operation)

- The affected valves were equipped (and at least partially operated) with surface-breakdown igniters.

The purpose of this discussion is to provide an explanation, in chemical terms, for the formation of the observed deposits. If successful, it will be a basis for predicting future events of this kind and for evaluating proposed means of preventing recorrences.

To have any chance of providing an accurate and useful explanation, any such hypothesis must acrount for the fact that such deposits do not always occur, must explain the geometric patterns observed in L1, and should provide a basis for understanding the physical differences among the deposits. Since the mechanism proposed here is based on a chemical. reaction with the silicon carbide of the surface breakdown igniter (SBI), it immediately accounts for the lack of deposits in valves without SBI and also explains the Ll patterns that visually suggest an origin near the SBI. However, such a hypothesis must also account for the fact that the maximum amount of SiC possibly consumed is not commensurate with the relatively large amounts of deposit found:

The process proposed is the successive occurrence of the following four chemical reactions:

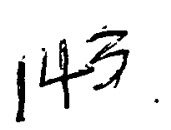




$$
\begin{array}{ll}
\mathrm{SIC}+3 / 2 \mathrm{O}_{2} & \rightarrow \mathrm{SiO}_{2}+\mathrm{CO} \\
\mathrm{SiC}+\mathrm{O}_{2} & \rightarrow \mathrm{SiO}+\mathrm{CO} \\
\mathrm{Mo}+6 \mathrm{CO} & \rightarrow \mathrm{Mo}(\mathrm{CO})_{6} \\
\mathrm{Mo}(\mathrm{CO})_{6}+\mathrm{hv} & \rightarrow \mathrm{Mo}+6 \mathrm{CO} \\
\mathrm{Mo}+\mathrm{hv} & \rightarrow \mathrm{Mo}^{+}+\mathrm{e}^{-}
\end{array}
$$

Reaction $(\mathrm{I})$ or, alternatively, (Ib) is the oxidation of silicon carbide in the SBI by oxygen dupplied by a small air leak. It is the most difficult point to justify, in this explanation. If correct, however, it completely explains the importance of the SBI in the deposit process. The fact that the carbon monoxide consumed in reaction (2) is completely liberated in reaction (3) makes it effectively a catalyst able to transport relatively large amounts of molybdenum. Finaliy, variations in the environment for reactions (3) and. (4) provide a variety of explanations for differences in the properties of the deposit. Two competing reactions,

$$
\mathrm{SiC}+2 \mathrm{O}_{2} \rightarrow \mathrm{SiO}_{2}+\mathrm{CO}_{2}
$$

and

$$
\mathrm{CO}+1 / 2 \mathrm{O}_{2} \rightarrow \mathrm{CO}_{2}
$$

must be mentioned because (5) would avoid the formation of co by reaction ( 1 ), and (6) would terminate the catalytic chain by consuming Co. However, these reactions require additional oxygen and would be handicapped by the low oxygen environment of a very small air leak. Reactions ( $1 \mathrm{a}$ ) and ( $\mathrm{lb}$ ) are known to be quite low. Indeed SiC can be very strongly heated in air without groww damage. However, the highly energetic plasma environment is a ready source for the activation energy needed to drive an otherwise slow reaction. Furthermore, thermodynamic considerations indicate that it must occur however slowly. The free energies of formation $\left(\Delta F_{f}\right)$ of silicon carbide and its reaction products are as follows:

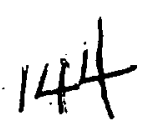




\begin{tabular}{|l|r|}
\hline \multirow{2}{*}{ Substance } & $\begin{array}{c}-\Delta \mathrm{F}_{\mathrm{f}}, \\
\mathrm{kcal} / \mathrm{g} \text { mole }\end{array}$ \\
\hline $\mathrm{SiC}$ & 15 \\
$\mathrm{SiO}$ & 33 \\
$\mathrm{SiO}_{2}$ & 217 \\
$\mathrm{CO}^{2}$ & 26 \\
$\mathrm{CO}_{2}$ & 94 \\
\hline
\end{tabular}

Reactions (1a) and (5) are' favored by their much greater increases in negative free energy, but ( $1 \mathrm{~b}$ ) has a competitive advantage in the low oxygen environment; indeed, it is probably the beginning of a stepwise formation of $\mathrm{SiO}_{2}$. Its solid product, SiO, is well known in the semiconductor device industries, where it is used as a first step toward producing a protective oxide film on some silicon products. Although the production of CO from SiC may be slow, there are three reasons for expecting it to be much faster than production of $\mathrm{CO}$ by analogous reactions with the boron carbide of the "finger" and "hidden" igniters present in all LMPVS:

$$
\begin{aligned}
& \mathrm{B}_{4} \mathrm{C}+7 / 2 \mathrm{O}_{2} \Rightarrow 2 \mathrm{~B}_{2} \mathrm{O}_{3}+\mathrm{CO} \\
& \mathrm{B}_{4} \mathrm{C}+5 / 2 \mathrm{O}_{2} \rightarrow 4 \mathrm{BO}+\mathrm{CO} \\
& \mathrm{B}_{4} \mathrm{C}+9 / 2 \mathrm{O}_{2}+4 \mathrm{BO}_{2}+\mathrm{CO}
\end{aligned}
$$

Here, reactions (7a) and (7b) correspond to reactions (1a) and (1b) of SiC. Reaction ( $7 c$ ) is the production of an additional oxide of boron, which is known to exist and has a superficial resemblance to $\mathrm{SHO}_{2}$, although it is much less stable than the latter. First, SiC is 50 at.\% carbon in contrast to the 20 at.\% of $\mathrm{B}_{4} \mathrm{C}$, and its oxidation will produce correspondingly more co. Second, reactions (7a) and (7b) require $7 / 3$ and $5 / 2$ times, respectively, as much oxygen as their counterparts, (la) and (1b). These numbers enter the rate equations for their respective reactions as powers of the very low oxygen concentration. Reaction (7c) is even less favorable from this standpoint. 
Finally, the silicon carbide reactions are thermodynamically favored by greater free energy driving force, as seen by comparison with the following data:

\begin{tabular}{|c|c|}
\hline Substance & $\begin{array}{c}-\Delta \mathrm{F}_{\mathrm{f}}, \\
\mathrm{kcal} / \mathrm{g} \text { mole }\end{array}$ \\
\hline $\mathrm{B}_{4} \mathrm{C}$ & 17 \\
$\mathrm{BO}$ & 17 \\
$\mathrm{~B}_{2} \mathrm{O}_{3}$ & 285 \\
$\mathrm{BO}_{2}$ & 72 \\
\hline
\end{tabular}

The $285 \mathrm{kcal}$ value seems large, but it is the total free-energy of formation of a mole of boric oxide. To evaluate it. as a driving force for consumption of oxygen, the limiting reagent, it is necessary to divide by the number of moles of $\mathrm{O}_{2}$ required for the reaction. Furthermore, if all seven oxygen atoms required for immediate completion of reaction ( $7 a)$ are not available simultaneous1y. There is very little driving force to initiate stepwise production of $\mathrm{B}_{2} \mathrm{O}_{3}$ by first producing a molecule of BO.

Reactions (2) and (3), in which molybdenum carbonyl is formed and. decomposed, are well known in other contexts and, under somewhat different conditions, are used as a commercial vapor plating process for molybdenum. When the objective is productio of carbonyl crystals by. reaction (2), conditions of $200^{\circ} \mathrm{F}$ and very high pressure (>200 atm) are useful, and the pressure is probably used only to compete with the concurrent decomposition, reaction (3). In the plating process, where much higher temperatures are used, economically useful reaction rates occur at much lower pressures. Furthermore, the pressure is much higher near cathode arc spots than elsewhere in the valve, and it may well exceed $1 \mathrm{~atm}$. The $\Delta \mathrm{F}_{\mathrm{f}}$ to produce $\mathrm{MO}(\mathrm{CO})_{6}$ from the elements is $-205 \mathrm{kcal} / \mathrm{g}$ mole, providing a net driving force of $49 \mathrm{kcal} / \mathrm{g}$ mole for its production from existing $C 0$. The vapor pressure of the carbonyl is extremely high 
(2.3 Torr at $55^{\circ} \mathrm{C}$ ). Thus, all of the reacted molybdenum immediately. enters the gas phase.

Reaction (3), the decomposition reaction, requires energy input, but this is readily available from several sources. The commercial platIng process decomposes the carbonyl vapor on the plated surface at temperatures ranging from 525 to $800^{\circ} \mathrm{C}$. However, handbook sources indicate that considerable thermal decomposition of the solid carbonyl. occurs at $150^{\circ} \mathrm{C}$. The reaction free energy of $49 \mathrm{kcal} / \mathrm{g}$ mole seems substantial in chemical terms, but, in relation to the energies of the plasma discharge, it is equal to only $2.1 \mathrm{eV} / \mathrm{molecule.} \mathrm{The} \mathrm{most} \mathrm{effi-}$ cient source of decomposition ehergy may weil be excited neutral mercury atoms, which are abundant in the plasma and have a metastable energy level of $4.8 \mathrm{eV}$.

In view of the abundance of energy sources, it seems certain that any Mo $(\mathrm{CO})_{6}$ formed will decompose by reaction (3), and it appears reasonable that the decomposition will be rapid in relation to the diffusion of this heavy(molecular weight $=264$ ) molecule.. The geometric pattern of the deposits in VI can be explained either by vapor phase decomposition of the carbonyl near its place of origin or, alternatively, by line-of-sight movement of the compound followed by surface reaction. of the two possibilities, the former is more consistent with the observed pattern because it accounts for release of the $\mathrm{CO}$ and repetition of reaction (2) at a location near the SBI. The combination of diffusion of the compound followed by vapor phase decomposition would tend to eliminate the shadowing and other geometric variations observed. other information about the plating process is also consistent with the present observations. Commercial operators typically maintain a total pressure less than or equal tn 0.1 Torr and find that excessive pressure causes a spongy, non-adherent deposit, such as was found in the affected engineering prototype valve. The presence of excess oxygen affects the plate quality. A concentration of $1 \%$ in the reaction environment is considered intolerable, but $0.1 \%$ does not affect plating quality. 
The absence of hydrogen, which commercial platers routinely include in their reaction medium, is found to cause "contamination" of the deposit by carbon and carbides. The prediction that carbon should, therefore, be present in the valve deposits has been confirmed with an amount substantially above the limit for $\mathrm{X}$-ray detection in two of three sample locations of the laboratory valve deposit. The only other elements detected were molybdenum and mercury. (The analyst was unaware of this prediction, and he identified it directly from the instrument readout).

Mention must be made of the chain terminating reaction

$$
2 \mathrm{CO} \rightarrow \mathrm{C}+\mathrm{CO}_{2}
$$

which, as seen above, is energetically favored. Nevertheless, the reaction rate is very low under most conditions, as seen from the lifetime of $\mathrm{CO}$ in ordinary experience. In the plating process; it occurs primarily at the time (and location) of surface thermal decomposition of the carbony1. This reaction probably accounts for the carbon found in commercially plated molybdenum when hydrogen is not present to remove it. Furthermore, to the extent that it occurs at all in the vapor space, the resulting isolated gaseous carbon atoms are extremely reactive and will tend to regenerate $C 0$ by reaction with any oxygen or moisture encountered:

$$
\begin{aligned}
& \mathrm{C}+1 / 2 \mathrm{O}_{2} \rightarrow \mathrm{CO} \\
& \mathrm{C}+\mathrm{H}_{2} \mathrm{O} \rightarrow \mathrm{CO}+\mathrm{H}_{2}
\end{aligned}
$$

Reaction (4), the ionization of molybdenum atoms, is not an essential part of the deposit-forming process. Molybdenum atoms have many alternative modes of travel to the solid surfaces and will adhere quantitatively on arrival. However, molybdenum's low (relative to the plasma energies) first ionization potential of $7.1 \mathrm{~V}$ permits ionization to occur and helps to explain the character of the anode deposit in the laboratory valve. Even allowing for charge-exchange collisions, those 
Lons that reach the anode during application of an inverse voltage (i.e., during the valve's "deionization margin") will provide the activation energy to permit themselves and several neighbors to undergo the atomicscale rearrangements needed to form the bright metallic crystals observed. Furthermore, the tendency of ions to follow field lines, . rather than Iine-of-sight paths, accounts for the heavy (peeling) deposit on the part of the anode shield nearest the SBI. Also, the bright, metallic anode deposit was the only one of three samples from V1 that lacked a detectable amount of carbon.

Attempts have been made to propose alternative mechanisms, but the only apparent success is one predicated on the existence of a freon leak, which does not appear to have occurred. No potential mechanism based on silicon, the other constituent of SiC, has been found, and efforts to base one on phosphorus a constituent of the igniter braze alloys, are subject to several objections. The phosphorus-based chemistry is inherently less convincing, does not include a volatile compound of the molybdenum, provides a phosphorus recycling reaction that is expected to operate (incompletely) only in the discharge environment, and makes only a slight quantitative distinction between the two types of igniter. Indeed, the slightly greater reactivity of the Nicrobraz 10 of the SBI may be more than offset by the more exposed location of the Nicrobraz 50 in the finger igniter.

In summary, the reaction mechanism proposed here seems inherently reasonable and (so far) to agree with the observed facts. On this basis, the only measure required to prevent recurrence of the deposits in future valves is one that good practice dictates in any case: LMPV!s should not be operated with even small air leaks.

It is also possible that this same mechanism, quantitatively limited by the residual oxygen in an unbaked valve, may be responsible for an initial cuntaminacion problem observed in the vicinity of the SBI. If so, it would be desirable to delay use of the SBI in the future unbaked valves to more completely remove oxygen. If experience should show that 
s higher oxygen tolerance of the SBI is desirable, this would be an incentive for seeking another semiconductor material to replace silicon carbide in the SBI design. 


\section{APPENDIX B}

MOLYBDENUM TRANSPORT RATE AS A FUNCTION OF OXYGEN CONCENTRATION

\section{A. INTRODUCTION}

The Appendix A examines, in chemical terms, the formation of disabling molybdenum deposits found in two LMPVs. The mechanism advanced consists of the reaction of oxygen from small air leaks or other sources with the silicon carbide of the surface breakdown igniter (SBI) to form carbon monoxide, followed by transport of lo by means of its reversible reaction with $\mathrm{CO}$.

$$
\begin{aligned}
& \mathrm{SiC}+3 / 2 \mathrm{O}_{2} \rightarrow \mathrm{SiO}_{2}+\mathrm{CO} \\
& \mathrm{SiC}+\mathrm{O}_{2} \rightarrow \mathrm{SiO}+\mathrm{CO} \\
& \mathrm{Mo}+6 \mathrm{CO} \rightarrow \mathrm{Mo}(\mathrm{CO})_{6} \\
& \mathrm{Mo}(\mathrm{CO})_{6}+\mathrm{hv} \rightarrow \mathrm{Mo}+6 \mathrm{CO}
\end{aligned}
$$

During the contract rev iew meeting in July 1977, it was decided that an attempt should be made to establish a quantitative relationship between deposit rate and actual oxygen concentration. This turned out not to be feasible. However, deductions about the possible form of the rate law have made it possible to draw useful conclusions about relative reaction rates. The quantity calculated here is the factor $\mathrm{f}_{\mathrm{O}}$ by which oxygen concentration $\left[\mathrm{O}_{2}\right]$ must be reduced to extend valve life by a factor of $10^{5}$ (e.g., from $1 \mathrm{hr}$ to $11.4 \mathrm{yr}$ ). An intermediate calculating step involves $f_{\mathrm{CO}}$, the corresponding factor for [CO].

The very low values of $\mathrm{f}_{\mathrm{O}_{2}}$ derived below indicate that a relatively modest reduction of the air leaks in the two disabled valves would have generally extended their lifetimes. The oxygen level in a tight, wellbaked valve should be so low that the carbonyl transport mechanism for molybdenum will have no role in normal end of valve life. 


\section{B. REACTION MECHANISMS AND RATES}

As with any chemical process, the rate relationship for this series. of reactions depends on the details of the reaction mechanism. Not only is it difficult, in this case, to determine which particular pathway dominates, but it seems likely that more than one alternative will contribute significantly to the overall rate. In the discussion that follows, values of $\mathrm{f}_{\mathrm{O}}$ are calculated for individual mechanisms (results summarized in Table.1) and their combination is condiered under the heading "Hybrid Cases." Cases differing in terms of interrupting the reaction and regeneration of $C \sigma$ are designated by numbers I through III. Cases differing in the arrival and reaction of oxygen are designated by letters A through E.

In general, the rate of a chemical reaction

$$
A+B+C+\ldots \quad x+\ldots
$$

is proportional to the product of the concentrations of the reactants. This is also true when two or more of the reactants are identical,

$$
n A+G+\ldots Y+\ldots,
$$

so that the number $n$ of identical reacting molecules appears in the rate equation as the corresponding exponent of the concentration of that reactant. An exception to this generality is discussęd for case IC" below, where it may be significant.

Table 1. Values of the Factor $f_{0}$ by which the Oxygen Concentration must be Reduced to Increase the Valve Operation Time by a Factor of $10^{5}$

\begin{tabular}{|l|c|c|c|c|c|}
\hline Case & A & B & C & D & E \\
\hline I & 6.8 & 2.6 & 6.8 & 3.6 & 1.9 \\
II & 17.8 & 4.2 & 17.8 & 6.8 & 2.6 \\
III & 10.0 & 3.2 & 10.0 & 4.6 & 2.2 \\
\hline
\end{tabular}




\section{Case TA}

In the A cases, oxygen is assumed to reach the SBI as $\mathrm{O}_{2}$ and reaction (1b) take place essentially as written. Therefore, it follows that

$$
\mathrm{f}_{\mathrm{O}_{2}}=\mathrm{f}_{\mathrm{CO}}
$$

The rate of reaction (2), the reaction that produces $\mathrm{Mo}(\mathrm{CO})_{6}$, is expected. to be proportional to the sixth power of [CO], and the rate of reaction (3) should be proportional to $\left[\mathrm{Mo}(\mathrm{CO})_{6}\right]$. The Case I assumption is that termination of the reaction chain results from a factor that is independent of [ $\mathrm{CO}$ ], such as termination of the arc as an energy source for reaction (3). In this case, therefore,

$$
f_{0_{2}}=f_{C O}=\left(10^{5}\right)^{1 / 6}=6.8
$$

Removal of the energy source is unlikely to totally terminate the deposition process, but it would contribute strongly to a hybrid situation by greatly favoring the energy-supplying process of Case II and the energy-independent one of Case III.

\section{Case IIA}

Here, it is assumed that the rate of metal deposition is determined by competition between reaction (2) and the reaction

$$
2 \mathrm{CO} \rightarrow \mathrm{CO}_{2}+\mathrm{C}
$$

and that the carbonyl chain process continues until interrupted by consumption of the co supply by reaction (4). The rate of reaction (2) is proportional to $[\mathrm{CO}]^{6}$ and that of reaction (4) to $[\mathrm{CO}]^{2}$. Therefore, the relative rate of reaction (2), which is the ratio of the individual reaction rates, is proportional to $[\mathrm{CO}]^{6-2}$ and

$$
\mathrm{f}_{\mathrm{O}_{2}}=\mathrm{f}_{\mathrm{CO}}=\left(10^{5}\right)^{1 /(6-2)}=17.8 \text {. }
$$




\section{Case IIIA}

In this case, it is assurin that the effective competition is between reaction (2) and co removal by the vacuum pump, which is directly proportional to $[\mathrm{CO}]$. Consequertily,

$$
\mathrm{f}_{\mathrm{O}_{2}}=\mathrm{f}_{\mathrm{CO}}=\left(10^{5}\right)^{1 /(6-1)}=10 \text {. }
$$

\section{Cases I to IIIB}

In the very likely event that a significant fraction of the oxygen atoms reach the SBI surface singly rather than paired in molecules (e.g., because of dissociation in the plasma discharge), the rate of reaction (1b) will be proportional to the square of [0], and [0] is directly proportional to $\left[\mathrm{O}_{2}\right]$. In the $B$ cases, therefore,

$$
\mathrm{f}_{\mathrm{O}_{2}}=\mathrm{f}_{\mathrm{CO}}^{1 / 2}
$$

Based on the previous calculations of $\mathrm{f}_{\mathrm{CO}}$, the $\mathrm{f}_{\mathrm{O}_{2}}$ values for Cases IB, IIb, and IIIB are $2.6,4.2$, and 3.2 , respectively. If the assumptions of Case IB hold, the overall deposition rate will be proportional to the 12 th power of $\left[\mathrm{O}_{2}\right]$.

An individual oxygen atom is much more reactive than its counterpart bound in an $\mathrm{O}_{2}$ molecule. Therefore, the importance of the $\mathrm{B}$ cases will be greater than would be inferred directly from the relative amounts of the two forms of oxygen reaching the SBI.

\section{Cases I to IIIC}

Although the reactions of single 0 atoms are believed to have little effect on the overall rate law, they cannot be totally discounted, particularly if atomic oxygen does reach the SBI due to dissociation of molccules in the discharge. These reactivis are

$$
\begin{array}{ll}
\mathrm{S} I \mathrm{C}+0 & \because \mathrm{SiO}+\mathrm{C} \\
\mathrm{C}+0 & +\mathrm{CO} \\
\mathrm{SiC}+0 & +\mathrm{Si}+\mathrm{CO} \\
\mathrm{Si}+0 . & +\mathrm{SiO}
\end{array}
$$


Reactions (5a) and (5b) represent a stepwise accomplishment of the same overall result as (1b). This would eliminate the requirement of the assumption in Case $B$ that both atoms be available for simultaneous reaction. Ordinarily, the existence of such a stepwise process would not affect the form of the rate law for the overall reaction. However, in some extreme cases, such as if one of the reactions (5a) and ( $5 b)$ were essentially instantaneous and the other a true rate-determining step, the effect on these calculations would be to square the otherwise applicable value of $\mathrm{f}_{\mathrm{O}_{2}}$.

The $\mathrm{f}_{\mathrm{O}_{2}}^{2}$ values shown for the $\mathrm{C}$ cases in Table 1 are based on the assumption that oxygen reaches the SBI as individual atoms and that $(5 a)$ or $(5 b)$ is a rate-determining reaction step. It seems unlikely that such single-atom reactions will be important where oxygen reaches the site as diatomic molecules. If such a process were to occur, the $\mathrm{f}_{\mathrm{O}_{2}}$ value would be the square of that tabulated for the corresponding $C$ case, or 46.4, 316, and 100 for Cases I, II, and III, respectively.

. Reactions (5c) and (5d) would also be a two-step oxidation process, but are very probably of little significance because reaction ( $5 c$ ) would compete poorly with reaction (5a). The net driving force, in terms of

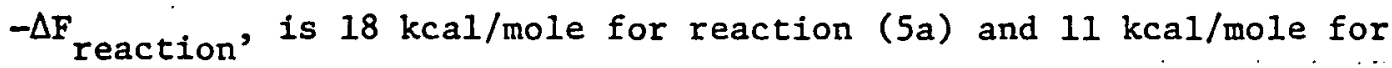
reaction ( $5 c)$.

Both the requirement and the source of activation energy for the two reactions are expected to be essentially identical, making their relative rates dependent only on the $\Delta F$. (Rate ratio $\approx e^{-\Delta(\Delta F) / k T}$.)

\section{Cases I to IIID and E}

To the extent that reaction (1a) rather than ( $1 b$ ) is the effective oxidation reaction, the effect would be to reduce the otherwise applicable value of $\mathrm{f}_{2}$ to its $2 / 3$ power. The tabulated $\mathrm{D}$ case values assume this reaction in conjunction with oxygen arriving as molecules, and the $E$ cases assume oxygen atoms.

However, to the extent that reaction (1b) may be a rate determining stage for production of $\mathrm{CO}$ by the stepwise accomplishment of reaction (1a), the remaining step(s) will not influence $\mathrm{f}_{\mathrm{O}_{2}}$ and the values 
calculated for the A and B cases apply. One possible reason for this would be that, because the oxidation of $\mathrm{SiO}_{\text {to }} \mathrm{SiO}_{2}$ is the conversion of one solid to another, it is likely to be slow and ineffective in competing for oxygen in the arc environment. However, the reaction is strongly favored energetically and would,probably continue to completion during the quiescent interpulse period.

\section{Hybrid Cases}

Where more than one mechanism for a reaction is possible, all occur in parallel and make their separate contributions to the reaction rate. In the present situation, it appears certain that more than one of the cases discussed above makes a significant contribution to the overall deposition process. Furthermore, their relative importance will be changed by varying $\left[\mathrm{O}_{2}\right]$. At the same time, oxygen is being consumed by additional competing reactions that form $\mathrm{CO}_{2}$ instead of $\mathrm{CO}$. Under such conditions, the effective overall value of $\mathrm{f}_{\mathrm{O}_{2}}^{\prime}$ is a complex weighted average of the values for the individual cases contributing.

\section{CONCLUSIONS}

The variable $\mathrm{f}_{\mathrm{O}_{2}}$ considered here is the factor by which the oxygen concentration of a valve must be reduced to extend its lifetime, in terms of transport of molybdenum by reversible formation of its carbonyl, by a factor of $10^{5}$. The actual value of $\mathrm{f}_{\mathrm{O}_{2}}$ has not been determined, but limits have been established.

The greatest value of $\mathrm{f}_{\mathrm{O}_{2}}$ that can be derived from these calculations is 316, as discussed under Case IIC. On this basis, reducing the oxygen concentration by a factor of 316 would increase valve life by a factor of $10^{5}$ and, if one may extrapolate to reduction by a factor of $10^{3}$, this would extend calculated valve life by a factor of $10^{6}$ in terms of this mechanism. 
The greatest value of $f$ that seems reasonable is 17.8 , based on Case IIA of the above analysis. This would mean that reducing the oxygen concentration by a factor of 17.8 would extend life by a factor of $10^{5}$. Extrapolating to a 100-fold reduction wouldindicate the extension of valve life by a factor of $10^{8}$.

Whatever may be the effective value of $\mathrm{f}_{\mathrm{O}_{2}}$ as it has been defined above, it is probably not valid to use that same value for extrapolation: rather a somewhat greater equivalent value probably pertains at the reduced oxygen concentrations involved in further increases in valve life. Nevertheless, there seems little reason to doubt that the limiting values of 316 and 17.8 remain applicable well beyond the lifetimes considered here.

- The oxygen level in a well-processed, leak-tight valve is expected to be far below the level ineeded to make this process significant to life expectancy. Even at the extreme limits of normal process variables, life, in terms of this process, is expected to be greatly in excess of that calculated for other mechanisms (such as sputtering). 


\section{THIS PAGE}

\section{WAS INTENTIONALLY \\ LEFT BLANK}




\section{APPENDIX C}

\section{SPECIFICATIONS OF THE DEEIVERABLE AUXILIARIES}

\section{A. IGNITER CONTROL PHILOSOPHY}

The igniter power supply. will not. be capable of providing an ignition pulse until after a firing gate is received. This will ensure that in the sensive cathode current sensing circuit does not cause the power supply to fire. The current rate of rise at Celilo will be about $1 \mathrm{~A} / \mu \mathrm{s}$. Thus, only $25 \mathrm{~A}$ will be flowing through the LMPV after $25 \mu \mathrm{s}$, the time allowed before a second ignition pulse is fired in the event of faulty ignition. This means that the information required to fire sequential ignition pulses will be obtained from less than $1 \%$ of the range of the $3000 \mathrm{~A}$. Hall current sensor, and, therefore, this system may be sensitive to EMI.

\section{B. IGNITER POWER SUPPLY}

A variac will be provided on the boron carbide igniter (BCI) power supply. The manually selected repetitive firing circuit for use in laboratory tests will not have provision for frequency. variability - it will operate only at $60 \mathrm{~Hz}$.

The circuitry, which provides for elimination of an inoperative igniter from the firing sequence, will also provide for reinsertion of such an igniter into the sequence after $\mathrm{l} \mathrm{hr}$ has elapsed; this is Lu ensure that an 1gniter that becomes shorted with mercury can be recovered. This reinsertion sequence will be repeated indefinitely. In addition, a reset common to the three igniters will be provided; it will be activated by a photusensor on the front panel of the cart (as with the ASEA valves).

We are presently obtaining information on thyratron life (thyratrons will be used in the SBI power supply). The inftial estimate is that with two in parallel we can easily expect $10^{4} \mathrm{hr}$. 


\section{IGNITER COOLING/HEATING}

The two BCIs will be connected in parallel. Each line will contain a filter, a flow switch, a visual flow meter (not visible from outside of cart), and a thermocouple. The thermocouple will not be monitoried but will be available in case measurements are required. The water valving and heater arrangement; which will allow the two BCIs to be warmed, will be automatically actuated whenever the 1ong-term ( $\sim$ min) average cathode current is zero.

\section{MERCURY FEED SYSTEM POWER SUPPLY}

Although this power supply will not supply sufficient current for LMPV operation at $28 \mathrm{kA}$ with $\mathrm{K}_{\mathrm{e}} / \mathrm{K}_{\mathrm{a}}=50$, it will be designed such that its maximum current will be supplied at $28 \mathrm{kA}$ (the power supply will saturate at an average cathode current of $11000 \mathrm{~A}) . \cdot$

The dc standby current is intended to be close to but less than that required to overcome the head and punch-through pressure drops.

A time-actuated pulsed current will be provided to meet the standby mercury flow requirements. The associated circuit will provide a 1-s long pulse eve-y $4 \mathrm{hr}$ at a current that will be manually variable and inderendent of all other adjustments. Because the standby flow is approximately $10^{4}$ times smaller than the nominal operating flow, the pulse circuit does not have to be disabled during operation (this simplifies the cirsuit iesign).

The mercury flow rate required for inverter operation is about $20 \%$ greater than that required for rectifier operation when operating with the same mercury pool surface area. Also, the arcback rate depends on the electron-to-atom ratio. Therefore, the feed system power supply will be designed to provide different flows depending on the mode of operation. The mode of operation will be sensed as the 10 cycle average of the anode/cathode voltage $(\bar{v}>0$ for inverter mode, $\bar{V}<0$ for rectifier mode). To accomplish the variable flow, it may be most convenient to insert a manually variable attenuator in the cathode current sensor 
output. when operating as a rectifier. This attenuator would be adjusted on the basis of experimental tests at HRL.

The proportionality constant relating EM pump current with the sensed LMPV discharge current will be variable from 0 to $0.04 \mathrm{~A} / \mathrm{amp}$ of discharge.

The manual current will be actuated by: (1) a push button switch located within easy reach of the LMPV window, and (2) a photocell relay located on the cart front panel - this will allow some flexibility after valve installation at Celilo.

\section{E. ANNUNCIATOR/ALARMS}

Two annunciator panels, one for each valve, will be located in the basement aisle. An abbreviated annunciator panel will be located in the control room on top of the Celilo control console. This panel will be hard-wired from the main annunciator panel, located $200 \mathrm{ft}$ away in the basement. Flexibility will be provided so that the annunciated quantities can be readily changed. Annunciation will be provided for the two HAC valves in common (i.e., the control room panel will not distinguish between the two Hughes valves). Type I faults will appear as red lights. This panel will be wired into the Celilo reset button. The firing signal will be connected into our pedastal when the cart is installed.

The fault monitoring (Table C-1) lists the possible faults, the fault level, whether a meter is located on the cart fiont panel or a ground potential, whether a multiplex channel or annunciator light is required, whether an annunciator will be located in the control room, and the name that will label the annunciator.

The fault monitoring denotes: (1) the various items of concern regarding the valve, (2) the fault level, (3) whether a meter will bc provided on the valve cart, (4) the existence of meters at ground potential, (5) the allocation of multiplex channels, and (6) the distribution of annunciator lights.

The fault levels are defined as: 
Table C-1. Fault Monitoring

$\bullet$ 


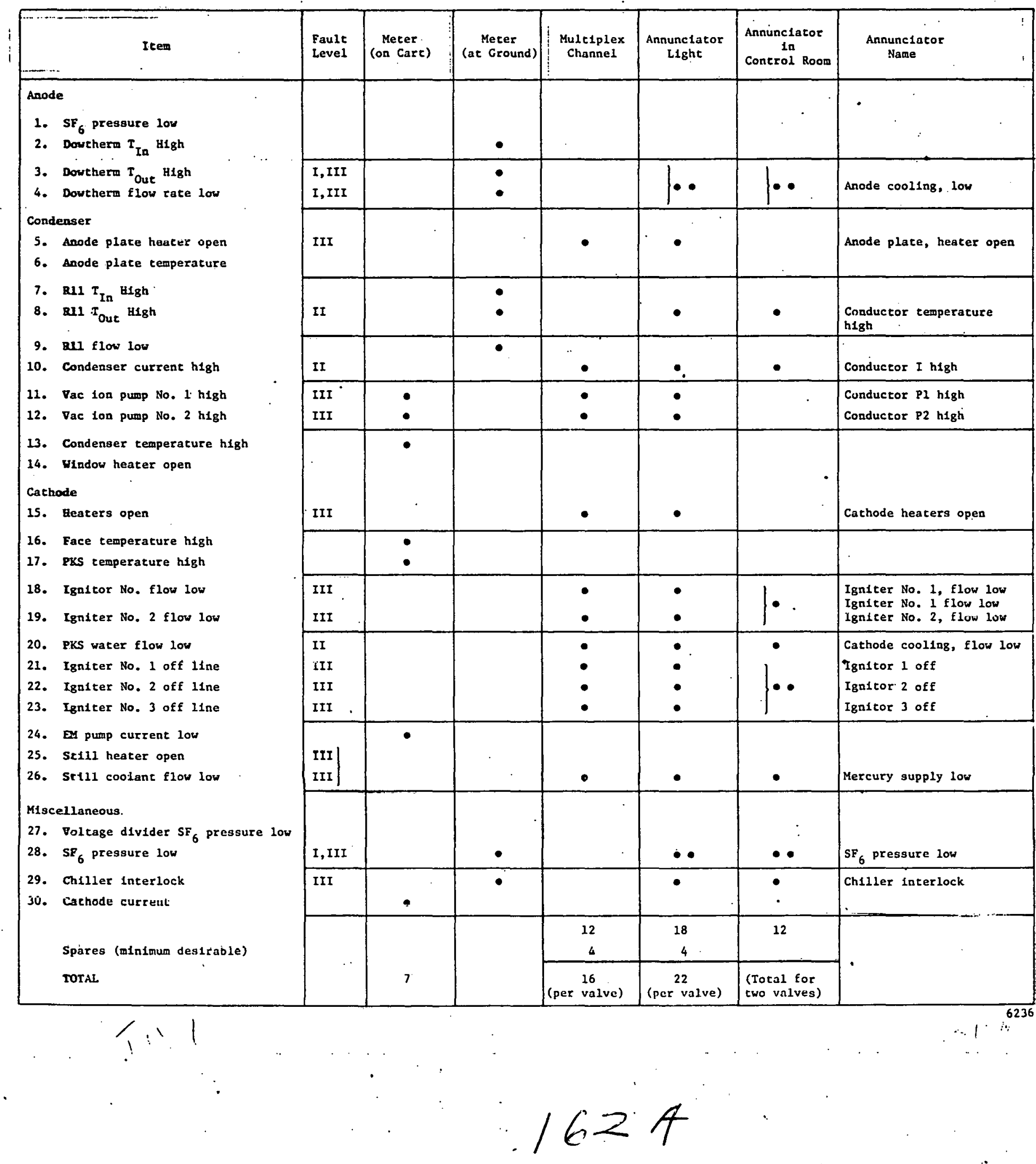


I - Mandatory shut down: when a Type I fault occurs, the valve group will be immediately diabled.

II - Conditional shut down: A Type II fault will inhibit the reset function subsequent to the next arc-back or any other group level fault. Existence of this fault also prevents initial group startup.

III - Annunciate only: A Type II fault will only cause an annunciator light to operate.

All three faults will cause the associated annunciator lights to flash and a common horn to sound. An acknowledge switch will be located on the front panel that will turn off the horn and cause the flashing fault lights to operate continuously. Override switches will be provided for each Type I and Type II channel. A common reset switch and an annunciator light test switch will also be provided.

Brief discussions of the philosophies of the various faults are presented below in the order in which they appear in Table $\mathrm{C}-1$.

1. We will operate the bushing, voltage divider, and pedestal at a common $\mathrm{SF}_{6}$ pressure of up to $30 \mathrm{psi}$. This pressure will be measured at ground potential, and fault monitoring is listed under Item 28 .

2. Dowtherm $\mathrm{T}_{\mathrm{In}}$ High. This will only be monitored by a meter on the Dowtherm system since all relevant information is included in the output temperature measurement.

3 and 4. The Dowtherm $T_{\text {Out }}$ and flow rate will each monitored at two levels and these will be combined to provide Type I and Type III fault indications. The Type III fault has been added to provide warning of an impending Type I situation.

5. An annunciator will be provided to indicate the condition of the anode plate heater.

6. The anode plate temperature meter on the cart has been eliminated because it is not considered useful.

7. Rll $\mathrm{T}_{\text {In }}$ High. Only a meter will be provided on the chiller system since all relevant fault information is contained in measurement of $\mathrm{T}_{\text {Out }}$ and flow rate. 


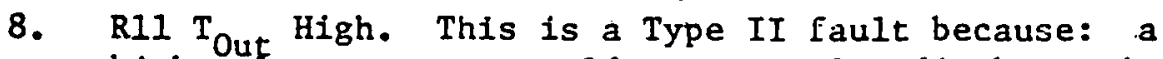
high valve pressure could cause a glow discharge in the bushing, thereby leading to reduced highvoltage standoff capability, and (b) experience with the Vac ion pump system has indicated a relatively. low reliability which means that dependence on direct pressure measurements may not be satisfactory.

9. RI1 Flow Low. Cessation of flow will only cause RII $T$ to increase, thereby resulting in a fault. Therefore, only a meter is provided on the chiller unit. Thermal isolation must exist between the RII output temperature sensor and the chiller to ensure that cessation of RII flow will cause the temperature to rise to a sufficient level to trigger the alarm.

10. Condenser Current High. This indicates faulty operation that may eventually lead to permanent valve damage. The condenser current should be averaged over two cycles to ensure that short-term fluctuations do not trigger the alarm.

11 and 12. Vac Ion Pump High. The two pumps have separate annunciators because we want to be able to sense high current operation in one when the other is shorted. High current will result in a Type III fault Type II was ruled out becauset there is a rather high probability of pump malfunction. The two pumps will be operated simultaneously.

13. Condenser Temperature High. One thermocouplc will be placed on the exterior condenser wall approximately midway between anode and cathode. A meter will be located on the cart front panel to provide data that can be compared with HRL results. Because of the sensitivity of this circuit, it will not be used as a fault sensor.

14. Window Heater Open. Once on the platform, it makes little difference whether or not this heater opens: : it would not lead to significant failure and nothing could be done about it.

15. Annunclation will be provided for an open cathode heater circuit.

16. Face Temperature High. A meter will be provided to obtain information comparable with HRL results.

17. Throat Temperature High. Same as No. 16.

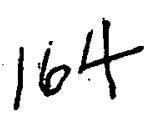


18. Igniter Flow Low. This will be indicated as a Type-III fault. Low coolant flow can quickly lead to Irrepairable damage to the igniter. A Type-I fault is too strong and a Type-II fault is inadequate since an arc back must occur before there can be a shutdown. Thus, a red fault light will simply be provided so that personnel can try to reset. If the fault persists,. then manual shutdown may follow.

19. Fault due to the importance of monitoring igniter conditions.

20. PKS Water Flow Low. Absence of water flow during operation could cause cracking of the cathode. An additional reason for making this a Type-II fault is to ensure that valve' startup cannot be undertaken without coolant flow.

21, 22, Igniter off Line. Same as 18 and 19. Provide two and 23. annunciator lights in the control room. One light labeled " 1 IGN OFF" will indicate when anyone of the six igniters is off line. The second light will come on when two igniters on a single valve are off line. This will be a red light to signify that the igniter power supply must be manually reset.

24. EM Pump Current Low. If the EM pump malfunctions, then the cathode will starve and either ignition will cease or a high current will be conducted to the condenser. Either will lead to faults more indicative of EM pump failure than a low EM pump current indication, which could be due to a failure in the fault sensor. A meter will be provided on the cart front panel to permit monitoring the current.

25 and 26. Still Heater Open/Still Coolant Flow Low. This is a Type III fault because it can eventually (several hours) lead to permanent damage to the EM pump. This condition can be verified by the presence of oscillations in the EM pump current that occur just as the pump runs dry and the damage process begins (there is time to: abort prior to suffering permanent damage). These two faults will be combined into one annunciator.

27. Voltage Divider $\mathrm{SF}_{6}$ Pressure Low. Same discussion as for №. 1 .

28. $\mathrm{SF}_{6}$ Pressure Low. The Type-III fault sensing is provided as a warning of a possible Type-I fault. The valve bushing, voltage divider, and pedestal will operate at the same $\mathrm{SF}_{6}$ pressure using a ground-based supply which connects to the cart through the pedestal.

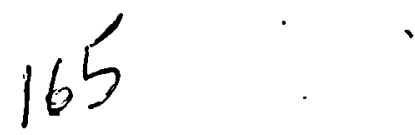


29. Chiller Interlock. This is presented as a Type-III fault because it can indicate an impending fault condi-.. tion that can be remedied.

30. Cathode Current. Meters will provide information on the average current being conducted by each valve during operation and processing.

There will be a single overall status light on the cart front panel. Where pilot lights are desirable, they should have narrow vlew angles: we will generally minimize the number of lights on the cart. At least one annunciator will be provided as a status. Indicator for the electronics. Opaque covers will be provided for lights that are always on due to malfunction. 
APPENDIX D

FIELD STRENGTH AND VIEW FACTOR CALCULATIONS FOR LMPV DESIGNS.

This appendix described some field strength and view factor calculations made for both the present LMPV and an alternative design in which some insulator shielding efficiency was sacrificed for lower field strength values. In searching for reduced field strength designs, it became apparent that there is a trade-off between minimum field strength and insulator shielding effectiveness. If future experiments show that the high degree of shielding present in the existing design is not required or that improved voltage breakdown capabilities are needed, then the calculations presented here could serve as a starting point for designs of this type. The preliminary alternate design presented here has the same cathode-anode geometry and outside diameter is the present design to facilitate comparing electric field strength values.

\section{A. FIELD STRENGTH CALCULATIONS}

These calculations were made using the Hughes version of the Stanford electron optics program. This program, which is used at HRL for the design of electron and ion sources and includes the effects of space charge and magnctic fields, is we1. suited to this Laplacian application. The program requires $280 \mathrm{~K}$ words on the IBM 370 , and program execution time is typically 15 to $20 \mathrm{sec}$ per problem. The program inputs are the electrode voltages and the special codes describing the boundary polnts; the program outputs are Calcomp plots of the boundary and equipotentials along with a tabulation of the electric field values at electrode surfaces.

Figure D-1 and D-2 show the result of one set of calculations made for both the present LMPV design and an alternate (non-optimized) design. The electric field strengths are shown in these figures at various positions on the anode and cathode surfaces and are for a total applied voltage of $465 \mathrm{kV}$. The present design has a maximum gradient of $\sim 255 \mathrm{kV} / \mathrm{cm}$ on the tubular anode support cylinder; the corresponding value on the 


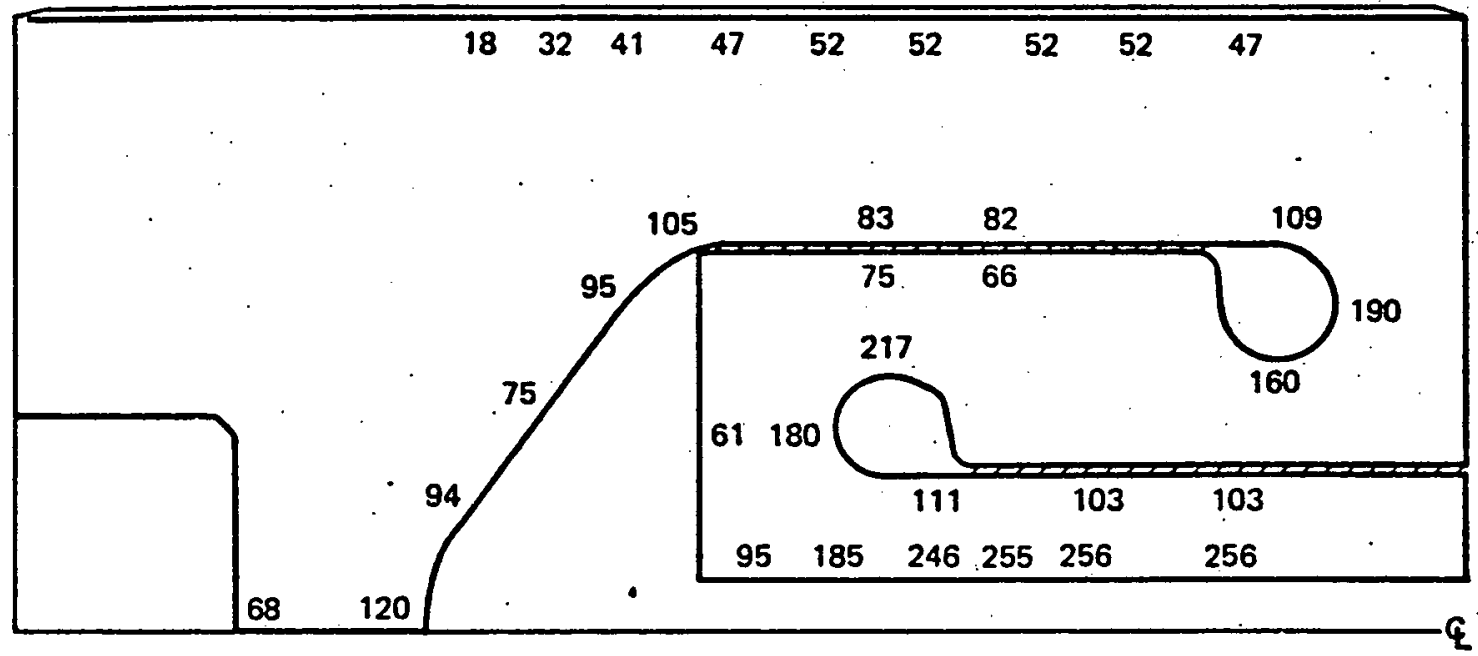

Figure D-1. Calculated electric field strength in $\mathrm{kV} / \mathrm{cm}$ at various $\therefore \because \therefore \quad$ cathode and anode locations for $\mathrm{V}_{\text {tot }}=465 \mathrm{kV}$ for present LMPV design.

$7578-14$

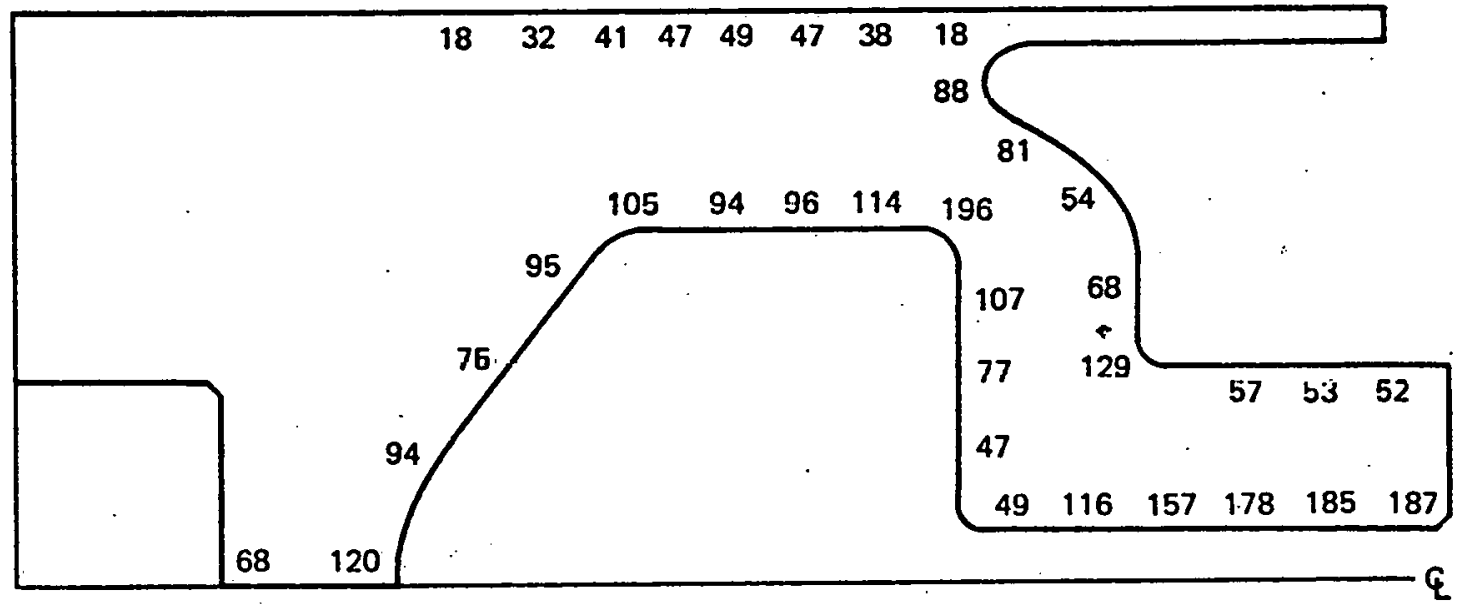

Figure D-?. Calculated electric field strengths in $\mathrm{kV} / \mathrm{cm}$ at various cathode and anode locations for $=46 \mathrm{j} \mathrm{kV}$ for altuliate LMPV design. 
alternate design is $187 \mathrm{kV} / \mathrm{cm}$. This is a reduction in maximum field strength of $\sim 25 \%$, which could be increased to $\sim 30 \%$ by increasing the inner tubular anode. support diameter of the alternate design to a value $1 / \mathrm{e}$ of the surrounding concentric cylinder. (This optimized ratio is already used on the present LMPV design.) It is estimated that a $50 \%$ field reduction could be obtained in the alternate design by increasing both cylinder radil and further reducing shielding efficienty. The example of such a design shown in Figure $D-2(a)$ is calculated to have a maximum gradient of $125 \mathrm{kV} / \mathrm{cm}$ at $465 \mathrm{kV}$. If, as is apparently the case, the present LMPV for this design would be to scale up the size (e.g., doubling all dimensions would hạlve the gradients).

\section{B. VIEW FACTOR CALCULATIONS}

As described above, the alternate LMPV design should provide improved voltage breakdown capability with a reduction in insulator shielding effectiveness. This reduction in shielding efficiency was estimated semi-quantitatively using a view factor analysis to calculate the number of particles striking the insulator end of the device from a source along the inside diameter of the cooled shroud which can see either the cathode or front anode surface. The upstream extent of this source was assumed to be determined by the line-of-sight from the cathode annulus grazing the outer anode surface (see Figures $D-3$ and $D-4$ ). The following additional simplifying assumptions were made in these view factor calculations :

- All: surfaces emit according to a cosine law.

- The source is a cold Hg surface at $-35^{\circ} \mathrm{C}$ with a condensation or sticking coefficient of one (i.e., all incident $\mathrm{Hg}$ atoms condense on first collision).

- The hot surfaces have a sticking coefficient of zeró so that all atoms re-evaporate from these surfaces on the first collisiun. 
The first assumption's primary justification 1s that without it the calculation could not be made. It permits us to use all the view factors worked out for radiant heat exchange (see Appendix A for further details on the properties and functional form for these quantities). The second and third assumptions follow from Wexler's review article on the deposition of atomic beams..$^{1}$ In using the latter assumption, we are implicitly assuming that super-thermal atoms have the same sticking coefficients as the thermal one. If this is not the case, we will, to a first approximation, be in error by the same scale factor for each geometry so that the results can still be compared.

From Figures. D-3 or D-4, the source for both geometries is about $29 \mathrm{~cm}$ long so. the area is $2 \pi(18)(29) \doteq 3300 \mathrm{~cm}^{2}$. At $-35^{\circ} \mathrm{C}$, the vapor pressure of $\mathrm{Hg}$ corresponds to an evaporation rate of about $10^{15}$ atoms $/ \mathrm{cm}^{2}-$ $s$, which corresponds to an equivalent $\mathrm{Hg}^{\circ}$ current density of $\sim 0.15 \mathrm{eq}$. $\mathrm{mA} / \mathrm{cm}^{2}$. The total $\mathrm{flux}$ of $\mathrm{Hg}$ atoms leaving surface 1 is therefore 0.15 x $3300 \doteq 500$ eq. mA. Figures $D-3$ and $D-4$ show how this flux is bounced around on the various secondary hot surfaces. The present IMPV design is clearly superior to the alternative design allowing only $\sim 1.5 \times 10^{-5} \mathrm{eq}$. $\mathrm{mA}$ to exit at the insulator end versus $\sim 0.7 \mathrm{eq} . \mathrm{mA}$ for the alternate design for a ratio of $\sim 5 \times 10^{4}$ between the two designs. Other calculations (not shown) using an annular rather than a cylindrical source produced a ratio of $\sim_{10}{ }^{3}$. Clearly, the use of the alternate design depends on the absolute value of the permitted efflux rather than any ratio. It is anticipated that future extended life tests of the present LMPV design w111 answer this quection. 


$$
E_{r}=\frac{\Delta v}{r \ln \left(\frac{r_{2}}{r_{1}}\right)}=\frac{465 \mathrm{kV}}{3.72(1)}=125 \mathrm{kV} / \mathrm{CM}
$$

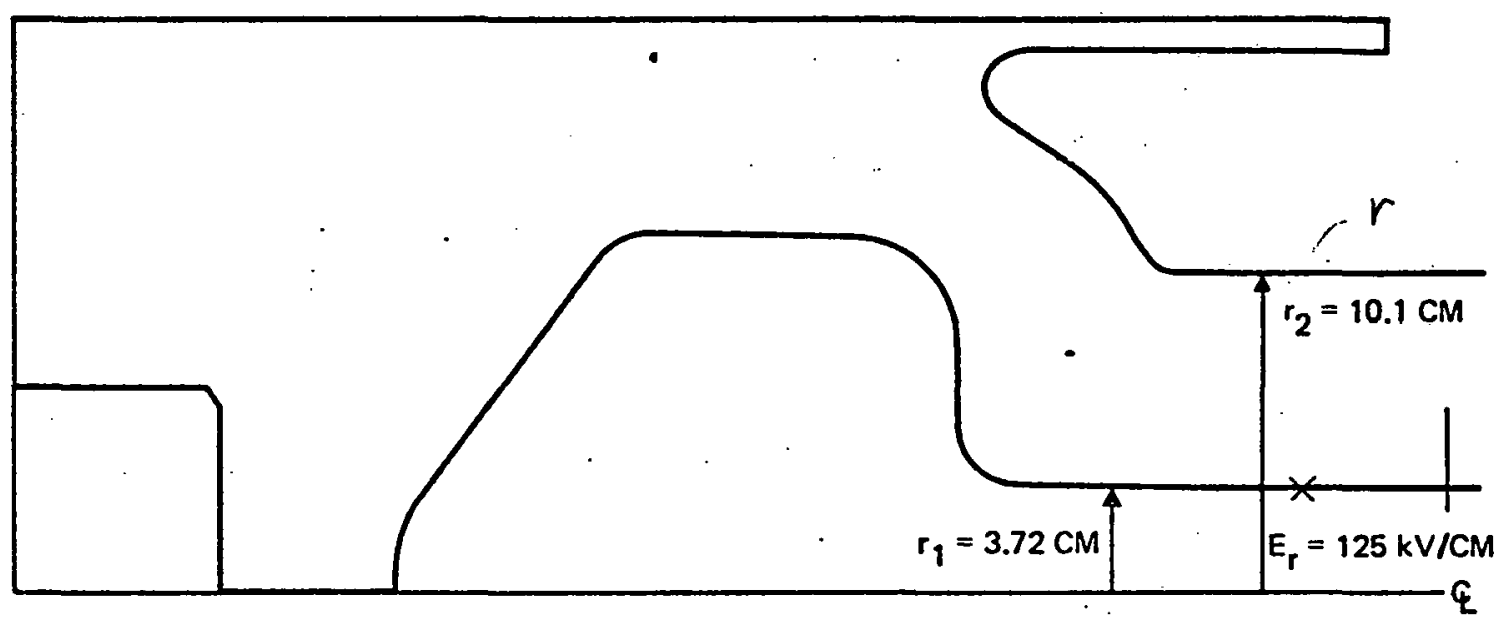

Figure 2(a). Modification of alternate design which is estimated to have maximum gradient of $125 \mathrm{kV} / \mathrm{cm}$, at $465 \mathrm{kV}$. 


$$
\begin{array}{ll}
F_{1,2}=0.056 & F_{4,6}=0.04 \\
F_{1,3}=0.007 & F_{5,6}=0.10 \\
F_{2,4}=0.019 & F_{6,7}=0.27 \\
F_{3,4}=0.12 & F_{7,8}=0.001 \\
F_{3,5}=0.044 &
\end{array}
$$

(1)

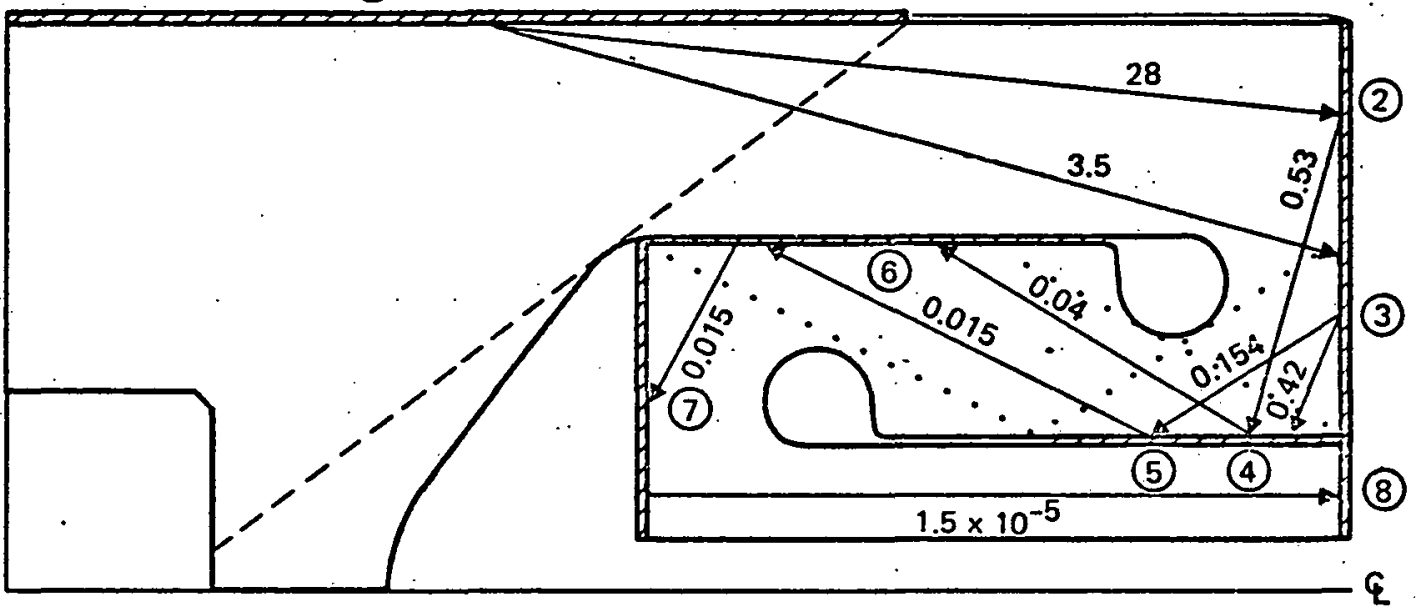

Figure 3. Calculated view factors and $\mathrm{Hg}^{\circ}$ fluxes for present LMPV geometry. Ratio of $\mathrm{Hg}$ flux arriving 


$$
\begin{aligned}
& F_{1,2}=0.057 \\
& F_{2,4}=0.18 \\
& F_{2,3}=0.096 \\
& F_{4,3}=0.25 \\
& F_{3,5}=0.17
\end{aligned}
$$
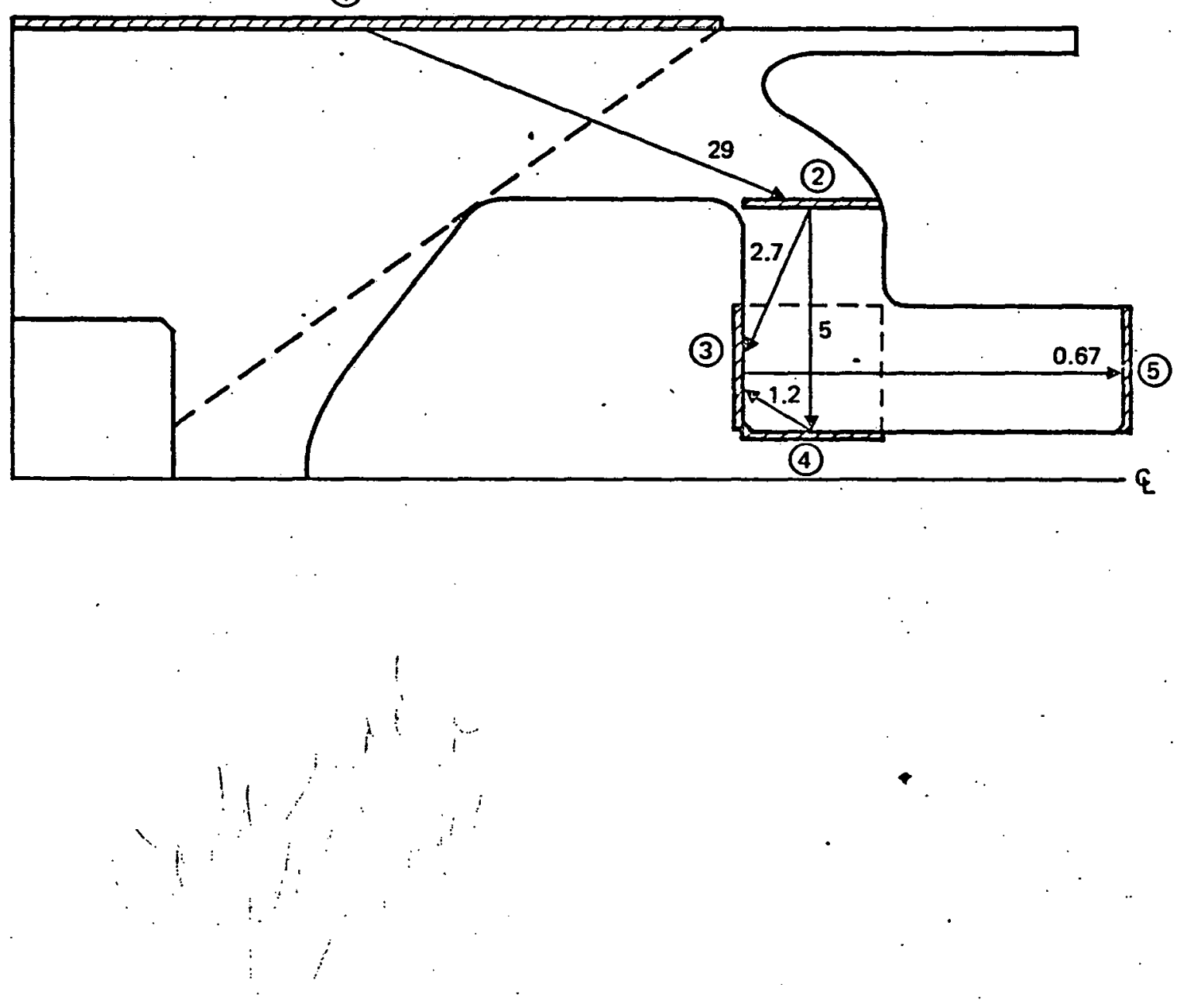


\section{THIS PAGE \\ WAS INTENTIONALLY \\ LEFT BLANK}




\section{APPENDIX E \\ MONITORING OF SYSTEM OPERATING CONDITIONS}

\section{A. GENERAL}

Appendix E includes an outline of the valve and group operating conditions to be monitored, and the criteria for automatic conditions to be monitored, and the criteria for automatic start-up of the transient recording apparatus. A summary functional description of the transient events recording system (TERS) is also presented. Detailed schematics and design and performance data on TERS are more fully characterized in the TERS manual, a supplement to this report.

B. SYSTEM OPERATING CONDITION STUDIES

The goal of these studies was to obtain valve and system characteristics when operating under service conditions. Valve positions SA and SC in Group I were selected as the valize positions: Figure E-I shows the valve group with these positions and the points at which current and voltage are monitored. Figure E-2 shows the normal valve currents. Figure E-3 shows the waveshapes of valve current following arc back. Figures E-.4 and E-5 compare the theoretical valve voltage waveshapes with the actual measured waveshapes, while Figure E- 6 shows the theoretical voltage waveshapes for large waveshapes: Table E-1 lists the expected $\mathrm{di} / \mathrm{dt}$ and $\mathrm{dv} / \mathrm{dt}$ conditions. The conditions for the automatic start-up of TERS are given in. Table E-2.

\section{c. SYSTEM MONITORING PACKAGE}

The monitoring station as installed consists of two major subsystems, the data terminal and transmitting subsystem (DTTS) and TERS. The integrated station records transient current and voltage information from the converter valve pair installed in positions SA and SC of Celilo

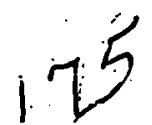




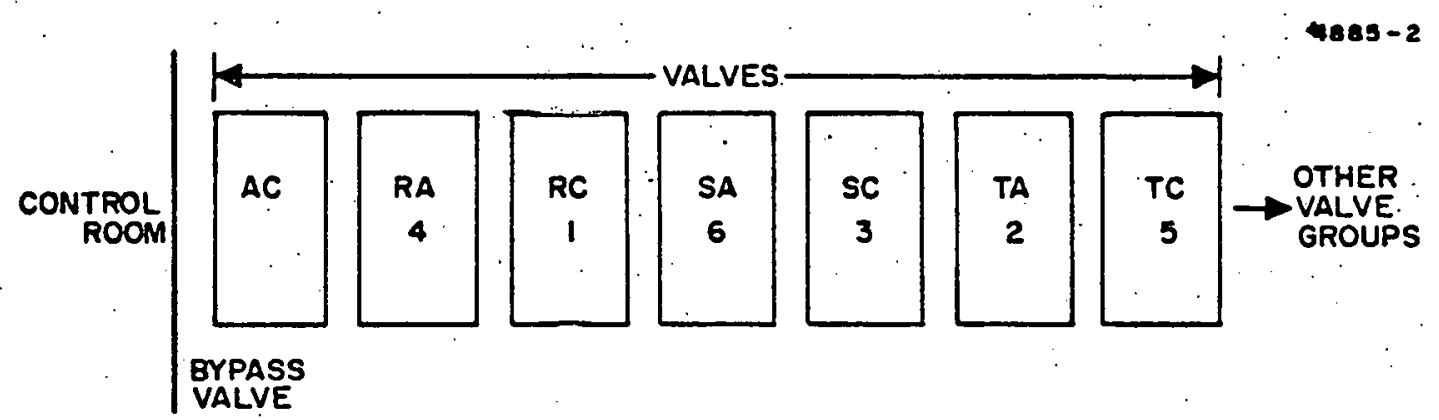

(0) LOCATION OF VALVES IN GROUP I

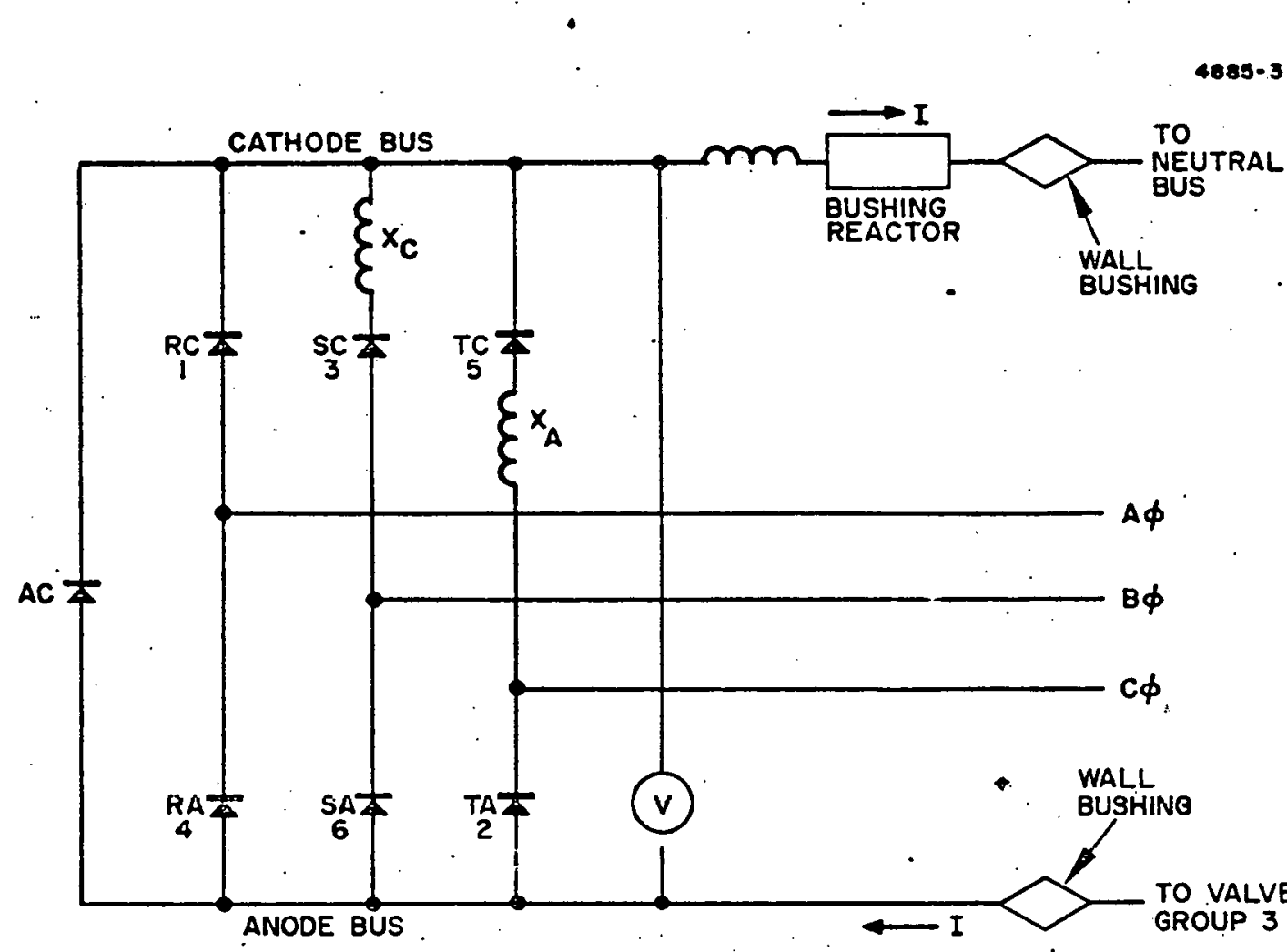

(b) CONNECTION DIAGRAM OF GROUP

Figure E-1. Layout of valves in group 1 . 

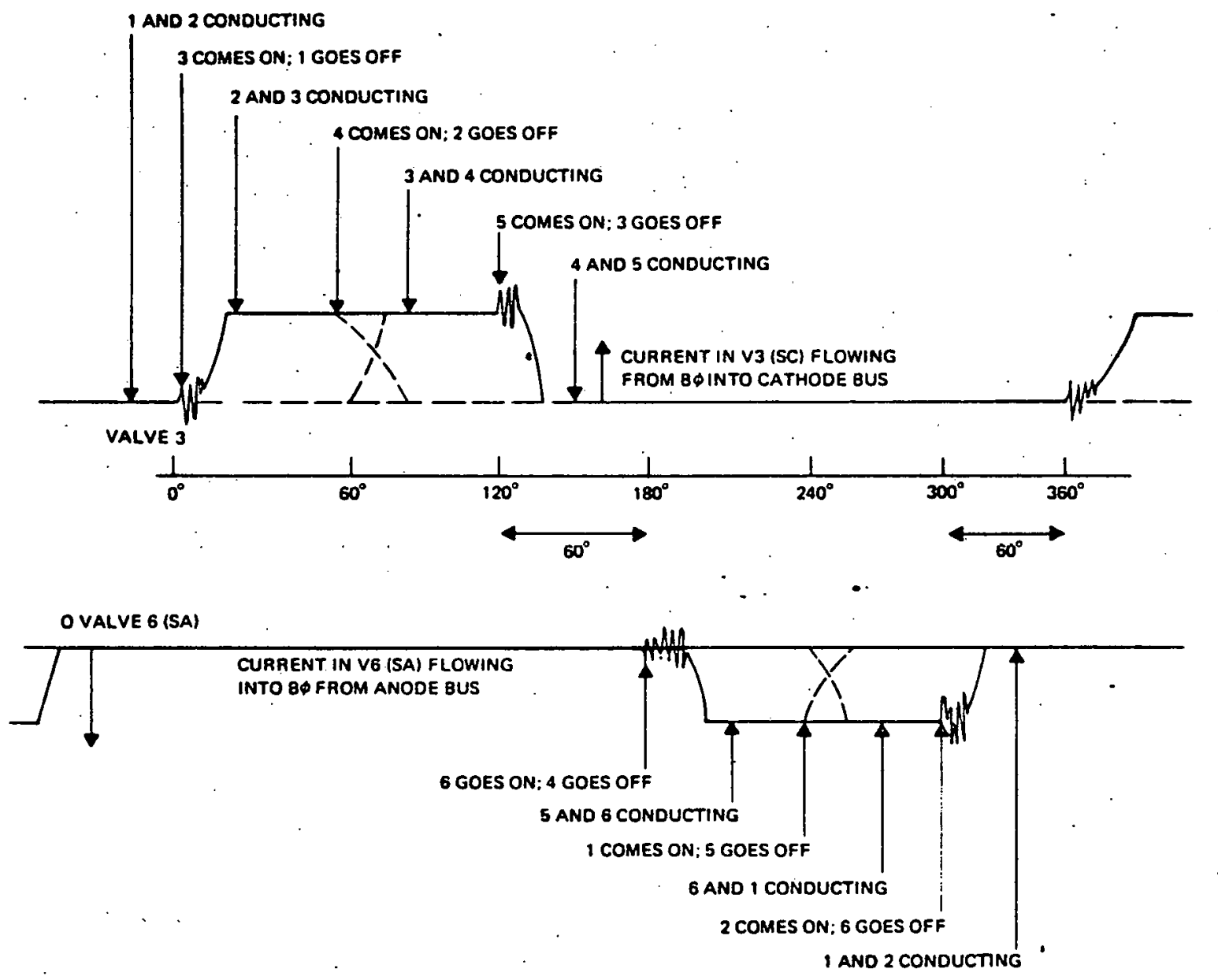

I ANO 2 CONDUCTING

Figure E-2. Normal valve currents - valves 3 (SC) and 6 (SA) Celilo in rectifier mode. 
VALVE 3 ARCBACK AFTER TURNOFr
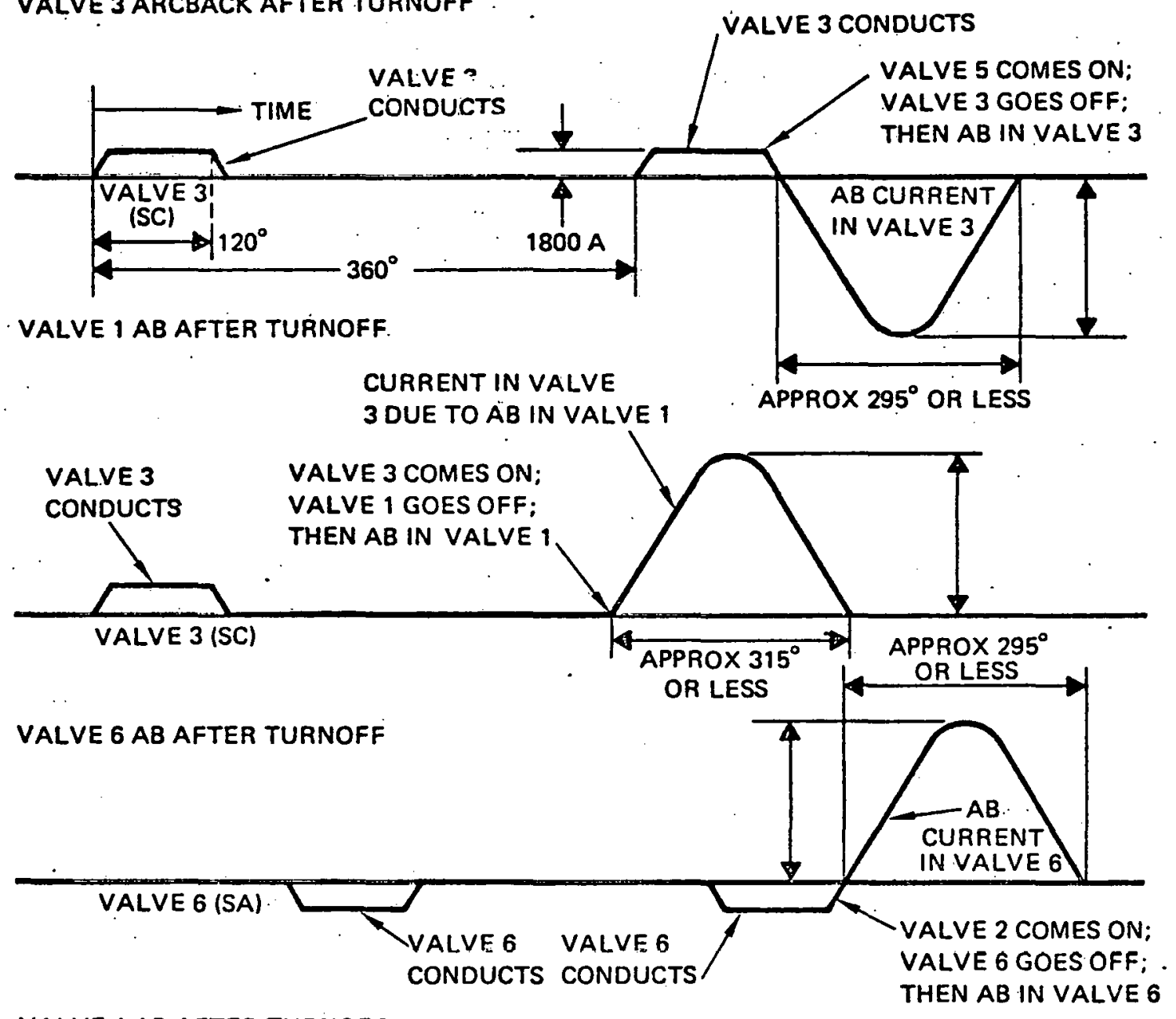

VALVE 4 AB AFTER TURNOFF

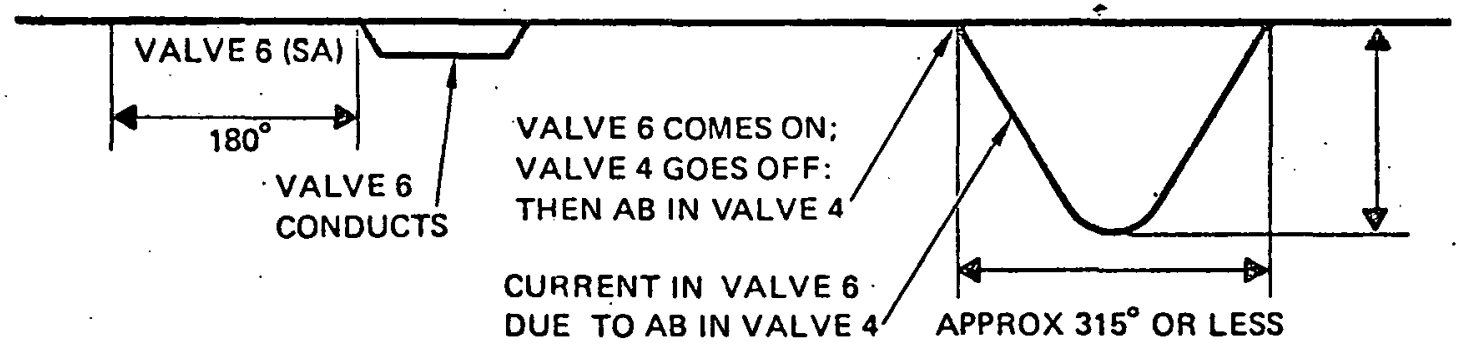

Figure E-3. Waveshapes of valve current following arc back. Celilo in rectifier mode. 


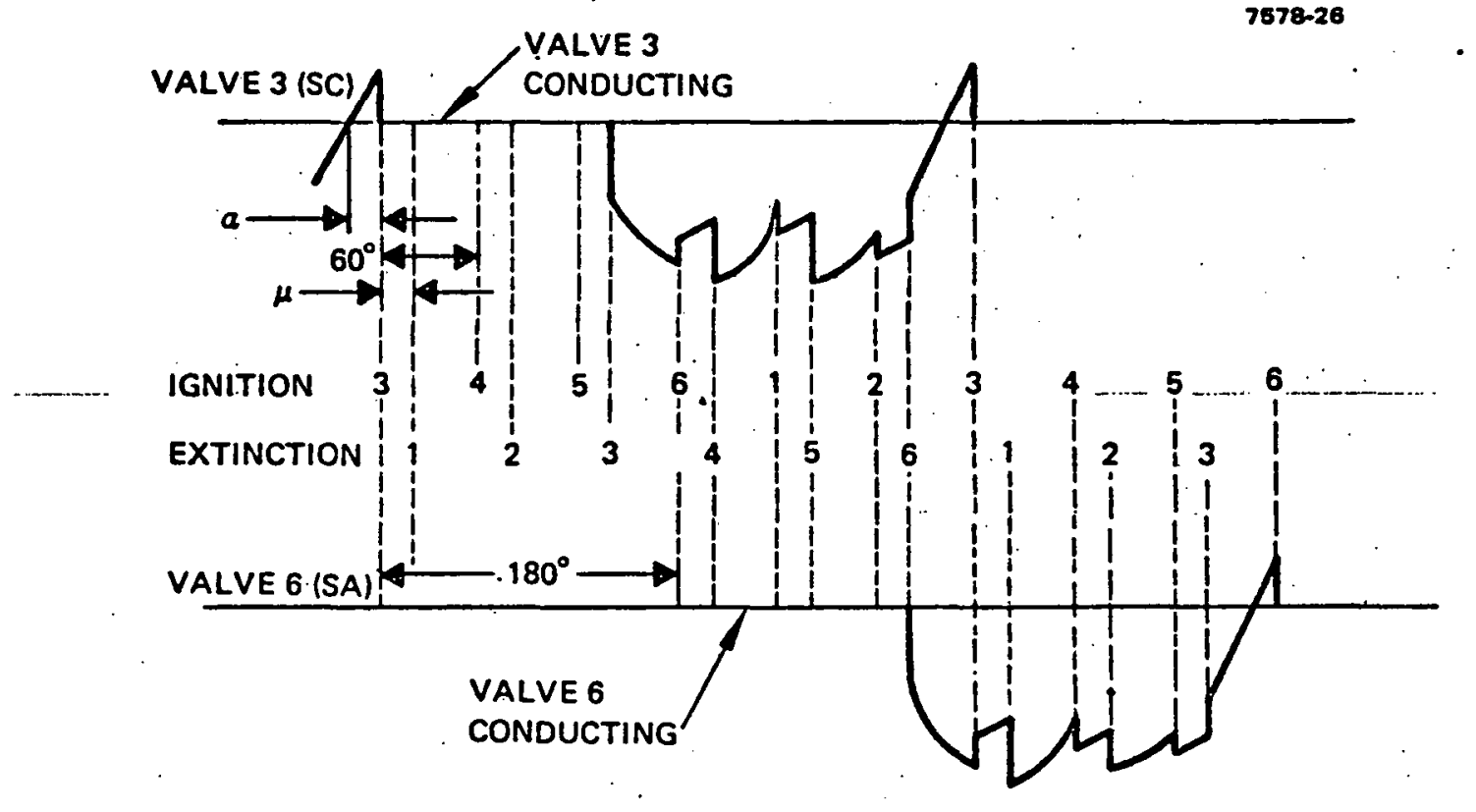

Figure E-4. Theoretical valve voltage waveshapes. Celilo in rectifier mode. 

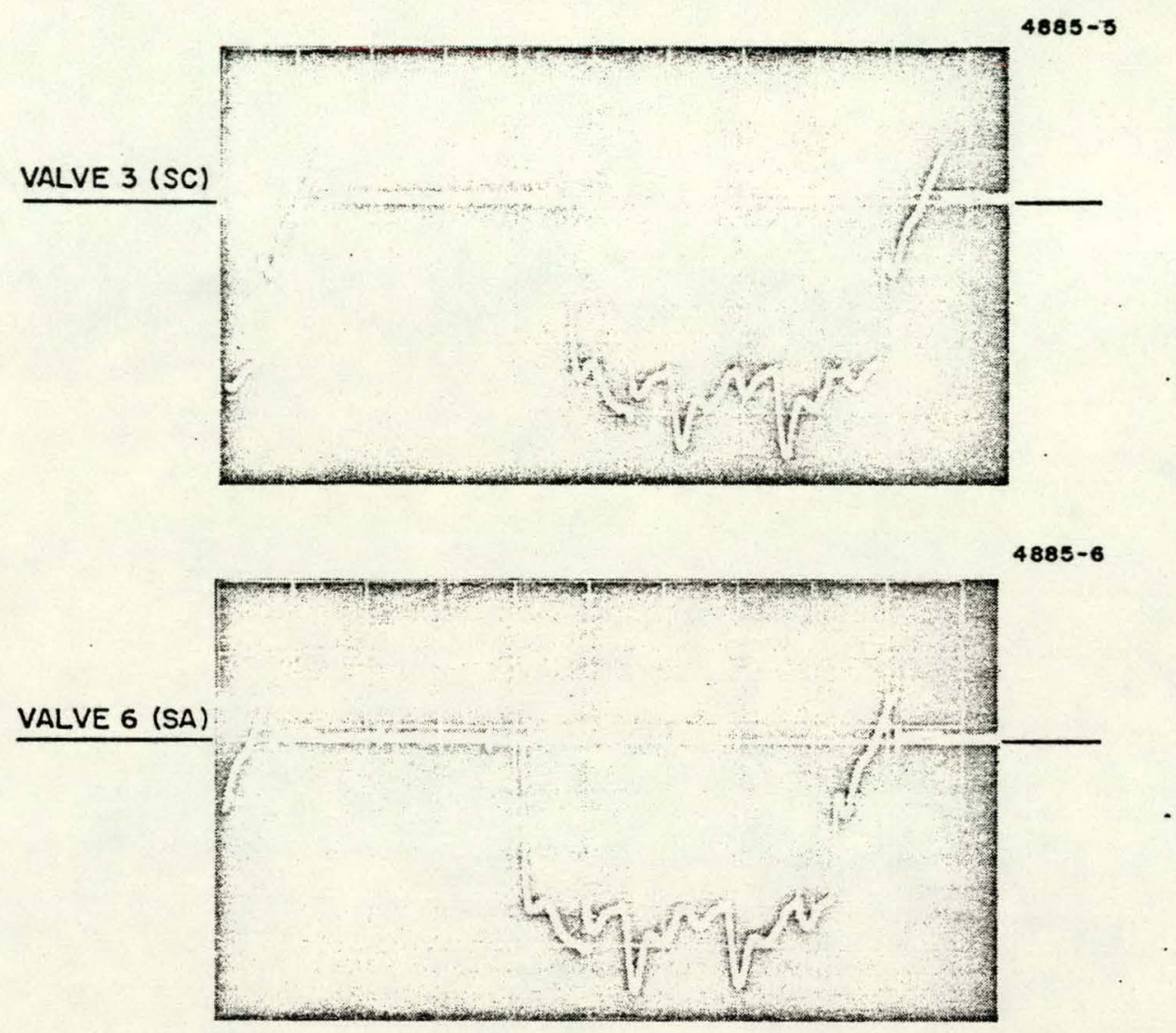

Figure E-5. Actual valve voltage waveshapes. Celilo in rectifier mode. 


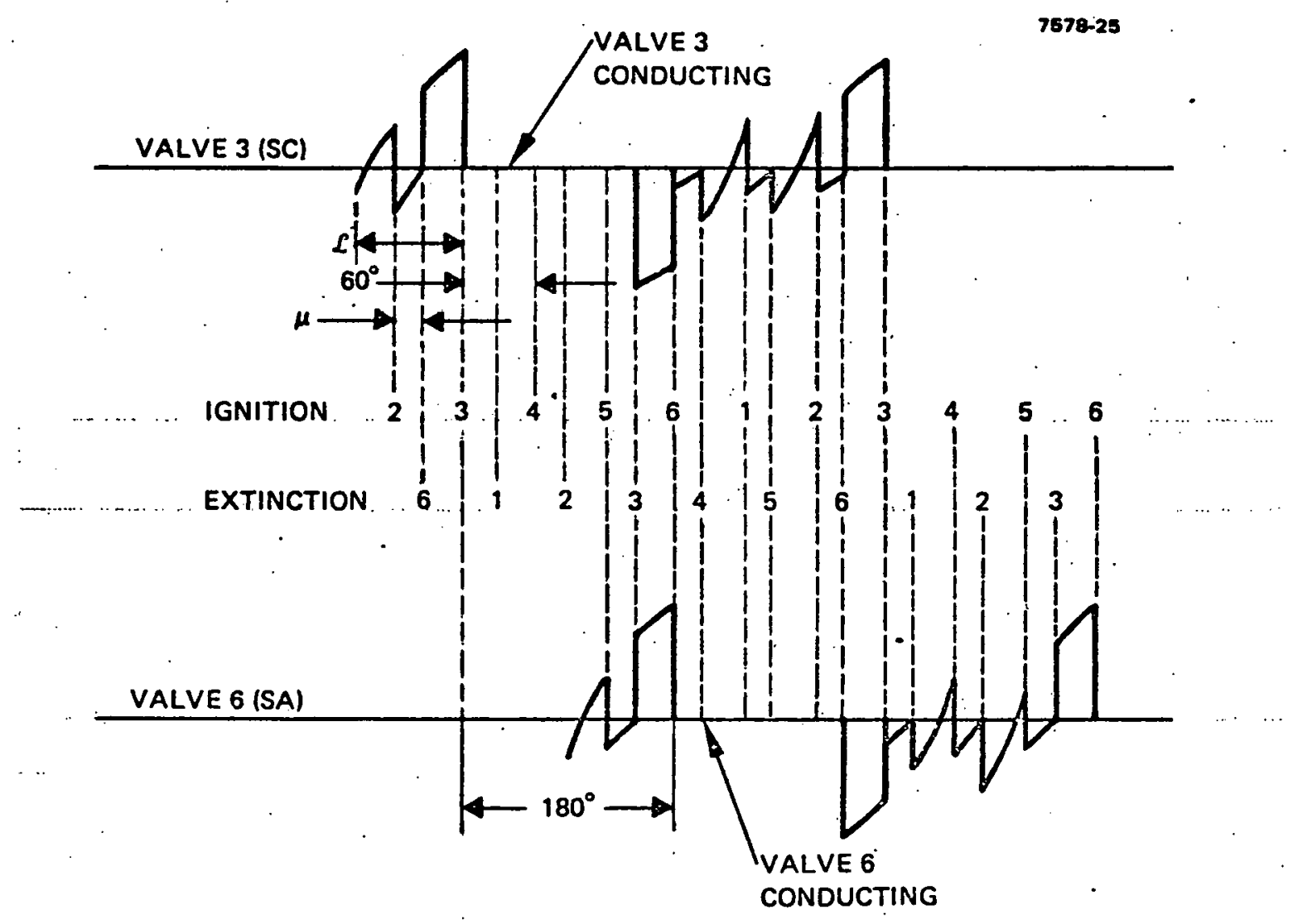

Figure E-6. Theoretical valve voltage waveshapes. Celilo in rectifier mode. 
Table E-1. Conditions for Automatic. Start of TERS

\section{Condition 1: Start TERS for temporary or permanent clock of valve group (VG) 1 . \\ Condition 2: Start TERS for temorary block of any pole 3 valve group (VG 1, 3, or 5). (Optional; conditions 1 and 2 would not be used at the same time.)}

Condition 3: Start TERS for permanent block of any pole 3 valve group. (VG 1, 3, or 5). (This will be used in conjunction with conditions $1,2,8$, or 9 when it is desired to start the TERS for a permanent block of any pole 3 valve group.)

Condition 4-1: Start TERS for restart, after temporary block, of VG 1.

Condition 4-3: Start TERS for restart, after temporary block, of VG 1 .

Condition 4-5: Start TERS for restart, after temporary block, of VG 5 .

(Condition 5 was eliminated.)

Condition 6: Start TERS for instantaneous commutation failure of VG 1.

Condition 7: Start TERS for instantaneous commutation failure of any pole 3 valve group (VG 1, 3, or 5). (Optional; conditions 6 and 7 would not be used at the same time.)

Condition 8: Start TERS for arc-back in VG 1 and subsequent temporary block of it. (Optional; this is used if condition 1 causes too many operations of TERS.)

Condition 9: Start TERS for arc-back and subsequent temporary block in any pole 3 valve group, (VG 1,3 , or 5). (Double option; would be used instead of conditions 1 or 8. )

Condition 10: Start TERS for permanent block of any pole 4 valve group (VG 2, 4, or 6).

Condition 11: Start TERS when fault to ground occurs on pole $3 \mathrm{dc}$ line; then, after fault has been cleared, start TERS again when dc line is re-energized. (The TERS will not start only when Celilo is a rectifier, not when it is operating as an inverter.) 
Converter Station Group I. Current and voltage information is also required from the dc bus associated with this group.

Bus and converter valve currents and voltages to $30 \mathrm{kA}$ peak and $350 \mathrm{kV}$ are monitored, with frequency response from dc to in excess of $100 \mathrm{kHz}$. System elements in the valve hall include the EMI-hardened. optical data links, the high-frequency current sensors, and the widebandcompensated voltage dividers. The voltage dividers, rated $465 \mathrm{kV} \mathrm{dc}$ and $650 \mathrm{kV}$ BIL, are free-standing structures mounted on insulated platforms. Current sensors and associated electronics and power supplies are installed in EMI-hardened enclosures, also mounted on support insulators. Valve hall equipment is coupled to the transient recorder in the control room by 130-m optical links. Major emphasis was afforded to assure design reliability and EMI and dielectric integrity.

Table E-2. Expected $d i / d t$ and $d v / d t$ Conditions

Normal Steady-State Conditions

$$
\begin{aligned}
& \alpha \approx 15^{\circ} \\
& \mathrm{di} / \mathrm{dt} \approx 1 \mathrm{~A} / \mu \mathrm{s} \\
& \mathrm{dv} / \mathrm{dt} \approx 1 \mathrm{kV} / \mu \mathrm{s}
\end{aligned}
$$

Normal Transient Conditions

Large $\alpha$, to give $\delta \approx 90^{\circ}$

$\mathrm{di} / \mathrm{dt} \approx 4 \mathrm{~A} / \mu \mathrm{s}$

$\mathrm{dv} / \mathrm{dt} \approx 2 \mathrm{kV} / \mu \mathrm{s}$

Partner Valve, Following Arc-back

$$
\begin{aligned}
& \alpha \approx 15^{\circ} \\
& \mathrm{di} / \mathrm{dt} \approx 1 \mathrm{~A} / \mu \mathrm{s} \\
& \mathrm{dv} / \mathrm{dt} \approx 1 \mathrm{kV} / \mathrm{\mu s}
\end{aligned}
$$

Large $\alpha$

$$
\begin{aligned}
& \mathrm{d} 1 / \mathrm{dt} \approx 4 \mathrm{~A} / \mu \mathrm{s} \\
& \mathrm{dv} / \mathrm{dt} \approx 2 \mathrm{kV} / \mathrm{\mu s}
\end{aligned}
$$


The transient recorder is an integrated six-channel data acquisition system. It consists of conditioning and sense electronics, a solid-state prefault buffer memory, and a wideband FM cartridge recorder/reproducer. An X-Y plotter, a time-of-day printer, a time coda generator, a.fast oscilloscope, and system control logic complete the major equipment complement.

A simplified block diagram of the installed monitoring station is given in Figure E-7. A block diagram of the wideband data link is given in Figure E-8. A photograph of the installed TERS unit appears as Figure E-9.

\section{START-UP TRIGGER INTERFACE}

TERS starts automatically for certain fault occurrences at Celilo that also now cause the Hathaway fault recorders to start.

The Hughes start condition isolation unit is installed within the control panel that houses the pole 3 Hathaway fault recorder. The isolation unit will be connected to the trigger unit of the transient event recording station by means of a multi-conductor cable. Within the isolation unit will be separate optical isolators, one for each start condition. All start conditions will be connected to the trigger unit, but not all will be used at any one time. The appropirate start conditions will be selected by switches on the front panel of the trigger unit.

In all cases except four, the start conditions (as outlined in Sertion B) are activated by relay contacts that stay closed for a specified time and then open. In these cases, the transient event recording station is started by the trigger unit when the contacts close. .

The other four cases are conditions 3, 5, and 11. In these cases, the start conditions are activated by more complex relay contact operations, which require special logic in the trigger unit.

Start conditions 1,3 , and $M-5$ operate from relay contacts which are normally closed when Celilo is in normal operation. The purpose of these start conditions is to automatically start the TERS when a valve group is restarted following a temporary block. When a temporary

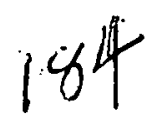


Valve Hall

vSC Current Installation Sensor

VSA Current Sensor

BR Current Sensor

SC Voltage

Sensor

SA Voltage

Sensor

BR Voltage

Sensor
Celilo Control

Room Installation

Optical Cable

Transmission

7 Channel Transient

Recorder and

Prefault Memory

Figure E-7. DOE monitoring station: simplified block diagram.

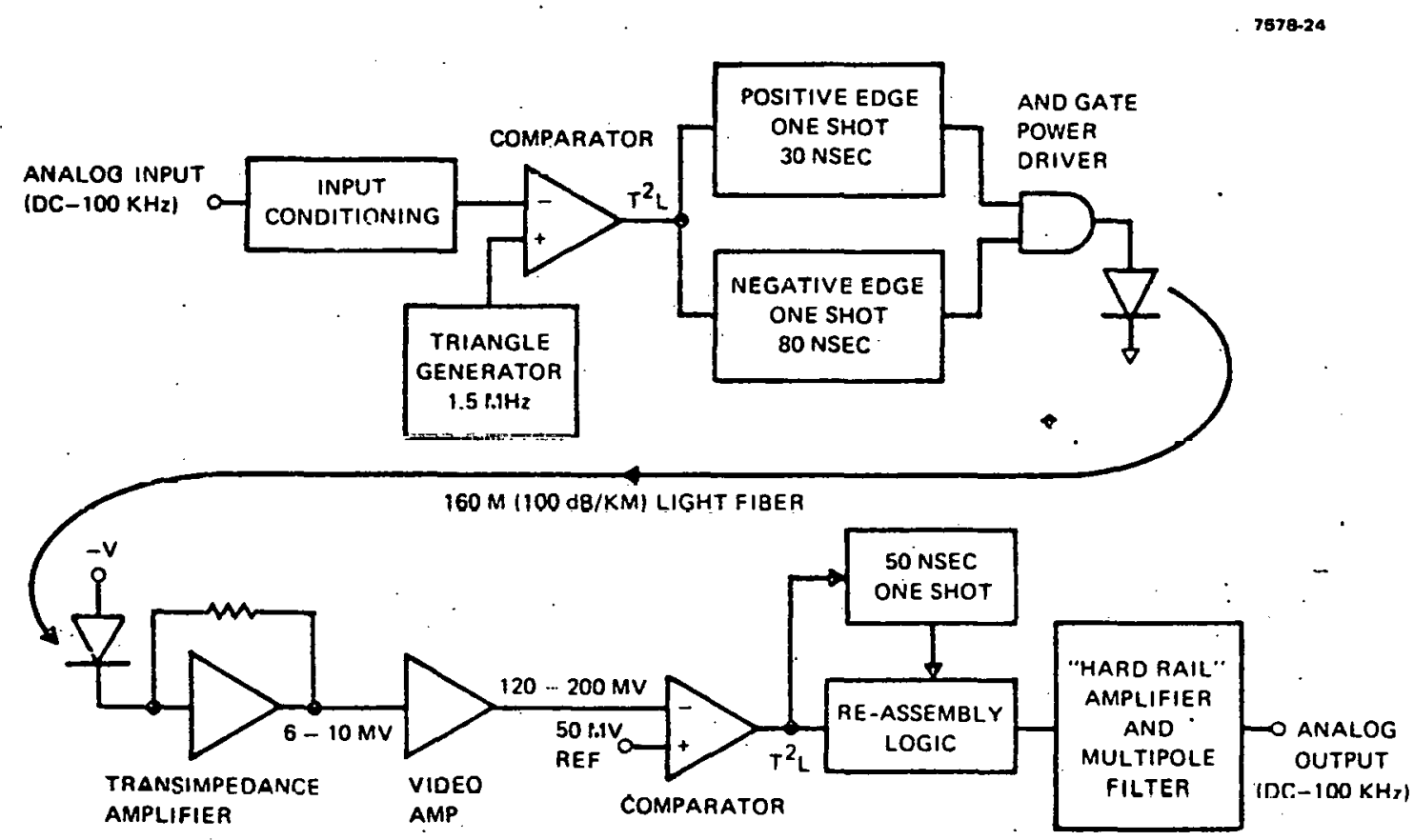

Figure E-8. High band data link.

Trigger

Signals

Other Station Inputs 


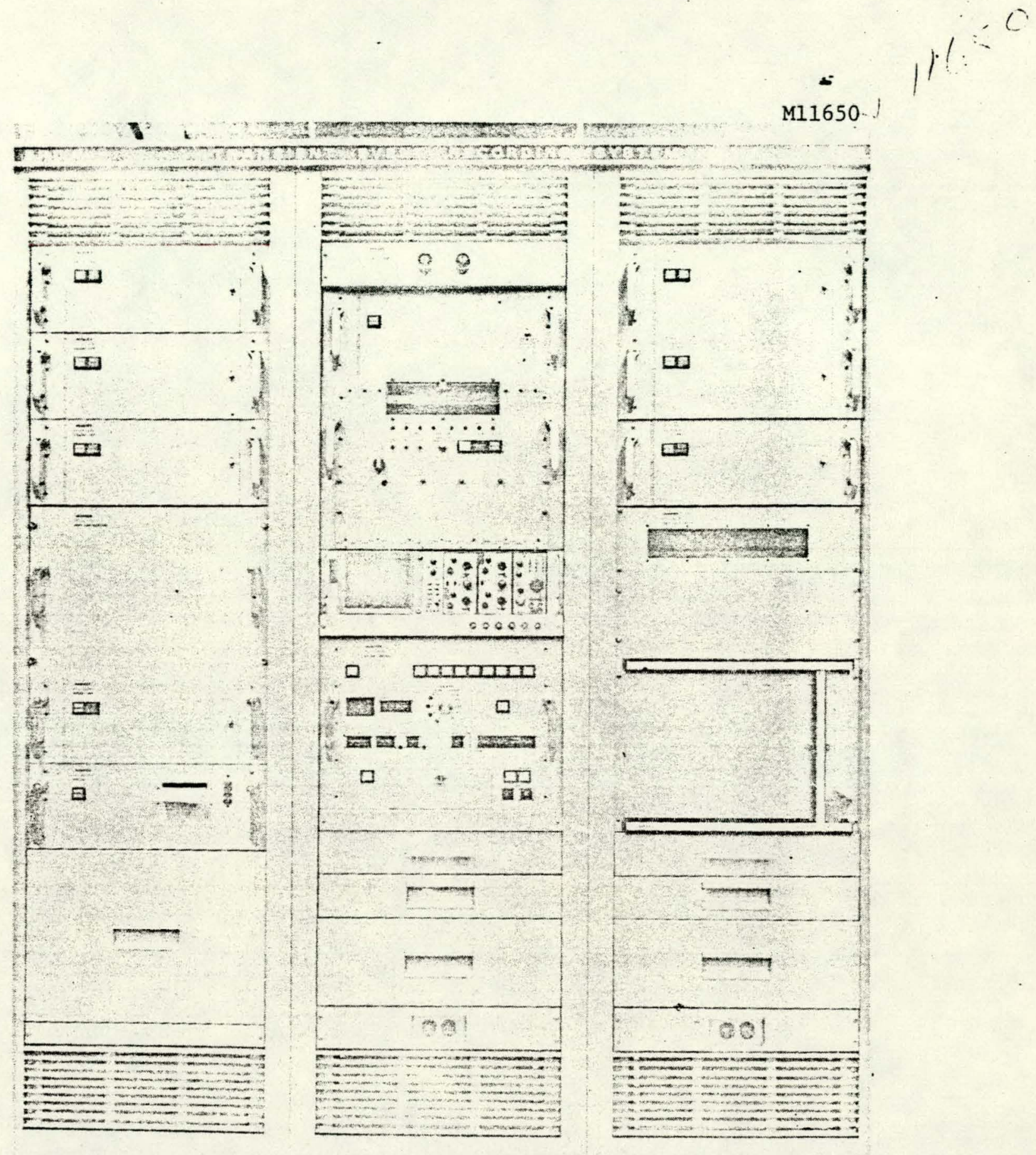

Enerr.

Figure E-9. Transient event recorder. 
block occurs, the normally closed contacts will open, but : the transient event recorder is not to be started. After a time delay of either $40 \mathrm{~ms}$ or $0.8 \mathrm{~s}$, the temporary block will be. removed, and the valve group will be returned to service. The transient event recorder will-then start and begin recording conditions as the valve group is returned to service. The contact reclosure is to initiate automatic start of the transient event recorder.

In the fourth case, number 11, that contact is normally open and will close when a fault occurs on the dc line to ground. This contact closure is to start the transient event recorder to record conditions as line fault protection is activated. Then later, after protection has cuased the fault to be cleared, the contact reopens and the line is reenergized. The transient event recorder again must be automatically started as the system is re-energized.

To summarize, the relay contact starts in the open position, then closes and stays closed for some time. Then. the contact reopens as the system is re-energized. The transient event recorder is to automatically start when the contact closes and also sometime later as the contact re-opens.

E. TERS SYSTEM RESPONSE MEASUREMENT

The overall response of TERS was measured. Each of the subsystems were tested for

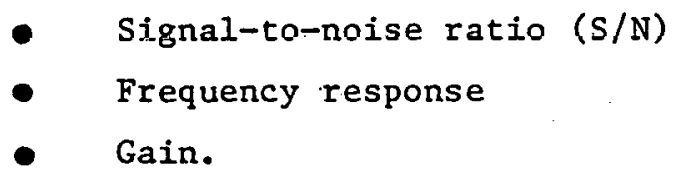

The whole system (i.e., input to light link transmitter; through the data links and TERS (into memory through recorder, back through memroy and out)) was then tested. No tests were done on the sensors themselves because these had been previously calibrated. The instruments used were 
- Ballantine True rms voltmeter (Model No. 323-06)

- Tektronix 7603 oscilloscope built into system 4-channe1

- Tektronix dual-beam oscilloscope (Model No. 502A)

- Tektronix storage scope (Model 564)

- Spectrum analyzer plug-in (Model 3L5)

- Cushman Electric. Loadmaster, selective voltmeter (Mode1 No. CE-24A)

- Krohnhite function generator Model No. 5400 B.

Figure E-10 is a block diagram of the system. The specified bandwidths of individual subsystems are

- Light 1inks:

- Memory:

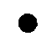

- Tape Recorder:

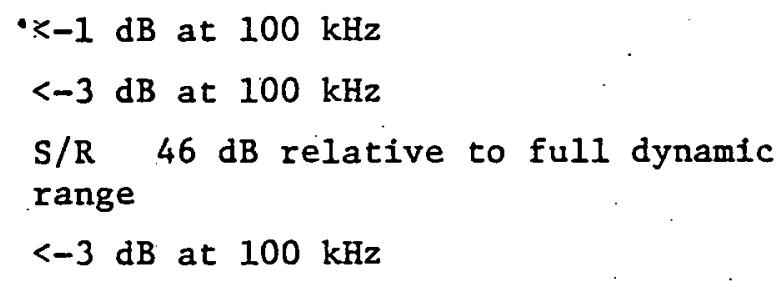

The approximate attenuation through the entire system (i.e., light links to memory, memory to tape recorder, tape recorder through memory and out) is $-10 \mathrm{~dB}$ at $100 \mathrm{kHz}$.

\section{Noise Measurements}

The input to the transmitter shorted. The output of the receiver was read at patch panel using a Ballantine Model 323-06 true rms voltmeter. The results are given below. Noise refers to full dynamic range

\begin{tabular}{|c|c|c|c|c|}
\hline $\begin{array}{c}\text { Channel } \\
\text { Number }\end{array}$ & $\begin{array}{c}\text { rms Noise, } \\
\text { Low Gain, } \\
\mathrm{mV}\end{array}$ & $\mathrm{dB}$ & $\begin{array}{c}\text { rms Noise, } \\
\text { High Gain, } \\
\mathrm{mV}\end{array}$ & $\mathrm{dB}$ \\
\hline 1 & 0.8 & -73 & 4.8 & -57.4 \\
3 & 3.4 to 4.2 & -60.4 to -58.5 & 3.8 to 4.2 & -59.4 to -58.5 \\
\hline
\end{tabular}




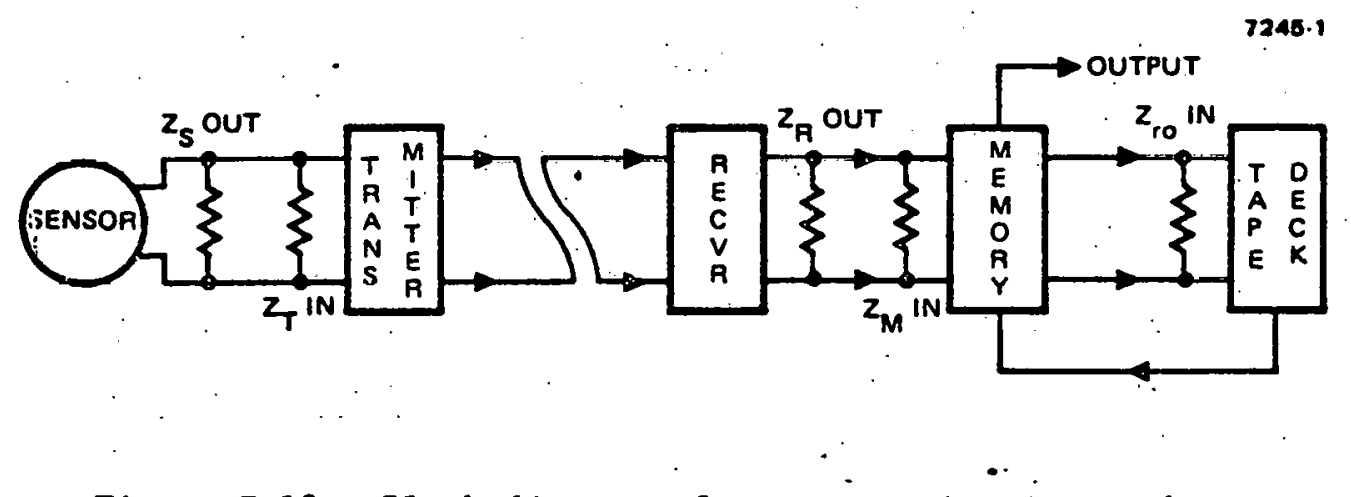

Figure E-10. Block diagram of system monitoring package. 
of $10 \mathrm{~V}$ peak to peak. $(\mathrm{p}-\mathrm{p})$ or $3.54 \mathrm{~V}$ rms. The $\mathrm{S} / \mathrm{N}$ (rms signal to rms noise) is $55 \mathrm{~dB}$ or better.

One channel of memory was measured. Noise (measured on a 502 A scope) : was $10 \mathrm{mV}$ peak to $10 \mathrm{~V} \mathrm{p}-\mathrm{p}$, yielding an $\mathrm{s} / \mathrm{N}$ of $60 \mathrm{~dB}$.

Noise through the transmitter, receiver, and memory was measured. A $10 / 1$ probe was used, with the memory set in $500 \mathrm{kHz}$ clock position. The recelver was set on a high gain. An $\mathrm{S} / \mathrm{N}$ of $34 \mathrm{~dB}$ was measured. This test was repeated with the receiver set for low gain; the result was an $\mathrm{S} / \mathrm{N}$ of $35 \mathrm{~dB}$. .

By using degaussed tape and shorting the input of each channel being checked we measured the following:

\begin{tabular}{|c|c|c|c|c|}
\hline \multicolumn{2}{|c|}{$\begin{array}{c}\text { Tape Recorder } \\
\text { Made }\end{array}$} & $\begin{array}{l}\text { Channel } \\
\text { Number }\end{array}$ & $\begin{array}{c}\text { rms Voltage, } \\
\text { mV }\end{array}$ & $\mathrm{dB}$ \\
\hline \multicolumn{2}{|l|}{ Record } & $\begin{array}{c}1 \\
2 \\
3 \\
4 \\
5 \\
6 \\
7 \\
\text { Average }\end{array}$ & $\begin{array}{l}71 \\
74 \\
67 \\
72 \\
71 \\
84 \\
67\end{array}$ & $\begin{array}{l}-34 \\
-33.7 \\
-34.5 \\
-33.9 \\
-34 \\
-32.6 \\
-34.5 \\
-33.9\end{array}$ \\
\hline \multicolumn{2}{|l|}{ Read } & $\begin{array}{c}1 \\
2 \\
3 \\
4 \\
5 \\
6 \\
7 \\
\text { Average }\end{array}$ & $\begin{array}{l}75 \\
77 \\
72 \\
71 \\
69 \\
82 \\
66\end{array}$ & $\begin{array}{l}-33.5 \\
-32.25 \\
-33.8 \\
-34 \\
-34.2 \\
-32.7 \\
-34.6 \\
-33.6\end{array}$ \\
\hline \multicolumn{5}{|c|}{$\begin{array}{l}\text { Note: Noise measurement is based on maximum } \\
\text { rms signal to rms noise. RMS volt- } \\
\text { ages were read using an HP } 400 \text { EL. }\end{array}$} \\
\hline
\end{tabular}


2. Bandwidth

a. Light Links

\begin{tabular}{|c|c|c|c|c|c|}
\hline $\begin{array}{l}\text { Channel } \\
\text { Number }\end{array}$ & $\begin{array}{l}\text { Frequency, } \\
\quad \mathrm{kHz}\end{array}$ & $\begin{array}{c}\text { RMS Voltage, } \\
\text { Low Gain }\end{array}$ & $\mathrm{dB}$ & $\begin{array}{l}\text { RMS Voltage, } \\
\text { High Gain }\end{array}$ & $\mathrm{dB}$ \\
\hline $\begin{array}{c}I=I_{S A} \\
\vdots\end{array}$ & $\begin{array}{r}20 \\
100 \\
150 \\
210 \\
230\end{array}$ & $\begin{array}{l}3.50 \\
3.04 \\
2.55 \\
1.98 \\
1.84\end{array}$ & $\begin{array}{l}-0.09 \\
-1.32 \\
-2.86 \\
-5.05 \\
-5.68\end{array}$ & $\begin{array}{l}3.50 \\
2.90 \\
2.33 \\
1.70 \\
1.52\end{array}$ & $\begin{array}{l}-0.09 \\
-1.73 \\
-3.63 \\
-6.37 \\
-7.34\end{array}$ \\
\hline $2=I_{S C}$ & $\begin{array}{r}20 \\
80 \\
150 \\
210\end{array}$ & $\begin{array}{r}3.50 \\
3.18 \\
2.55 \\
-1.98 \\
\end{array}$ & $\begin{array}{l}-0.09 \\
-0.92 \\
-2.86 \\
-5.1\end{array}$ & $\begin{array}{l}3.50 \\
3.08 \\
2.33 \\
1.70\end{array}$ & $\begin{array}{l}-0.09 \\
-1.21 \\
-3.63 \\
-6.4\end{array}$ \\
\hline $3=I_{V G}$ & $\begin{array}{r}50 \\
--100 \\
150 \\
230\end{array}$ & $\begin{array}{r}3.39 \\
3.08 \\
2.62 \\
1.84\end{array}$ & $\begin{array}{l}-0.36 \\
-1.21 \\
-2.63 \\
-5.7\end{array}$ & $\begin{array}{l}3.36 \\
2.97 \\
2.40 \\
i .73\end{array}$ & $\begin{array}{l}-0.52 \\
-1.52 \\
-3.36 \\
-6.2\end{array}$ \\
\hline $4^{b}=V_{S A}$ & $\begin{array}{r}50 \\
100 \\
150 \\
230\end{array}$ & $\begin{array}{l}1.34 \\
1.20 \\
1.03 \\
0.74\end{array}$ & $\begin{array}{l}-0.44 \\
-1.4 \\
-2.73 \\
-5.6\end{array}$ & $\begin{array}{l}3.39 \\
2.97 \\
2.55 \\
1.84\end{array}$ & $\begin{array}{l}-0.36 \\
-1.52 \\
-2.86 \\
-5.68\end{array}$ \\
\hline $5^{b}=v_{S C}$ & $\begin{array}{r}80 \\
150 \\
210 \\
230\end{array}$ & $\begin{array}{l}1.27^{-} \\
1.0 \\
0.81 \\
0.71\end{array}$ & $\begin{array}{l}-0.91 \\
-3.0 \\
-4.84 \\
-5.98\end{array}$ & $\begin{array}{l}3.64 \\
2.69 \\
1.98\end{array}$ & $\begin{array}{l}-1.03 \\
-3.66 \\
-6.3\end{array}$ \\
\hline $6^{b}=V_{G 1}$ & $\begin{array}{r}80 \\
1.50 \\
240\end{array}$ & $\begin{array}{l}1.34 \\
1.03 \\
0.71\end{array}$ & $\begin{array}{l}-0.44 \\
-2.73 \\
-6\end{array}$ & $c^{+}$ & c \\
\hline
\end{tabular}

$a_{3.50}=0 \cdot d B$.

b Summarize bandwidth of light links:

- The low gain amplifier position is $-3 \mathrm{~dB}$ at $150 \mathrm{kHz}$ plus.

- The high gain amplifier position is $3.5 \mathrm{~dB}$ at $150 \mathrm{kHz}$.

- The $6 \mathrm{~dB}$ point is at $230 \mathrm{kHz}$ for the high gain position and at $240 \mathrm{kHz}$ for low gain position.

$\mathrm{c}_{\text {Ref }}=4.1 \mathrm{~V} \mathrm{rms}=0 \mathrm{~dB}$. 


\section{b. Memory: Bandwidth}

The signal is fed into memory input at patch panel and read at output of memory at patch panel. The signal is a sine wave $10 \mathrm{~V} \mathrm{p}-\mathrm{p}$ fed from a Krohnhite function generator (Model 5400B). Test made on one channel only.

\begin{tabular}{|c|c|c|c|}
\hline $\begin{array}{c}\text { Frequency, } \\
\mathrm{kHz}\end{array}$ & $\begin{array}{c}\text { Voltage } \\
\text { Out, p-p, }\end{array}$ & $\begin{array}{c}\text { Voltage } \\
\text { Converted } \\
\text { to RMS; V }\end{array}$ & $\begin{array}{c}\mathrm{dB} \\
\text { Down }\end{array}$ \\
\hline 0.1 & 10 & 3.56 & 0 \\
20 & $10 \cdot$ & $3.56(-)$ & $0(-)$ \\
50 & 8.8 & 3.11 & -1.17 \\
80 & 6.8 & 2.41 & -3.39 \\
95 & 5.6 & 1.98 & -5.1 \\
\hline
\end{tabular}

Feeding a 1-kHz square wave from the Krohnhite function generator $10 \mathrm{~V} \mathrm{p}-\mathrm{p}$ into the memory output read on a 7603 oscilloscope reads $9.6 \mathrm{~V}$ p-p, down $0.36 \mathrm{~dB}$ (see Figure E-11); sweep speed was $200 \mathrm{~s} / \mathrm{cm}$. Rise time of output square wave was approximately. $20 \mathrm{~s}$. There is no noticeable distortion in the picture.

F'eeding a 10-kHz square wave tnto the input of the memory, $10 \mathrm{~V}$ $p-p$, and reading the output on the 7603 oscilloscope, with a sweep speed of $20 \mathrm{~s} / \mathrm{cm}$ output $=9.6 \mathrm{~V}(+) \mathrm{P}$ to $\mathrm{P}$, gives the waveform shown in Figure E-12 Rise time is $7 \mathrm{~s}$, with the top $40 \mathrm{~s}$. A small oscillation appears $24 \mathrm{~s}$ along the top of the wave (to right of start of flattop) approximately $0.7 \mathrm{~V} \mathrm{p}-\mathrm{p}$.

\section{c. Bandwidth of Tape Recorder}

A signal in equal to $3.55 \mathrm{~V}$ rms, read $\mathrm{p}-\mathrm{p}$ on an oscilloscope and converted to rms, yiclds the results shown below. 


\begin{tabular}{|c|c|c|}
\hline $\begin{array}{c}\text { Channe1 } \\
\text { Number }\end{array}$ & $\begin{array}{c}\text { Frequency, } \\
\mathrm{kHz}\end{array}$ & $\begin{array}{c}\mathrm{dB} \\
\text { Down }\end{array}$ \\
\hline 1 & 100 & -3.12 \\
2 & 100 & -2.88 \\
3 & 100 & -2.88 \\
4 & 100 & -2.88 \\
5 & 100 & -2.77 \\
6 & 100 & -2.77 \\
7 & 100 & -2.88 \\
\hline
\end{tabular}

The bandwidth through entire system, with clock and sweep speed varied through the memory, is

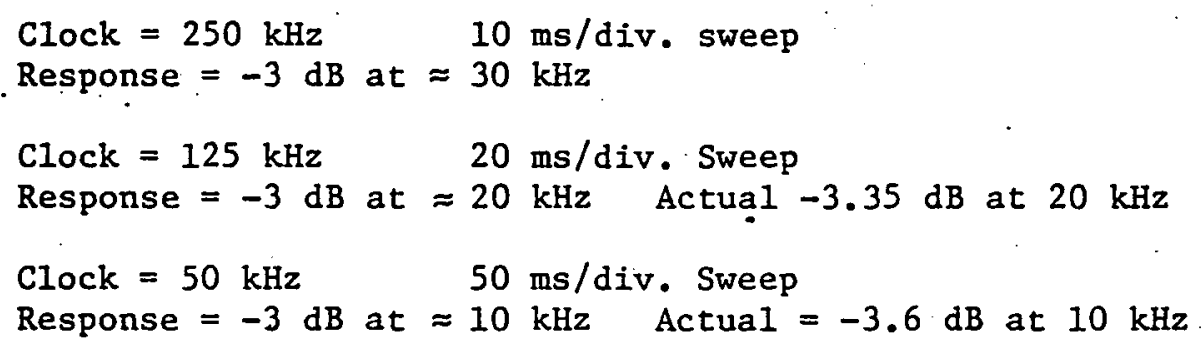

\section{Summary}

The $\mathrm{S} / \mathrm{N}$ based on a peak signal of $10 \mathrm{~V} \mathrm{p}-\mathrm{p}$ or $3.56 \mathrm{~V}$ rms to rms noise. The light links can be considered to have an SNR of $55 \mathrm{~dB}$ or better. The $S / N$ from the transmitter through the receiver and through the memory, with the receiver in the high-gain position, is between 30 and $34 \mathrm{~dB}$. With the rereiver in the low gain position; it is about $35 \mathrm{~dB}$. The $\mathrm{S} / \mathrm{N}$ of the tape recorder is between 33.6 and $33.9 \mathrm{~dB}$ average for all seven channels. Bandwidth of the various components and the system as a whole is as follows:

The bandwidth of the light links is

$\begin{array}{lll}100 \mathrm{kHz} & \begin{array}{l}\text { Low Gain } \\ \text { High Gain }\end{array} & \begin{array}{l}1.2 \text { to } 1.4 \mathrm{~dB} \\ 1.5 \text { to } 1.73 \mathrm{~dB}\end{array} \\ 150 \mathrm{kHz} & \begin{array}{l}\text { Low Gain } \\ \text { High Gain }\end{array} & 2.73 \text { to } 2.86 \mathrm{~dB} \\ & & \\ & & \\ 210 \mathrm{kHz} & \text { Low Gain } 3.66 \mathrm{~dB} \\ & \text { High Gain } & 4.84 \text { to } 5.1 \mathrm{~dB} \\ & & 5.8 \text { to } 6.4 \mathrm{~dB}\end{array}$




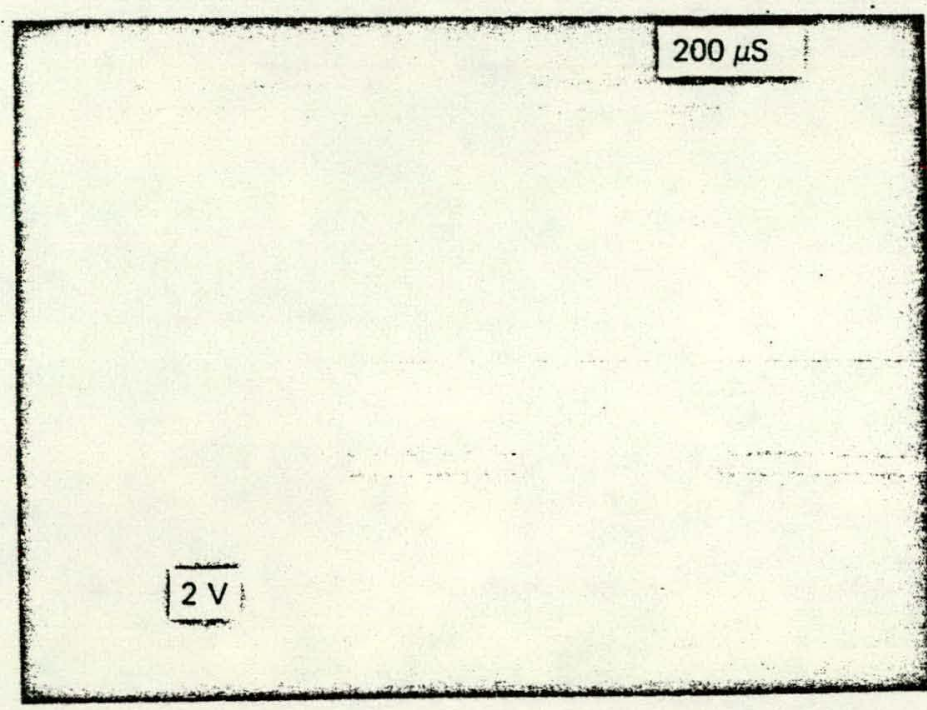

Figure E-11.

Voltage out of memory. $10 \mathrm{~V}$ peak-to-peak square wave applied at $1 \mathrm{kHz}$; output shown is $2 \mathrm{~V} / \mathrm{cm}$ on the vertical axis, and $200 \mu \mathrm{s} / \mathrm{cm}$ on the horizontal axis.

Figure E-12.

Voltage out of memory. $10 \mathrm{~V}$ peak-to-peak square wave applied at $10 \mathrm{kHz}$; output shown is $2 \mathrm{~V} / \mathrm{cm}$ on the vertical axis, and $20 \mu \mathrm{s} / \mathrm{cm}$ on the horizontal axis.

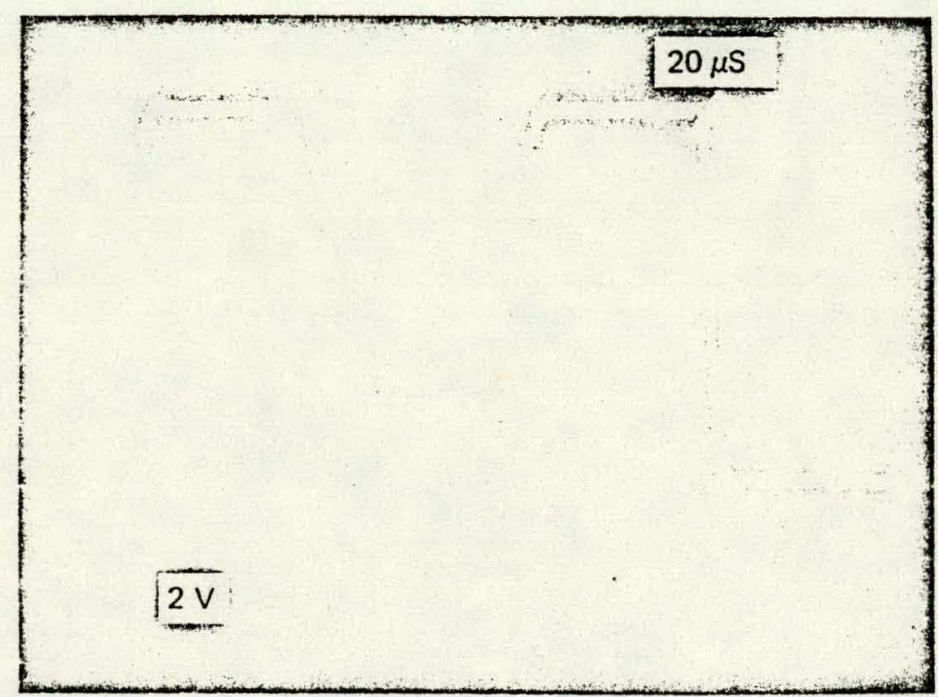


- The bandwidth of the memory in the wideband position is approximately

$3 \mathrm{~dB}$ down between 75 to $80 \mathrm{kHz}$

5. $\mathrm{dB}$ down at $95 \mathrm{kHz}$

- Averaging all seven cha-nels shows the tape recorder to be flat within $2.9 \mathrm{~dB}$ to $100 \cdot \mathrm{kHz}$.

- The bandwidth of the entire system (from the transmitter:to the receiver from the receiver to the memory, from the memory to the recorder, and from the recorder back to the output). In the wideband position, the response is within

$$
\begin{aligned}
& 2.6 \mathrm{~dB} \text { at } 50 \mathrm{kHz} \\
& 6.75 \mathrm{~dB} \text { at } 70 \mathrm{kHz} \\
& 13.2 \mathrm{~dB} \text { at } 100 \mathrm{kHz} .
\end{aligned}
$$

Using the design characteristics of each individual piece of equipment and cascading them, the loss at $100 \mathrm{kHz}$ would have ideally been $10 \mathrm{~dB}$. As the measurements indicate, some additional high-frequency attenuation is observed.

F. FUNCTIONAL DESCRIPTION OF THE TRANSIENT EVENT RECORDING SYSTEM

The purpose of this appendix is to describe the operation of the transient event recording system (TERS) from both an operators viewpoint and in terms of information flow. Major performance parameters will be. described and specified, with actual values provided where available and predicted values provided when they are not. The primary purpose of TERS is data acquisition. Its secondary function is selective retrieval and display of this data. Operation of the system in each mode is explained. 
1. TERS Hardware Overview

The major hardware modules of which TERS is composed are indicated in Figure E-13. A brief description of each of these follows:

- The light link receivers receive encoded optical signals from the sensors and produce analog outputs that are linearly related to the sensor outputs.

- The memory units sample and digitize analog information to 8-bit words from either the light link receivers or the tape recorder. They store this digitized information and use it to reproduce the analog input at a later time.

- The tape recorder is a seven-channel analog recorder with very fast start-up characteristics. It has a $100-\mathrm{kHz}$ bandwidth and a tape speed of $30 \mathrm{in.} / \mathrm{s}$.

- The scope is a Tektronix model 7603 four trace unit. It is used in $X-Y$ mode for displaying the contents of the memory units and is also used as a test and diagnostic instrument.

- The plotter is an incremental X-Y plotter (Houston Instruments Model DP-10). It is used to plot the contents of the memory units.

- The time code generator is. a Systron Donner Model 8155. It receives time code information via a microwave link and displays nine decimal digits of time information: day of year, hour, minute, and second. Twelve BDC encoded digits of time code information, which are sent to system control, define time with millisecond resolution.

- The portion of the trigger interface located in TERS contains line receivers for receiving the start condition signals sent from the Hathaway. It also contains switches for enabling a start command to be generated from any of the start conditions. It sends start commands and encoded start condition information to system control:

- System control has all operator controls on its front panel. The front panel also has a number of system status indicators. The System Control logic controls the operation of the memory units, tape recorder and all output devices. It provides all sequencing and computational functions required for all modes of TERS operation. 


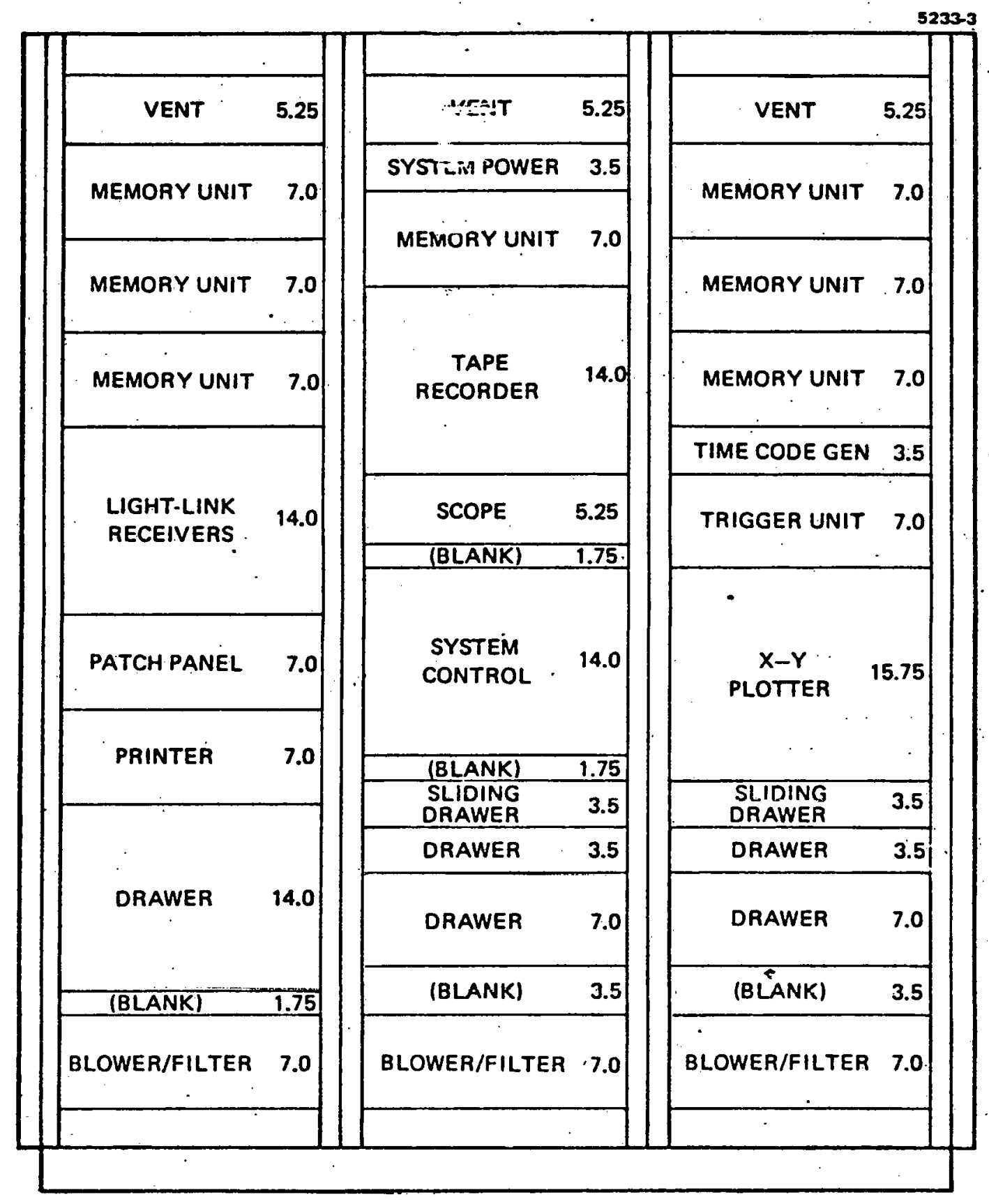

Figure E-13. Transfent event recording system. 


\section{Overview: Data Acquisition Mode}

The outputs of several voltage and current sensors located in. the valve hall provide the data which TERS stores. The -sensor-outputs are pulse width modulated at their sources. The pulse-width-modulated signals are transmitted optically via fiber optics light pipes to optical receivers located in TERS. The receivers detect and demodulate the pulse-width-modulated signals. Their outputs are linear copies of the sensor outputs. The throughputs response of the optical link transmitter Input to receiver output is down less than $1 \mathrm{~dB}$. at $100 \mathrm{kHz}$......

The optical receiver outputs are sent to the memory units. A memory unit is associated with each optical receiver. In the data acquisition mode, the memory units function as delay lines. Ideailly, the output of a memory unit is the same as its input delayed by $65 \mathrm{~ms}$. The actual transfer function of the memory units in this mode is not simply a pure delay, it is also a function of frequency. Its response is down less than $3 \mathrm{~dB}$ at $100 \mathrm{kHz}$. The $S / R$ of the memory units is limited by quantization error which is about $46 \mathrm{~dB}$ relative to full. dynamic range.

The outputs of the memory units are connected to the tape recorder inputs via an analog multiplexer. An encoded stream of digital data is present at the second input of these analog multiplexers. When a fault trigger condition is sensed, it is sent from the Hathaway to the TERS, where it is used to. start a TERS record acquisition.

At this time, the tape recorder is started and the time of trigger occurrence is stored. The time of occurrence, to the nearest millisecond, is taken from the time code generator. After the tape recorder is up to speed and has achieved phase lock, a short ID field. (approximately $2 \mathrm{~ms}$ in time) is written redundantly on all tape tracks. After this is completed, the outputs of the memory units are connected to the tape recorder inputs and recorded for a minimum time of $500 \mathrm{~ms}$. The actual recording period will extend $500 \mathrm{~ms}$ beyond the time that the last trigger is received during the recording of the analog data. After the recording of analog data is complete, a status field is written redundantly on all channels. After this is written, tape is kept in. 
motion for another $1500 \mathrm{~ms}$ and then halted. All during the period, the TERS is armed to write another record, should more triggers be received. The 12-column printer in the-TERS prints four lines of information when a record is recorded. The printer format and the recording format are described in detail below.

Each record generated has a unique (on a particular tape) physical address. Normally, adjacent records are numbered sequentially.

\section{Output Mode: Data Retrieval}

The TERS is capable of selectively retrieving the information contained in specified records. It will print the information contained in the status field and load the memory units with specified portions of the analog data field. The analog outputs of the tape recorder are connected to the inputs of the memory units. These inputs will be sampled and digitized after a specified time has elapsed from the beginning of the analog field. This time is cietermined by operator-controlled entry switches on the control panel. The length of the data field that will be sampled and loaded into memory is determined by the setting of the time base switch on the control panel. In the cases where more than 65 ms of data is loaded into memory, the signal bandwidth is reduced proportionally.

To retrieve information from tape and load it into memory, the operator sets the FILE SELECT switches on the control panel to the desired record address and actuates the LOAD switch. The TERS hardware will search the tape for the specified record and load the memory units with the portion of the analog data field specified by the memory delay switches and the time base switch. The contents of the status field are printed out by the system printer and used to condition the system for signal routing when it is in the DISPLAY mode.

After the memory units have been loaded from the tape recorder, the TERS is in display mode. The entire contents or selected portions of four of the memory units can be displayed simultaneously on the CRT display in the TERS. Hard copy output plots can also be generated on the incremental. plotter. 
4. Data Acquisition Mode: Initialization

The TERS is put into the data acquisition mode by switching the ON/OFF LINE switch to ON LINE. This inftiates the ON LINE initialization sequence.

The purpose of the ON LINE initialization sequence is to ensure: that no previously acquired records will be written over and to initialize the record counter so that the next record that is written on the tape will have an address or record number that is one higher than the last previously written record.

The first step in initiating the system for automatic data acquisition is to back the tap eup to Beginning of tape (BOT). Forward tape motion is then commanded. When the tape has advanced sufficiently to turn BOT off, and tape acceleration is complete, a 10-D delay, TMRL, is initiated. Since this delay is longer than any single record on. the tape, if a record exists beyond the start of this delay, it will be found before the end of TMRL.

.If a header mark is found when TMRL is active, TMRL is reinitiated and an attempt is made to read the ID field. If the ID field sync mark is not found, the no record found (NRF) flag is set in the controller and the TERS begins to look for the next header mark. The NRF flag indicates that a read operation could not be completed. If the sync mark is found, the TERS advances to point $F$ of the flow diagram. The data are loaded into the record counter and the file register of the last record read flip-flop (LRR) is not set. After 12 bits of data have been read, a four-bit cyclic parity check is performed. If a parity errors is detected, the parity $\mathrm{flag}$ is set and the LRR flag is interrogated. If it is not set, the system returns and looks for the next header mark. If no header mark is found when TMRL is active, a jump is made. If end of tape (EOT or EOTW) has been reached, the TERS halts. If not, the parity error flag is examined. If it is set, the TERS jumps back after masking off the track which was being used, and the whole sequence of operations is repeated. 
If the parity error flag is not set, the LRR flip flop is set. The TERS goes through the same sequence as before until the ID field is read. Since the LRR flip flop is set, the contents of the file register w111 not be changed and a jump will be made when the reading is complete. If the parity error flag is set, a return to an earlier point in the sequence will be made, otherwise the record counter and file register contents will be compared. If the file register contents are greater than the file count, a return to the same point is made. If the file register contents are less than the file count, an error has been made and the machine halts. When the register and counter contents are. equal, the last record delay (TLRD) is initiated. When TLRD is over, tape motion is halted and the TERS enters the data-acqusition mode. At this time, the ON LINE indicator is illuminated.

\section{Data Acquisition Mode}

On entering the data-acqusition mode, the TERS enters a waiting state with the tape drive stopped. When a fault condition is detected, trigger information is sent to the TERS and the active data acquisition sequence is initiated.

Twelve trigger conditions are sent from the Hathaway to the TERS via optically isolated transmitters. Since power for the opto-isolated transmitters is provided by the TERS, no electrical connection between the TERS and the Hathaway will exist. These signals are received by the trigger interface in the TERS. Switches for maskigg each of the trigger condition signals are provided in the trigger interface. When any of the signal lines, whose mask switches are set, go to an active state, a start command is sent to the system control logic and a record cycle is initiated. The address or ID of the active trigger condition line is encoded into a four-bit character and sent to the system control logic.

Immediately following the start command, the following events take place: 


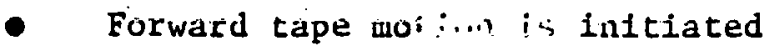

The ID code of th- Tigger condition is stored, and the trigger counter is incremented.

- A request for tjmo nde generator data is made; it will be granted at the next time code generator strobe time (within 1 ms).

- The record time out delay is started and the record counter is incremented.

When data from the clock is obtained, it is stored for writing on tape and loaded into the printer buffer, so time printout will be initiated almost immediately. When the tape recorder has achieved phase: lock, writing of the count field is begun.

The format of the count field and encoding scheme consists of the count field header mark, count field sync mark, the 12-bit record count (most significant bit is recorded first), 4 bits of parity, and a postamble. The count field is written on all tape recorder channels.

After the count field has been written, the memory unit outputs are switched to the tape recorder inputs, and the recording of analog data is started. At this time, the $500 \mathrm{~ms}$ data delay (TDD) is initiated. Analog recording will continue until TDD is no longer active. If another trigger occus while TDD is active, the trigger ID is stored and the grigger counter is incremented. IF the trigger count is less than 10, TDD is reinstated. When TDD resets, the writing of the status field will commence.

The status field consists of (1) status header mark, (2) status synch mark, (3) status data field and parity, (4) postamble, and

(5) gap. The status data field consits of:

- Time of occurrence of first start trigger (1.2 BCD characters)

- File number (3 BCD characters)

- Identification of first three tirggers that occurred during record (6 BCD characters) 
- Status of enable mask switches (5 BCD characters); $\left(3 /{ }^{-}\right.$ character, 1 spare).

- Trigger count (2 BCD characters)

- Length of analog data record to 100 ms resolution (2 BCD characters)

- Patch Switch States - Seven switches at 1 BCD character each (7 BCD characters),

- Transmitter gain switches - 1 bit per transmitter (3 BCD characterș)

- Parity (I BCD character).

This information is printed out by the 12 column printer. The The format of the printout is as follows:

Line $1=$ Time of occurrence

\begin{tabular}{|c|c|c|c|c|}
\hline Characters & 1 & - & 3 & Day of year \\
\hline & 4 & - & 5 & Hour of day \\
\hline & 6 & - & 7 & Minute \\
\hline & 8 & - & 9. & Second \\
\hline . & 10 & - & 12 & Millisec \\
\hline
\end{tabular}

Line $2=$

$\begin{array}{rlrll}\text { Characters } & 1 & - & 3 & \begin{array}{l}\text { Record number } \\ \text { IDs of first three triggers } \\ \text { occurring within the record }\end{array} \\ 410^{-} & - & 9 & 12 & \begin{array}{l}\text { Location of first trigger } \\ \text { from start of analog data }\end{array}\end{array}$

Line $3=$

$\begin{array}{llll}\text { Characters } 1 & -5 & \begin{array}{l}\text { States of Trigger Masks } \\ \text { encoded in octal (1 spare } \\ \text { character included) }\end{array} \\ 6 & -7 & \begin{array}{l}\text { Trigger count } \\ 8\end{array} \\ 10 & -9 & \begin{array}{l}\text { Record length (100 ms resolution) } \\ \text { Unassigned }\end{array}\end{array}$


Line $4=$

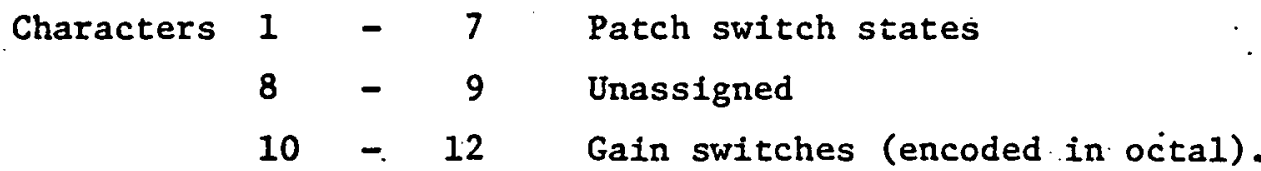

If another trigger occurs during the writing of the status field, it is stored and will be used to initiate another record cycle after the status field has been written. If a trigger has not occurred, a 100-ms delay is initiated, and, when it and the two-second record timeout are complete, tape motion is halted and the TERS returns to a waiting state.

\section{Data Retrieval}

Any record on tape may be read by specifying its physical address (record number) and initiating a load operation. The TERS will automatically search the tape for the specified record, print the contents of the status field as when the information was recorded, and load the memory units with a portion of the recorded analog data.

The portion of the analog data that is loaded into memory is determined by the settings of the memory delay switches and the time base switch on the system control panel. The settings of the memory delay switches determining when data will start being loaded into memory from the start of the analog data field. The setting of the time base switch determines the sampling rate of the data and, therefore, the effective time length of the memory units. - The sampling rate also determines the signal bandwidth that can be recovered from the digitized samples.

When information is recorded on tape, the incoming data is sampled at a $500-\mathrm{kHz}$ rate. With a $100-\mathrm{kHz}$ sinusoidal input, the output is down between 2 and $3 \mathrm{~dB}$. For time base switch settings of $5 \mathrm{~ms} / \mathrm{div}$ or less, the same sample rate is used to sample read data from the tape recorder. At this sample rate, approximately $65 \mathrm{~ms}$ of data will be stored in memory. In this case, the LED indicator by the 5 ms position will be illuminated. 
When a LOAD operation is initiated with the time base switch in the 10-, 20-, or 50-ms position, the data from the tape recorder will be sampled at $250 \mathrm{kHz}, 125 \mathrm{kHz}$, and $50 \mathrm{kHz}$, respectively. The bandwidths are limited correspondingly to $50 \mathrm{kHz}, 25 \mathrm{kHz}$, and $10 \mathrm{kHz}$. Approximately 130 ms of data will be sampled in the $10 \mathrm{~ms} / \mathrm{div}$ setting, $260 \mathrm{~ms}$ in the 20-ms position, and $650 \mathrm{~ms}$ in the 50 -ms position. The corresponding LED indicator will be illuminated in each case.

When information is recorded, the same digital information is recorded on all tape channels. This redundancy is taken advantage of when executing a search or reload command. The data recovery logic locks onto the first channl on which a record header mark is detected. However, if subsequent read sequence errors occur, a retry is made after masking off the channel that was being used.

\section{Display Output}

After the memory units have been loaded, their'contents may be selectively displayed on the display oscilloscope. The channel selection switches on the system control panel select the parameter that is to be displayed on each of the four scope channels. The states of the patch panel switches at the time the information was recorded specify the tape channel that each of the parameters was recorded on. The states of these switches are written on tape whenever a record is written. When the record is read, this information is used by the TERS in performing logical addressing of the various parameters. The setting of the channel A switch also specifies the parameter that will be plotted by the incremental plotter.

The portion of the analog data that will be displayed on the scope is determined by the begin file switches and the time base switch. The begin file switches determine the time from the beginning of memory that the display will start. The time base switch determines the time length of the display on the scope. Two LED indicators are part of the begin file switch assembly. These are used to indicate what the delay is in milliseconds. When a search or reload is executed with the time 
base switch specifying less than $10 \mathrm{~ms} / \mathrm{div}$, the LED between the sècond and third digits of the begin file switch will be illuminated, so that delay is specified in the 100-ms increments. With the time base switch specifying more than $5 \mathrm{~ms} / \mathrm{div}$, the LED to the right of the third digit will be illuminated so that delay will be specified in $1 \mathrm{~ms}$ increments.

The gain of all scope displayed channels may be varied by one full scale switch on the system control panel. The full scale siwtch is a 10-position switch. Only four different gains may be selected for the scope display. These four settings will yield the following display heights for maximum peak to peak outputs fromithe memory units: 2 divisions, 4 divisions, 8 divisions, 16 divisions.

\section{Plotter Operation}

The incremental plotter will produce hard copy output plots of any of the parameters being monitored versus time. The output is on "B" size chart paper: The parameter to be plotted is specified by the channel A selection switch. The time represented per inch on the horizontal axis is specified by the time base switch. The vertical gain (amplitude) is selected by the full scale switch. The peak-to-peak height of the plot for full scale memory unit output is twice the setting of the full scale switch in inches.

The other plotter controls and indicators are located in the lower right portion of the system control panel. The PEN DOWN indicating switch is illuminated whenever the pen is down. The pen can be raised or lowered by actuating the switch. The pen is initially positioned by the $X$ and $Y$ zero lever wheel switches. These specify the location of $X$ and $Y$ zero with respect to the lower left corner of the paper in inches. The information specified by the channel A select switch and the begin file switches is plotted by actuating the PLOT switch. The PLOT switch will bc illuminated until the operation is completed. When the plotter Is active, the contents of the memory units will not be displayed on the scope. 
9. OFF LINE Printer Operation

The TERS will generate new print tapes in the same format as in data-acquisition mode. To make the printout, the TERS must be off line. The tape is first rewound to BOT, and then the. PRINT sivitch, located on the maintenance subpanel, is actuated. The switch will be illuminated and remain so until the PRING operation is complete. The information in the status field of each record on the tape will be printed out.

\section{Patch Panel Operation}

The patch panel allows the analog inter-module connections to be easily changed. It also provides a central monitoring point for major analog signals in the system. The outputs of the optical receivers and the tape recorder can be routed to different memory unit inputs. The outputs of the memory units can be connected to any of the tape recorder inputs.

This capability allows the tape recorder channel that a given parameter is recorded on to be varied. Therefore, a set of thumb wheel switches is provided on the patch panel to indicate what parameter is being written on each of the tape recorder channels. The states of these switches are written in the status field of each record.

\section{Summary of Operator and Maintenance Switches and Indicators}

All operator switches and indicators are located on the front system control panel. Maintenance switches and indicators are located on the system control subpanel, tape recorder subpanel, and patch panel. These controls and indicators are listed below with a brief description of their functions and operation.

The operator switches and indicators (starting from upper left cor- . ner of system control panel) are listed below: 
ON LINE/OFF LINE = Split lf . ? andicating switch. Automatic data acquisition takes place when ON LINE indicator is illuminated. This Indicator is turned on when system is switched to ON LINE and On Line Inftialization has been completed. When switch is made to OFF LINE, data retrieval, display and output functions become operative. $\underline{\text { STOP }}=$ Indicator which is illuminated when tape recorder is stopped. $\underline{\text { RECORD }}=$ Indicator which is illuminated when record enable control line is asserted.

FWD/REV = Split level indicator which indicates direction of tape motion. If either is illuminatęd, STOP will not be. $\underline{\text { BOT/EOT }}=$ Split level indicator which indicates if tape position is at beginning or end of tape. SPEED LOCK = Indicator. which is illuminated when tape is moving forward at $\mathrm{read} / \mathrm{write}$ speed.

$\underline{\text { RUN }}=$ Indicator which is illuminated when TERS is busy executing a command or a data acquisition sequence.

$\underline{\text { READY }}=$ Indicator which is illuminated when TERS is not busy and is in state where normal operations can be executed.

$\underline{\text { ERROR }}=$ Indicator which is illuminated whenever a commanded sequence cannot be completed.

CHANGE TAPE = Indicator which is illuminated when the ON LINE and EOT indicators are activated.

FILE NO: = Three-decimal digit display of last file number or address was read or written.

FILE SELECT = Three-decimal digit lever wheel switch assembly. It specifies the address of the record to be retrieved in a SEARCH or RELOAD operation.

MEMORY DELAY $=$ Four-decimal digit lever wheel switch assembly which specifies how long a time in ms. from the beginning of analog data that memory loading will begin in a SEARCH or RECORD operation. 
BEGIN FILE = Three-decimal digit lever wheel switch assembly and Ewo LED indicators. The switches specify the time in ms from the beginning of memory that a scope display or plot is to begin. One of the LED is illuminated to indicate the location of the decimal point. TIME BASE = Twelve-position switch and four LED indicators. The switch specifies the sampling rate and data bandwidth used and the time represented per division in display mode. The LEDs indicate the sampling rate and bandwidth that was specified during the previous. LOAD operation. $\underline{\text { LOAD }}=$ Indicating switch. Used to command the memory load operation. Illuminated during the LOAD operation.

FULL SCALE = Thumbwheel switch that specifies the gain for scope display or plotter output.

CHANNEL SELECT $\doteq$ Four thumbwheel switches which specify the parameters to be displayed on the four scope traces. Channel A select also specifies the parameter to be plotted. The IDENT switches are used to locate the trace associated with each channel.

$\underline{\text { REWIND }}=$ Used to initiate tape rewind. System must be off line. Switch will be illuminated during rewind.

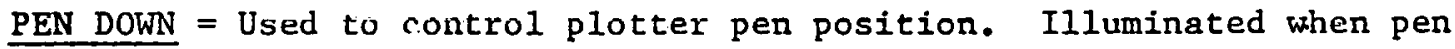
is down.

$\underline{\text { PLOT }}=$ Used to initiate a plotting operation. Illuminated while plot is being made.

$X$ and $\bar{Y}$ ZERO $=$ Lever wheel switches which specify the location of zero in inches with respect to the lower left corner of the plotting area..

The maintenance switches are listed below.

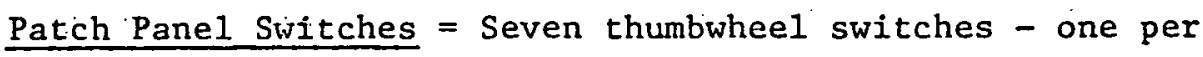
channel. Specify the parameter that is being recorded on that channel. 


\section{System Control (subpanel) \\ Normal/Test $=$ Split indicator switch in test position, portions of automatic sequencing are disabled. \\ PRINT = Used to command theoff line generation of a print tape. \\ ON LINE TEST $=$ Generates a start command to control logic. Used for testing ON LINE automatic operation. MASTER CLEAR: System clear \\ Transmitter Gain $=$ Eight two-position switches which ........ . control the gain in each of the optical transmitters.}


REVIEW OF THE DOWTHERM-COOLED MOLYBDENUM HVDC CONVERTER ANODE An evaluation of the Dowtherm cooled converter anode was solicited from a thermodynamic specialist in another division of Hughes Aircraft. This was done to verify the adequacy of the original analysis and design. Internal correspondence describing the technical results, included in this appendix. 


\author{
TO: H.J. King \\ ORG: $\quad 30-22$ \\ SUBJECT: HVDC Converter \\ Anode Cooling
}

\author{
CC: K.M. Brown \\ W.F. Earhart \\ R.B. Hasselquist \\ - F.J. McClung \\ P.F. Taylor
}
DATE: 10 ApriI. 1975
REF. $73311.32 / 412$
FROM: R.G. Finucane
ORG. 73-11-32

BLDG. 6

MAIL STA. E-125

Loc. CC EXT. 3888

A brief review of the Dowtherm cooled molybdenum high voltage direct current converter anode has been completed. The aim of this study was to offer criticism of the previous analytical methods and results, and to recommend short and long term design changes which might offer improved performance and reliability.

The previous analysis performed by R.B. Hasselquist was reviewed and deemed faultless in concept and detail. The analysis was extended to include other cases, and some pressure drop calculations were performed as well. The following specific recommendations and conclusions are presented.

1. The assumption of uniform flux density over the entire anode surface should be retained only as a worst case condition at the outer periphery. At the tip of the anode, a 4:1 peak to average flux of 205 watts $/ \mathrm{cm}^{2}$ was assumed.

2. The current design is adequate for the uniform flux case. As shown by $R$. Hasselquist, maximum wall temperature is $543^{\circ} \mathrm{F}$ at the outer edge, with the fluid boiling point being about $580^{\circ} \mathrm{F}$.

3. Modifying the design to include extended surfaces was considered briefly. While appropriate simple fins can offer a factor of four performance improvement with no increase in coolant flow, fabrication hazards abound. Molybdenum finstock should be considered for future applications.

4. By increasing coolant flow to 30 gallons per minute and using a constant performance gap, starting at $.12^{\prime \prime}$ at the center and tapering to $.02^{\prime \prime}$ at the outer edge, a film heat transfer coefficient of $1900 \mathrm{BTU} / \mathrm{hrf}^{2} \mathrm{~F}$ can be attained with a pressure drop of about 65 psi. A slight increase in feeder tube diameter to (for example) .6" reduces the total pressure drop to 32 psi. This design will accept a flux density of $205 \mathrm{w} / \mathrm{cm}^{2}$ over a 4.2" diameter spot at the nose of the anode, and $51 \mathrm{w} / \mathrm{cm}^{2}$ anywhere else on the surface.

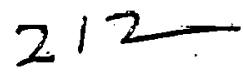


5. A,more reasonable estimate of the flux profile of the anode should be obtained. The original assumption of uniform flux seems untenable, and the $4: 1$ peak to average used here may be exceeded in actual practice. Detalls are presented in the enclosure.

R.G. Finucane, Head

Optical Device Engineering Group

Adaptive \& High Power Optics Department

RGF : wh

Enc

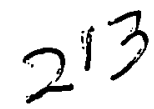


1. Extended surfaces.

The first approach considered was̀ machining circumferential grooves on the inner surface of the outer . 25 " molybdenum plate. To attain a substantial increase in effective heat transfer area, relatively narrow grooves separated by thin lands are required. . Considering rectangular fins of wavelength $s$, depth $l$, and thickness $s / 2$, we have

$$
\mathrm{AR}=1+\cdots \frac{2 \ell}{\mathrm{s}}
$$

Assuming a maximum depth $\ell$ of .05" for structural reasons, and a desired area ratio $A R$ of 5 , the required fin wavelength becomes $.025^{\prime \prime}$, and the fins are only .012" thick. The efficiency of such a fin is

$$
\phi=\frac{\tan \text { ml }}{\mathrm{ml}}
$$

where $\mathrm{m}=\frac{4 \mathrm{~h}}{\mathrm{ks}}, \mathrm{h}$ is heat

transfer coefficient, and $k$ is conductivity, giving an effective area ratio of about 4.37. Figure 1 presents results for other fin spacings. While substantial increases in performance can be attained in theory, practical difficulties in machining .01" - .02" thick molybdenum fins prohibits their use. The use of molybdenum finstock brazed to the inner surface is a possible long range solution requiring substantial development before implementation.

2. Variable gap, constant flow Heat transfer performance at constant flow rate of $7.5 \mathrm{gpm}$ and variable gap size is presented in Figure 2 . The heat transfer coefficients are calculated from the relation,

$$
\mathrm{h}=\frac{.02 \mathrm{n} \mathrm{K} \mathrm{K}_{1}}{\mathrm{D}} \quad \frac{\mathrm{Q}}{\pi \mathrm{r \nu}}{ }^{.8} \mathrm{Pr}^{.3} \frac{\mu \mathrm{n}}{\mu}:^{14}
$$

which was used in previous analyses. The pressure drop is calculated as follows: 


$$
\therefore \Delta \mathrm{p}=\frac{\mathrm{c}_{\mathrm{o}} \rho \mathrm{v}_{\mathrm{o}}^{2}}{2}+.3164 \rho \int \frac{\mathrm{v}^{2}}{\mathrm{D} \sqrt[4]{\mathrm{Re}}} \mathrm{dr}
$$

In the preceding equations, $k_{1}$ is fluid conductivity, $D$ is hydraulic dlameter, $Q$ is volume flow, $r$ is arc length, and the other symbols have their usual meanings. $C_{0}$ is the experimental pressure drop. coefficient which occurs at the center of the anode where the coolant makes a $90^{\circ}$ turn, and represents a substantial portion of the system pressure losses. Figure 2 demonstrates the difficulty with a constant or linearly tapering gap: extremely high heat transfer and pressure drop occur at the tip of the anode, but performance rapidly drops off. The dashed line labeled "required" assumes all the power is concentrated at the tip of the anode at a 4:I peak to average ratio. At the .020" minimum gap size and $7.5 \mathrm{gpm}$, the coolant begins to boil at about one inch from the tip, and the situation deteriorates with arc length.

3. Recommended design The optimum anode design maintains the required heat transfer coefficient with minimum pressure drop and gap size not less than .02". A formula for gap size may be written:

$$
\begin{aligned}
& g=\frac{.0323\left(\frac{Q}{\pi r v}\right)^{.8}\left(T_{B O I L}-T_{F}\right)}{8} \\
& T_{F}=T_{0}+\frac{2 \pi}{Q_{\rho} C_{P}} \int 8 \mathrm{rdr}
\end{aligned}
$$

An iterative approach to this system was taken: $Q$ was varied until the gap size reached .02" at an arc length of about 2.2 inches, then the gap size computed for the rest of the anode. The results are drawn on figure 3 and summarized in the equation: 


$$
g=\frac{3.736 \times 10^{-2}}{r^{.8}}, r<2.18^{\prime \prime}
$$

The gap is assumed constant thereafter at $g=.02 . "$

The pressure drop calculation for the system (not including the $90^{\circ}$ turn at the tip) reduces to

$$
\begin{aligned}
\Delta P & =\frac{\rho}{2} \int_{.225}^{2.2} \frac{.3164}{\sqrt[4]{R e}} \frac{v^{2}}{D} d r \\
\frac{\rho}{2} & \left.=6.584 \times 10^{-3} \mathrm{psi} / \dot{(f / s e c}\right)^{2} \\
\sqrt[4]{\operatorname{Re}} & =\left(\frac{15045}{r}\right)^{1 / 4} \\
v^{2} & =\left(\frac{41.00}{r^{.2}}\right)^{2} \\
D_{h} & =3.4 \times 10^{-5}\left(\frac{15045}{r}\right): 8
\end{aligned}
$$

where the constants are for arc length in inches. For $r \times 2.18, " D_{h}=$ $.04 "$ and $v=76.6 / \mathrm{r}$. A total pressure drop of about 18.5 psi was calculated.

At the nose, the pressure drop is approximately

$$
\Delta P=\left(I+1.5\left(\frac{v_{0}}{V_{0}}\right)^{2}\right) \cdot \frac{1}{2} \rho v_{1}^{2}
$$

where $v_{1}$ is the velocity in the tube. The pressure drop is inversely proportional to the fourth power of tube diameter, as shown in figure 4. 


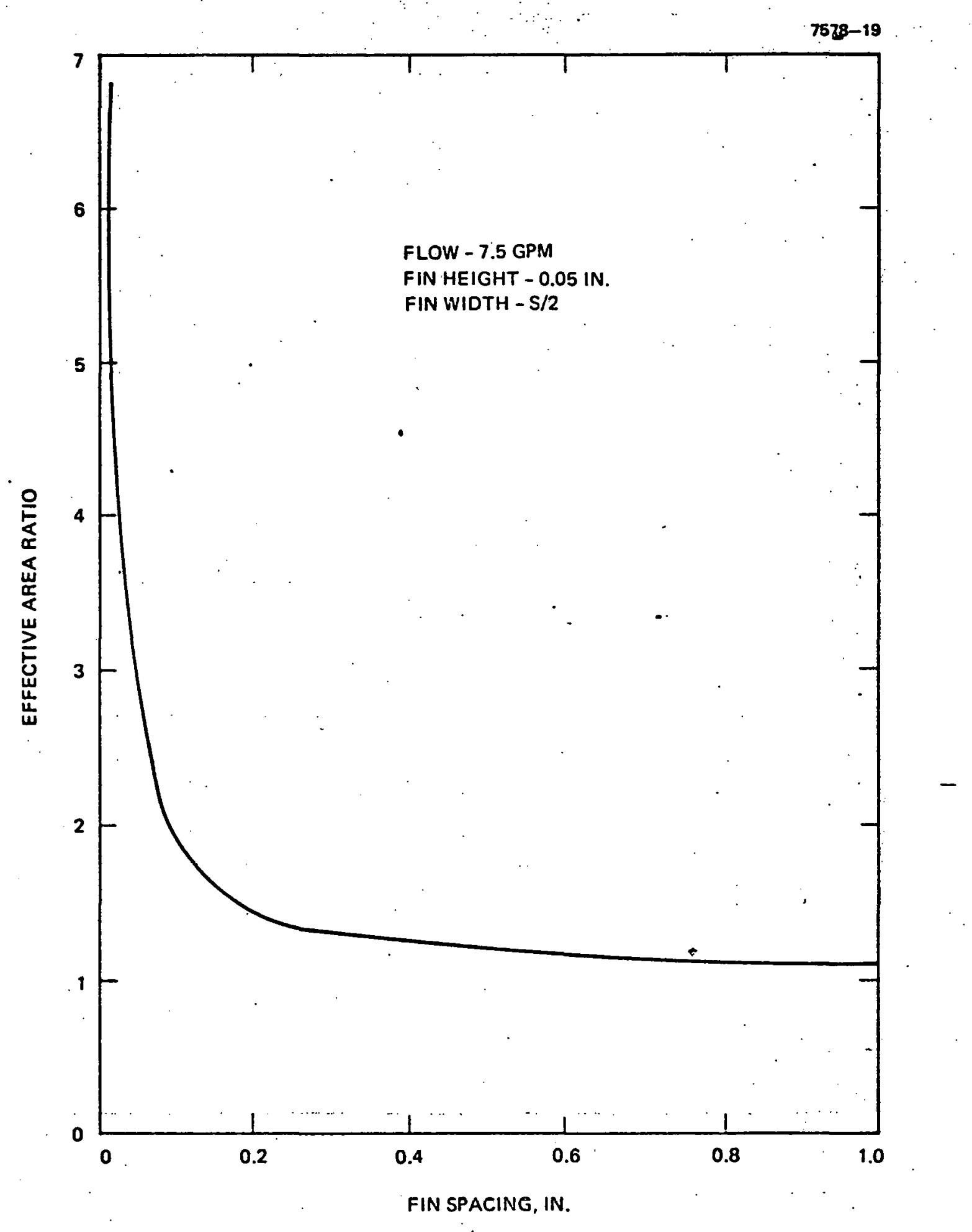

Figure 1

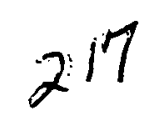




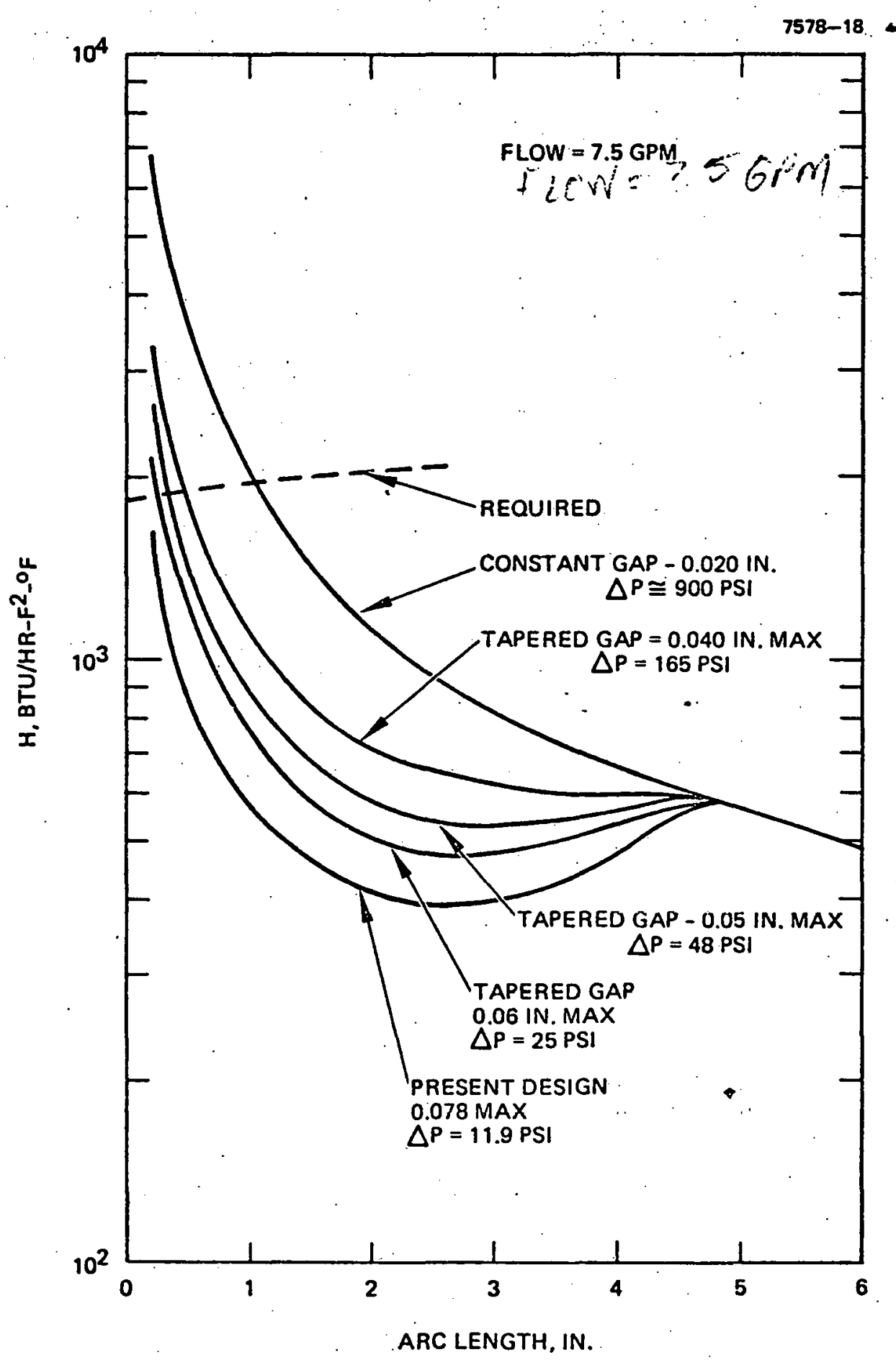

Figure 2

218 


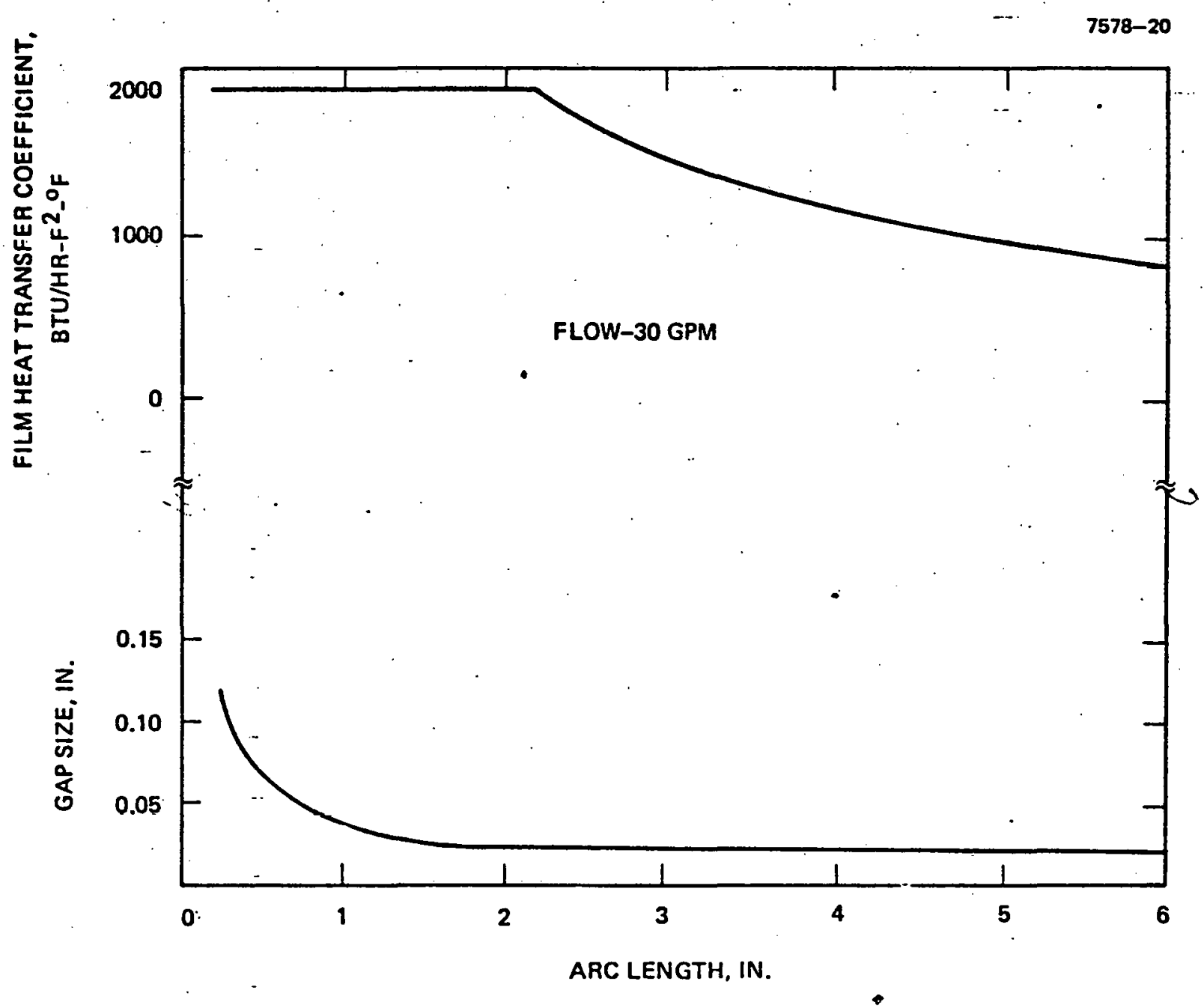

Figure 3 


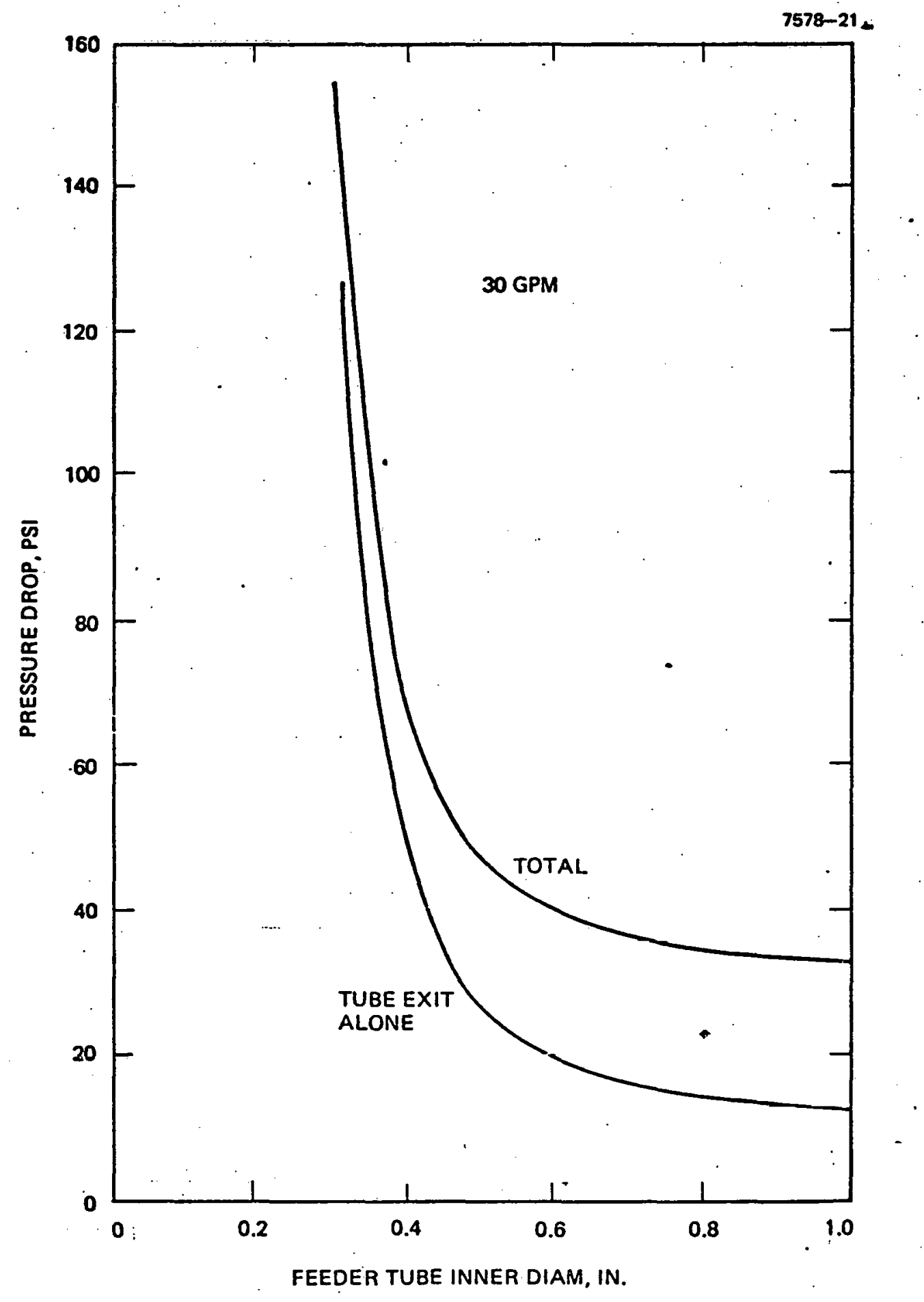

Figure 4

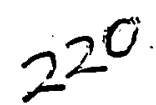

